ROMILDO DE CAMPOS PARADELO JUNIOR

\title{
PROTEÇÃO DE SOBRECORRENTE EM SISTEMAS DE DISTRIBUIÇÃO DE ENERGIA ELÉTRICA ATRAVÉS DE ABORDAGEM PROBABILÍSTICA
}

Dissertação apresentada à Escola Politécnica da Universidade de São Paulo para obtenção do título de Mestre em Engenharia.

São Paulo 
ROMILDO DE CAMPOS PARADELO JUNIOR

\section{PROTEÇÃO DE SOBRECORRENTE EM SISTEMAS DE DISTRIBUIÇÃO DE ENERGIA ELÉTRICA ATRAVÉS DE ABORDAGEM PROBABILÍSTICA}

Dissertação apresentada à Escola Politécnica da Universidade de São Paulo para obtenção do título de Mestre em Engenharia.

Área de Concentração:

Sistemas de Potência

Orientador:

Prof. Dr. Hernán Prieto Schmidt

São Paulo 
FICHA CATALOGRÁFICA

Paradelo Junior, Romildo de Campos

Proteção de sobrecorrente em sistemas de distribuição de energia elétrica através de abordagem probabilística / R. de C. Paradelo Junior. -- São Paulo, 2006.

p.

Dissertação (Mestrado) - Escola Politécnica da Universidade de São Paulo. Departamento de Engenharia de Energia e Automação Elétricas.

1.Redes de distribuição de energia elétrica (Proteção) I.Universidade de São Paulo. Escola Politécnica. Departamento de Engenharia de Energia e Automação Elétricas II.t. 
"As pessoas que vencem neste mundo, são as que procuram as circunstâncias de que precisam e, quando não as encontram as criam."

Churchill 


\section{AGRADECIMENTOS}

Ao Prof. Dr. Hernán Prieto Schmidt pela belíssima orientação e oportunidade que me concedeu para a elaboração desta pesquisa; pela sua dedicação em sempre poder me ajudar no que foi preciso; por todas as horas, dias, finais de semana e feriados gastos para fazer as revisões e correções nos meus textos, pela compreensão e ajuda nos momentos de dificuldade, sempre fornecendo palavras de apoio e de incentivo.

A todos os professores das sete disciplinas cursadas na pós-graduação, que foram de grande valia e agregaram muito valor a este trabalho.

A todos os meus colegas de Pós Graduação da Escola Politécnica da Universidade de São Paulo.

Ao professor Dr Eduardo César Senger pelas valiosas observações apresentadas durante a exposição do exame de qualificação deste trabalho.

Ao professor Dr Ernesto João Robba pelo apoio na utilização da ferramenta computacional no estudo e simulação de casos, bem como pelas horas valiosas de seu tempo dispensadas na análise de dúvidas e esclarecimentos adicionais.

Ao meu colega, Engenheiro Maurício Viana da Silva, pelo incentivo e motivação dado nestes últimos anos e, principalmente, por ter me liberado das atividades profissionais para tratar de assuntos ligados ao desenvolvimento deste trabalho.

A todos os meus colegas do departamento de Suporte técnico da empresa Schneider Electric Brasil Ltda que trabalharam por mim nos momentos em que estive ausente da empresa para poder me dedicar ao mestrado.

Finalmente aos meus pais Romildo e Brasilina, a minha irmã Regiane e a minha namorada Marli, pelo apoio prestado no decorrer destes anos. 


\section{RESUMO}

Este trabalho apresenta um estudo de proteção de sobrecorrente de redes primárias aéreas de distribuição de energia elétrica através de uma abordagem probabilística.

Abordagens convencionais para o problema de proteção de sobrecorrente não levam em conta a natureza probabilística das principais variáveis envolvidas: tipo da falta, localização da falta e impedância de defeito para faltas envolvendo a terra. Neste caso, por exemplo, torna-se muito difícil avaliar as conseqüências de situações nas quais a coordenação total entre os dispositivos não pode ser alcançada por alguma razão.

A abordagem probabilística permite, por outro lado, quantificar o risco de não haver coordenação entre dois dispositivos de proteção adjacentes. Esta informação é extremamente valiosa para os engenheiros de proteção na fase de projeto da rede elétrica.

No trabalho, a metodologia probabilística é apresentada em detalhe e sua aplicação é ilustrada através de alguns estudos de aplicação, nos quais procurou-se avaliar a influência dos principais parâmetros do modelo na coordenação dos dispositivos de proteção. 


\begin{abstract}
This work describes the study of distribution system overcurrent protection through a probabilistic approach.

Conventional approaches for overcurrent protection do not consider the probabilistic nature of the main variables involved, such as fault location, fault type and fault impedance for faults involving the ground. In this case, for instance, it is very difficult to assess the impact of situations where full coordination cannot be attained for some reason.
\end{abstract}

The probabilistic approach, on the other hand, allows quantifying the risk of two adjacent protective devices operating in a non-coordinated way. This information is extremely valuable for electrical engineers at design level.

In this work, the proposed methodology is illustrated through a few detailed application studies, including various sensitivity analyzes for assessing the influence of model parameters on the coordination of protective devices. 


\section{ÍNDICE}

\section{LISTA DE FIGURAS}

LISTA DE TABELAS

RESUMO

\section{ABSTRACT}

1. INTRODUÇÃO. . .1

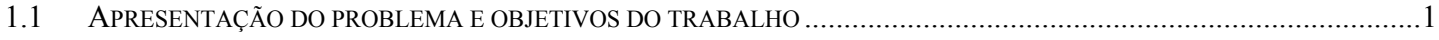

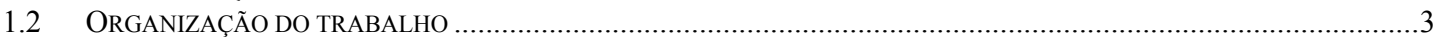

2. PROTEÇÃO CONVENCIONAL DE SOBRECORRENTE EM REDES PRIMÁRIAS DE

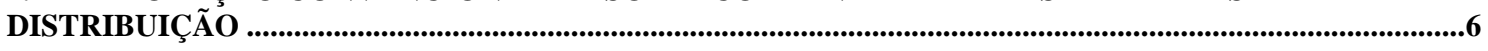

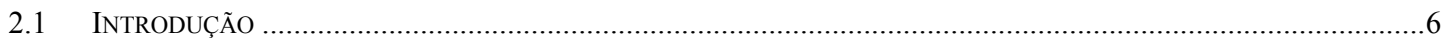

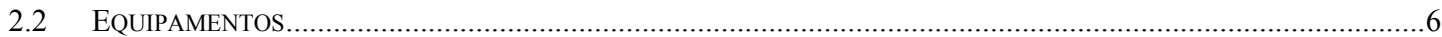

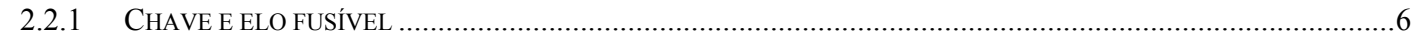

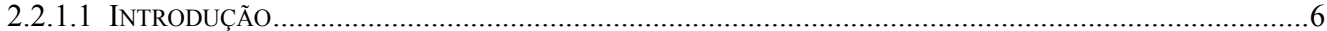

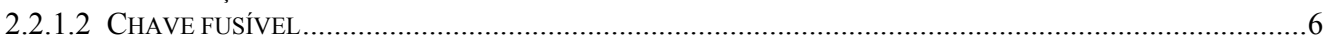

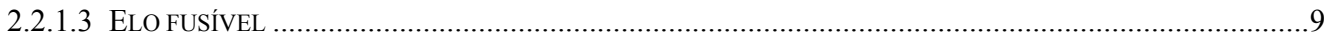

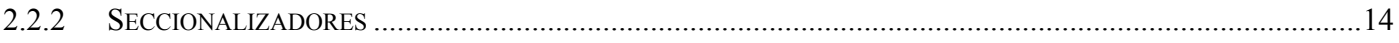

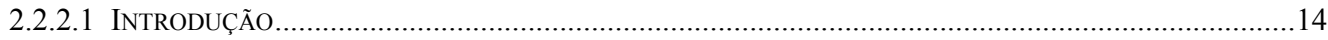

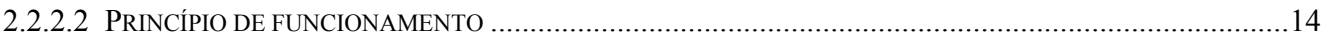

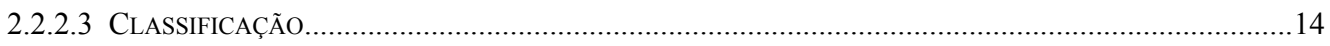

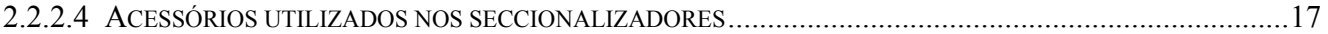

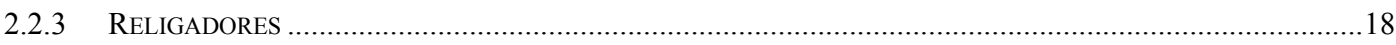

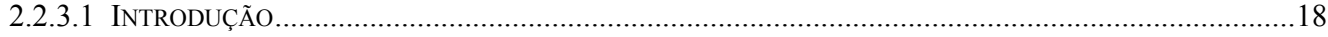

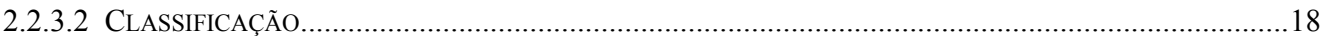

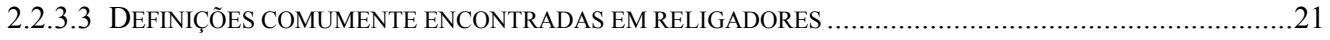

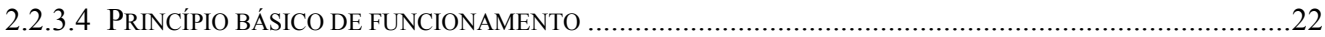

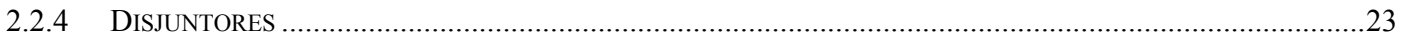

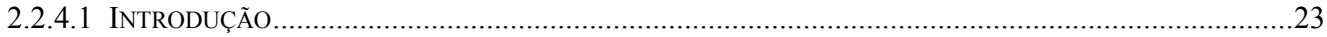

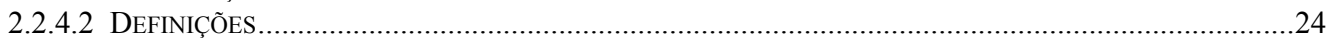

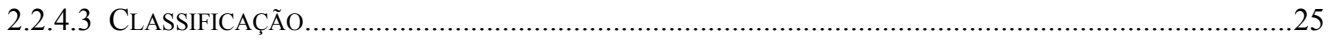

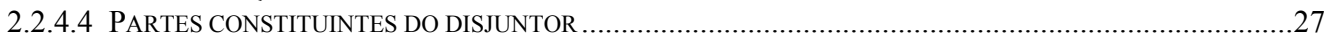

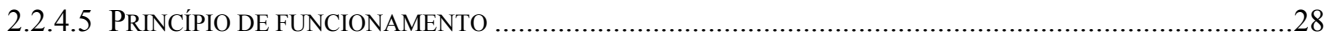

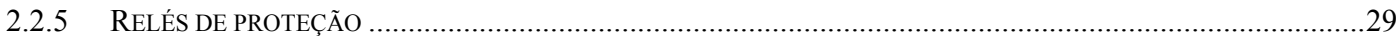

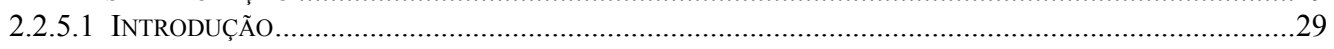

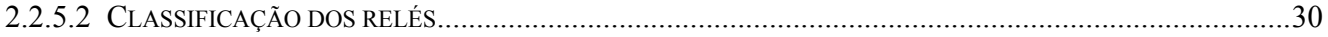

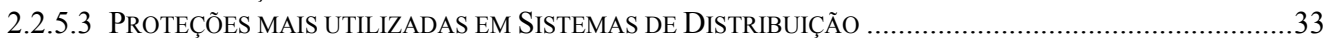

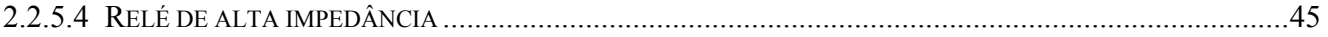

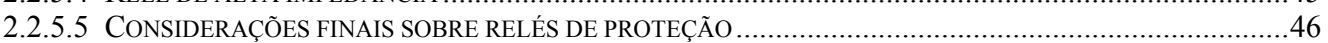

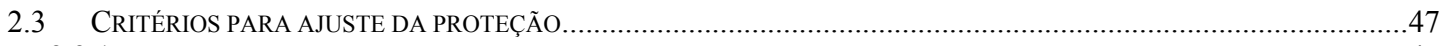

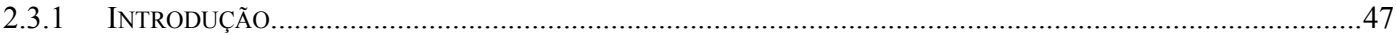

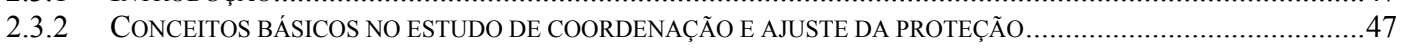

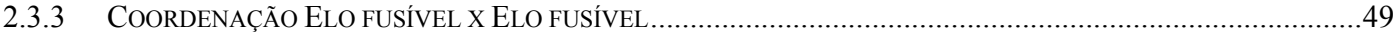

2.3.4 COORDENAÇÃo ENTRE RELIGADOR, SECCIONALIZADOR E ELO FUSÍVEL ..............................................53

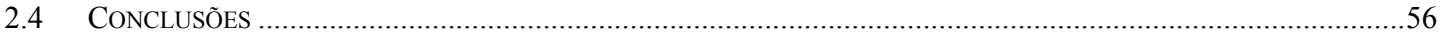

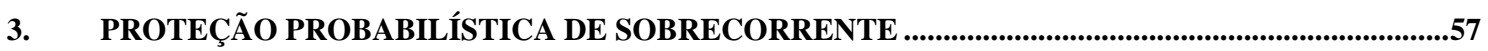

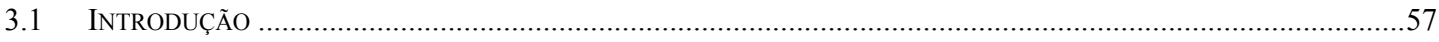

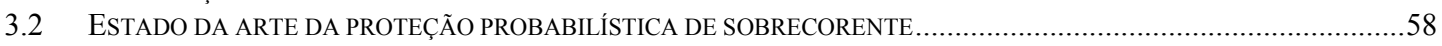

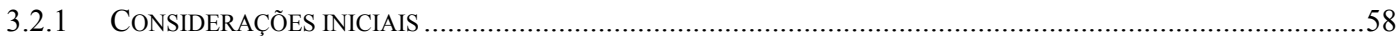

3.2.2 ANÁLISE DE CURTO-CIRCUITO PROBABILÍSTICO PELO MÉTODO DE MONTE CARLO ..................................59

3.3 DETERMINAÇÃO ANALÍTICA DA DISTRIBUIÇÃO DAS CORRENTES DE DEFEITO....................................................63

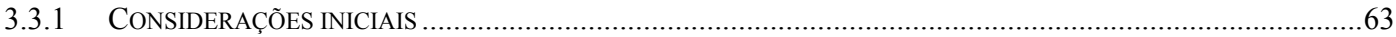




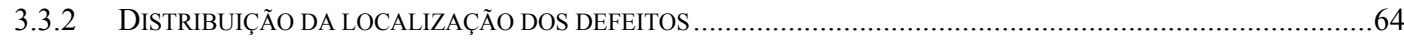

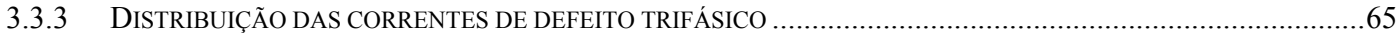

3.3.4 DISTRIBUIÇÃO DAS CORRENTES DE DEFEITO DUPLA FASE....................................................................67

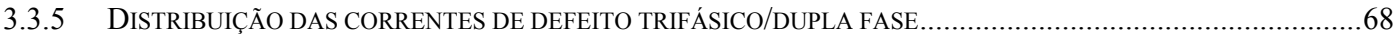

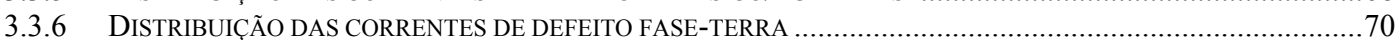

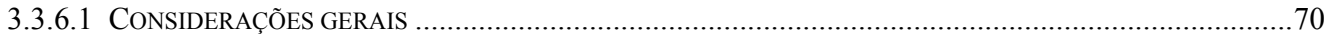

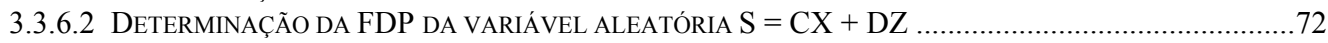

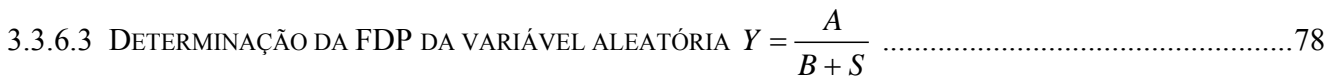

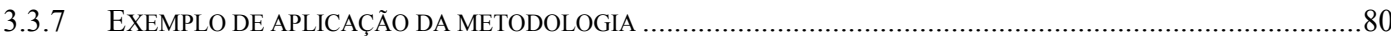

3.4 DETERMINAÇÃO DA DISTRIBUIÇ̃̃O DAS CORRENTES DE DEFEITO ATRAVÉS DE SIMULAÇÃO .............................83

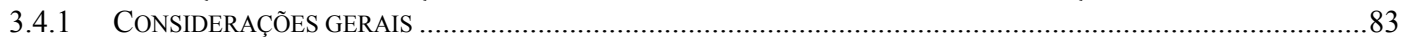

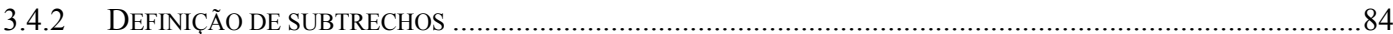

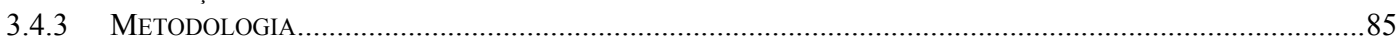

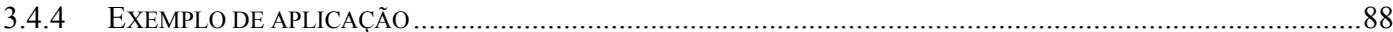

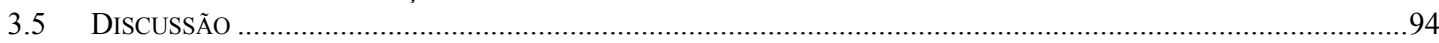

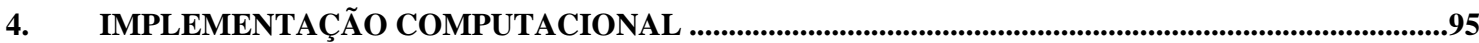

4.1 INTRODUÇ̃̃

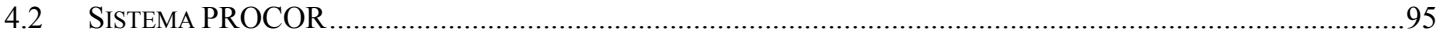

5. APLICAÇÃO DA METODOLOGIA DE COORDENAÇÃO PROBABILÍSTICA DA PROTEÇÃO.107

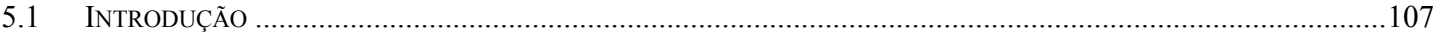

5.2 DADOS UTILIZADOS NO ESTUDO

5.3 COORDENAÇÃO DA PROTEÇÃO ATRAVÉS DE ABORDAGEM CONVENCIONAL …..........................................111

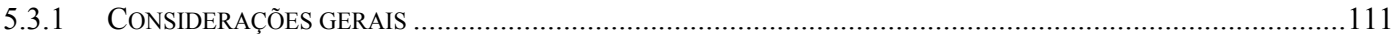

5.3.2 DIMENSIONAMENTOS E AJUSTES DOS DISPOSITIVOS DE PROTEÇÃO ….................................................111

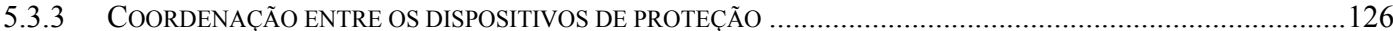

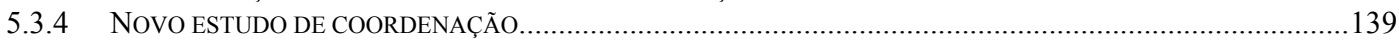

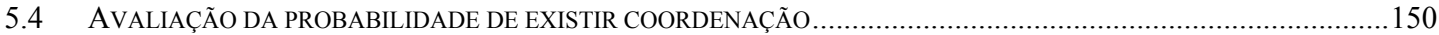

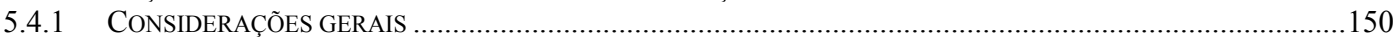

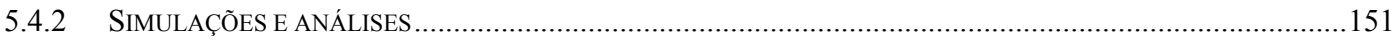

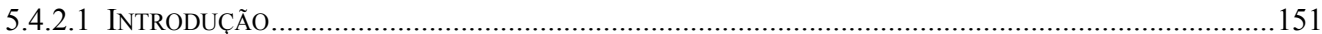

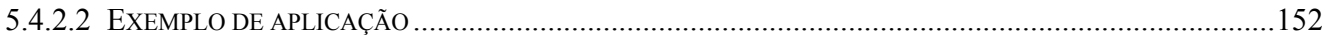

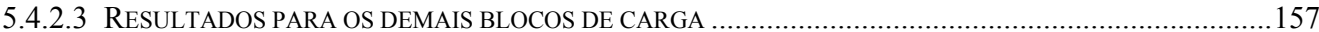

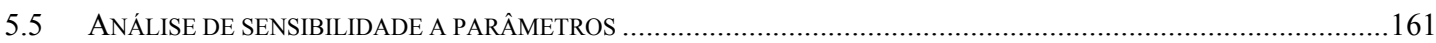

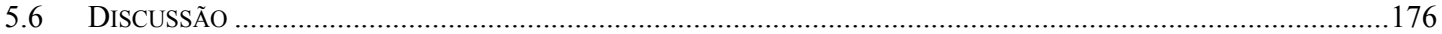

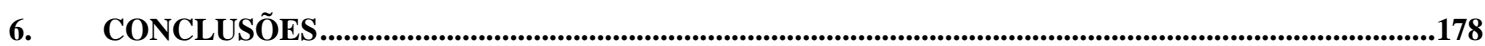

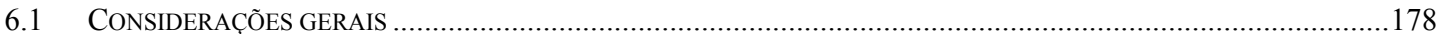

6.2 CONTRIBUIÇÕES DO TRABALHO

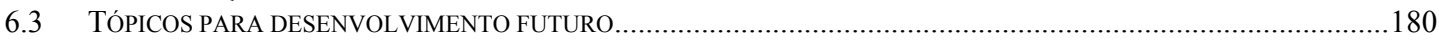

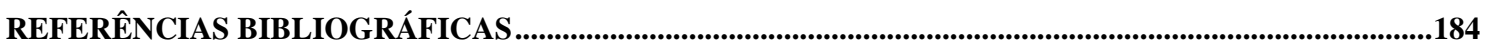

ANEXO A - TABELAS COM INFORMAÇÕES GERAIS DA REDE EM ESTUDO .......................................188

ANEXO B - CURVAS DE TEMPO X CORRENTE DOS DISPOSITIVOS DE PROTEÇÃO UTILIZADOS

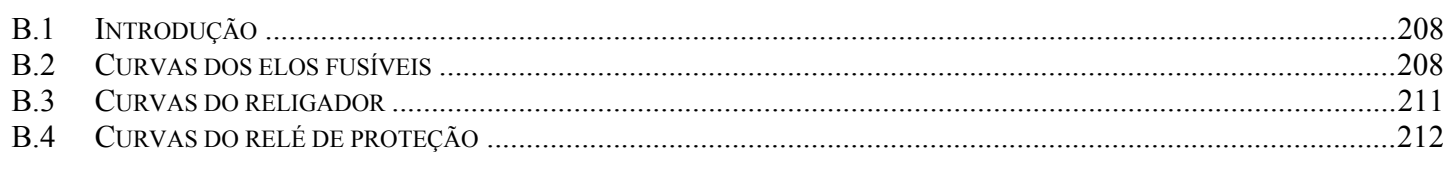

ANEXO C - RESULTADOS GLOBAIS DAS SIMULAÇÕES REALIZADAS ..............................................213

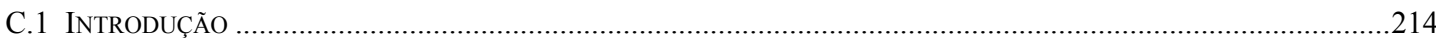

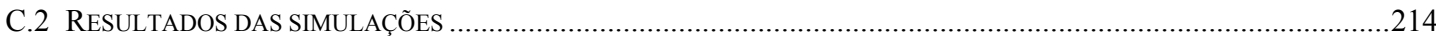

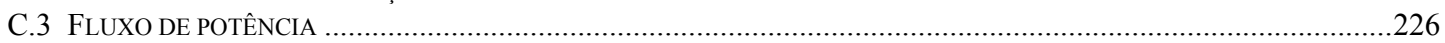

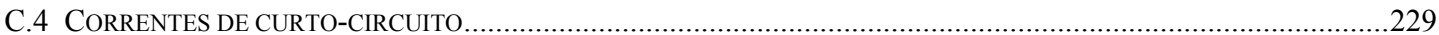




\section{LISTA DE FIGURAS}

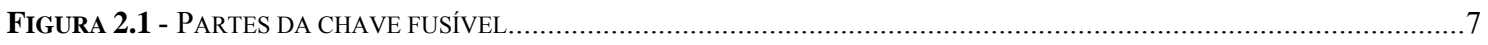

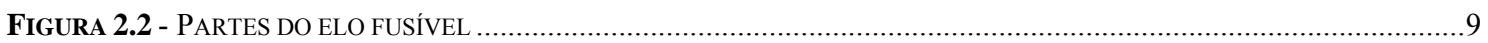

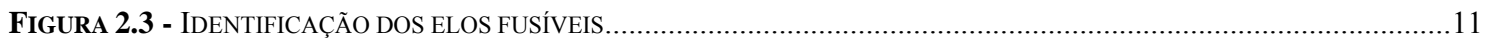

FIGURA 2.4 - CURVA DO TEMPO DE MÁXIMA FUSÃO EM FUNÇÃO DA CORRENTE DOS ELOS 25T E 25K .............................13

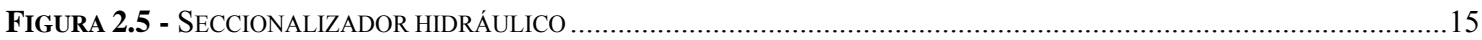

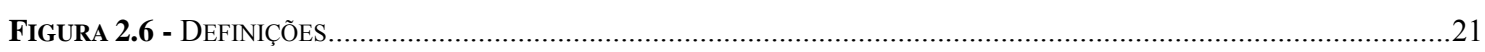

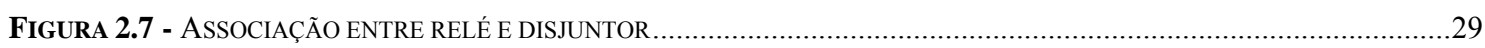

FiguRA 2.8 - DiAgRAMA DE BLOCOS DO HARDWARE DO RELÉ DigitAL COM 3 CANAIS ANALÓGICOS...............................32

FIGURA 2.9 - EXEMPLO DE APLICAÇÃO DOS ELEMENTOS DE SOBRECORRENTE ................................................................36

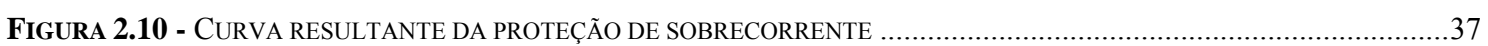

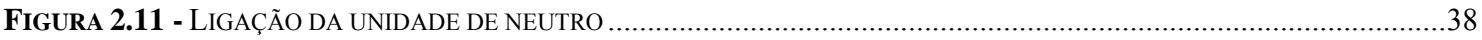

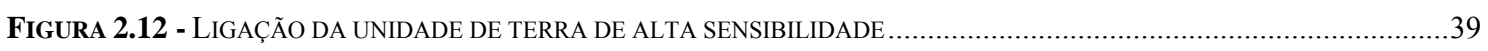

FIGURA 2.13 - OSCILOGRAFIA ILUSTRANDO O FUNCIONAMENTO DA FUNÇÃO DE RELIGAMENTO .....................................41

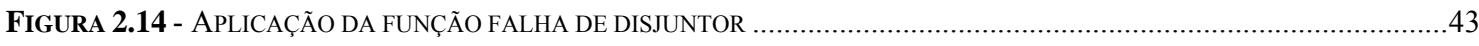

FIGURA 2.15 - ARRANJO TÍPICO PARA A SUPERVISÃO DO CIRCUITO DE ABERTURA ………...........................................4

FIGURA 2.16 - DEFINIÇÃO DO CONCEITO DE COORDENAÇÃO OU SELETIVIDADE ...............................................................48

FIGURA 2.17 - CURVAS E COORDENAÇÃO ENTRE OS ELOS FUSÍVEIS 15T E 25T ….........................................................53

FIGURA 2.18 - TOPOLOGIA DA REDE - RELIGADOR, SECCIONALIZADOR E ELO FUSÍVEL .................................................54

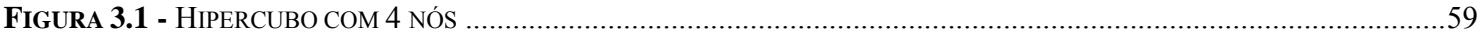

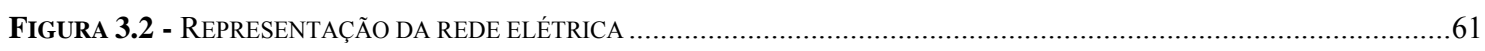

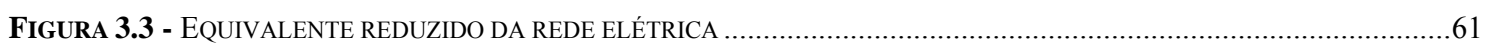

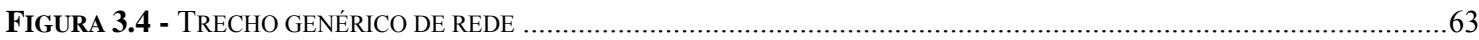

FIGURA 3.5 - FDP E FPA PARA DISTRIBUIÇÃO UNIFORME DA LOCALIZAÇÃO DOS DEFEITOS.............................................64

FIGURA 3.6 - CURTO-CIRCUITO TRIFÁSICO NO PONTO X DO TRECHO GENÉRICO DE REDE ................................................65

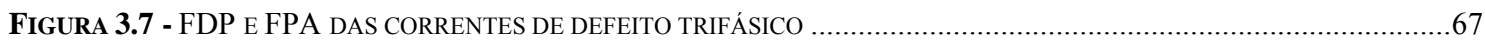

FIGURA 3.8 - FDP DAS CORRENTES DE DEFEITO DE FASE (TRIFÁSICO E DUPLA FASE COMBINADOS) ................................69

FIGURA 3.9 - CURTO-CIRCUITO FASE-TERRA NO PONTO X DO TRECHO GENÉRICO DA REDE ..............................................71

FIGURA 3.10 - DISTRIBUIÇÕES ADOTADAS PARA AS VARIÁVEIS INDEPENDENTES .......................................................... 71

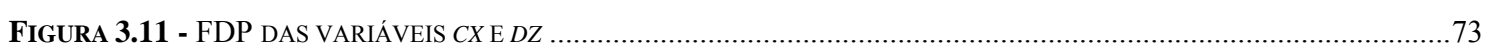

FIGURA 3.12 - COMBINAÇÕES POSSÍVEIS PARA OBTENÇÃO DOS LIMITES DE INTEGRAÇ̃̃O - CASO 1 .................................74

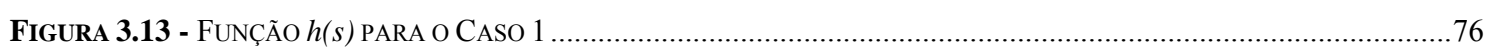

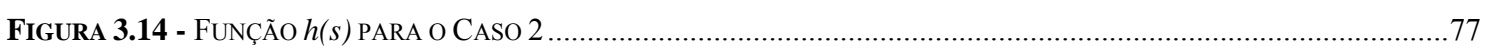

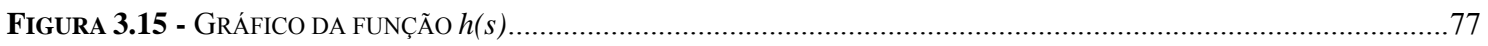

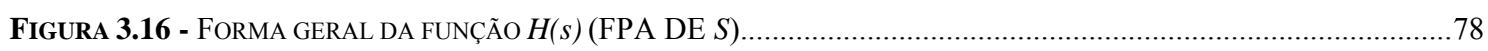

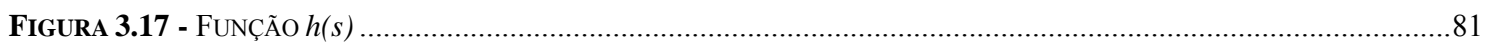

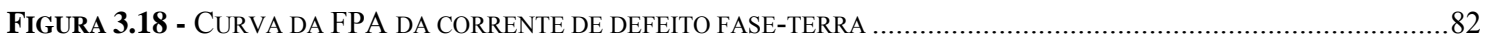

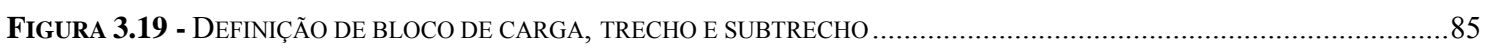

FIGURA 3.20 - DEFINIÇÃO DE SUBTRECHOS EM UM BLOCO DE CARGA …….................................................................8

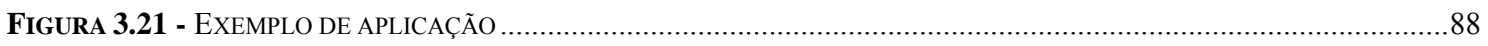

FigURA 3.22 - CURVA DE DISTRIBUIÇÃO DA CORRENTE DE DEFEITO TRIFÁSICO PARA O BLOCO DE CARGA B .....................93 
Figura 4.1 - MENU PRINCIPAL DO SISTEMA PROCOR.

FigURA 4.2 - TELA GRÁFICA CONTENDO A REDE EM ESTUDO COM OS BLOCOS DE CARGA …..........................................102

FIGURA 4.3 - TELA PARA AJUSTE DOS DISPOSITIVOS DE PROTEÇÃO ............................................................................. 103

Figura 4.4 - DiSTRIBUIÇÃO DAS CORRENTES DE FASE E NEUTRO DE UM BLOCO DE CARGA ............................................104

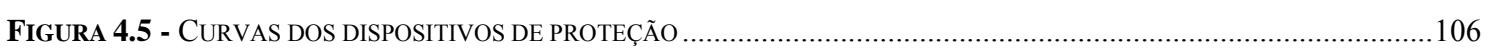

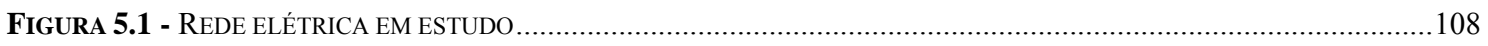

FIGURA 5.2 - DIAGRAMA DE BLOCOS DA REDE ELÉTRICA EM ESTUDO …..................................................................108

FIGURA 5.3 - ANÁLISE DOS DEFEITOS DE TERRA PARA O BLOCO DE CARGA 15 ….......................................................127

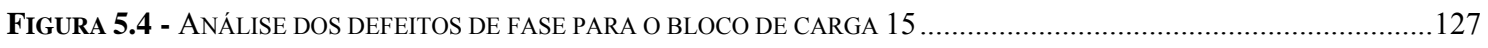

FIGURA 5.5 - ANÁLISE DOS DEFEITOS DE TERRA PARA O BLOCO DE CARGA 13 ................................................................129

FIGURA 5.6 - ANÁLISE DOS DEFEITOS DE FASE PARA O BLOCO DE CARGA 13 …...............................................................129

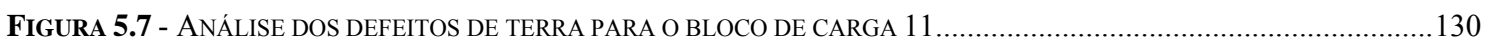

FIGURA 5.8 - ANÁLISE DOS DEFEITOS DE FASE PARA O BLOCO DE CARGA 11 ...............................................................131

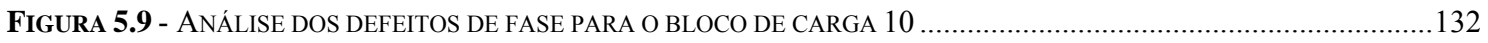

FIGURA 5.10 - ANÁLISE DOS DEFEITOS DE TERRA PARA O BLOCO DE CARGA 9 …...........................................................133

FIGURA 5.11 - ANÁLISE DOS DEFEITOS DE TERRA PARA O BLOCO DE CARGA 8 …....................................................... 134

FIGURA 5.12 - ANÁLISE DOS DEFEITOS DE FASE PARA O BLOCO DE CARGA 8 ….....................................................134

FIGURA 5.13 - ANÁLISE DOS DEFEITOS DE TERRA PARA O BLOCO DE CARGA 6 ..............................................................136

FIGURA 5.14 - ANÁLISE DOS DEFEITOS DE FASE PARA O BLOCO DE CARGA 6 ...............................................................136

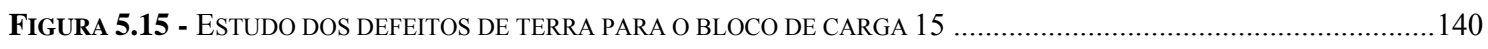

FIGURA 5.16 - ESTUDO DOS DEFEITOS DE FASE PARA O BLOCO DE CARGA 15 ...............................................................141

FIGURA 5.17 - ESTUDO DOS DEFEITOS DE TERRA PARA O BLOCO DE CARGA 13 ..............................................................142

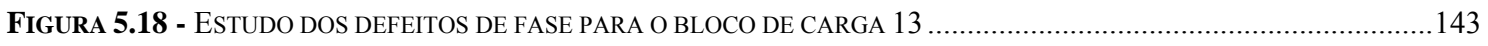

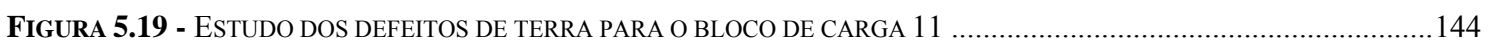

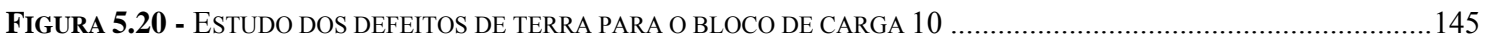

FIGURA 5.21 - ESTUDO DOS DEFEITOS DE TERRA PARA O BLOCO DE CARGA 9 …...........................................................146

FIGURA 5.22 - ESTUDO DOS DEFEITOS DE TERRA PARA O BLOCO DE CARGA 6 ..........................................................148

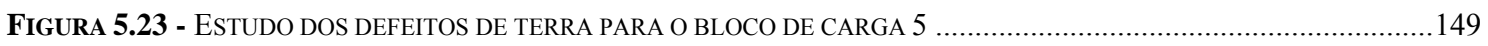

FigURA 5.24 - DiAGRAMA DE BLOCOS DA REDE ELÉTRICA FINAL CONTENDO OS DISPOSITIVOS DE PROTEÇÃO ..................150

FIGURA 5.25 - ANÁLISE DAS PROBABILIDADES PARA OS DEFEITOS A TERRA NO BLOCO DE CARGA 11 ............................153

FIGURA 5.26 - ANÁLISE DAS PROBABILIDADES PARA OS DEFEITOS DE FASE NO BLOCO DE CARGA 11 ............................156

FIGURA 5.27 - FPA RELATIVA AS SIMULAÇÕES 1 E 3 PARA OS DEFEITOS DE TERRA - BLOCO 11...................................163

FIGURA 5.28 - FPA RELATIVA AS SIMULAÇÕES 1 E 3 PARA OS DEFEITOS DE FASE - BLOCO 11......................................164

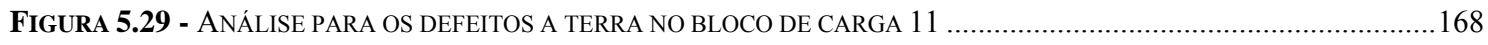

FIGURA 5.30 - AÇÃO CORRETIVA PROPOSTA PARA OS DEFEITOS A TERRA NO BLOCO DE CARGA 11 .................................169

FIGURA 5.31 - ANÁLISE PARA O BLOCO DE CARGA 6 COM A TROCA DO ELO FUSÍvEL .....................................................175

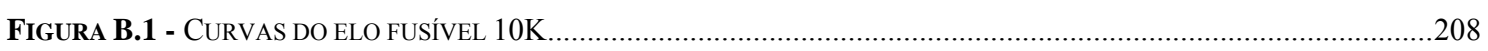

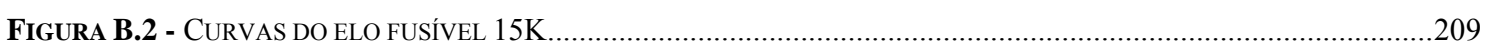

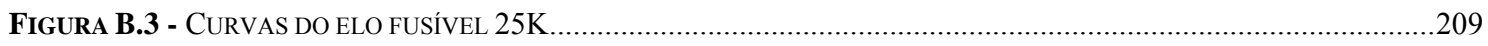

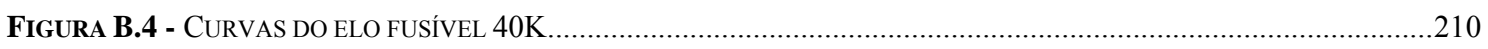

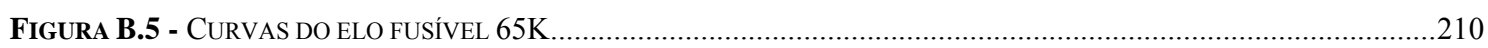

FIGURA B.6 - CURVAS DA UNIDADE DE SOBRECORRENTE DE FASE DO RELIGADOR ….............................................211

FIGURA B.7 - CURVAS DA UNIDADE DE SOBRECORRENTE DE TERRA DO RELIGADOR ...................................................211 


\section{LISTA DE TABELAS}

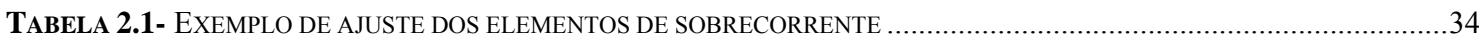

TABELA 2.2 - CONSTANTES $k, \alpha$ e $\beta$ PARA AS CURVAS INVERSAS, CONFORME IEC 255-3 ….............................................35

TABELA 2.3 - AJUSTES DE PROTEÇÃO EFETUADOS PARA O RELÉ DE RELIGAMENTO ......................................................40

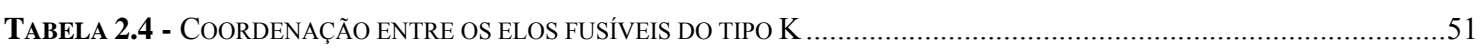

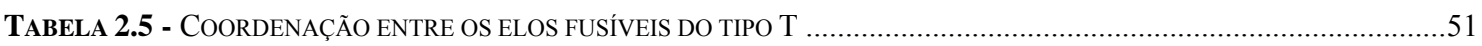

TABELA 2.6 - COORDENAÇÃO ENTRE OS ELOS FUSÍVEIS DO TIPO K E H..................................................................51

TABELA 2.7 - COORDENAÇ̃̃o ENTRE OS ELOS FUSÍVEIS DO TIPO T E H .......................................................................52

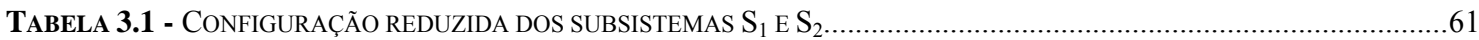

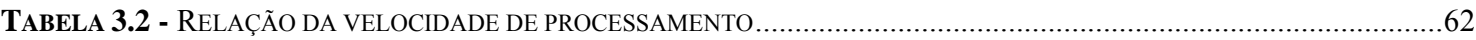

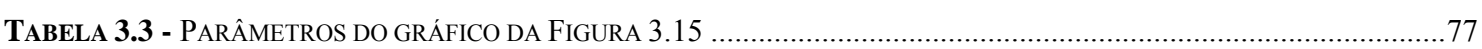

TABELA 3.4 - DADOS PARA EXEMPLO DE TRECHO DE REDE

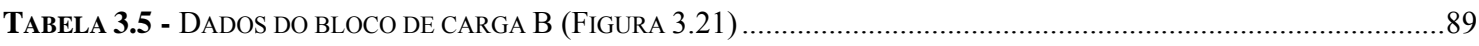

TABELA 3.6 - DADOS ELÉTRICOS PARA CÁLCULO DAS CORRENTES DE CURTO-CIRCUITO ..................................................89

TABELA 3.7 - CORRENTES DE DEFEITO EM CADA SUBTRECHO DO BLOCO DE CARGA B .................................................99

TABELA 3.8 - CORRENTES DE DEFEITO E PROBABILIDADES PARA O BLOCO DE CARGA B .................................................91

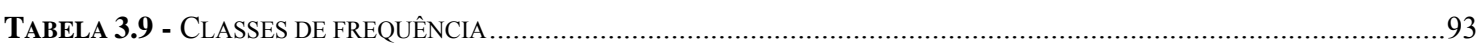

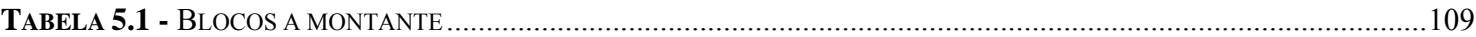

TABELA 5.2 - CARACTERÍSTICAS PRINCIPAIS DA REDE ELÉTRICA EM ESTUDO ................................................................110

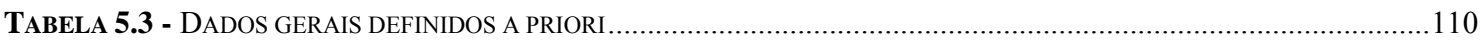

TABela 5.4 - Probabilidades de haVER ou NÃo COORDENAÇÃo ENTRE OS DiSPOSITIVOS DE PROTEÇão

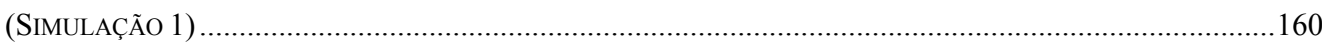

TABELA 5.5 - COMPARAÇ̃̃O DAS VARIÁVEIS MODIFICADAS EM RELAÇÃO A SIMULAÇ̃̃o 1 …..........................................162

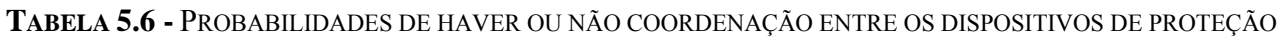

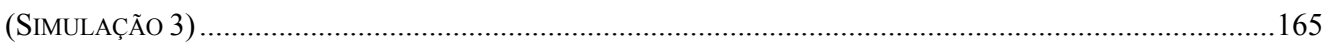

TABELA 5.7 - PONTOS DAS CURVAS DE RESISTÊNCIA DE DEFEITO A E C …….............................................................166

TABela 5.8 - Probabilidades de HAVER OU NÃo COORDENAÇÃo ENTRE OS DiSPOSITIVOS DE PROTEÇÃo

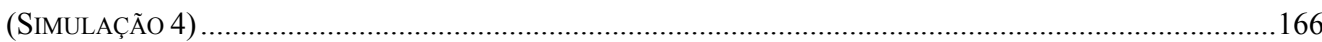

TABELA 5.9 - NÚMERO DE TRECHOS MODIFICADOS POR PARÂMETRO........................................................................ 170

TABElA 5.10 - ProbabilidAdeS DE HAVER OU NÃo COORDENAÇão ENTRE OS DiSPOSITIVOS DE PROTEÇÃO

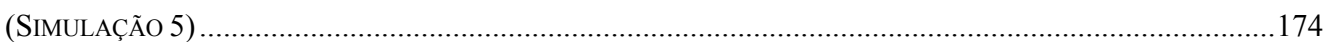

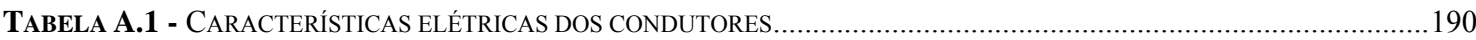

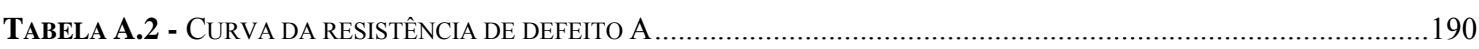

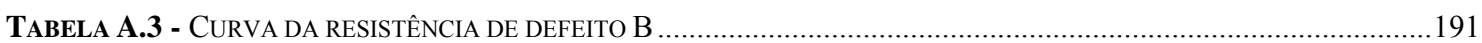

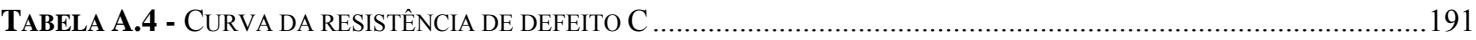

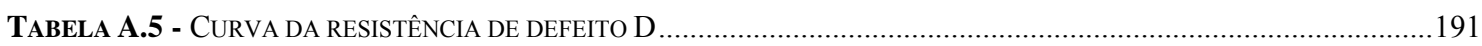

TABELA A.6 - FATORES DE ASSIMETRIA EM FUNÇÃO DA RELAÇÃO X/R …..................................................................192

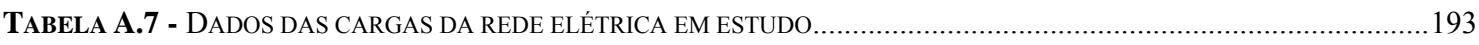

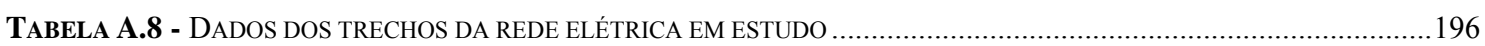

TABELA A.9 - TRECHOS DO BLOCO DE CARGA 1 COM AS RESPECTIVAS PROBABILIDADES DE OCORRÊNCIA DOS DEFEITOS E TIPO DA CURVA DE RESISTÊNCIA DE DEFEITO 
TABela A.10 - Trechos do bloco de CARGa 2 COM AS RESPeCtiVAS PROBABILIDADES DE OCORRÊNCIA DOS DEFEITOS E TIPO DA CURVA DE RESISTÊNCIA DE DEFEITO

TABELA A.11 - TRECHOS DO BLOCO DE CARGA 3 COM AS RESPECTIVAS PROBABILIDADES DE OCORRÊNCIA DOS DEFEITOS E TIPO DA CURVA DE RESISTÊNCIA DE DEFEITO

TABELA A.12 - TRECHOS DO BLOCO DE CARGA 4 COM AS RESPECTIVAS PROBABILIDADES DE OCORRÊNCIA DOS DEFEITOS E TIPO DA CURVA DE RESISTÊNCIA DE DEFEITO

TABEla A.13 - TReChOS do Bloco DE CARGa 5 COM AS RESPECTIVAS PROBABILIDADES DE OCORRÊNCIA DOS DEFEITOS E TIPO DA CURVA DE RESISTÊNCIA DE DEFEITO

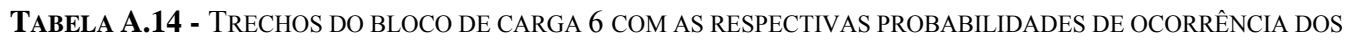
DEFEITOS E TIPO DA CURVA DE RESISTÊNCIA DE DEFEITO

TABELA A.15 - TRECHOS DO BLOCO DE CARGA 7 COM AS RESPECTIVAS PROBABILIDADES DE OCORRÊNCIA DOS DEFEITOS E TIPO DA CURVA DE RESISTÊNCIA DE DEFEITO

TABELA A.16 - TRECHOS DO BLOCO DE CARGA 8 COM AS RESPECTIVAS PROBABILIDADES DE OCORRÊNCIA DOS DEFEITOS E TIPO DA CURVA DE RESISTÊNCIA DE DEFEITO

TABElA A.17 - Trechos do BLOCO DE CARGa 9 COM AS RESPECTIVAS PROBABILIDADES DE OCORRÊNCIA DOS DEFEITOS E TIPO DA CURVA DE RESISTÊNCIA DE DEFEITO

TABEla A.18 - TRECHOS DO BLOCO DE CARGA 10 COM AS RESPECTIVAS PROBABILIDADES DE OCORRÊNCIA DOS DEFEITOS E TIPO DA CURVA DE RESISTÊNCIA DE DEFEITO

TABEla A.19 - Trechos do BLOCO DE CARGA 11 COM AS RESPECTIVAS PROBABILIDADES DE OCORRÊNCIA DOS DEFEITOS E TIPO DA CURVA DE RESISTÊNCIA DE DEFEITO

TABELA A.20 - TRECHOS DO BLOCO DE CARGA 12 COM AS RESPECTIVAS PROBABILIDADES DE OCORRÊNCIA DOS DEFEITOS E TIPO DA CURVA DE RESISTÊNCIA DE DEFEITO

TABela A.21 - Trechos do bloco de CARGA 13 COM AS ReSpeCtiVAS PROBABILIDADES DE OCORRÊNCIA DOS DEFEITOS E TIPO DA CURVA DE RESISTÊNCIA DE DEFEITO

TABElA A.22 - Trechos DO BLOCO DE CARGA 14 COM AS RESPECTIVAS PROBABILIDADES DE OCORRÊNCIA DOS DEFEITOS E TIPO DA CURVA DE RESISTÊNCIA DE DEFEITO

TABELA A.23 - TRECHOS DO BLOCO DE CARGA 15 COM AS RESPECTIVAS PROBABILIDADES DE OCORRÊNCIA DOS DEFEITOS E TIPO DA CURVA DE RESISTÊNCIA DE DEFEITO

TABELA C.1 - FPA DAS CORRENTES DE DEFEITO FASE-TERRA - SIMULAÇ̃̃o 1 ................................................................216

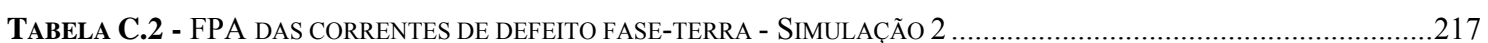

TABELA C.3 - FPA DAS CORRENTES DE DEFEITO FASE-TERRA - SiMULAÇÃo 3 …..........................................................218

TABELA C.4 - FPA DAS CORRENTES DE DEFEITO FASE-TERRA - SIMULAÇ̃̃o 4 ...............................................................219

TABELA C.5 - FPA DAS CORRENTES DE DEFEITO FASE-TERRA - SIMULAÇão 5 …..........................................................2220

TABELA C.6 - FPA DAS CORRENTES DE DEFEITO FASE-FASE - SiMULAÇÃO 1 ……………......................................221

TABELA C.7 - FPA DAS CORRENTES DE DEFEITO FASE-FASE - SiMULAÇÃO 2 …..........................................................222

TABELA C.8 - FPA DAS CORRENTES DE DEFEITO FASE-FASE - SIMULAÇ̃̃ 3 …….....................................................22

TABELA C.9 - FPA DAS CORRENTES DE DEFEITO FASE-FASE - SiMULAÇão 4 ..................................................................22

TABELA C.10 - FPA DAS CORRENTES DE DEFEITO FASE-FASE - SiMULAÇão 5 .............................................................22

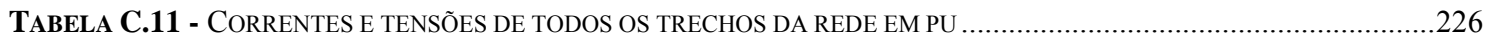

TABELA C.12 - CORRENTES DE DEFEITO EM TODOS OS TRECHOS DA REDE EM ESTUDO.................................................229 


\section{INTRODUÇÃO}

\section{1 - Apresentação do problema e objetivos do trabalho}

As redes de distribuição de energia elétrica têm por objetivo transportar a energia disponibilizada pelo sistema de transmissão até os consumidores finais. Tal distribuição é feita em níveis de tensão compatíveis com os blocos de energia envolvidos no processo. Assim, tem-se as redes de distribuição primária que emergem das subestações de distribuição e que operam em tensões nominais próximas de $15 \mathrm{kV}$. Estas redes alimentam os consumidores primários e os transformadores de distribuição, sendo que estes últimos são os responsáveis por abaixar a tensão para valores nominais em torno de $200 \mathrm{~V}$ e alimentar as redes secundárias, às quais estão conectados os consumidores finais de baixa tensão (residenciais, comerciais e alguns industriais).

Existem diversos padrões construtivos para as redes de distribuição primárias e secundárias. O presente trabalho irá tratar especificamente das redes primárias aéreas, as quais, no caso brasileiro, respondem pela grande maioria das redes primárias de distribuição. As redes aéreas se desenvolvem através de postes; em áreas urbanizadas a posteação é ditada pela planta urbana (ruas, avenidas, etc.) e em áreas rurais ela normalmente acompanha o trajeto de caminhos e estradas.

Por razões fundamentalmente econômicas, as redes primárias aéreas operam na condição radial. Isto significa que um alimentador primário emergindo de uma subestação não troca carga com outro alimentador próximo, em condições normais de operação. Assim, os consumidores ligados a um determinado alimentador possuem uma única fonte de energia. No sentido de melhorar a confiabilidade de um sistema radial sem incorrer em custos excessivos, chaves que operam normalmente no estado aberto são colocadas em pontos convenientes da rede, de forma a permitir a troca temporária de carga entre alimentadores e subestações. 
As redes primárias de distribuição contam com sistemas de proteção destinados a desenergizar porções da rede que venham a operar em condições anormais tais como: curto-circuitos, sobretensões devido a descargas atmosféricas, abalroamentos, etc. O sistema de proteção é constituído por disjuntores, relés, elos fusíveis e demais equipamentos que são instalados na subestação de distribuição e também ao longo da rede. Entre os requisitos do sistema de proteção estão a seletividade e a proteção de retaguarda. Seletividade significa que, na ocorrência de um defeito, a menor porção possível da rede seja desenergizada, minimizando os efeitos indesejáveis da interrupção do fornecimento de energia. Proteção de retaguarda significa que, no caso de falha do dispositivo de proteção mais próximo de um defeito (isto é, no caso de o dispositivo de proteção não ser capaz de cumprir sua função), exista algum outro equipamento que seja capaz de detectar o defeito e executar essa interrupção, naturalmente afetando um número maior de consumidores com relação à situação ideal (inexistência de falha do primeiro dispositivo).

Em um sistema elétrico procura-se alcançar seletividade e proteção de retaguarda através da adequada coordenação entre os diferentes dispositivos de proteção. A coordenação da proteção em sistemas de distribuição vem sendo estudada há mais de 50 anos, razão pela qual ela já alcançou um estágio de elevada maturidade [1]-[7]. Os últimos avanços nesta área têm se verificado no âmbito tecnológico, com a introdução de relés estáticos e relés digitais em anos recentes.

A abordagem tradicional da coordenação da proteção em redes de distribuição parte de uma descrição determinística das principais variáveis independentes do problema: localização e tipo dos defeitos e impedâncias externas envolvidas. Estas variáveis contribuem para estabelecer a principal variável dependente do problema, que é a corrente de defeito e cujo conhecimento é fundamental para estabelecer uma adequada coordenação da proteção.

Muitas vezes a abordagem tradicional da coordenação se mostra inadequada para representar alguns fenômenos verificados na prática. Um exemplo disto é a resistência de defeito, nos casos em que o defeito envolve a terra - por exemplo, um cabo rompido que toca o chão e através do qual irá circular corrente de fuga. Neste caso, a resistência 
de defeito irá depender de muitos fatores não controlados (resistividade do solo, material da superfície do solo, condições de umidade, etc.) que implicarão variações elevadas da resistência de defeito e por conseqüência variações elevadas da corrente de defeito. Como estes fatores não são normalmente incorporados no modelo tradicional, um sistema de proteção ajustado segundo um estudo tradicional de coordenação da proteção poderá apresentar comportamento insatisfatório em algumas situações.

O principal objetivo deste trabalho é desenvolver uma nova abordagem para o problema de coordenação da proteção. Nesta nova abordagem, de natureza probabilística, as variáveis citadas anteriormente serão definidas e tratadas como variáveis aleatórias. Para as variáveis independentes (tipo e localização dos defeitos e impedâncias externas) assumir-se-á que as correspondentes distribuições de valores são conhecidas, de forma que a distribuição de probabilidades da variável dependente (corrente de defeito) possa ser determinada através do cálculo de probabilidades e da teoria de curto-circuito.

Um segundo objetivo importante do trabalho é aplicar a metodologia desenvolvida em redes reais de distribuição primária, permitindo identificar parâmetros críticos da metodologia e permitindo ainda estabelecer suas vantagens e desvantagens em relação a abordagem tradicional da coordenação da proteção.

\section{2 - Organização do trabalho}

O trabalho em questão está organizado em seis capítulos e três anexos, conforme apresentado nas linhas abaixo.

No Capítulo 1 é feita uma apresentação e a abordagem inicial do problema proposto para o trabalho em questão. 
O Capítulo 2 é estruturado em duas partes:

a) Descrição dos equipamentos de proteção utilizados:

Neste tópico é feita uma abordagem detalhada dos equipamentos elétricos utilizados para a proteção das redes de distribuição primária radiais. Tais equipamentos são: chave e elo fusível, seccionalizadores, religadores automáticos, relés e disjuntores.

O objetivo deste item é conhecer os princípios básicos de funcionamento de cada um dos equipamentos acima citados, bem como a aplicação e as principais características elétricas e mecânicas dos mesmos.

b) Coordenação entre os equipamentos de proteção:

O objetivo deste item é apresentar os critérios utilizados na coordenação entre os equipamentos de proteção. A metodologia e os critérios de coordenação serão apresentados para as seguintes combinações:

- Elo fusível x Elo fusível;

- Religador, Seccionalizador e Elo fusível;

O Capítulo 3 aborda a metodologia e o estado da arte para a determinação da distribuição de probabilidades das correntes de defeito. O capítulo apresenta dois exemplos de aplicação da metodologia estudada.

O Capítulo 4 apresenta sucintamente a ferramenta computacional utilizada para o processamento dos casos práticos do problema de coordenação probabilística da proteção de sobrecorrente em redes de distribuição primária.

O Capítulo 5 ilustra inicialmente o projeto básico para a escolha dos dispositivos de proteção a serem instalados em cada um dos blocos de carga da rede elétrica proposta 
para ser estudada. Com esta definição parte-se para a simulação de 5 casos práticos para elucidar a influência das variáveis taxa de falha, probabilidades de ocorrência de cada um dos tipos de defeito, comprimento do subtrecho e resistência de defeito, na coordenação entre os dispositivos de proteção.

O Capítulo 6 trata das conclusões, contendo as considerações finais, contribuições do trabalho e tópicos para posterior desenvolvimento.

Além dos capítulos acima descritos, foram desenvolvidos 3 anexos, conforme segue:

- O $\underline{\text { Anexo A, }}$ que apresenta os dados gerais relativos a todos os trechos da rede em estudo, tais como: pontos das curvas de resistência de defeito, características elétricas dos condutores, probabilidades de ocorrência de um tipo de defeito e taxa de falha;

- O Anexo B, que ilustra as curvas de tempo em função da corrente de todos os equipamentos de proteção utilizados no presente trabalho;

- O Anexo C, que indica os resultados detalhados das cinco simulações realizadas, bem como as tensões e correntes de carga e curto-circuito, em cada barra, no ano inicial e no horizonte de estudo (5 anos). 


\section{PROTEÇÃO CONVENCIONAL DE SOBRECORRENTE EM REDES PRIMÁRIAS DE DISTRIBUIÇÃO}

\section{1 - Introdução}

O objetivo deste capítulo é apresentar os equipamentos utilizados na proteção de sistemas de distribuição primária, tais como os elos fusíveis, os seccionalizadores, os religadores e os disjuntores equipados com relés de proteção.

Finalizando o capítulo, serão analisadas as coordenações entre os equipamentos de proteção estudados.

\section{2 - Equipamentos}

\subsection{1 - Chave e elo fusível}

\subsubsection{1 - Introdução}

A chave fusível é um equipamento amplamente utilizado na proteção contra sobrecorrentes em redes primárias de distribuição de energia elétrica. A sua operação consiste basicamente na fusão do elo fusível, quando o mesmo é percorrido por uma magnitude de corrente elétrica acima da nominal, dentro de um determinado tempo, conforme a sua característica de tempo em função da corrente.

\subsubsection{2 - Chave fusível}

As chaves fusíveis são constituídas pelas seguintes partes, conforme Figura 2.1 (página 55 / Figura 2.1 - Mamede Filho, João. MANUAL DE EQUIPAMENTOS ELÉTRICOS $-2^{\mathrm{O}}$ Edição volume 1, publicado em língua portuguesa por LTC - Livros Técnicos e Científicos Editora SA Copyright (C) 1994, reproduzido com permissão da editora.) e descritas em detalhe nas linhas subseqüentes: 


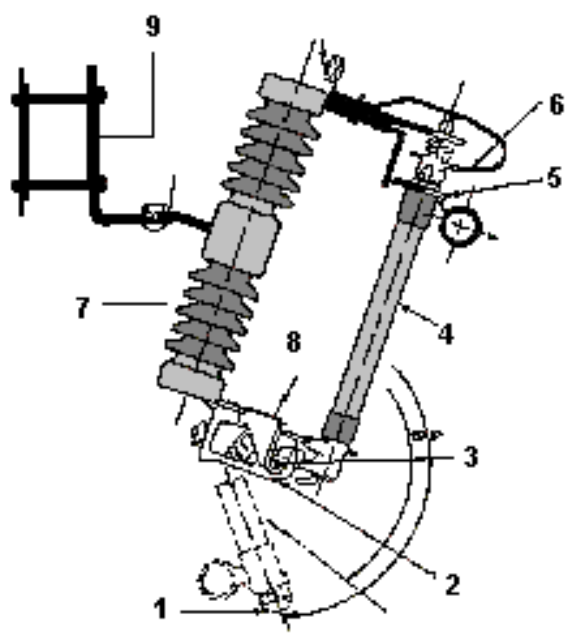

Figura 2.1 - Partes da chave fusível [1]

\section{Legenda:}

1 - Posição de repouso

2 - Limitador de $180^{\circ}$

3 - Limitador de recuo

4 - Cartucho ou porta fusível

5 - Gancho para abertura em carga

6 - Terminais superiores

7 - Isoladores

8 - Articulação

9 - Suporte de fixação

- Isolador: Tem por finalidade garantir a isolação da chave fusível. São constituídos de porcelana vitrificada que apresentam uma resistência mecânica condizente para suportar a abertura e ao fechamento da chave. Podem ser de corpo único (aplicados em sistemas cuja corrente é menor ou igual a 200 A) [1], ou do tipo pedestal (com dois isoladores), sendo estes utilizados em subestações para que possa ser feita a manutenção de disjuntores e religadores automáticos, sem a interrupção no fornecimento de energia elétrica.

- Gancho para abertura em carga: É acoplado nos terminais da chave fusível e tem por função possibilitar a abertura da mesma em carga. Sem este gancho não seria possível manobrar a chave sob carga, uma vez que ela não possui um sistema para a extinção do arco elétrico.

- Cartucho ou porta fusível: É um elemento principal da chave fusível, sendo constituído por uma fibra de vidro revestida internamente por uma fibra óssea, que aumenta a sua robustez e gera, em parte, os gases desionizantes (Hidrogênio e monóxido de carbono) que provocam a interrupção do arco elétrico. Existem cartuchos onde a saída destes gases ocorre em sua parte inferior e outros pela parte superior. A escolha de um ou de outro está diretamente relacionada com a capacidade de interrupção almejada para a chave fusível. 
- Articulação: Corresponde à estrutura responsável pela movimentação da chave fusível, exercendo uma função fundamental na operação da mesma. É composta pelas seguintes partes:

- Limitador de recuo, cuja função é intertravar diretamente o cartucho no corpo da chave;

- Amortecedor, cuja função é minimizar o impacto decorrente da abertura do porta fusível;

- Limitador de abertura de $180^{\circ}$, cuja função é a de não permitir que o cartucho atinja a estrutura adjacente inferior durante a sua abertura;

- Batentes dos contatos, que têm por função proteger os contatos contra choques mecânicos e deformações permanentes.

- Terminal superior: É composto por três partes metálicas com a finalidade de garantir um engate perfeito do cartucho e também um bom contato elétrico. Resumidamente, as três partes são:

- Contatos principais, constituídos por uma liga de cobre com alta resistência aos esforços mecânicos e térmicos decorrentes da corrente de curto-circuito. A sua forma construtiva permite uma auto limpeza durante as operações de abertura e fechamento;

- Tranca de contato, têm por funções: impedir a abertura acidental da chave fusível, evitar a queima dos contatos principais durante uma interrupção normal, reduzir a queima dos contatos principais quando a chave é fechada em condições de curto circuito;

- Guarda do contato, cuja função é guiar o cartucho durante o fechamento da chave, evitando que ele se solte e também proteger os contatos principais contra avarias durante o manuseio e operação da chave.

- Suporte de fixação: Tem por finalidade dar sustentação à chave fusível para que a mesma seja fixada em uma estrutura metálica. 
Nos parágrafos anteriores, foram descritas as partes principais da chave fusível e a seguir será dada maior ênfase ao elo fusível, que corresponde ao coração do equipamento.

\title{
2.2.1.3 - Elo fusível
}

a) Introdução e partes constituintes

Fisicamente, o elo fusível é montado dentro do cartucho e é composto de um elemento metálico que na passagem de uma corrente elétrica elevada, funde-se dentro de um intervalo de tempo determinado. A corrente e o tempo de fusão variam inversamente, ou seja, maior a corrente, menor o tempo de fusão e vice versa.

Os elos fusíveis são constituídos pelas seguintes partes, conforme Figura 2.2 e descritas em detalhe nas linhas subseqüentes:

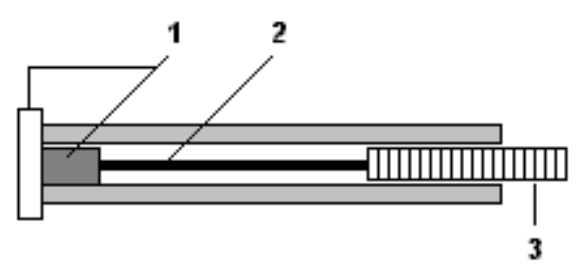

\author{
Legenda: \\ 1 - Cabeça com botão \\ 2 - Elemento fusível \\ 3 - Rabicho ou cordoalha
}

Figura 2.2 - Partes do Elo fusível [3]

- Cabeça com botão: tem por função fixar o elo fusível ao cartucho e estabelecer o contato elétrico.

- Elemento fusível: É fixado em uma extremidade na cabeça com botão e na outra a uma cordoalha ou rabicho. O elemento fusível deve ser constituído por um material de tal forma que as suas características não sejam modificadas quando ocorrer à passagem da corrente nominal. Para que as curvas características tempo em função da corrente do elo fusível não sejam alteradas, é necessário utilizar um material que seja um metal ou liga metálica, não sujeitas a oxidação e que tenha uma temperatura de trabalho e ponto de fusão baixo. Com base nisto, o cobre não é indicado para ser utilizado como elemento fusível, uma vez que o seu ponto de fusão é $1083^{\circ} \mathrm{C}$ [1] e temperatura de 
trabalho de $300^{\circ} \mathrm{C}$ [2], causando, portanto, uma carbonização do revestimento interno do cartucho. O chumbo que é largamente utilizado em fusíveis de baixa tensão [1] não é apropriado para a média tensão, pois não tem a dureza necessária para evitar uma deformação. Neste sentido, uma liga de estanho se torna amplamente adequada para ser utilizada como elemento fusível, pois além de ter uma boa resistência mecânica, possui uma temperatura de trabalho menor do que $100^{\circ} \mathrm{C}$ e ponto de fusão em $230^{\circ} \mathrm{C}$ [1], [2]. As dimensões do elemento fusível (diâmetro e comprimento) e a resistividade elétrica determinam o seu tempo de fusão em função da corrente passante, sendo este dependente, conforme [2], da temperatura ambiente, da corrente, do grau de envelhecimento e do tipo de material utilizado.

- Rabicho ou cordoalha: Formado por um condutor estanhado, composto de vários micro fios. O diâmetro da cordoalha, conforme [1] é igual a $4 \mathrm{~mm}$ para elos de 1 a $50 \mathrm{~A}$, $6,5 \mathrm{~mm}$ para elos de 65 a $100 \mathrm{~A}$ e 9,5 mm para elos de 140 a $200 \mathrm{~A}$.

Para elos até $100 \mathrm{~A}$, existe um tubo protetor de fibra isolante entre o elemento fusível e o rabicho, com a função de proteger o elemento fusível contra danos mecânicos e atuar como estabilizador do tempo de fusão, produzindo gases com a finalidade de interromper o arco elétrico para pequenas sobrecorrentes [2].

b) Princípio de funcionamento

Os elos fusíveis quando submetidos a passagem da corrente elétrica, transferem calor por condução à cordoalha. O comprimento do elemento fusível determina a quantidade de calor transferida, sendo que quando temos uma baixa corrente e elemento fusível longo, ocorre no centro deste a formação de um ponto quente que ocasionará a sua fusão. Em contrapartida, com a mesma corrente e comprimento pequeno, todo o calor é transferido para a cordoalha e conseqüentemente não temos a formação do ponto quente no centro do elemento fusível e, portanto, não haverá a sua fusão. No caso particular da passagem da corrente de curto-circuito, não há tempo suficiente para que o calor seja transferido a cordoalha, formando assim um ponto quente no elemento fusível ocasionando a sua fusão. Com base nisto, um elo fusível para uma dada corrente nominal tem um elemento fusível de diâmetro e comprimento especificados, de tal 
forma que o mesmo responda a uma característica de tempo de operação em função da corrente, de acordo com a norma NBR 5359 / 1989 da Associação Brasileira de Normas Técnicas - ABNT [27].

Com a fusão do elo, ocorre a formação de um arco elétrico que é extinto devido à ação de gases desionizantes, que proporcionam uma elevação da rigidez dielétrica, resultando em uma elevada resistência, provocando assim a interrupção da corrente quando ela passar pelo zero, impedindo a reignição do arco elétrico.

c) Definições

Alguns conceitos importantes relativos a elos fusíveis, que serão utilizados amplamente nos capítulos posteriores:

- Elo fusível protetor: É aquele que é instalado no lado da carga;

- Elo fusível protegido: É aquele que é instalado no lado da fonte;

A Figura 2.3 elucida as definições acima apresentadas.

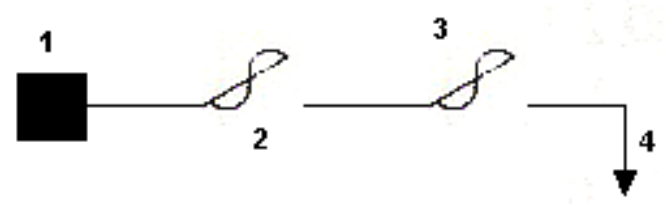

Figura 2.3 - Identificação dos elos fusíveis

\section{Legenda:}

1 - Fonte (Subestação de distribuição)

2 - Elo fusível protegido

3 - Elo fusível protetor

4 - Carga

- Tempo mínimo de fusão: Corresponde ao tempo transcorrido em função da corrente de atuação, desde o instante em que a corrente começou a circular pelo elo fusível até o momento da sua fusão;

- Tempo máximo de fusão: Corresponde ao tempo mínimo de fusão, em função da corrente de atuação, mais uma margem de tolerância admitida pelo fabricante do elo fusível; 
- Tempo de extinção do arco: Corresponde ao tempo máximo de fusão, em função da corrente de atuação, mais o tempo necessário para a extinção do arco elétrico;

- Corrente de curta duração: É a corrente suportada pelo elo fusível, por um determinado tempo, sem que o mesmo sofra fusão;

- Corrente nominal: É a máxima corrente que pode ser conduzida continuamente pelo elo fusível sem que o mesmo sofra fusão;

- Capacidade de interrupção: Corresponde a máxima corrente de curto-circuito que o elo fusível é capaz de interromper;

- Relação de rapidez ou de velocidade $(\rho)$ : Corresponde a razão entre as correntes de mínima fusão nos tempos 0,1 segundos e 300 segundos para elos até 100 A. Para elos maiores de 100 A, esta relação é obtida dividindo-se as correntes mínimas de fusão nos tempos 0,1 e 600 segundos.

d) Tipos de Elos

Existem três tipos de elos fusíveis, utilizados em sistemas de distribuição primária, sendo que cada um deles possui uma característica diferenciada de tempo de fusão em função da corrente. Os três tipos de elos são:

- Tipo K: São elos fusíveis rápidos com correntes nominais padronizadas pela NBR 5359/1989 [27] de 6, 10, 15, 25, 40, 65, 100, 140 e 200 A, com correntes mínimas de atuação iguais a 2,0 vezes a corrente nominal [3]. Para designar em um projeto ou em uma especificação técnica, que o elo é do tipo K, coloca-se a corrente nominal do elo, seguida pela letra K. Assim, a indicação 40K, significa um elo fusível com corrente nominal de 40 A do tipo K. São amplamente utilizados na proteção de redes aéreas de distribuição primária. 
- Tipo T: São elos fusíveis lentos com correntes nominais padronizadas pela NBR 5359/1989 [27] de 6, 10, 15, 25, 40, 65, 100, 140 e 200 A, com correntes mínimas de atuação iguais a 2,0 vezes a corrente nominal [3]. Para designar em um projeto ou em uma especificação técnica, que o elo é do tipo T, coloca-se a corrente nominal do elo, seguida pela letra T. Assim, a indicação 10T, significa um elo fusível com corrente nominal de 10 A do tipo T. São pouco utilizados aqui no Brasil [1] e geralmente aplicados na proteção de ramais das redes de distribuição primária.

- Tipo H: São elos fusíveis destinados a proteção de transformadores de distribuição instalados no lado de média tensão (primário). São elos fusíveis capazes de suportarem correntes de alto surto, tais como as de magnetização, dos transformadores, sem provocar a fusão do elemento fusível. Estão disponíveis nas correntes de 1, 2, 3 e 5 A, com correntes mínimas de atuação iguais a 3, 5, 6,5 e 9 A, respectivamente [1,2]. Existe também elos do tipo $\mathrm{H}$ de $8 \mathrm{~A}$, com corrente mínima de atuação igual a 15 A [3].

Segue na Figura 2.4, a curva característica do tempo de máxima fusão dos elos fusíveis $25 \mathrm{~T}$ e $25 \mathrm{~K}$, em função da corrente.

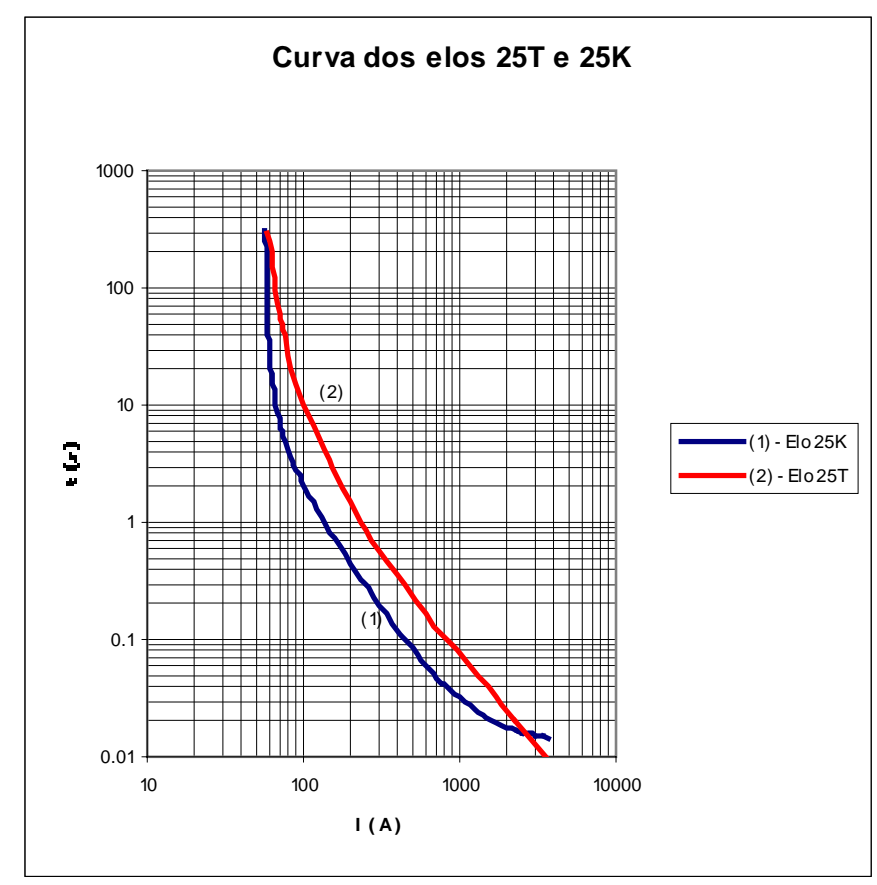

Figura 2.4 - Curva do tempo de máxima fusão em função da corrente dos elos $25 \mathrm{~T}$ e $25 \mathrm{~K}[2]$ 


\subsection{2 - Seccionalizadores}

\subsubsection{1 - Introdução}

O seccionalizador é um equipamento que tem a função de abrir um determinado trecho de uma rede de distribuição primária quando ocorre um defeito elétrico em um ponto situado a jusante de sua instalação, cuja corrente é interrompida por um equipamento de retaguarda, tais como o religador e o disjuntor dotado de um relé de sobrecorrente com religamento.

Os seccionalizadores não têm capacidade para interromper as correntes de curto circuito, sendo este processo executado pelo equipamento situado a montante, conforme explanado no parágrafo anterior.

\subsubsection{2 - Princípio de funcionamento}

Construtivamente, um seccionalizador é constituído por: um sensor que detecta as sobrecorrentes no circuito, um equipamento que registra o número de operações do equipamento situado a montante e por contatos principais e dispositivos para travamento da chave na posição aberto.

Quando através do seccionalizador passar uma corrente maior do que o limite ajustado no elemento sensor, o equipamento será preparado para uma contagem, que será iniciada tão logo ocorra a abertura do equipamento de retaguarda. O número de contagens é ajustado no equipamento, sendo que no momento em que for registrada a última contagem, o seccionalizador abrirá os seus pólos definitivamente, isolando apenas o trecho da rede com falha. Após a sua operação, o seccionalizador fica travado na posição aberto, podendo apenas ser fechado manualmente.

\subsubsection{3 - Classificação}

a) Quanto ao número de fases: 
- Monofásicos: Aplicados em redes monofásicas de distribuição primária;

- Trifásicos: Aplicados em redes trifásicas de distribuição primária.

b) Quanto ao tipo de controle:

- Controle hidráulico: Estes modelos possuem como sensor de corrente, uma bobina inserida em série com o circuito principal dimensionada para operar, quando a corrente passante for maior do que $160 \%$ da sua corrente nominal [4], [5]. Além da bobina série, o seccionalizador com controle hidráulico é composto em linhas gerais por um êmbolo, um pistão ou haste de disparo, uma mola de restauração, e duas válvulas de retenção, sendo uma inferior e outra superior, conforme mostrado na Figura 2.5 (página 401 / Figura 18.2 b) - Mamede Filho, João. MANUAL DE EQUIPAMENTOS ELÉTRICOS $-2^{\mathrm{O}}$ Edição volume 2, publicado em língua portuguesa por LTC - Livros Técnicos e Científicos Editora SA Copyright (C) 1994, reproduzido com permissão da editora.).

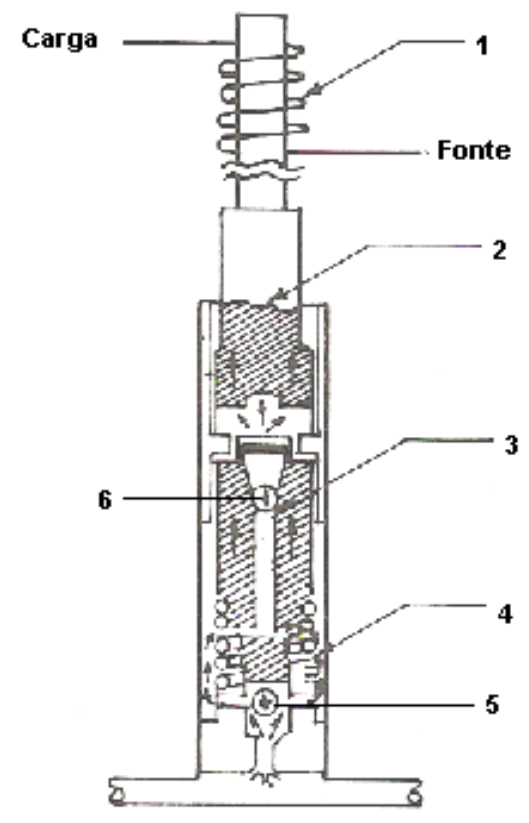

\section{Legenda:}

1 - Bobina Série

2 - Haste de disparo

3 - Êmbolo

4 - Mola de restauração

5 - Válvula de retenção inferior

6 - Válvula de retenção superior

Figura 2.5 - Seccionalizador Hidráulico [4], [5]

Quando há uma corrente de carga circulando pela bobina série, a pressão da mola faz com que o êmbolo fique na parte superior de seu curso. Na situação em que a corrente através da bobina série atinge o seu valor de atuação, a força eletromagnética será maior 
do que a força da mola de restauração, o que ocasionará um movimento do êmbolo para baixo. Com isto, ocorre o fechamento da válvula de retenção inferior, situada na base do equipamento e, simultaneamente, uma carga de óleo é empurrada para cima, que irá se depositar no espaço vazio deixado pelo êmbolo. A pressão do óleo na parte superior do equipamento provocará a abertura da válvula de retenção superior, possibilitando o escoamento do fluxo de óleo. O êmbolo fica travado na posição inferior, até que a corrente passante através da bobina série seja menor do que 40\% [4], [5] do seu valor de referência ( $160 \%$ da corrente nominal). Após a ocorrência deste evento, a força da mola será maior do que a força eletromagnética, fazendo com que o êmbolo e a haste de acionamento sejam impulsionados para cima.

O processo acima descrito é repetido até ser atingido o número de contagens ajustado no equipamento, após o qual provocará a abertura definitiva dos pólos do seccionalizador, impulsionada pela haste de disparo.

Convém ressaltar, que no caso de faltas temporárias, o êmbolo e a haste de disparo são movimentadas para cima, mas tão logo as condições no circuito voltem ao normal, os mesmos retornam a sua condição de repouso.

- Controle eletrônico: Os seccionalizadores com controle eletrônico executam o monitoramento da corrente passante através do circuito de distribuição primária. São instalados transformadores de corrente (TCs) do tipo bucha com relação de 1000/1 [5], para que a corrente seja reduzida a níveis condizentes com a eletrônica do sistema de controle do equipamento. Analogamente aos seccionalizadores com controle hidráulico, o equipamento fica preparado para executar uma contagem, quando é detectada uma sobrecorrente na rede e completam o processo quando ocorrer a interrupção da corrente pelo equipamento situado a montante, que pode ser um religador ou disjuntor composto por relé de religamento. Após ser atingido o número de contagens ajustado no equipamento, um sinal de disparo é enviado para uma bobina que provocará a abertura definitiva dos pólos do seccionalizador.

Os seccionalizadores com controle hidráulico e eletrônico apresentam uma característica muito importante no estudo de coordenação da proteção em redes de 
distribuição primária. Tal característica representa o tempo de memória, que para o seccionalizador com controle hidráulico representa o tempo que o pistão leva para atingir a posição de repouso após o registro de uma contagem. Já para os equipamentos dotados com controle eletrônico, este tempo corresponde a um período ajustável em 30 , 45 e $90 \mathrm{~s}$ [2], [5], no qual o seccionalizador aguarda para que o número de contagens ajustado seja atingido. Caso isto não aconteça, o registrador de contagens e zerado.

\subsubsection{4 - Acessórios utilizados nos seccionalizadores}

Em sistemas críticos, onde a coordenação é um pouco difícil, são aplicados alguns acessórios no equipamento, de tal forma que seja possível aumentar a flexibilidade na aplicação dos seccionalizadores. Tais acessórios são:

- Restritor de tensão: A aplicação deste acessório faz com que o seccionalizador conte somente as operações do dispositivo situado no lado da fonte, ou seja, o seccionalizador somente contará as interrupções apenas quando a tensão sob o mesmo for nula. Este acessório é disponível somente para seccionalizadores trifásicos de controle hidráulico;

- Restritor de corrente: Este acessório desempenha as mesmas funções do item anterior, fazendo com que o seccionalizador conte as interrupções, somente quando a corrente no lado da fonte for nula. Este acessório já é padrão na maioria dos seccionalizadores [5] e aplicado somente em equipamentos de controle eletrônico.

- Restritor da corrente de magnetização: Em alimentadores contendo transformadores é muito comum aparecer na sua energização, correntes elevadas devido a um transitório eletromagnético. Tais correntes são chamadas de "correntes de inrush" ou de magnetização, que para um alimentador com apenas um transformador, corresponde a um valor até 12 vezes a corrente nominal [3]. O tempo na qual o equipamento fica submetido a magnitude desta corrente é na ordem de 100, $130 \mathrm{~ms}$ [3]. Para os circuitos que apresentam este problema e quando não é possível solucioná-lo, através do aumento da corrente de atuação do seccionalizador, é possível acrescentar um acessório ao equipamento que retardará a atuação do mesmo nas condições de magnetização do transformador, de tal forma que ocorra a interpretação adequada deste fenômeno, 
evitando assim uma operação incorreta do equipamento. Este acessório é projetado apenas para seccionalizadores com controle eletrônico.

\subsection{3 - Religadores}

\subsubsection{1 - Introdução}

Um religador é um equipamento amplamente utilizado em sistemas aéreos de distribuição primária, executando as funções de abertura do circuito quando a corrente passante superar o valor ajustado dentro de uma característica de tempo em função da corrente e, também, efetuar o fechamento automático do mesmo segundo uma seqüência de operações previamente ajustada.

A maioria dos defeitos nas redes aéreas de distribuição é de natureza temporária, tais como queda de galhos de árvores na rede, queda de postes e presença de aves na rede, ocasionando um curto-circuito entre fases. Nestas condições, a utilização de um religador é essencial, pois evita que para um defeito temporário toda a rede seja desligada, e ainda, impede o deslocamento de uma equipe de manutenção da concessionária de energia elétrica até o local para religar a rede manualmente.

O religador é instalado a montante de um seccionalizador e de uma chave fusível, tornando a rede mais seletiva e coordenada, conforme será visto nos tópicos posteriores.

\subsubsection{2 - Classificação}

a) Quanto ao número de fases:

- Monofásicos: Aplicados em redes monofásicas de distribuição primária;

- Trifásicos: Aplicados em redes trifásicas de distribuição primária. Podem ter a operação e o bloqueio trifásico, ou a operação monofásica e o bloqueio trifásico. No primeiro caso, quando ocorre a falta de uma fase a terra, por exemplo, haverá a 
operação e o bloqueio das três fases, após serem excedidos os ciclos de religamento disponíveis no equipamento. Já na outra possibilidade, existem três religadores monofásicos que trabalham independentemente, porém caso somente uma fase opere, as outras duas são abertas e o equipamento fica com as 3 fases bloqueadas, após serem excedidos os ciclos de religamento, através de um mecanismo interno que interliga os religadores monofásicos.

b) Quanto ao tipo de controle:

- Controle hidráulico: São religadores mais primitivos, onde há basicamente uma bobina de abertura em série com a rede de distribuição primária, com a função de abrir o religador, caso a corrente que flua por ela seja superior ao seu nível mínimo de atuação. O fechamento do circuito para religadores com corrente nominal até 200 A [5] é feito através de molas de fechamento que se carregam quando ocorre o movimento do núcleo da bobina série ou de abertura. Uma parte da energia proveniente do movimento da bobina série é utilizada na abertura, e uma outra parte utilizada para o fechamento. Já para correntes nominais maiores do que 200 A [5], o fechamento do religador é efetuado através de uma bobina de fechamento, energizada pela tensão da rede.

- Controle Eletrônico: Os religadores dotados deste tipo de controle correspondem a uma segunda geração, onde o monitoramento e o controle da rede de distribuição são feitos através de uma unidade composta por componentes e circuitos eletrônicos, tais como resistores, capacitores, dentre outros. Os sinais injetados na entrada da unidade de controle são provenientes de transformadores de corrente, que convertem as correntes de linha para valores menores, sendo estes iguais a 1 ou 5 A. Podem ser ajustados nestes religadores, a corrente de atuação, a curva característica de operação e o número de ciclos de religamento.

- Controle digital microprocessado: São os religadores dotados de unidades de controle digitais e microprocessadas. A parte física da unidade, composta pelo microprocessador, memória e componentes eletrônicos constituem o hardware da unidade, e o programa que executa as operações com base nos ajustes definidos pelo usuário corresponde ao software. Estas unidades contemplam um número bem amplo de 
funções de proteção, medição e controle, além de fornecerem o histórico das últimas operações do religador, contendo a leitura das principais grandezas no momento do disparo e indicando a distância entre o equipamento e o ponto de defeito. Isto é de suma importância, uma vez que o defeito é rapidamente identificado pela equipe de manutenção da empresa distribuidora, fazendo com que o circuito seja restabelecido em um menor espaço de tempo. Além destas características, existe no equipamento uma porta de comunicação serial na qual é possível ajustar e ler as grandezas e parâmetros disponíveis na unidade, remotamente, através de um computador. As funções de proteção disponíveis nas unidades são: sobrecorrente temporizada e instantânea de fase e neutro, sobrecorrente de seqüência negativa, sobrecorrente direcional de fase e de neutro, sub e sobretensão, religamento, sub e sobrefreqüência. Já as medições disponíveis são: correntes de fase e de neutro, tensões de fase e de linha, potências ativa, reativa e aparente, fator de potência, demanda de potência ativa e reativa, energia ativa e reativa e eventos horodatados. Possuem ainda oscilografia incorporada, que corresponde a visualização da forma de onda na ocorrência de um evento programado, tal como uma sobrecorrente, seguida por um religamento. As funções descritas nas linhas anteriores serão abordadas em maiores detalhes no item relativo a relés de proteção.

c) Quanto ao meio de Interrupção

- Óleo: O religador é composto por um tanque contendo óleo mineral, dentro do qual se encontram os contatos principais do equipamento. Ocorrendo a abertura do religador, haverá o aparecimento de um arco elétrico que provoca a elevação da temperatura do óleo mineral. Com isto, tem-se a formação de gases, dentre eles o hidrogênio que é o principal responsável pela extinção do arco elétrico, retirando o calor da região onde o mesmo se formou. Estes tipos de religadores também utilizam o óleo para isolação entre as partes vivas e a carcaça do equipamento.

- Vácuo: Neste tipo de religador, há uma ampola de vácuo onde estão instalados os contatos principais do equipamento. O vácuo é o meio responsável pela extinção do arco elétrico que aparece no momento em que ocorre a abertura do religador. Os religadores a vácuo são isolados a gás SF6 (hexafluoreto de enxofre) 


\subsubsection{3 - Definições comumente encontradas em religadores}

- Tempo morto: Também conhecido como tempo de religamento, corresponde ao intervalo de tempo entre a abertura e o fechamento do religador.

- Ciclo de religamento: Corresponde ao número de vezes que o religador permanece aberto aguardando o término do tempo morto para efetuar um religamento. $\mathrm{O}$ número máximo de ciclo rápidos e lentos que podem ser ajustados no equipamento é igual a quatro, sendo que transcorrido o tempo morto do último ciclo de religamento, o equipamento permanecerá travado na posição aberta e somente poderá ser fechado manualmente.

- Tempo de recuperação: Corresponde ao tempo, após o restabelecimento do circuito primário, no qual a unidade de controle do religador avalia se a falta foi realmente sanada. Caso durante este período surja uma nova falta na rede, o ciclo seguinte de religamento é ativado, ou seja, se o circuito foi fechado após o primeiro ciclo de religamento e ocorrer uma falta durante o seu respectivo tempo de recuperação, será ativado o segundo ciclo de religamento. Encerrado o tempo de recuperação e se não existirem mais faltas na rede, o defeito que provocou a abertura do circuito e ativou o respectivo ciclo de religamento é considerado sanado.

A Figura 2.6 ilustra as três definições apresentadas acima, onde considera-se um exemplo, no qual a falta é sanada após o segundo ciclo de religamento.

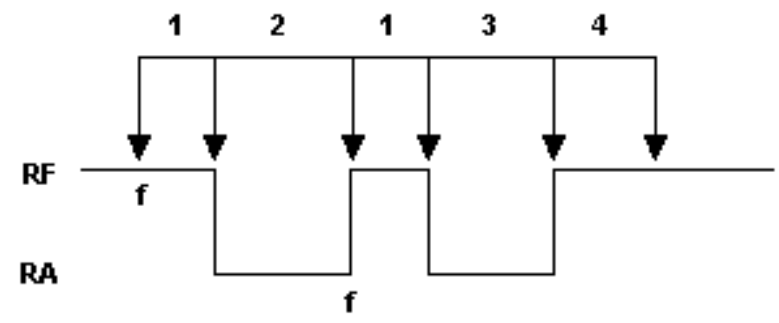

Figura 2.6 - Definições

\section{Legenda:}

RF - Religador Fechado

RA - Religador Aberto

1 - Tempo de atuação da proteção e abertura

2 - Tempo morto do $1^{\circ}$ ciclo de religamento

3 - Tempo morto do $2^{\circ}$ ciclo de religamento

4 - Tempo de recuperação

$\mathrm{f}$ - Instante em que ocorre a falta 
- Capacidade de interrupção: Corresponde a máxima corrente que o religador é capaz de interromper, sob tensão nominal, sem que as suas características elétricas e mecânicas sejam alteradas.

- Nível Básico de Impulso (NBI): Corresponde a tensão de crista suportada pelo religador durante $1,2 \mu$ s. Os religadores são ensaiados com a forma de onda padronizada 1,2 x $50 \mu$ s, sendo que o tempo $1,2 \mu$ s representa o valor de crista da onda e em $50 \mu \mathrm{s}$ este valor é reduzido pela metade.

- Corrente nominal: É a máxima corrente que pode ser conduzida continuamente através dos pólos do religador.

- Tensão nominal: É a máxima tensão suportada continuamente que pode ser aplicada ao religador.

\subsubsection{4 - Princípio básico de funcionamento}

Algumas informações sobre os religadores foram descritas nas linhas anteriores, mas para finalizar este item, será descrito sucintamente o princípio de funcionamento de um religador. No desenvolvimento, considera-se religadores com controle digital e microprocessado.

Os transformadores de corrente instalados na rede de distribuição primária enviam um sinal para as entradas analógicas de corrente da unidade de controle do religador. Quando a corrente através da rede primária ultrapassar o valor de atuação ajustado na unidade de sobrecorrente temporizada de fase, por exemplo, haverá uma atuação da respectiva função de proteção após um determinado tempo, que provocará a abertura dos pólos do religador. O primeiro ciclo de religamento entra neste momento em ação, enviando uma ordem de fechamento após o respectivo tempo morto ajustado na unidade de controle. Após o restabelecimento do circuito, caso a falta ainda persista, o segundo ciclo de religamento é ativado e transcorrido o tempo morto relativo a este ciclo, haverá o envio de uma nova ordem de fechamento para o religador que restabelecerá o circuito. O processo se repete, até que o número máximo de ciclos de religamento, ajustado na 
unidade de controle seja atingido, ou quando ocorrer o restabelecimento definitivo do circuito, caso a falta seja sanada.

A ativação dos ciclos de religamento é dada pela atuação de uma função de proteção associada a este evento, ou seja, podem ser ajustadas na unidade de controle, quais serão as proteções que quando atuadas, provocarão um religamento no circuito. No exemplo mostrado na Figura 2.6, foi considerado que a unidade de sobrecorrente temporizada de fase foi programada para ativar o primeiro e segundo ciclos de religamento. Esta peculiaridade descrita no parágrafo em questão será retomada no item relés, mais especificamente quando for abordada a função de religamento.

\subsection{4 - Disjuntores}

\subsubsection{1 - Introdução}

O disjuntor é um equipamento elétrico destinando a interromper e restabelecer um circuito elétrico situado a sua jusante. Ele tem plena capacidade para seccionar um circuito sob carga nominal e também sob condições anormais, tais como sobrecargas e curto-circuitos.

Isoladamente em uma rede elétrica, o disjuntor não executa nenhuma função de monitoramento de uma determinada grandeza elétrica. Em outras palavras, se um disjuntor for instalado em uma rede elétrica, sem um dispositivo que faça o monitoramento das grandezas elétricas como, por exemplo, correntes e tensões, o equipamento ficará totalmente inerte e não executará o devido seccionamento do trecho de rede, quando o mesmo estiver sendo submetido a uma condição de defeito, tal como um curto-circuito.

Este dispositivo de monitoramento chama-se relé de proteção, que será discutido em maiores detalhes no item 2.2.5, sendo que neste capítulo será dada uma ênfase maior aos disjuntores utilizados em redes de distribuição primária. 


\subsubsection{2 - Definições}

Algumas definições apresentadas a seguir para os disjuntores são similares as apresentadas para os religadores.

- Corrente nominal: É a máxima corrente que pode ser conduzida continuamente através dos pólos do disjuntor.

- Capacidade de interrupção: É a máxima corrente que o disjuntor é capaz de interromper, sob tensão nominal, sem que as suas características elétricas e mecânicas sejam alteradas. É muito comum a capacidade de interrupção do disjuntor também ser expressa em termos da potência máxima de interrupção em MVA.

- Nível Básico de Impulso: Corresponde a tensão de crista suportada pelo disjuntor, durante $1,2 \mu \mathrm{s}$. Os disjuntores são ensaiados utilizando uma forma de onda padronizada $1,2 \times 50 \mu$ s, sendo que o tempo 1,2 $\mu$ s equivale ao valor de crista da onda e em $50 \mu \mathrm{s}$ este valor é reduzido pela metade

- Tensão nominal: É a máxima tensão suportada continuamente que pode ser aplicada ao disjuntor sem que o mesmo seja danificado.

- Corrente suportável de curta duração: É o valor eficaz da máxima corrente suportada pelo disjuntor, na posição fechado, durante um tempo de 3 segundos [31].

- Tensão de restabelecimento transitória (TRT): É uma sobretensão que aparece entre os terminais do disjuntor após a interrupção de uma determinada corrente elétrica. Esta sobretensão permanece ativa durante o período transitório após a interrupção da corrente.

- Seqüência de operações: Corresponde a um ciclo de operações que o disjuntor é capaz de executar. Ele é expresso pelos fabricantes, por exemplo, da seguinte maneira:

$\mathrm{O}-\mathrm{t}-\mathrm{CO}$ 
em que:

O Significa uma operação de abertura;

CO Significa uma operação de fechamento seguida imediatamente de uma operação de abertura;

t É o intervalo de tempo entre a abertura e o fechamento do disjuntor

Um disjuntor que tem a seqüência de operações: $\mathrm{O}-0,3 \mathrm{~s}-\mathrm{CO}$ efetua a primeira abertura e deve esperar 0,3 s para ser fechado. Assim que ele atingir esta condição, poderá ser aberto imediatamente.

\subsubsection{3 - Classificação}

a) Quanto ao meio de extinção do arco elétrico:

- Disjuntores a óleo: São aqueles que utilizam o óleo mineral para a interrupção e extinção do arco elétrico;

- Disjuntores a Vácuo: São aqueles que utilizam ampolas de vácuo com a finalidade de interromper e extinguir o arco elétrico;

- Disjuntores a Hexafluoreto de Enxofre (SF6): São aqueles que utilizam o gás Hexafluoreto de Enxofre para a interrupção e extinção do arco elétrico. 
b) Quanto ao tipo de execução:

- Execução fixa: Neste tipo de execução, todas as partes do disjuntor estão em uma única estrutura. No caso de manutenção ou troca do equipamento, todas as conexões de potência devem ser desconectadas.

- Execução extraível: Neste tipo de execução, o disjuntor possui duas partes, que são o chassi e a estrutura. No chassi é conectado o circuito de potência e na estrutura se situam as partes mecânicas do disjuntor e os elementos de comando, tais como contatos auxiliares, bobinas de abertura e fechamento. Uma grande vantagem dos disjuntores extraíveis é a possibilidade de se fazer testes no equipamento, sem haver a necessidade de desconexão dos barramentos ou cabos.

c) Quanto ao tipo de comando elétrico

Considera-se na descrição, disjuntores que apresentam o fechamento a mola précarregada, ou seja, antes do fechamento do disjuntor a sua respectiva mola de fechamento deverá estar carregada. O comando elétrico pode ser manual ou motorizado e será descrito em detalhes, conforme segue:

- Comando manual: Nesta topologia, o carregamento da mola de fechamento do disjuntor é efetuado através de uma alavanca situada no frontal do equipamento. Como este processo é manual, não existe a possibilidade do disjuntor ser fechado remotamente via um sistema de controle e supervisão, sem que antes o operador se dirija até o equipamento e carregue a mola manualmente.

- Comando motorizado: Nesta topologia, o carregamento da mola de fechamento do disjuntor é executado por um motor elétrico, alimentado com a tensão do circuito de comando. Partindo de uma condição de repouso, o motor efetua o carregamento da mola de fechamento que se mantém carregada até o momento que o equipamento é acionado, sendo que nesta condição, uma parte da energia mecânica armazenada é utilizada para carregar a mola de abertura e uma outra é utilizada para fechar os contatos principais do 
equipamento. Logo após o disjuntor ser acionado, o motor efetua novamente o carregamento da mola de fechamento e o ciclo pode ser repetido indefinidamente. Com isto, é plenamente possível fechar o disjuntor à distância a qualquer momento, desde que o mesmo não esteja recebendo um sinal de abertura.

\subsubsection{4 - Partes constituintes do disjuntor}

Apresenta-se a seguir, resumidamente, as partes principais de um disjuntor. São elas:

- Pólo: Corresponde a parte principal do disjuntor, onde há o acesso para a conexão elétrica de potência através dos terminais superiores e inferiores. Internamente ao pólo, existem os contatos principais fixos e móveis, cuja finalidade é conduzir continuamente a corrente elétrica nominal do equipamento, e também, os contatos fixos e móveis de arco, cuja finalidade é conduzir a corrente resultante do arco elétrico que surge devido à abertura do disjuntor. Para a extinção e interrupção do arco e isolação dos contatos, o pólo é preenchido com um dielétrico, conforme apresentado no item 2.2.4.3 a);

- Molas: São responsáveis pelo armazenamento da energia mecânica necessária para a abertura (mola de abertura) e para o fechamento (mola de fechamento) do disjuntor;

- Mecanismo de comando: Corresponde aos elementos responsáveis pelo comando e sinalização do disjuntor. Podem ser encaixadas neste grupo, as bobinas de abertura, fechamento e mínima tensão, os contatos auxiliares, o motor de carregamento da mola de fechamento, contato indicador de mola carregada e contato indicando que o disjuntor está pronto para ser fechado;

- Estrutura: Corresponde ao corpo do disjuntor, onde em linhas gerais são montados os pólos, as molas e o mecanismo de comando do equipamento. 


\subsubsection{5 - Princípio de funcionamento}

A operação de abertura ou fechamento de um disjuntor ocorre através de uma ação manual, via botões de liga e desliga no frontal do equipamento, ou via sinal elétrico enviado às bobinas de abertura e de fechamento, dispostas no compartimento de comando.

Ao receber um comando de abertura, o contato móvel do disjuntor começa a se separar do contato fixo. Neste momento, a condução de corrente ocorre através dos contatos de arco, até o momento que eles se separam e há o surgimento do arco elétrico entre os mesmos. A interrupção deste arco deverá ser feita rapidamente e o dielétrico utilizado deverá desionizar o meio logo após a passagem da corrente pelo valor zero, e garantir a rigidez dielétrica suficiente entre os contatos de arco, para evitar uma reignição.

As técnicas existentes de interrupção nos disjuntores de média tensão são: autocompressão, auto-expansão, arco rotativo e vácuo.

O comando de fechamento pode ser efetuado a distância, desde que exista no disjuntor um motorredutor que será o responsável pelo carregamento das molas de fechamento, conforme descrito anteriormente.

Convém ressaltar, que caso o disjuntor receba ordens simultâneas mantidas de comando nas bobinas de abertura e fechamento, um mecanismo interno mantém o disjuntor travado na posição aberto, evitando que o mesmo fique desnecessariamente abrindo e fechando repetidas vezes. Nesta condição, para fechar o disjuntor através da bobina de fechamento será necessário primeiramente interromper o seu respectivo circuito de comando, além de não haver nenhum sinal de tensão na bobina de abertura, ou ausência, no caso de abertura por bobina de mínima tensão. 


\subsection{5 - Relés de proteção}

\subsubsection{1 - Introdução}

Os relés de proteção são equipamentos responsáveis pelo gerenciamento e monitoramento das grandezas elétricas em um determinado circuito. A sua função principal é enviar um sinal de disparo, através de um contato seco, para uma bobina de abertura ou de mínima tensão dos disjuntores associados. A Figura 2.7 mostra a associação entre um relé de proteção e um disjuntor.

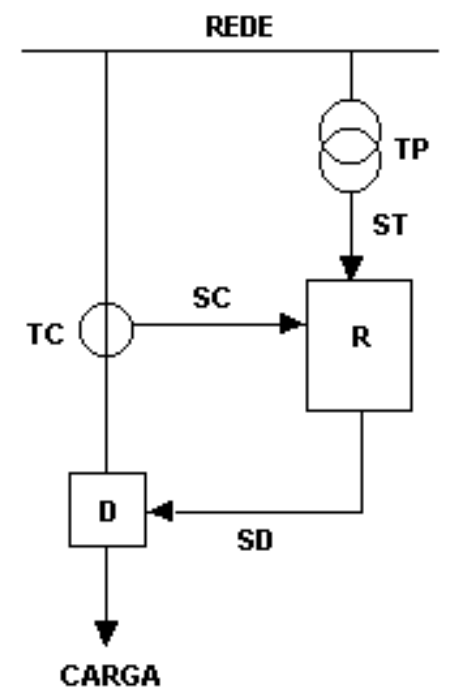

\section{Legenda:}

TC - Transformador de corrente

TP - Transformador de potencial

$\mathrm{R}$ - Relé de proteção

D - Disjuntor

ST - Sinal de tensão

$\mathrm{SC}$ - Sinal de corrente

$\mathrm{SD}$ - Sinal de disparo

Figura 2.7 - Associação entre relé e disjuntor

No decorrer dos últimos anos, houve um avanço muito grande na área de desenvolvimento de relés de proteção, sendo que atualmente os equipamentos são dotados das mais altas tecnologias estudadas até então. A presente abordagem levará em conta os equipamentos mais modernos, mas os mesmos não serão analisados em detalhe. Não é o objetivo deste trabalho, explorar os detalhes intrínsecos do relé e sim descrever sucintamente o que ele é, bem como analisar as suas principais funções e características.

A presente análise será mais focada nas proteções específicas das redes de distribuição primária. 


\subsubsection{2 - Classificação dos relés}

a) Quanto ao tipo de acionamento:

- Ação direta: São aqueles instalados diretamente no circuito primário protegido;

- Ação indireta: São aqueles que recebem os sinais de tensão e corrente através de transformadores de potencial (TPs) e transformadores de corrente, respectivamente. Atualmente os relés disponíveis no mercado são de ação indireta, razão pela qual na presente análise, serão considerados relés com este tipo de acionamento.

b) Quanto ao tipo de temporização:

- Instantâneos: Correspondem aqueles que são acionados instantaneamente quando uma determinada grandeza monitorada pelo relé ultrapassa um valor de referência ajustado no equipamento;

- Temporizados: Correspondem aqueles que são acionados após um tempo determinado, quando uma grandeza monitorada ultrapassa o valor ajustado no equipamento.

c) Quanto à função de proteção:

Os relés têm as suas funções de proteção identificadas por números, de acordo com a Amercian National Standards Institute (ANSI). A lista vai de 1 a 99, e em alguns casos após o número da proteção existe uma ou duas letras representando uma característica adicional da proteção. As proteções mais comumente aplicadas e associadas a redes de distribuição primária são:

- 50 - Sobrecorrente instantânea de fase;

- 51 - Sobrecorrente temporizada de fase; 
- $50 \mathrm{~N}$ - Sobrecorrente instantânea de neutro (terra);

- $51 \mathrm{~N}$ - Sobrecorrente temporizada de neutro (terra);

- 50GS - Sobrecorrente instantânea de terra de alta sensibilidade;

- 51GS - Sobrecorrente temporizada de terra de alta sensibilidade;

- 79 - Religamento automático;

- 86 - Relé de Bloqueio;

- $50 \mathrm{BF}$ - Falha de disjuntor;

- 74TC - Supervisão do circuito de abertura do disjuntor.

d) Quanto à tecnologia:

- Eletromecânicos: São relés mais antigos, constituídos por uma estrutura de ferro, uma bobina de operação, um disco de alumínio, um eixo, um contato fixo e um móvel. Quando a bobina de operação é energizada, ocorre o movimento do disco de alumínio até um ponto que o contato móvel, preso ao eixo, alcança o contato fixo provocando a operação do relé;

- Estáticos: São relés cuja unidade de controle é constituída por circuitos eletrônicos analógicos, compostos por resistores, capacitores e diodos. São relés mais precisos, mais rápidos e menores quando comparados aos eletromecânicos. As características, como por exemplo, tempo e corrente, podem ser ajustadas no frontal do equipamento através de potenciômetros ou micro chaves;

- Digitais: São os relés mais modernos e avançados tecnologicamente e dispõem de várias funções de proteção, medição e controle em uma única unidade. O relé digital é composto por duas partes, hardware e software, que serão descritas em detalhe a seguir.

- Hardware: O hardware do relé digital é composto pelas seguintes partes, conforme Figura 2.8. 


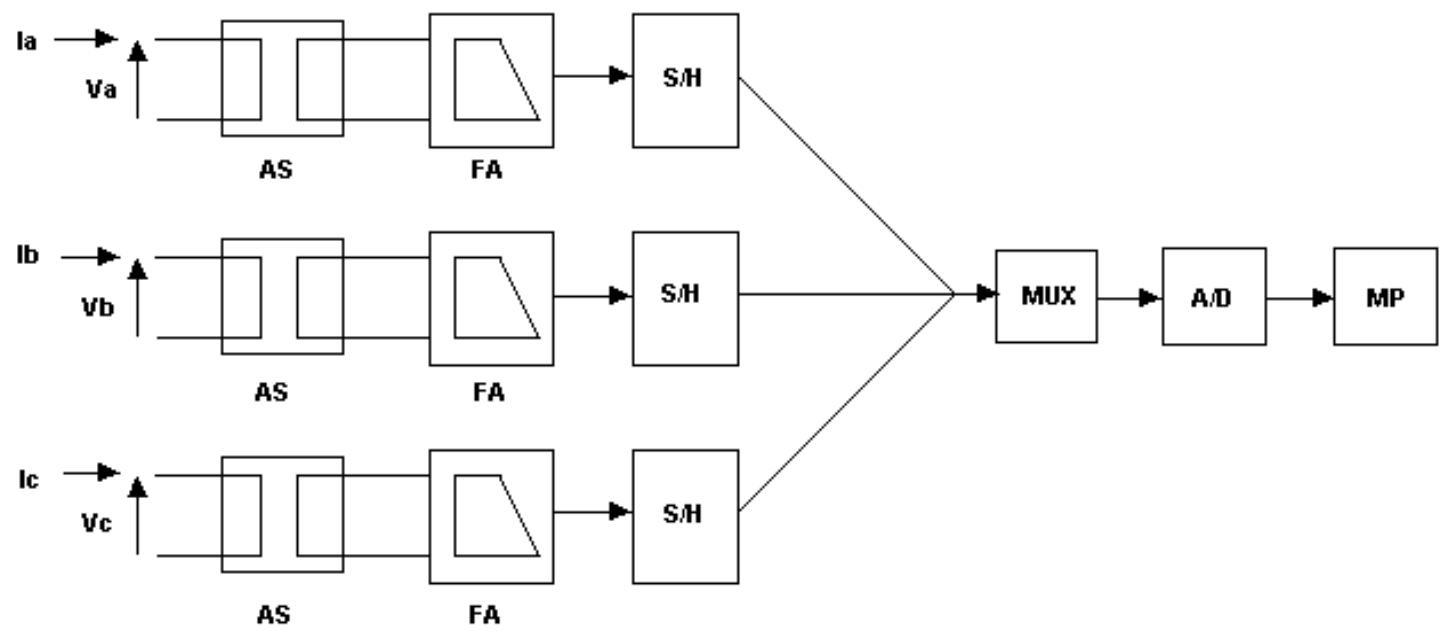

Figura 2.8 - Diagrama de blocos do hardware do relé digital com 3 canais analógicos

Segue sucintamente a função de cada um dos blocos acima identificados.

Acondicionamento do sinal (AS): Este bloco tem for finalidade converter os sinais de corrente e tensão provenientes dos TCs e TPs para um sinal de tensão de $\pm 5 \mathrm{~V}$ ou $\pm 10 \mathrm{~V}$ [6]. Também são responsáveis por fornecer a isolação galvânica entre a rede de potência e o circuito eletrônico do relé;

$\underline{\text { Filtro analógico (FA) }}$ : É constituído por um filtro passa baixa que fornece uma significativa atenuação para freqüências maiores do que metade da freqüência de amostragem. Os filtros analógicos classe Butterworth [6] atendem a estas recomendações. A freqüência de amostragem é o número de amostras por ciclo multiplicado pela freqüência da componente fundamental $(60 \mathrm{~Hz})$;

Sample Hold (S/H): Tem por finalidade manter o sinal na entrada do conversor analógico digital constante durante todo o tempo gasto para esta tarefa ser executada;

$\checkmark$ Multiplexador (MUX): Corresponde a uma chave analógica, que recebe os sinais analógicos provenientes do "Sample Hold" mais uma combinação de "n" bits provenientes de um sistema de controle. O sinal da saída do bloco varia de acordo com as informações recebidas, apresentando um ganho de 0 até 1 [6]; 
$\checkmark$ Conversor Analógico digital (A/D): É o responsável pela conversão de um sinal analógico em um sinal digital que será processado pelo microprocessador;

$\checkmark$ Microprocessador (MP): É o coração do relé digital, onde todas as operações são processadas e analisadas, para que o relé tome a decisão correta de mandar abrir um determinado disjuntor.

Ia, Ib e Ic, correspondem aos sinais de corrente provenientes dos TCs das fases a, b e c, respectivamente e $\mathrm{Va}, \mathrm{Vb}$ e $\mathrm{Vc}$ correspondem aos sinais de tensão provenientes dos TPs das fases a,b e c, respectivamente.

Na Figura 2.8, foi mostrada a arquitetura do hardware do relé digital com 3 canais analógicos, podendo ser todos de tensão ou todos de corrente.

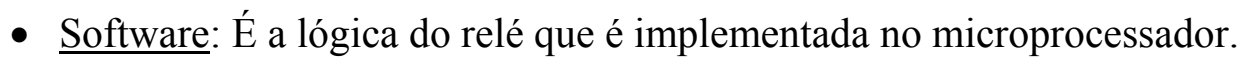

e) Quanto a forma de alimentação auxiliar:

- Auto-alimentado: São aqueles que a alimentação da eletrônica do relé é feita pela própria corrente de carga;

- Alimentação independente: São aqueles que necessitam uma tensão auxiliar para a alimentação do relé. Esta alimentação deve ser proveniente de uma fonte confiável, tais como no breaks ou banco de baterias.

\subsubsection{3 - Proteções mais utilizadas em Sistemas de Distribuição}

Neste item serão analisadas em detalhes as proteções mais utilizadas em redes de distribuição primária, conforme descrito no tópico 2.2.5.2 c). 
a) Sobrecorrente temporizada e instantânea de fase

A função de sobrecorrente de fase consiste em avaliar se a corrente passante pelo circuito no qual o relé está instalado, ultrapassa um valor de referência, dentro de uma característica de tempo específica. Caso esta condição ocorra, o relé enviará através de um contato seco uma ordem de abertura para os disjuntores correspondentes.

Os ajustes da proteção de sobrecorrente são subdvididos em elementos, onde em cada um deles são ajustados: a corrente de atuação, o tipo de curva característica e o dial de tempo.

As curvas características são padronizadas de acordo com a International Electrotechnical Commission 255-3 (IEC 255-3) [7], [28] em normal inversa, muito inversa, extremamente inversa, tempo longo inverso e moderadamente inversa. As mais utilizadas são as curvas IEC normal inversa, muito inversa e extremamente inversa.

Para a proteção instantânea, utiliza-se uma unidade de sobrecorrente com característica de atuação a tempo definido, ficando a cargo do projetista dar um retardo pequeno (geralmente entre 50 e $100 \mathrm{~ms}$ ), ou ajustar o tempo igual a zero.

A título ilustrativo, a Tabela 2.1 apresenta um exemplo contendo os ajustes da proteção de sobrecorrente com 4 elementos.

\begin{tabular}{|c|c|c|c|c|}
\hline Ajustes & Elemento 1 & Elemento 2 & Elemento 3 & Elemento 4 \\
\hline Corrente de atuação & $100 \mathrm{~A}$ & $300 \mathrm{~A}$ & $500 \mathrm{~A}$ & $1000 \mathrm{~A}$ \\
\hline Tipo de curva & NI & MI & EI & TD \\
\hline Dial de tempo & 0,34 & 0,36 & 0,40 & 0,0 \\
\hline
\end{tabular}

Tabela 2.1 - Exemplo de ajuste dos elementos de sobrecorrente 


\section{Legenda:}

NI - Curva normal inversa

MI - Curva muito inversa

EI - Curva extremamente inversa

TD - Tempo definido

A equação padrão para as curvas: normal inversa, muito inversa, extremamente inversa, de acordo com IEC 255-3 [28] é dada pela Equação (2.1).

$$
t_{o p}(I)=\frac{k}{\left(\frac{I}{I_{a t}}\right)^{\alpha}-1} \cdot \frac{T}{\beta},
$$

em que:

$t_{o p}(I)$ é o tempo de operação do relé em função da corrente passante (s);

I é a corrente passante pelo circuito primário (A);

$I_{a t}$ é a corrente de atuação do relé em valor primário (A);

$T$ é o tempo de operação do relé para uma corrente igual a $10 I_{a t}(\mathrm{~s})$;

$k, \alpha$ e $\beta$ são constantes e variam de acordo com o tipo de curva, conforme IEC 255-3 [28] e apresentados na Tabela 2.2

\begin{tabular}{|l|c|c|c|}
\hline \multicolumn{1}{|c|}{ Tipo de curva } & $\boldsymbol{k}$ & $\boldsymbol{\alpha}$ & $\boldsymbol{\beta}$ \\
\hline Normal Inversa & 0,14 & 0,02 & 2,97 \\
\hline Extremamente Inversa & 80,0 & 2,0 & 0,808 \\
\hline Muito Inversa & 13,5 & 1,0 & 1,50 \\
\hline
\end{tabular}

Tabela 2.2 - Constantes $k, \alpha$ e $\beta$ para as curvas inversas, conforme IEC 255-3

A relação entre os parâmetros $T$ e $\beta$ define o multiplicador ou dial de tempo da curva de atuação ajustada. 
Para as unidades de tempo definido, o ajuste do dial corresponde ao tempo de operação quando a corrente passante pelo circuito primário atingir o seu respectivo valor de atuação. Assim sendo, a Equação (2.1) é válida somente para as curvas inversas.

As curvas características dos ajustes efetuados nos 4 elementos de sobrecorrente indicados na Tabela 2.1 são apresentadas na Figura 2.9.

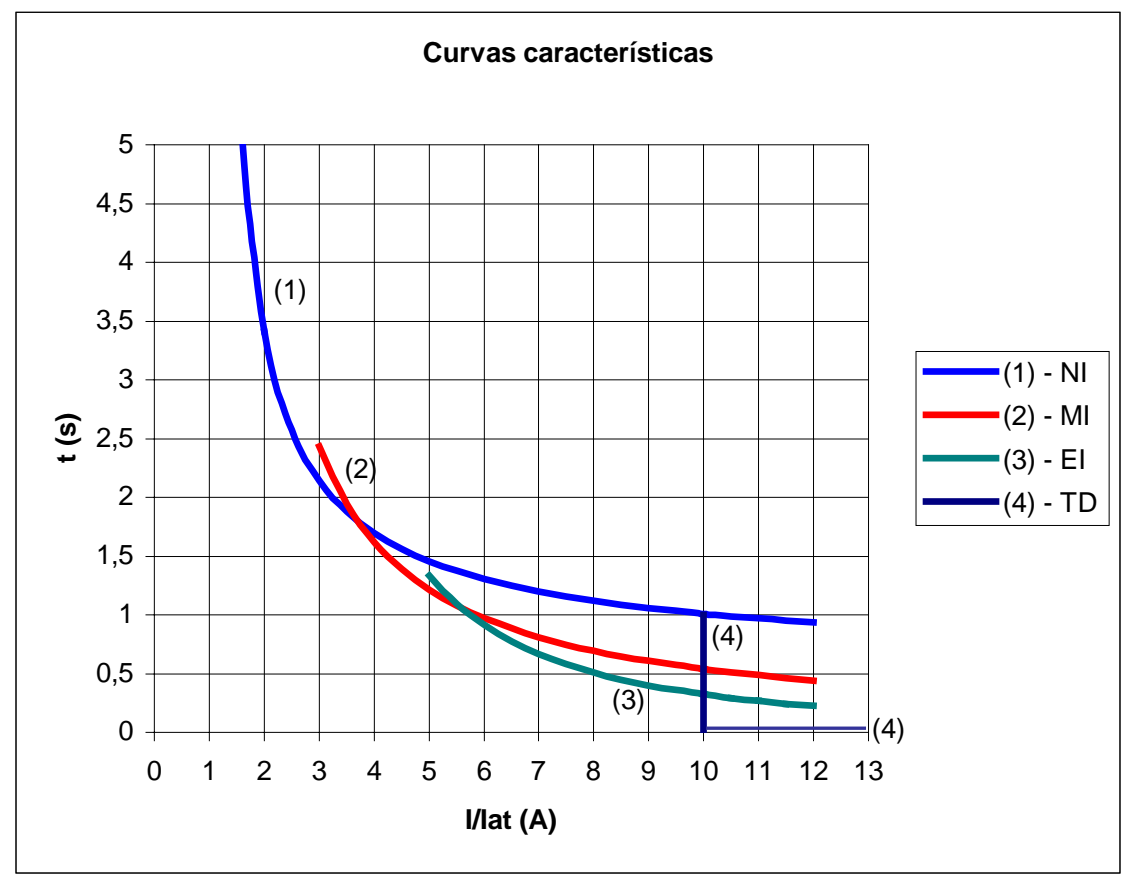

Figura 2.9 - Exemplo de aplicação dos elementos de sobrecorrente

Pelas curvas acima, desenhadas em um mesmo gráfico, observa-se que no intervalo entre $1,5 \leq \mathrm{I} /$ Iat $<3,7$ a proteção será atuada pelo elemento 1 . Já no intervalo de $3,7 \leq$ $\mathrm{I} /$ Iat $<5,5$ a atuação da proteção ocorrerá pelo elemento 2. Para relações de I/Iat entre 5,5 e 10, a atuação ocorrerá pelo elemento 3 e, finalmente, para correntes maiores do que 10 vezes a corrente de atuação, a unidade instantânea será a responsável pela operação. A Figura 2.10, mostra a curva resultante da proteção de sobrecorrente. 


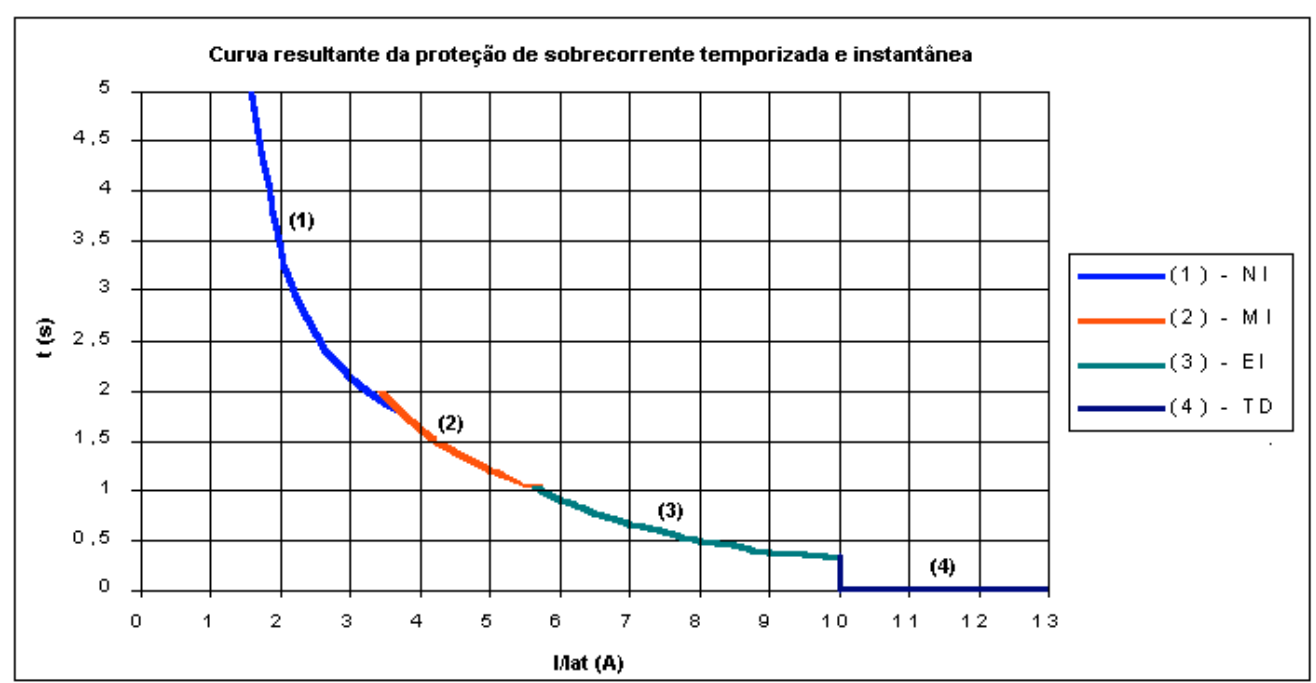

Figura 2.10 - Curva resultante da proteção de sobrecorrente

b) Sobrecorrente temporizada e instantânea de neutro (terra)

A função de sobrecorrente de neutro (terra) segue o mesmo princípio da proteção de fase. Quando o valor da corrente de neutro ultrapassar o valor de atuação, dentro de uma determinada característica de tempo em função da corrente, o relé será disparado, abrindo o disjuntor. Os parâmetros ajustados e os tipos de curvas disponíveis são iguais aos apresentados para a proteção de fase.

A ligação da unidade de neutro é feita de tal forma que os pontos comuns dos três transformadores de corrente, $\mathrm{TCa}, \mathrm{TCb}$ e $\mathrm{TCc}$ e o ponto comum na entrada do relé resultem em uma conexão residual. A Figura 2.11 elucida o esquema de ligação da unidade de neutro. 


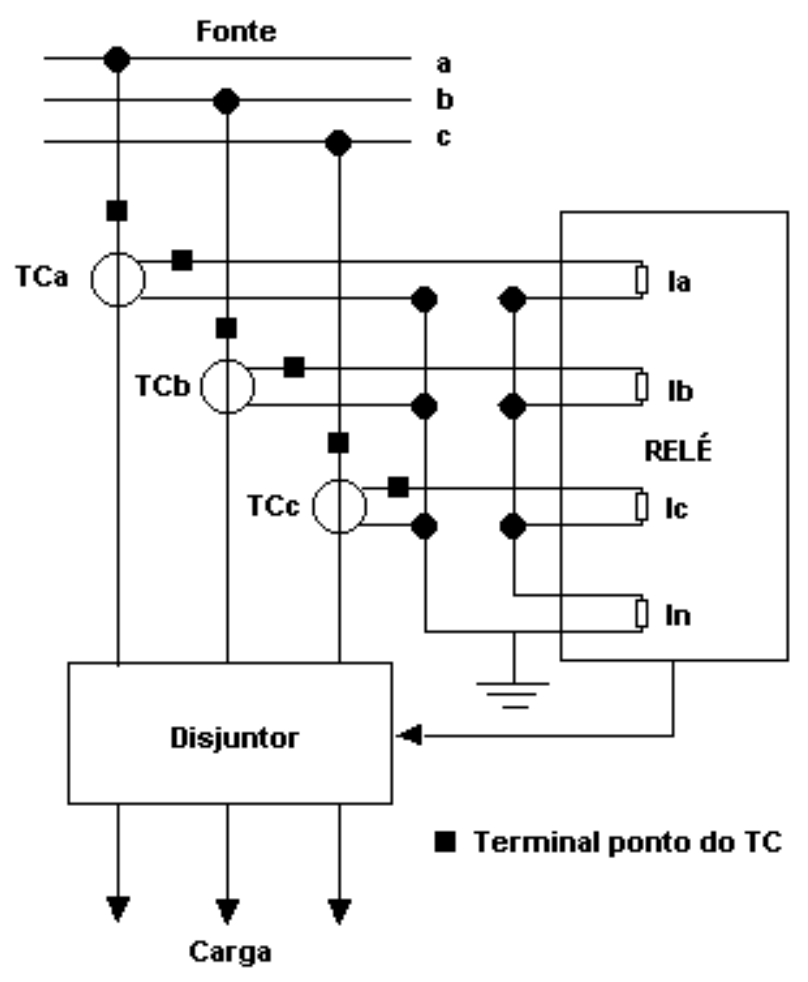

Figura 2.11 - Ligação da unidade de neutro

Alguns relés existentes podem também executar a proteção de neutro através da somatória vetorial das correntes nas 3 fases, utilizando este valor para a unidade de neutro.

c) Sobrecorrente temporizada e instantânea de terra de alta sensibilidade

Esta função utiliza um transformador de corrente toroidal que envolve os três condutores de fase, sendo que um sinal resultante da somatória destas correntes é enviado diretamente para a unidade de terra. O esquema de conexão típico para esta função é ilustrado na Figura 2.12

Os ajustes são os mesmos executados na unidade de fase. A vantagem desta função está na sensibilidade, onde o relé e capaz de enxergar "pequenas" correntes de defeito para a terra. 


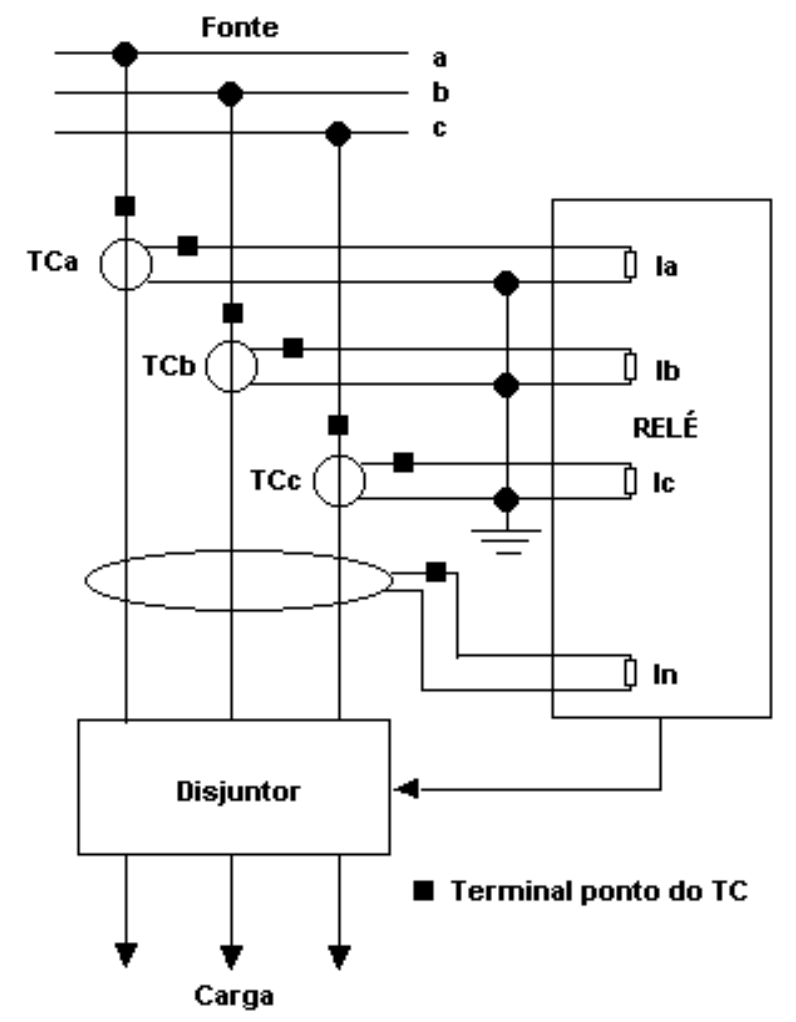

Figura 2.12 - Ligação da unidade de terra de alta sensibilidade

d) Religamento Automático

A função de religamento foi apresentada em linhas gerais no item 2.2.3.4, porém agora, será dada uma maior ênfase aos exemplos e aplicações extraídos de um relé de proteção digital microprocessado.

A unidade de religamento é acionada quando ocorre o disparo das unidades de proteção de sobrecorrente de fase e de terra. É possível ser ajustado no relé de proteção qual função será a responsável pela ativação dos ciclos de religamento. Ou seja, é possível definir, por exemplo, que o primeiro ciclo de religamento será ativado pela unidade de sobrecorrente instantânea de fase e que os demais ciclos serão ativados pela unidade de sobrecorrente temporizada de fase. Analogamente o mesmo comentário pode ser estendido às unidades de neutro, ou de terra de alta sensibilidade.

Além do ajuste definindo qual unidade de proteção ativará um determinado ciclo de religamento, ajusta-se também o número de ciclos ou de tentativas de religamento, 
sendo o mínimo de 1 e o máximo de 4 ciclos. O tempo morto também é ajustado, sendo que o intervalo típico de ajuste está entre 0,1 e $300 \mathrm{~s}$ [7]. Existe também o ajuste do tempo de recuperação, que corresponde ao intervalo de tempo no qual a unidade de proteção, após o fechamento do disjuntor via função de religamento, verifica se a falta ainda está presente ou não. Se a falta não aparecer mais neste intervalo, ela é considerada sanada, mas se ela persistir, o próximo ciclo de religamento é ativado ou ocorrerá a abertura definitiva do alimentador no caso de ser este o último ciclo de religamento.

A título ilustrativo é mostrada na Figura 2.13 uma oscilografia extraída do relé de proteção modelo Sepam 1000 plus S41 de fabricação Merlin Gerin / Schneider Electric, onde é possível identificar o comportamento da função de religamento [7].

Os ajustes de proteção efetuados no referido relé são apresentados na Tabela 2.3.

\begin{tabular}{|c|c|}
\hline Parâmetros & Ajustes \\
\hline Corrente de atuação da sobrecorrente de fase & $800 \mathrm{~A}$ \\
\hline Curva Característica & Tempo definido \\
\hline Tempo de atuação & Instantâneo -0 \\
\hline Número de ciclos de religamento & 4 \\
\hline Ativação do religamento & Sobrecorrente instantânea de fase \\
\hline${\text { Tempo morto do } 1^{\circ} \text { ciclo de religamento }}$ & $2,0 \mathrm{~s}$ \\
\hline Tempo morto do $2^{\circ}$ ciclo de religamento & $2,0 \mathrm{~s}$ \\
\hline Tempo morto do $3^{\circ}$ ciclo de religamento & $2,0 \mathrm{~s}$ \\
\hline Tempo morto do $4^{\circ}$ ciclo de religamento & $2,0 \mathrm{~s}$ \\
\hline Tempo de recuperação & 0 \\
\hline
\end{tabular}

Tabela 2.3 - Ajustes de proteção efetuados para o relé de religamento

Foi simulada no relé em questão a ocorrência de uma sobrecorrente instantânea de fase, em que a falta foi sanada no quarto ciclo de religamento. 


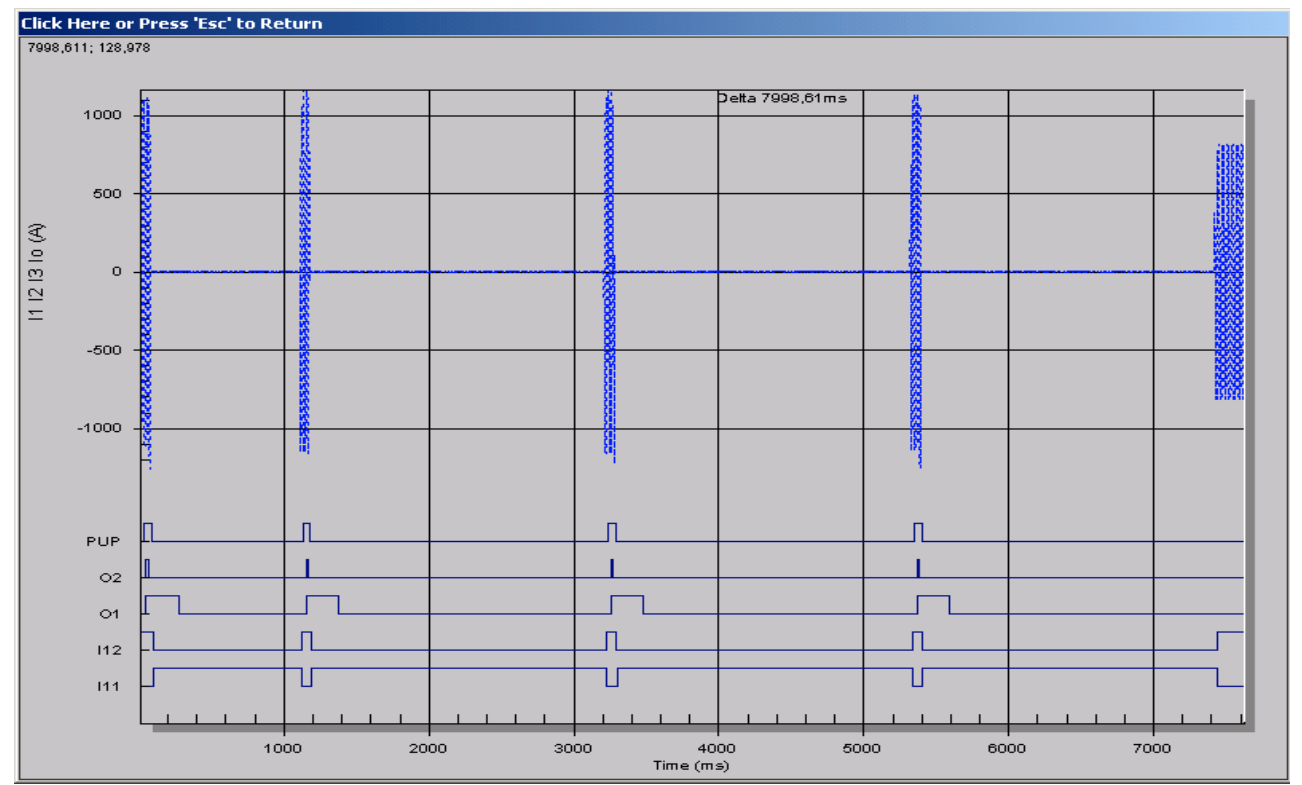

Figura 2.13 - Oscilografia ilustrando o funcionamento da função de religamento

Na Figura 2.13, I1 1 significa a indicação de disjuntor aberto e I12 significa indicação de disjuntor fechado. O1 indica a atuação do contato de operação da proteção.

Observa-se que a corrente ultrapassou o seu valor de atuação e o primeiro ciclo de religamento foi ativado pela proteção de sobrecorrente instantânea de fase. O disjuntor ficou aberto por $1,0 \mathrm{~s}$ que corresponde ao tempo morto do primeiro ciclo de religamento. Logo em seguida, o relé enviou uma ordem de religamento, mas como a corrente estava acima do valor de atuação da unidade de sobrecorrente instantânea de fase $(800 \mathrm{~A})$, ocorreu a ativação do segundo ciclo de religamento e o circuito ficou aberto por 2,0 s, que corresponde ao tempo morto do segundo ciclo de religamento. Este mesmo fenômeno ocorreu para o terceiro e quarto ciclos de religamento. Após o tempo morto do quarto ciclo, uma ordem de religamento foi enviada para o disjuntor ou religador associado e observou-se que a corrente se encontrava abaixo do valor de atuação da unidade de sobrecorrente instantânea de fase. Assim sendo, o circuito foi restabelecido após o quarto e último ciclo de religamento.

O sinal de oscilografia obtido tem 12 amostras por ciclo, portanto, com uma freqüência de amostragem de $720 \mathrm{~Hz}$. O número de ciclos pré falta ajustado para a função de oscilografia é igual a quatro. 
Convém ressaltar que para os disjuntores ou religadores com comando motorizado, é possível enviar para o relé de proteção, um sinal digital informando que a sua mola de fechamento se encontra carregada. Durante o processo de religamento, caso o tempo morto tenha se esgotado e o disjuntor ou religador não esteja com a mola carregada, um tempo morto adicional previamente configurado, entra em ação fazendo com que após este tempo os equipamentos estejam em condições de executar a ordem de fechamento.

A função de religamento é de extrema importância em uma rede de distribuição primária, uma vez que na ocorrência de faltas temporárias, o alimentador pode ser religado sem a necessidade de haver um deslocamento de uma equipe de manutenção no local de defeito. Isto faz com que a empresa distribuidora de energia tenha uma boa imagem junto aos seus consumidores, além de reduzir os seus custos operacionais.

e) Proteção contra falha de disjuntor

No caso da ocorrência de um defeito em uma rede primária, os relés de sobrecorrente irão ser sensibilizados, enviando um sinal de disparo no disjuntor a ele associado. Porém, caso exista uma falha de operação do referido disjuntor, e o mesmo não execute o comando de abertura, a função de falha de disjuntor entra em ação, enviando um sinal de disparo para os disjuntores adjacentes situados a montante. Com isto, no caso de uma falha do disjuntor situado mais próximo do ponto de defeito, o sinal de disparo enviado aos disjuntores de retaguarda provocará a abertura dos mesmos, eliminado assim o defeito no alimentador.

No exemplo da Figura 2.14, há a ocorrência de um defeito no ponto $\mathrm{F}$ sendo sensibilizada a função de sobrecorrente que manda o sinal de disparo SD3 para o disjuntor D3, que falha e não abre o circuito. A unidade de falha de disjuntor do relé R é sensibilizada e envia os sinais de disparo SD1, SD2 para os disjuntores D1 e D2, respectivamente, situados a montante.

Se, por exemplo, forem ajustados o tempo da proteção da sobrecorrente de fase do disjuntor D3 em 0,3 s, o tempo da função falha de disjuntor em 0,2 s e o tempo dos disjuntores D1 e D2 igual a 0,6 s, no caso de falha do disjuntor D3, os disjuntores D1 e 
D2 abrirão em $0,5 \mathrm{~s}(0,3 \mathrm{~s}$ do D3 mais $0,2 \mathrm{~s}$ da função falha de disjuntor). Isto representa um ganho no tempo de abertura dos disjuntores D1 e D2, na condição de falha do disjuntor D3. Ou seja, sem a função falha de disjuntor, os disjuntores D1 e D2 abririam após $0,6 \mathrm{~s}$ da ocorrência da falta, mas com a implementação desta função, este tempo sofre uma redução de $0,1 \mathrm{~s}$, que em termos de proteção é muito bom.

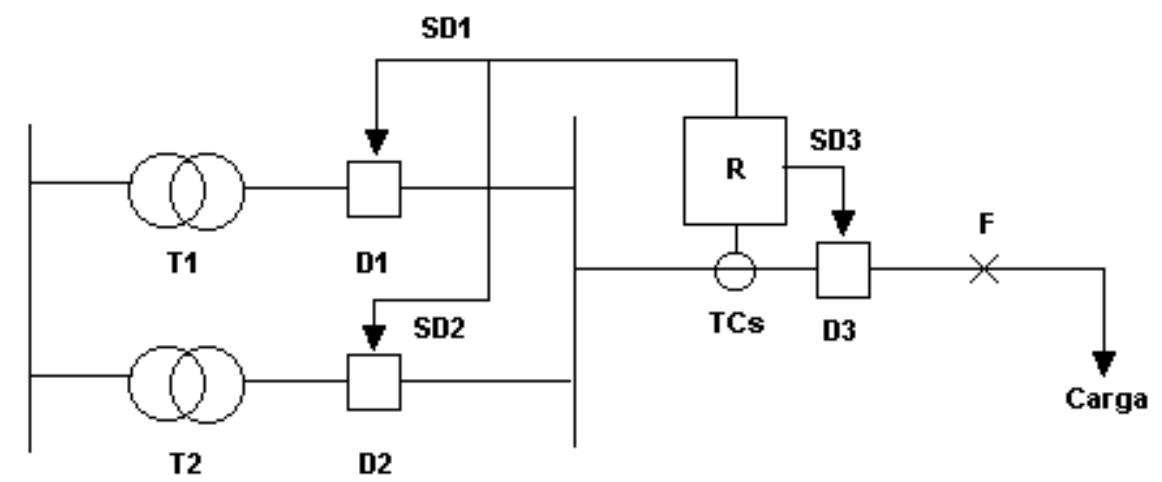

Figura 2.14 - Aplicação da função falha de disjuntor

\section{Legenda:}

T1 - Transformador 1

T2 - Transformador 2

D1 - Disjuntor instalado no secundário do transformador T1

D2 - Disjuntor instalado no secundário do transformador T2

D3 - Disjuntor para a proteção do alimentador

F - Ponto de defeito

$\mathrm{R}$ - Relé de Proteção

TCs - Transformadores de corrente

SD1 - Sinal de disparo enviado ao disjuntor D1

SD2 - Sinal de disparo enviado ao disjuntor D2

SD3 - Sinal de disparo enviado ao disjuntor D3 
f) Supervisão do circuito de abertura do disjuntor

A supervisão do circuito de abertura do disjuntor é muito importante, pois através dela é possível identificar se a bobina de abertura está danificada, ou se a fiação do circuito de comando está rompida.

Um arranjo típico, conforme [7] é ilustrado na Figura 2.15, de tal forma que quando as entradas digitais E1 e E2 estiverem no mesmo nível lógico, significará para o relé que existe algum problema com o circuito de abertura exigindo, portanto, uma ação corretiva o mais rápido possível. No caso das entradas E1 e E2 estarem com níveis lógicos distintos, ou seja, uma energizada e a outra não, significará para o relé que o circuito de abertura está em perfeitas condições de funcionamento.

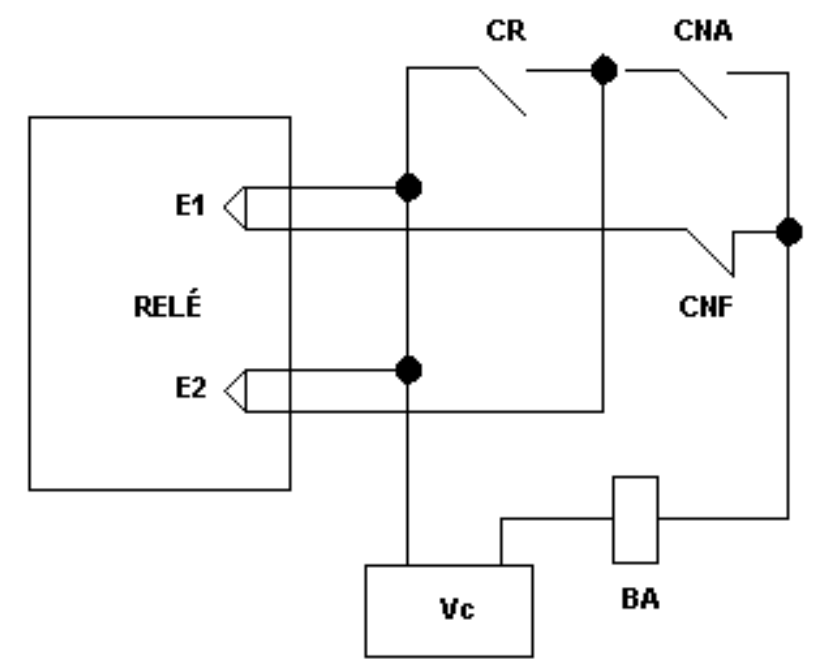

\section{Legenda:}

E1 - Entrada digital 1 do relé

E2 - Entrada digital 2 do relé

CR - Contato de atuação do relé

CNA - Contato NA do disjuntor

CNF - Contato NF do disjuntor

BA - Bobina de abertura

Vc - Tensão de comando

Figura 2.15 - Arranjo típico para a supervisão do circuito de abertura

g) Relé de Bloqueio

Este relé tem por finalidade bloquear o fechamento do disjuntor, quando o mesmo recebe um sinal de disparo do relé de proteção correspondente. Para liberar o fechamento do disjuntor, será necessária a ida do operador até o local em que se encontra instalado o relé e executar um determinado comando no equipamento. 


\subsubsection{4 - Relé de alta impedância}

Um defeito de alta impedância é caracterizado por correntes pequenas que não são vistas pelas unidades de proteção contra sobrecorrente.

No caso específico de uma rede de distribuição primária, pode acontecer o rompimento do cabo de média tensão e o mesmo tocar o solo, sendo que a corrente de defeito pode encontrar uma superfície de contato que apresenta uma impedância elevada como, por exemplo, asfalto, concreto. Assim, é difícil saber o valor exato da impedância do solo, pois em um determinado dia o tempo está mais seco e em outro pode estar mais úmido, além da resistividade do solo variar de região para região.

Existem algumas técnicas e métodos estudados para a detecção de defeitos de alta impedância, dentre as quais podemos citar:

a) Análise das harmônicas da corrente de terceira ordem:

Este método consiste na medição da corrente do circuito de terceira ordem, em módulo e fase [8], sendo que uma média dos valores lidos fica armazenada na unidade de proteção. A cada nova aquisição desta corrente de terceira harmônica, o equipamento de proteção faz uma subtração vetorial entre este último valor lido e a média. Se a resultante desta operação estiver acima de um valor de referência, a unidade mandará o disjuntor abrir devido a um defeito de alta impedância. Estas unidades foram colocadas em serviço no começo da década de 90 .

b) Monitoramento digital do defeito de alta impedância através de um algoritmo:

Um sistema para o monitoramento dos defeitos de alta impedância através de um algoritmo foi proposto por pesquisadores americanos da Universidade do Texas [8] no início dos anos 90. 
Foi desenvolvido um sistema digital, onde foi implementado um algoritmo capaz de fazer a distinção entre o surgimento do arco elétrico na condição de condutor aberto e caído ao solo e na condição de condutor intacto. $\mathrm{Na}$ ocorrência de rompimento do condutor de uma fase, haverá uma perda de carga e uma sobrecorrente nas demais fases. Assim sendo, o sistema detecta a ocorrência de um defeito de alta impedância, quando antes do surgimento do arco elétrico, tiver sido observada uma perda de carga ou uma sobrecorrente no alimentador. Caso contrário, o sistema não visualizará um defeito de alta impedância e sim uma indicação de que, por exemplo, os isoladores do alimentador estão com problemas, carecendo uma manutenção que pode ser desde uma simples limpeza da superfície externa até a troca dos mesmos.

c) Análise das tensões de seqüência negativa e zero na rede

$\mathrm{Na}$ ocorrência do rompimento de um condutor de fase, haverá um desbalanço nas tensões e por conseqüência o aparecimento de tensões de sequências negativa e zero. No caso em que ocorre a abertura de uma das fases do alimentador, as parcelas destas componentes em um ponto da rede a montante do local em que houve a ruptura do cabo variam de 50 a $100 \%$ da componente de seqüência positiva [9]. No caso de rompimento de 2 fases do alimentador, com transformadores conectados entre fase e neutro (monofásicos), as componentes de seqüência negativa e zero são iguais a $100 \%$ da componente fundamental [9]. Já para o rompimento de 2 fases do alimentador com 3 transformadores ligados em delta, e defeito situado no lado da carga, os níveis das componentes de seqüência zero e negativa são similares ao resultado obtido para o rompimento de apenas um condutor. No caso de defeitos no lado da fonte, haverá apenas a componente de seqüência zero [9].

\subsubsection{5 - Considerações finais sobre relés de proteção}

Conforme apresentado nos itens anteriores, os relés de proteção são equipamentos de grande complexidade dotados das mais diversas características e recursos.

Os relés digitais representam uma solução confiável e segura no gerenciamento de redes de distribuição elétrica, sendo que todas as partes vitais de hardware e software são 
continuamente monitoradas e em caso de algum defeito, imediatamente o mesmo pode ser identificado e a unidade defeituosa rapidamente substituída.

O recurso de comunicação dos relés também é de grande valia, permitindo ao usuário, ajustar as proteções remotamente bem como ter um histórico de todos os eventos ocorridos na rede no qual se encontram instalados.

\section{3 - Critérios para ajuste da proteção}

\subsection{1 - Introdução}

O objetivo desta seção é inicialmente avaliar os principais conceitos pertinentes ao estudo clássico da proteção de um sistema de distribuição primária, bem como estudar a coordenação entre os equipamentos utilizados para tal.

A análise de coordenação entre os dispositivos de proteção é muito ampla e extensa apresentando diversas combinações e topologias [2], [3], [4], [5]. Serão ilustradas aquelas de maior interesse que servirão como embasamento teórico para a aplicação prática a ser implementada no capítulo 5 do presente trabalho.

\subsection{2 - Conceitos básicos no estudo de coordenação e ajuste da proteção}

Para o melhor entendimento dos itens subseqüentes se faz necessário o conhecimento dos seguintes termos:

a) Zona de proteção primária: Corresponde aos trechos de rede situados a jusante da instalação de um determinado dispositivo de proteção, onde na ocorrência de um defeito qualquer (temporário ou permanente), o dispositivo resultará sensibilizado.

b) Defeito temporário: São defeitos causados na rede de distribuição oriundos de fatores externos, tais como umidade, vento, chuva, salinidade, galhos de árvores, neve. Em outras palavras, ocorre na rede um curto circuito sem haver um defeito físico na mesma. 
c) Defeito permanente: São os defeitos que ocorrem na rede de distribuição e que necessitam de um reparo para haver o restabelecimento do circuito.

d) Coordenação ou seletividade: Dois dispositivos de proteção estão coordenados, quando na ocorrência de um defeito, haver primeiramente a atuação daquele que estiver mais próximo do ponto de defeito. De acordo com a Figura 2.16, na ocorrência de um defeito no ponto A, o dispositivo mais próximo (D1) deverá atuar e isolar o trecho de rede defeituoso. Nestas condições, o restante do alimentador continuará energizado e alimentando os demais trechos de rede que não apresentam defeito.

e) Proteção de Retaguarda: É o dispositivo de proteção que está situado a montante daquele que está instalado na zona de proteção primária. Na Figura 2.16, para um defeito no ponto A, a proteção primária corresponde ao dispositivo D1 e a proteção de retaguarda corresponde ao dispositivo D4.

f) Tempo de rearme: É o tempo que um dispositivo automático leva para retornar a sua posição de repouso. No caso dos relés digitais, corresponde ao tempo que ele leva para voltar a condição de repouso após um comando de reset. Já para os seccionalizadores é o tempo que o equipamento leva para zerar as contagens realizadas e finalmente para um religador é o tempo que ele leva para retornar a contagem zero do número de ciclos de religamento, após uma seqüência completa ou incompleta de operações do mesmo.

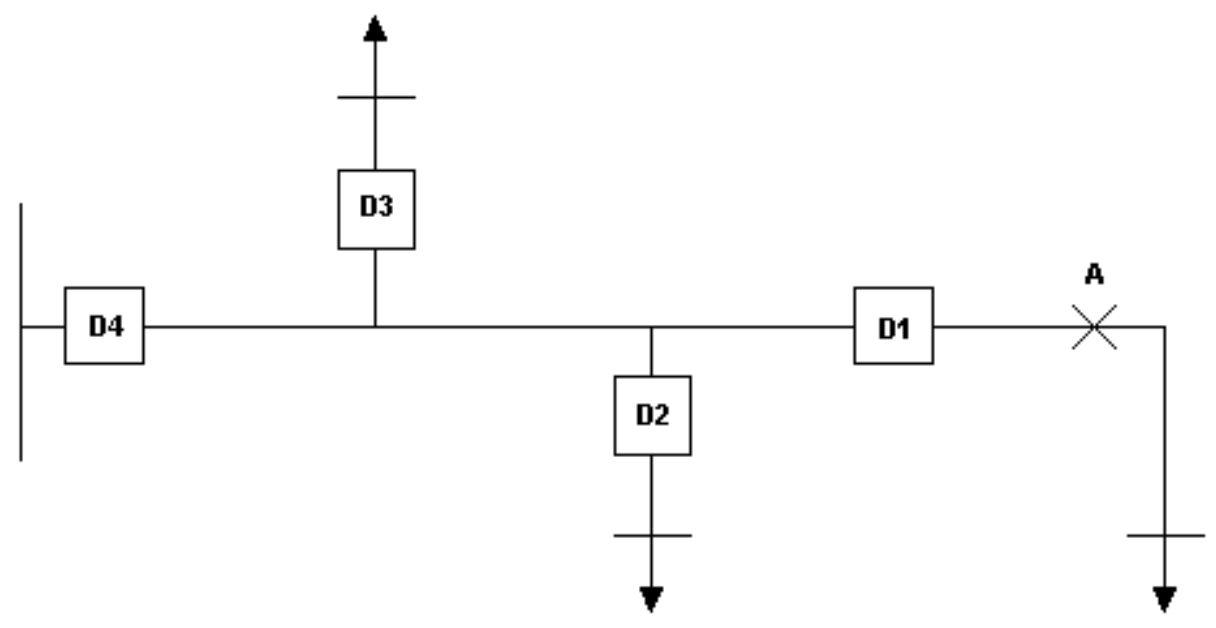

Figura 2.16 - Definição do conceito de coordenação ou seletividade 
Após o estudo dos conceitos principais, serão avaliadas nos itens subseqüentes, as seguintes combinações de coordenações entre dispositivos de proteção:

- Elo Fusível x Elo fusível;

- Elo Fusível x Seccionalizador x Religador

\subsection{3 - Coordenação Elo fusível x Elo fusível}

Antes de iniciar o estudo de coordenação entre os elos fusíveis, deve ser feito o dimensionamento dos mesmos. Para tanto, devem ser observados os seguintes critérios [3]:

- A corrente nominal do elo fusível deve ser maior do que a corrente de carga, sendo que a esta deve ser acrescida a previsão anual de crescimento. Tal parcela de crescimento anual pode ser calculada de acordo com a Equação (2.2) [2]:

$k=\left(1+\frac{c}{100}\right)^{n}$

em que:

k é o fator de crescimento de carga no período considerado;

c corresponde a taxa anual percentual prevista de crescimento;

n corresponde ao número de anos (horizonte de estudo).

- Os elos fusíveis devem ser capazes de suportar a corrente de magnetização na energização do circuito, durante $130 \mathrm{~ms}$ [2]. Ou seja, a corrente mínima de fusão do elo fusível no instante $130 \mathrm{~ms}$ deve ser maior do que a corrente de magnetização. 
- A corrente de mínima fusão do elo fusível no instante $300 \mathrm{~s}$ deve ser menor que a corrente de curto-circuito fase-terra mínimo (com impedância de defeito) na sua zona de proteção primária. Para os fusíveis situados a montante esta recomendação também é válida, considerando a corrente fase-terra mínima no trecho no qual estes elos se encontram instalados [2].

- O tempo máximo total de interrupção do elo fusível protetor deve ser menor ou igual a 75\% do tempo mínimo de fusão do elo protegido;

- A corrente nominal do elo fusível deve ser menor ou igual a um quarto da corrente de curto-circuito fase-terra mínima no final do trecho em que ele está atuando como proteção primária;

- O elo fusível protegido deve coordenar com o elo fusível protetor para o maior valor da corrente de curto-circuito no ponto de instalação do elo protetor.

Os fabricantes de elos fusíveis fornecem tabelas informando o máximo valor de corrente no qual haverá a coordenação entre o elo protegido e protetor.

Segue nas Tabelas 2.4, 2.5, 2.6 e 2.7 alguns exemplos de coordenação entre elos fusíveis [5], onde no cruzamento da linha com a coluna equivale ao valor máximo da corrente em A no qual ocorre coordenação entre o elo fusível protetor e o protegido. 


\begin{tabular}{|c|c|c|c|c|c|c|}
\hline \multirow{2}{*}{$\begin{array}{c}\text { Elo fusível } \\
\text { protetor }\end{array}$} & \multicolumn{6}{|c|}{ Elo fusível protegido } \\
\cline { 2 - 7 } & $\mathbf{1 0 K}$ & $\mathbf{1 5 K}$ & $\mathbf{2 0 K}$ & $\mathbf{2 5 K}$ & $\mathbf{4 0 K}$ & $\mathbf{6 5 K}$ \\
\hline $\mathbf{6 K}$ & 190,0 & 510,0 & 650,0 & 840,0 & 1340 & 2200 \\
\hline $\mathbf{1 0 K}$ & ----- & 300,0 & 540,0 & 840,0 & 1340 & 2200 \\
\hline $\mathbf{1 5 K}$ & ----- & ----- & ----- & 430,0 & 1340 & 2200 \\
\hline $\mathbf{2 0 K}$ & ----- & ----- & ----- & ----- & 1100 & 2200 \\
\hline $\mathbf{2 5 K}$ & ----- & ----- & ----- & ---- & 660,0 & 2200 \\
\hline $\mathbf{4 0 K}$ & ----- & ----- & ----- & ----- & ----- & 1100 \\
\hline
\end{tabular}

Tabela 2.4 - Coordenação entre os elos fusíveis do tipo K [5]

\begin{tabular}{|c|c|c|c|c|c|c|}
\hline \multirow{2}{*}{$\begin{array}{c}\text { Elo fusível } \\
\text { protetor }\end{array}$} & \multicolumn{6}{|c|}{ Elo fusível protegido } \\
\cline { 2 - 7 } & $\mathbf{1 0 T}$ & $\mathbf{1 5 T}$ & $\mathbf{2 0 T}$ & $\mathbf{2 5 T}$ & $\mathbf{4 0 T}$ & $\mathbf{6 5 T}$ \\
\hline $\mathbf{6 T}$ & 350,0 & 920,0 & 1200 & 1500 & 2540 & 4100 \\
\hline $\mathbf{1 0 T}$ & ----- & 530,0 & 1100 & 1500 & 2540 & 4100 \\
\hline $\mathbf{1 5 T}$ & ----- & ----- & ---- & 730,0 & 2500 & 4100 \\
\hline $\mathbf{2 0 T}$ & ----- & ----- & ----- & ----- & 2100 & 4100 \\
\hline $\mathbf{2 5 T}$ & ----- & ----- & ---- & ---- & 1400 & 4100 \\
\hline $\mathbf{4 0 T}$ & ----- & ----- & ----- & ----- & ----- & 1700 \\
\hline
\end{tabular}

Tabela 2.5 - Coordenação entre os elos fusíveis do tipo T [5]

\begin{tabular}{|c|c|c|c|c|c|c|}
\hline \multirow{2}{*}{$\begin{array}{c}\text { Elo fusível } \\
\text { protetor }\end{array}$} & \multicolumn{6}{|c|}{ Elo fusível protegido } \\
\cline { 2 - 7 } & $\mathbf{1 0 K}$ & $\mathbf{1 5 K}$ & $\mathbf{2 0 K}$ & $\mathbf{2 5 K}$ & $\mathbf{4 0 K}$ & $\mathbf{6 5 K}$ \\
\hline $\mathbf{1 H}$ & 230,0 & 510,0 & 650,0 & 840,0 & 1340 & 2200 \\
\hline $\mathbf{2 H}$ & 45,0 & 450,0 & 650,0 & 840,0 & 1340 & 2200 \\
\hline $\mathbf{3 H}$ & 45,0 & 450,0 & 650,0 & 840,0 & 1340 & 2200 \\
\hline $\mathbf{5 H}$ & 45,0 & 450,0 & 650,0 & 840,0 & 1340 & 2200 \\
\hline
\end{tabular}

Tabela 2.6 - Coordenação entre os elos fusíveis do tipo K e H [5] 


\begin{tabular}{|c|c|c|c|c|c|c|}
\hline \multirow{2}{*}{$\begin{array}{c}\text { Elo fusível } \\
\text { protetor }\end{array}$} & \multicolumn{6}{|c|}{ Elo fusível protegido } \\
\cline { 2 - 7 } & $\mathbf{1 0 T}$ & $\mathbf{1 5 T}$ & $\mathbf{2 0 T}$ & $\mathbf{2 5 T}$ & $\mathbf{4 0 T}$ & $\mathbf{6 5 T}$ \\
\hline $\mathbf{1 H}$ & 520,0 & 920,0 & 1200 & 1500 & 2540 & 4100 \\
\hline $\mathbf{2 H}$ & 500,0 & 920,0 & 1200 & 1500 & 2540 & 4100 \\
\hline $\mathbf{3 H}$ & 500,0 & 920,0 & 1200 & 1500 & 2540 & 4100 \\
\hline $\mathbf{5 H}$ & 500,0 & 920,0 & 1200 & 1500 & 2540 & 4100 \\
\hline
\end{tabular}

Tabela 2.7 - Coordenação entre os elos fusíveis do tipo T e H [5]

Na Figura 2.17 são indicadas as curvas características do tempo mínimo de fusão e de interrupção (extinção do arco) dos elos fusíveis 25T (Protegido) e 15T (Protetor) bem como a curva correspondente a $75 \%$ do tempo mínimo de fusão do elo protegido.

Utilizando a Tabela 2.5, observa-se que os elos fusíveis $15 \mathrm{~T}$ e $25 \mathrm{~T}$ estão coordenados para um valor de corrente menor ou igual a 730 A. Na Figura 2.17 verifica-se por inspeção que a curva de extinção do arco do elo fusível 15T se encontra abaixo da curva correspondente a 75\% do tempo mínimo de fusão do elo fusível $25 \mathrm{~T}$ até uma corrente de $730 \mathrm{~A}$. 


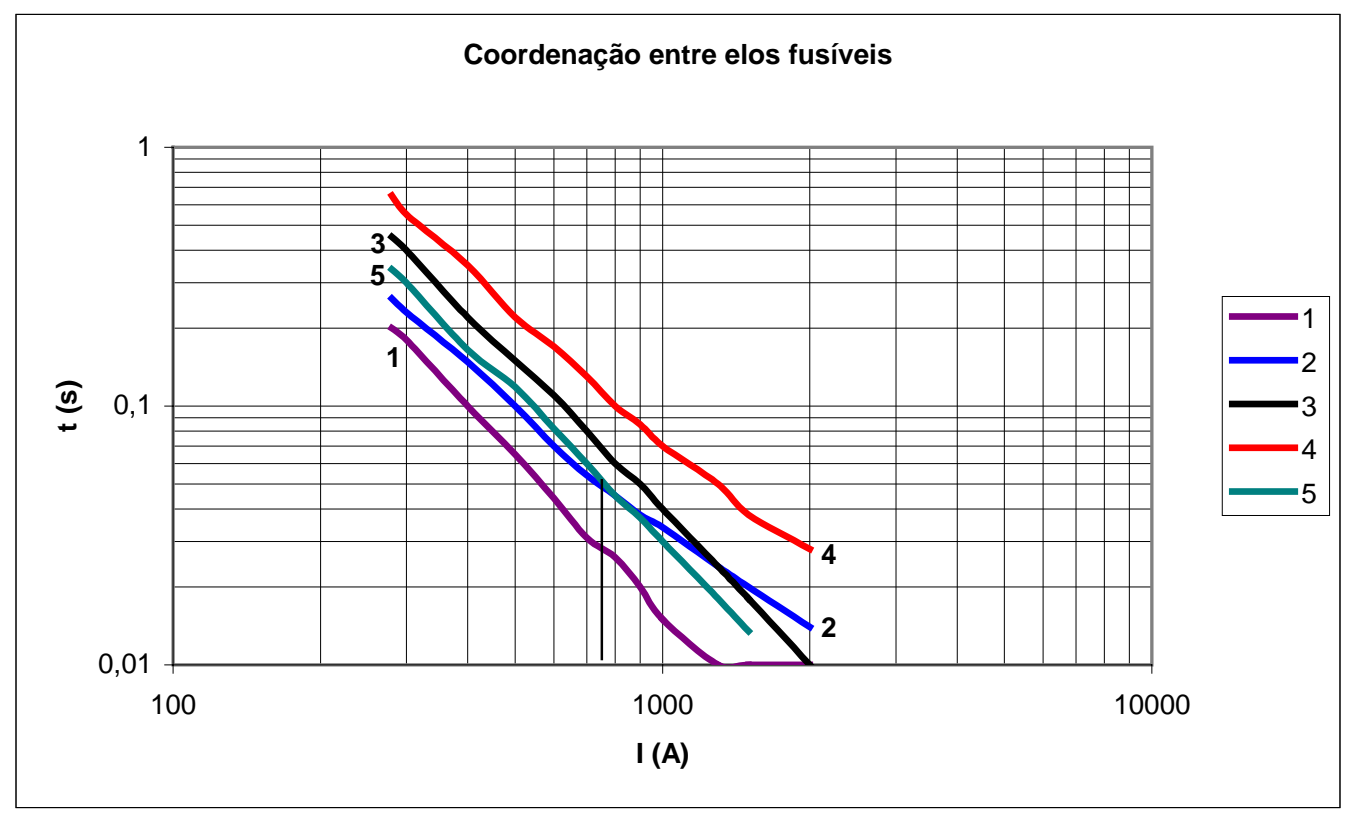

Figura 2.17 - Curvas e coordenação entre os elos fusíveis 15T e 25T [3]

em que:

1 - Curva de mínima fusão do elo fusível 15T;

2 - Curva de interrupção (extinção do arco) do elo fusível 15T;

3 - Curva de mínima fusão do elo fusível 25T;

4 - Curva de interrupção (extinção do arco) do elo fusível 25T;

5 - Curva equivalente a $75 \%$ do tempo de mínima fusão do elo $25 \mathrm{~T}$.

\subsection{4 - Coordenação entre religador, seccionalizador e elo fusível.}

A grande maioria das redes elétricas de distribuição primária possui religadores, seccionalizadores e elos fusíveis. O estudo de coordenação entre estes equipamentos é muito importante, e agrega muito valor para as empresas distribuidoras de energia elétrica, principalmente quando se trata de defeitos temporários.

Neste tipo de topologia, o seccionalizador fica entre o religador e o elo fusível, conforme ilustrado na Figura 2.18. Para defeitos temporários no trecho no qual o elo fusível é proteção primária, o religador irá operar nos ciclos rápidos sem que ocorra a fusão do elo fusível. Porém, se a falta não for sanada durante os ciclos rápidos, o elo 
fusível irá fundir isolando apenas o trecho sob defeito. Por exemplo, se ocorrer um defeito no ponto $\mathrm{A}$, o religador irá operar nos dois ciclos rápidos e se após estes eventos a falta ainda persistir, o Elo 1 fundirá e conseqüentemente o trecho a sua jusante será isolado e o alimentador manterá a continuidade de serviço nas demais cargas instaladas. Caso ocorra um defeito na saída do seccionalizador, o religador operará nos ciclos rápidos e se a falta ainda estiver presente, todos os trechos a sua jusante serão abertos, ou seja, a zona de proteção primária compreendida pelos fusíveis 1 e 2 . Observa-se que após a abertura do seccionalizador e isolação do defeito, os trechos de rede protegidos pelo elo fusível 3 não serão mais interrompidos.

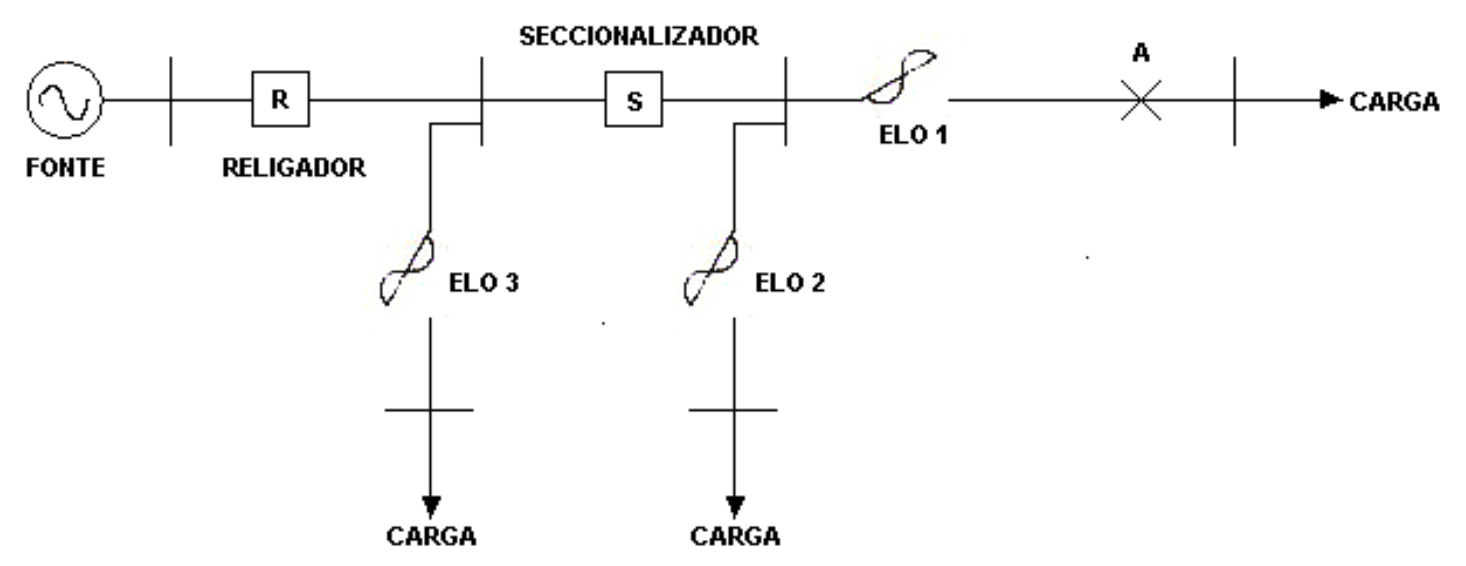

Figura 2.18 - Topologia da rede - Religador, Seccionalizador e Elo fusível.

Para que a coordenação entre religador, seccionalizador e elo fusível ocorra de maneira adequada, devem ser levados em conta os seguintes critérios:

- O valor da corrente mínima de atuação das unidades de fase e terra do seccionalizador deve ser igual a 80\% da corrente mínima de ajuste do religador [2], [4], [5]. No caso de seccionalizadores que não contemplam unidades para a proteção de terra e para os equipamentos (religador e seccionalizador) com controle hidráulico que não possuem bobina série com mesma capacidade de corrente, este limite de $80 \%$ pode ser diminuído para que seja possível ter uma coordenação adequada entre os equipamentos em questão; 
- O religador deve ser ajustado para sentir a corrente de curto-circuito fase-fase mínima (para as unidades de fase) e fase-terra mínima (para as unidades de terra) no final do trecho no qual o seccionalizador é o equipamento de proteção primária;

- A corrente de ajuste do seccionalizador deve ser menor ou igual a corrente de curto circuito mínimo na zona de proteção primária deste equipamento;

- O número de contagens ajustada no seccionalizador deve ser igual ao número de ciclos de religamento ajustado no equipamento de retaguarda menos um;

- No caso de seccionalizadores com controle hidráulico que possuam o acessório restritor de tensão, é possível serem ajustadas 2 operações lentas e 2 rápidas, uma vez que este acessório somente permite a contagem de uma operação do seccionalizador quando a tensão em seus terminais de entrada for igual a zero, ou seja, somente quando o religador abrir. Assim, para 2 operações rápidas o seccionalizador irá registrar 2 contagens e com a abertura do elo fusível não será registrada nenhuma contagem adicional, uma vez que o religador não atuou. No caso de falha do fusível, após serem decorridas as duas operações rápidas, o religador atuará na primeira operação lenta fazendo com que o seccionalizador registre a sua terceira e última contagem, abrindo o circuito definitivamente para trechos situados a sua jusante;

- Nos seccionalizadores com controle eletrônico podem ser ajustadas duas operações rápidas e duas lentas, uma vez que os mesmos possuem o acessório restritor de corrente que irá impedir a sua abertura após a fusão do elo fusível;

- O tempo de interrupção do elo fusível para todos os valores possíveis da corrente de curto-circuito deverá ser menor do que o tempo mínimo de abertura do religador na curva lenta;

- Em linhas gerais, o religador deve ser ajustado com 2 operações lentas e 2 rápidas. Já o seccionalizador deve ser ajustado para registrar 3 contagens; 
- O ajuste da corrente de disparo da unidade de sobrecorrente de fase do religador deve ser menor do que a corrente de curto-circuito dupla fase mínima (No final do trecho no qual o religador é a proteção primária), dividida por um fator de segurança $\left(\mathrm{F}_{\mathrm{s}}\right)$. Este fator de segurança está no intervalo de 1,5 a 2,0 e é considerado no cálculo com o intuito de considerar eventuais erros oriundos no cálculo das correntes de defeito. Além disto considera também erros da unidade de proteção do religador e do TC associado;

- O ajuste da corrente de disparo da unidade de sobrecorrente de neutro (terra) deve ser menor do que a corrente de defeito fase-terra mínimo no final do trecho no qual o religador é proteção primária. Além disto este ajuste deve ser maior do que a corrente de retorno para o neutro, no caso de cargas desequilibradas;

- O tempo de interrupção do elo fusível para todos os valores possíveis da corrente de curto-circuito deverá ser menor do que o tempo mínimo de abertura do religador na curva lenta.

\section{4 - Conclusões}

O presente capítulo ilustrou inicialmente os dispositivos de proteção utilizados em redes de distribuição primária de energia elétrica para que na seqüência fosse possível avaliar as topologias mais comuns de coordenação entre eles.

Os conceitos aqui apresentados servem de base para que o Engenheiro de proteção efetue o estudo de coordenação da rede elétrica da maneira mais adequada possível, mantendo a integridade do sistema como um todo na ocorrência de qualquer tipo de anormalidade.

Este estudo de coordenação, baseado em regras e conceitos amplamente difundidos na literatura técnica é chamado de abordagem determinística ou clássica. 


\section{PROTEÇÃO PROBABILÍSTICA DE SOBRECORRENTE}

\section{1 - Introdução}

A variação das correntes de defeito em sistemas elétricos se deve à existência de fatores não controlados, tais como localização dos pontos de defeito ao longo da rede, tipo dos defeitos (trifásico, fase-terra, etc.) e impedâncias externas envolvidas nos defeitos. Assim, o problema de determinar os níveis esperados de correntes de defeito em um determinado sistema pode ser melhor estudado utilizando-se uma abordagem probabilística, na qual algumas variáveis do problema são tratadas como variáveis aleatórias.

Uma variável aleatória resulta perfeitamente definida quando se conhece sua distribuição de valores; isto é, para cada possível valor da variável (ou intervalo de valores) conhece-se a correspondente probabilidade (ou densidade de probabilidade).

A principal variável aleatória no presente estudo é a variável corrente de defeito. Esta variável será considerada dependente de três outras variáveis aleatórias independentes, localização dos defeitos, tipo do defeito e resistência de defeito, para as quais a distribuição de valores é considerada conhecida. Em tudo quanto se segue será visto como utilizar a distribuição das variáveis independentes, juntamente com o equacionamento da teoria de curto-circuito em sistemas elétricos, para obtenção da distribuição das correntes de defeito.

A distribuição das correntes de defeito pode ser obtida através de método analítico ou através de simulação de curto-circuito da rede elétrica. $\mathrm{O}$ método analítico somente é viável para trechos simples de rede, e a consideração de impedâncias complexas aumenta consideravelmente o grau de dificuldade de sua dedução. Por esta razão, no presente trabalho adotou-se o método de simulação da rede elétrica, com o qual pode-se tratar redes contendo um elevado número de trechos e no qual a consideração de impedâncias complexas não oferece nenhuma dificuldade adicional. 
O presente capítulo está organizado como se segue. Inicialmente apresenta-se o estado da arte da proteção probabilística de sobrecorrente, baseado em um artigo técnico publicado relacionado à implementação de um sistema computacional capaz de fazer a geração e o processamento das distribuições das correntes de defeito utilizando o método de Monte Carlo [16]. Na seqüência serão abordadas em detalhes, as duas metodologias existentes para a determinação da distribuição das correntes de defeito, apresentando as vantagens e desvantagens de cada uma delas. O desenvolvimento de cada metodologia será acompanhado por um exemplo de aplicação, para melhor ilustrar os conceitos apresentados.

\section{2 - Estado da arte da proteção probabilística de sobrecorrente}

\subsection{1 - Considerações iniciais}

No decorrer dos anos tem havido um crescimento muito significativo no estudo de metodologias probabilísticas como uma ferramenta principal na análise de problemas de engenharia nas mais diversas áreas. No âmbito da eletricidade, tais ferramentas são aplicadas em estudos de confiabilidade, fluxo de potência e curto-circuito, sendo este último o objeto do trabalho em questão.

Foram realizadas árduas pesquisas em diversas instituições e constatou-se que existem poucas publicações a respeito da abordagem probabilística da proteção de sobrecorrente em redes de distribuição primária de energia elétrica. Mais especificamente foram observados dois artigos técnicos.

Sato; Garcia; Monticelli (1993) apresentaram um trabalho [16], propondo um sistema computacional com o intuito de gerar a distribuição das correntes de defeito em um Sistema de Potência através do método de Monte Carlo.

Robba et al. (1998) apresentaram um trabalho [17] relacionado à proteção de redes de distribuição de energia elétrica com enfoque probabilístico. Para melhor avaliar o problema, foi desenvolvido em 1996, pelo Centro de Excelência em Distribuição de 
Energia Elétrica da Universidade de São Paulo (CED/USP), um sistema que simula com extrema facilidade, redes elétricas de distribuição primária com centenas e milhares de trechos. Tal sistema se chama PROCOR [3], [17].

Nos itens subseqüentes serão apresentados resumidamente os resultados alcançados por Sato; Garcia; Monticelli, em seu trabalho e no próximo capítulo será ilustrado o sistema computacional PROCOR.

\subsection{2 - Análise de curto-circuito probabilístico pelo método de Monte Carlo}

O método de Monte Carlo consiste em um processo de geração de números aleatórios com distribuição uniforme os quais são utilizados na amostragem de outras variáveis aleatórias de interesse. A principal vantagem oferecida por este método é a flexibilidade que permite trabalhar com redes elétricas de alto grau de complexidade. $\mathrm{O}$ esforço computacional requerido é bastante significativo, mas consegue-se resultados amplamente satisfatórios e que ajudam muito no estudo da proteção de sobrecorrente em redes elétricas de distribuição primária.

Para a determinação da distribuição de probabilidade das correntes de defeito foi proposto [16] um sistema computacional de alta performance contendo 64 processadores ligados em paralelo em uma arquitetura também chamada de "hipercubo". A Figura 3.1 ilustra um exemplo contendo uma arquitetura "hipercubo" com 4 nós (processadores)
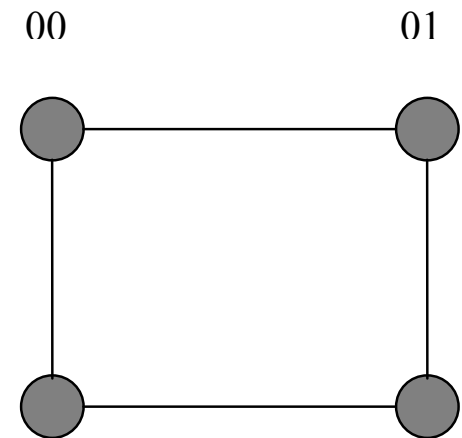

10

11

Figura 3.1 - Hipercubo com 4 nós 
Todos os processadores trabalham independentemente, sendo que o de número zero é o responsável por coletar as correntes de curto-circuito de todos os processadores existentes (incluindo o número zero).

O computador onde se encontram localizados os processadores ligados em paralelo é conectado em uma rede, sendo possível acessá-lo através de outras estações de trabalho conectadas nesta mesma rede. Isto significa que existe um único computador conectado a esta onde se encontram instalados todos os componentes de hardware necessários para a execução dos processamentos matemáticos utilizados na geração das curvas de distribuição das correntes de defeito.

Para a determinação da distribuição das correntes de defeito usando o método de Monte Carlo através de uma unidade de processamento extremamente complexa, uma modelagem da rede elétrica apropriada é necessária.

Tal modelagem consiste na determinação de um equivalente reduzido do sistema em estudo, com o intuito de facilitar o problema. Para tanto, monta-se a matriz de admitâncias nodais, também conhecida como $Y_{B U S}$, substituindo os trechos de rede com menor probabilidade de ocorrência de defeito, por um gerador de corrente equivalente, determinado de acordo com a Equação (3.1). O conjunto dos trechos de rede que foram substituídos pelo gerador de corrente equivalente são chamados de regiões menos críticas, enquanto que as demais regiões de interesse são chamadas de mais críticas. A Figura 3.2 ilustra as regiões acima definidas, enquanto que a Figura 3.3 mostra a substituição das regiões menos críticas pelo gerador de corrente equivalente.

$$
[I]=\left[Y_{B U S}\right] \cdot[V]
$$

em que:

$[I]$ representa o vetor coluna das correntes nodais da rede em estudo;

$\left[Y_{B U S}\right]$ representa a matriz de admitâncias nodais da rede em estudo;

$[V]$ representa o vetor de tensões nodais da rede em estudo. 


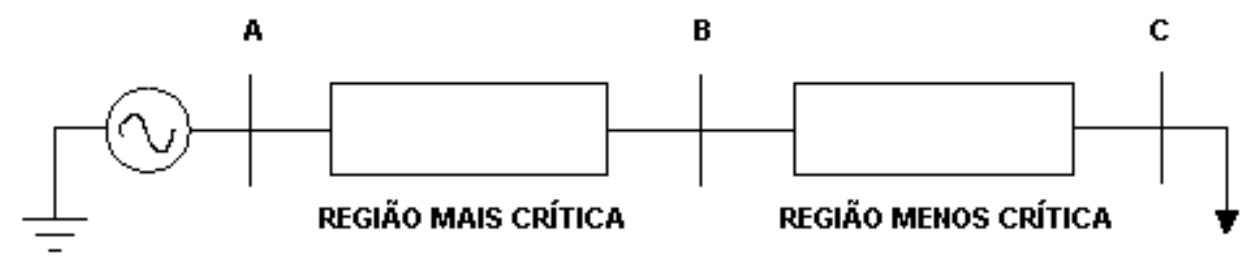

Figura 3.2 - Representação da rede elétrica

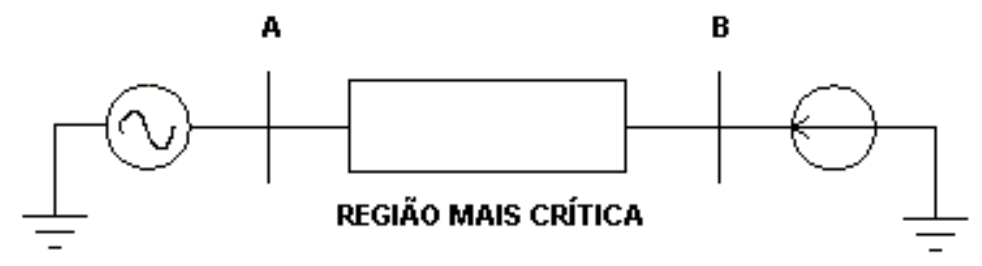

Figura 3.3 - Equivalente reduzido da rede elétrica

As simulações realizadas para a determinação da distribuição de probabilidades das correntes de defeito, usando a estrutura de hardware baseada na arquitetura "hipercubo" foram realizadas para um sistema contendo 1333 barras, 2463 ramos e 787 acoplamentos mútuos entre trechos. Como a quantidade de barras, ramos $\mathrm{e}$ acoplamentos mútuos são elevados, foi adotada como solução a divisão deste sistema em dois subsistemas identificados pelas letras $S_{1}$ e $S_{2}$. Nestes subsistemas foram consideradas apenas as regiões com maior probabilidade de ocorrência de defeito (Mais críticas) sendo o restante substituído por um gerador de corrente equivalente.

Com estas considerações, os subsistemas ficaram com a configuração que é ilustrada na Tabela 3.1.

\begin{tabular}{|c|c|c|c|}
\hline Subsistema & Barras & Ramos & Acoplamentos mútuos \\
\hline \hline $\mathrm{S}_{1}$ & 144 & 237 & 26 \\
\hline $\mathrm{S}_{2}$ & 22 & 59 & 130 \\
\hline
\end{tabular}

Tabela 3.1 - Configuração reduzida dos subsistemas $\mathrm{S}_{1}$ e $\mathrm{S}_{2}$

Foram realizados alguns processamentos para o subsistema $\mathrm{S}_{1}$, com o intuito de observar o efeito do número de amostras ou simulações de Monte Carlo na precisão da 
estimativa da distribuição de probabilidade das correntes de defeito. Inicialmente obteve-se a distribuição das correntes de defeito (de fase e de terra) para uma faixa de simulações de Monte Carlo variando de 500 a 2500 e observou-se que o resultado não apresentou uma precisão e uma qualidade significativa que possibilitasse chegar a alguma conclusão adequada.

Assim sendo, foram realizados outros processamentos para um número maior de simulações de Monte Carlo e observou-se que quanto maior este número mais precisa é a distribuição de probabilidade das correntes de defeito. Para este novo processamento foram determinadas as curvas de distribuição de probabilidades das correntes de defeito (fase e terra), considerando 5.000, 10.000, 20.000 e 30.000 simulações de Monte Carlo.

Além de analisar o efeito do número de simulações de Monte Carlo na precisão da distribuição das correntes de defeito, foi abordado o tempo de processamento em função da arquitetura de hardware escolhida. O critério para a determinação de tal topologia foi a velocidade de processamento que depende diretamente do número de simulações de Monte Carlo e do número de nós do processador. Como se deseja obter um resultado preciso, o que acarreta um número elevado de simulações, em um tempo pequeno, optou-se no presente estudo em utilizar uma arquitetura "hipercubo" com 64 nós. A Tabela 3.2 ilustra a relação de velocidade de processamento entre um hardware "hipercubo" de 1 nó, um de 32 e um outro de 64 nós, em função do número de simulações de Monte Carlo.

\begin{tabular}{|c|c|c|c|c|}
\hline \multirow{2}{*}{ Número de nós } & \multicolumn{4}{|c|}{ Número de simulações de Monte Carlo } \\
\cline { 2 - 5 } & $\mathbf{4 . 0 0 0}$ & $\mathbf{1 6 . 0 0 0}$ & $\mathbf{5 0 . 0 0 0}$ & $\mathbf{1 0 0 . 0 0 0}$ \\
\hline \hline $\mathbf{1}$ & 1,00 & 1,00 & 1,00 & 1,00 \\
\hline $\mathbf{3 2}$ & 22,4 & 28,9 & 30,9 & 31,4 \\
\hline $\mathbf{6 4}$ & 34,1 & 52,5 & 59,7 & 61,8 \\
\hline
\end{tabular}

Tabela 3.2 - Relação da velocidade de processamento

De acordo com a Tabela 3.2, observa-se que quanto maior o número de nós, mais rápido será o tempo de processamento. Por outro lado, quanto maior o número de simulações 
de Monte Carlo maior será a relação da velocidade de processamento entre um processador com " $n$ " cubos e um com apenas 1 cubo. Exemplificando, com base na Tabela 3.2, um processamento para a determinação da distribuição das correntes de defeito com um hardware de 64 nós, utilizando 100.000 simulações de Monte Carlo, é 61,8 vezes mais rápido do que se este mesmo processamento fosse realizado para um hardware contendo apenas 1 nó.

\section{3 - Determinação analítica da distribuição das correntes de defeito}

\subsection{1 - Considerações iniciais}

Seja o trecho genérico de rede de comprimento $L$ representado na Figura 3.4. Associado ao trecho de rede existem impedâncias de entrada de seqüência positiva e de seqüência zero $\left(z_{e} 1\right.$ e $z_{e} 0$, respectivamente), que representam as impedâncias equivalentes de Thévenin do sistema "atrás" do trecho em consideração. O trecho em si possui impedâncias de seqüência positiva e seqüência zero dadas por $z_{t 1}$ e $z_{t 0}$, respectivamente. Destaca-se que em tudo quanto se segue considerar-se-á que todas as impedâncias envolvidas são puramente indutivas.

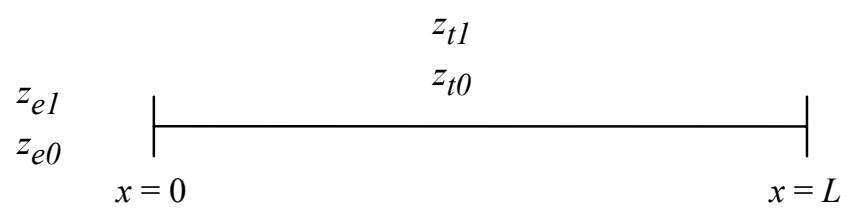

Figura 3.4 - Trecho genérico de rede

Conhecendo-se as variáveis aleatórias: localização dos defeitos e resistência de defeito através de suas funções de probabilidade acumulada (FPA) e densidade de probabilidade (FDP), deseja-se determinar a distribuição das correntes de defeito que surgirão quando defeitos trifásicos, dupla fase, fase-terra e dupla fase-terra ocorrerem no trecho. Ou seja, deseja-se determinar a FPA ou a FDP da variável corrente de defeito no trecho. 
Em primeiro lugar, observa-se que a variável localização dos defeitos só poderá assumir valores entre 0 (início do trecho) e $L$ (comprimento do trecho). Também observa-se que a resistência de defeito só será relevante naqueles defeitos que envolvem a terra (faseterra e dupla fase-terra).

Nos próximos subitens será abordada a obtenção da distribuição das seguintes variáveis aleatórias: localização dos defeitos, correntes de defeito trifásico, correntes de defeito dupla fase, correntes de defeito trifásico/dupla fase (combinados) e correntes de defeito fase-terra.

\subsection{2 - Distribuição da localização dos defeitos}

Considerando-se distribuição uniforme dos pontos de defeito no trecho genérico de rede da Figura 3.4, tem-se:

FDP: $f(x)=\frac{1}{L}$,

e FPA: $\quad F(x)=P(X \leq x)=\int_{0}^{x} f(x) d x=\frac{x}{L}$

em que: $0 \leq x \leq L \quad(L=$ comprimento do trecho $)$.

A Figura 3.5 ilustra ambas funções para este caso.

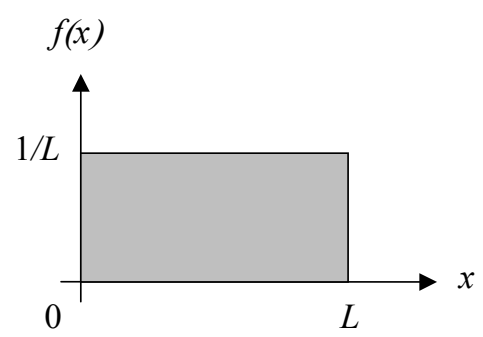

(a) - FDP

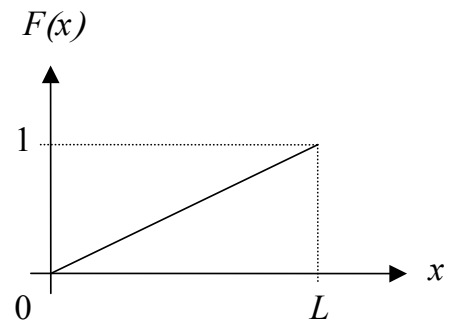

(b) - FPA

Figura 3.5 - FDP e FPA para distribuição uniforme da localização dos defeitos 


\subsection{3 - Distribuição das correntes de defeito trifásico}

Para um ponto genérico $x$ da Figura 3.6, a corrente de curto-circuito trifásico $y$ é dada por:

$y=\frac{1}{z_{e 1}+\frac{z_{t 1}}{L} \cdot x}$,

em que:

$y=$ corrente de defeito trifásico no ponto $x(\mathrm{pu})$;

$z_{e 1}=$ impedância de seqüência positiva na posição $x=0$ (entrada do trecho) (pu);

$z_{t 1}=$ impedância de seqüência positiva total do trecho (pu).

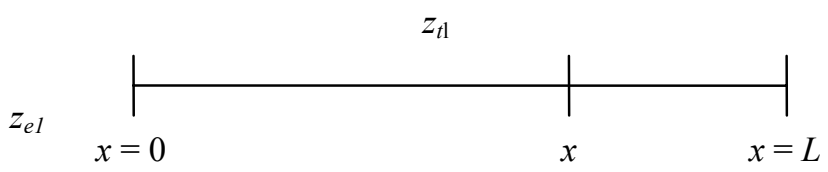

Figura 3.6 - Curto-circuito trifásico no ponto $x$ do trecho genérico de rede

O problema que se apresenta é: dada uma distribuição uniforme da localização dos defeitos (representada pela variável aleatória $X$ ), qual será a distribuição das correntes de defeito trifásico, representada pela variável $Y$ e obtida a partir da Equação (3.4)?

O método geral para determinar a FPA/FDP de uma variável dependente de uma outra variável aleatória é resumido nos passos a seguir:

a) Determinação de $F(x)$ (FPA de $X$ );

b) Determinação dos eventos $Y$ equivalentes aos eventos $X$, utilizando a relação funcional existente entre ambas as variáveis; 
c) Determinação de $G(y)$ (FPA de $Y$ );

d) Determinação de $g(y)=\frac{d}{d y} G(y)$.

No caso em análise, tem-se:

$$
\begin{aligned}
& G(y)=P(Y \leq y)=P\left(\frac{1}{z_{e 1}+\frac{z_{t 1}}{L} \cdot x} \leq y\right) \\
& =P\left(X \geq-\frac{z_{e 1} \cdot L}{z_{t 1}}+\frac{L}{z_{t 1}} \cdot \frac{1}{y}\right) \\
& =1-P\left(X \leq-\frac{z_{e 1} \cdot L}{z_{t 1}}+\frac{L}{z_{t 1}} \cdot \frac{1}{y}\right) \\
& =1-F\left(-\frac{z_{e 1} \cdot L}{z_{t 1}}+\frac{L}{z_{t 1}} \cdot \frac{1}{y}\right) \\
& =1+\frac{z_{e 1}}{z_{t 1}}-\frac{1}{z_{t 1}} \cdot \frac{1}{y} .
\end{aligned}
$$

Assim,

$$
\begin{aligned}
& G(y)=\frac{z_{t 1}+z_{e 1}}{z_{t 1}}-\frac{1}{z_{t 1}} \cdot \frac{1}{y} . \\
& g(y)=\frac{d}{d y} G(y)=\frac{1}{z_{t 1}} \cdot \frac{1}{y^{2}}, \\
& \operatorname{com} y_{L}=\frac{1}{z_{e 1}+z_{t 1}} \leq y \leq \frac{1}{z_{e 1}}=y_{0} .
\end{aligned}
$$

A FPA e FDP da corrente de defeito trifásico (Equações 3.6 e 3.7) são ilustradas na Figura 3.7. Note-se que o valor da FPA nos pontos extremos obedece às propriedades de toda FPA: 


$$
G\left(y_{0}\right)=G\left(\frac{1}{z_{e 1}}\right)=1 \quad \text { e } \quad G\left(y_{L}\right)=G\left(\frac{1}{z_{e 1}+z_{t 1}}\right)=0
$$

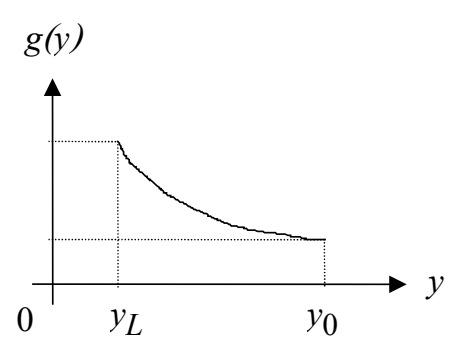

(a) - FDP

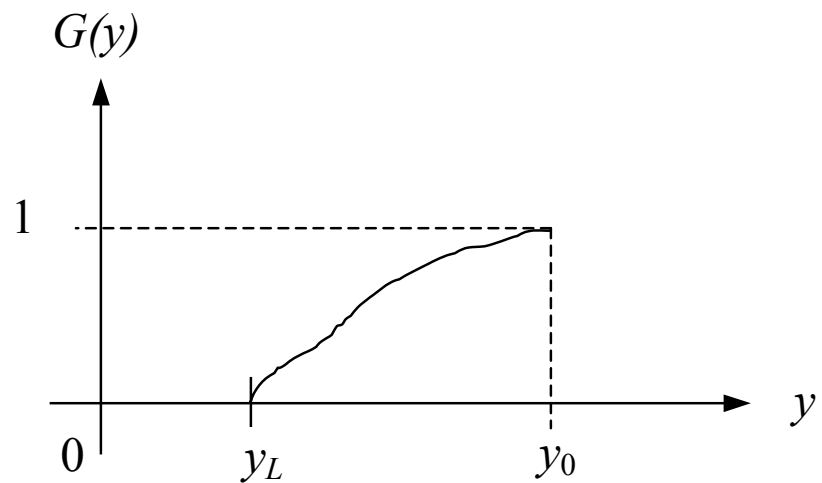

(b) - FPA

Figura 3.7 - FDP e FPA das correntes de defeito trifásico

\subsection{4 - Distribuição das correntes de defeito dupla fase}

O procedimento para obtenção da distribuição das correntes de defeito dupla fase é exatamente o mesmo do caso precedente, lembrando que a corrente de defeito dupla fase é $(\sqrt{3} / 2)$ vezes a corrente de defeito trifásico. Assim, para o defeito dupla fase tem-se:

$H(y)=\frac{z_{t 1}+z_{e 1}}{z_{t 1}}-\frac{\sqrt{3}}{2 z_{t 1}} \cdot \frac{1}{y}$

e $h(y)=\frac{d}{d y} H(y)=\frac{\sqrt{3}}{2 z_{t 1}} \cdot \frac{1}{y^{2}}$

$\operatorname{com} \quad y_{L}=\frac{\sqrt{3}}{2\left(z_{e 1}+z_{t 1}\right)} \leq y \leq \frac{\sqrt{3}}{2 z_{e 1}}=y_{0}$. 


\subsection{5 - Distribuição das correntes de defeito trifásico/dupla fase}

Uma vez determinada a distribuição das correntes de defeito trifásico e defeito dupla fase, deve-se compor ambas distribuições de forma a obter a distribuição da corrente para os dois tipos de defeito combinados, defeitos de fase, a qual será usada no estudo da proteção de sobrecorrente de fase. Conhecendo-se:

a) A probabilidade de defeito trifásico $\left(p_{3}\right)$ e probabilidade de defeito dupla fase $\left(p_{2}\right)$ no trecho de rede considerado;

b) A FDP para defeitos trifásicos: $g(y)$;

c) A FDP para defeitos dupla fase: $h(y)$;

Obtém-se a FDP para defeitos de fase (trifásicos e dupla fase) através de:

$k(y)=p \cdot g(y)+(1-p) \cdot h(y)$,

em que:

$p=\frac{p_{3}}{p_{3}+p_{2}}$

e $\quad 1-p=\frac{p_{2}}{p_{3}+p_{2}}$.

As probabilidades $p$ e (1-p), obtidas como indicado acima são conseqüência do teorema de Bayes, isto é, o valor $p$ é a probabilidade de ocorrer um defeito trifásico dado que houve um defeito de fase (probabilidade condicionada), e a probabilidade (1- $p$ ) é a probabilidade de ocorrer um defeito dupla fase dado que houve um defeito de fase. Note-se que a soma $\left(p_{3}+p_{2}\right)$ não é, em geral, igual a 1 , ao contrário do que acontece 
com as probabilidades condicionadas $p$ e (1-p). Desta forma, a FDP da Equação (3.10) e sua correspondente FPA continuam satisfazendo as suas propriedades [15].

A Figura 3.8 ilustra a composição das distribuições indicadas na Equação (3.10).

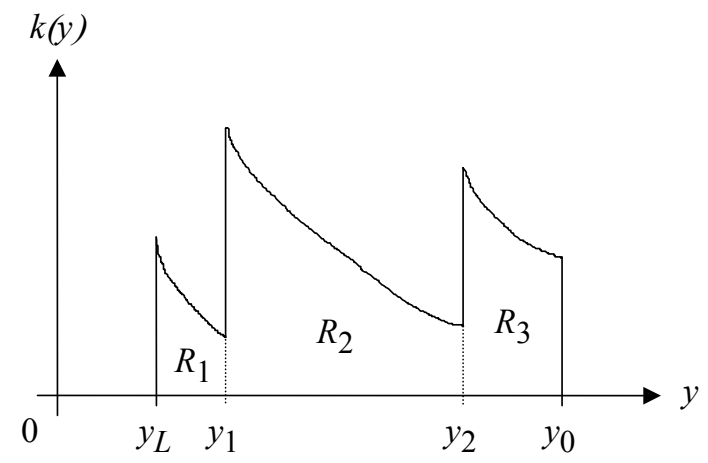

Figura 3.8 - FDP das correntes de defeito de fase (trifásico e dupla fase combinados)

Os limites de corrente na Figura 3.8 são dados por:

$y_{L}=\frac{\sqrt{3}}{2\left(z_{e 1}+z_{t 1}\right)}$

$(2 \phi \min$.

$y_{1}=\frac{1}{z_{e 1}+z_{t 1}}=\frac{2}{\sqrt{3}} y_{L}$

(3申 min.)

$y_{2}=\frac{\sqrt{3}}{2 z_{e 1}}=\frac{\sqrt{3}}{2} y_{0}$

(2ф máx.)

$y_{0}=\frac{1}{z_{e 1}}$

(3ф máx.)

A expressão analítica das três regiões na Figura 3.8 é indicada a seguir.

- Região R1 (somente correntes de defeitos dupla fase)

$y_{L} \leq y<y_{1}: k(y)=(1-p) \cdot \frac{\sqrt{3}}{2 z_{t 1}} \cdot \frac{1}{y^{2}} ;$ 
- Região R2 (correntes de defeitos trifásicos e dupla fase)

$$
y_{1} \leq y<y_{2}: k(y)=(1-p) \cdot \frac{\sqrt{3}}{2 z_{t 1}} \cdot \frac{1}{y^{2}}+p \cdot \frac{1}{z_{t 1}} \cdot \frac{1}{y^{2}}
$$

- Região R3 (somente correntes de defeitos trifásicos)

$$
y_{2} \leq y \leq y_{0}: k(y)=p \cdot \frac{1}{z_{t 1}} \cdot \frac{1}{y^{2}} .
$$

\subsection{6 - Distribuição das correntes de defeito fase-terra}

\subsubsection{1 - Considerações gerais}

Para um ponto genérico $x$ da Figura 3.9, a corrente de curto-circuito fase-terra $y$ é dada por:

$$
y=\frac{3}{\left(2 z_{e 1}+z_{e 0}\right)+\left(2 z_{t 1}+z_{t 0}\right) \frac{x}{L}+3 z_{a}},
$$

em que:

$y$ é a corrente de defeito fase-terra no ponto $x(\mathrm{pu})$;

$z_{e l}$ é a impedância de seqüência positiva vista na entrada do trecho $(x=0)(\mathrm{pu})$;

$z_{e 0}$ é a impedância de seqüência zero vista na entrada do trecho $(x=0)(\mathrm{pu})$;

$z_{t l}$ é a impedância de seqüência positiva total do trecho (pu);

$z_{t 0}$ é a impedância de seqüência zero total do trecho (pu);

$z_{a}$ é a resistência de defeito no ponto de curto-circuito (pu); 


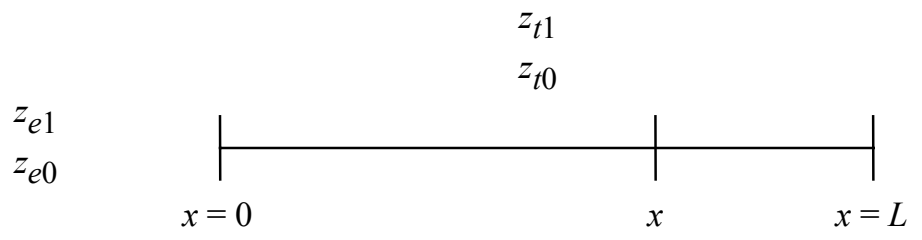

Figura 3.9 - Curto-circuito fase-terra no ponto $x$ do trecho genérico de rede

Neste caso adotar-se-ão as seguintes distribuições:

a) Distribuição uniforme da localização dos defeitos (variável independente $x$, Figura $3.10 \mathrm{a})$;

b) Distribuição uniforme truncada da resistência de defeito (variável independente $z$, Figura 3.10b).

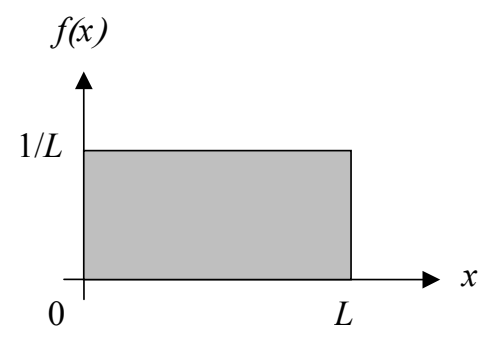

(a) - localização dos defeitos

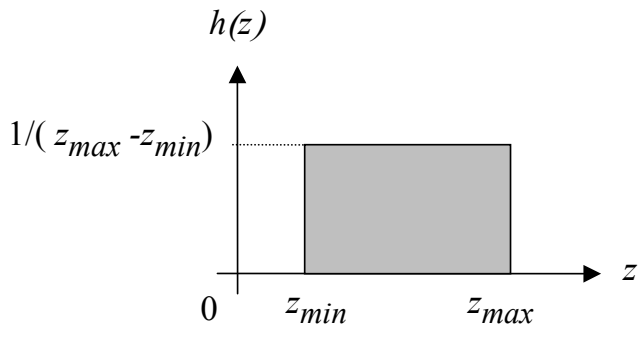

(b) - resistência de defeito

Figura 3.10 - Distribuições adotadas para as variáveis independentes

O problema que se apresenta é: dadas as distribuições da localização dos defeitos (representada pela variável $X$ ) e da resistência de defeito (representada pela variável $Z$ ), qual será a distribuição das correntes de defeito fase-terra, representada pela variável $Y$ e obtida a partir da Equação (3.11)?

Inicialmente observa-se que a corrente de curto-circuito fase-terra tem a seguinte forma equivalente: 
$y=\frac{A}{B+C x+D z}$,

em que:

$A=3$;

$B=2 z_{e 1}+z_{e 0}$

$C=\frac{2 z_{t 1}+z_{t 0}}{L} \quad \operatorname{com} \quad 0 \leq x \leq L$, o que equivale a:

$C=1 \quad$ e $\quad 0 \leq x \leq x_{\max }=2 z_{t 1}+z_{t 0} ;$

$D=3 \quad$ e $\quad z_{\min } \leq z \leq z_{\max }$.

Observa-se também que no denominador aparece uma soma de duas variáveis aleatórias $(C X$ e $D Z)$ que neste caso serão consideradas independentes. Para resolver o problema acima formulado, é necessário executar as seguintes etapas:

a) Determinação da FDP da variável aleatória $S=C X+D Z$;

b) Determinação da FDP da variável aleatória $Y=\frac{A}{B+S}$.

As quais serão abordadas no item seguinte.

\subsubsection{2 - Determinação da FDP da variável aleatória $S=C X+D Z$}

A Figura 3.11 apresenta a FDP das variáveis $C X$ e $D Z$ que serão consideradas na presente dedução ( $C$ e $D$ representam valores constantes). 


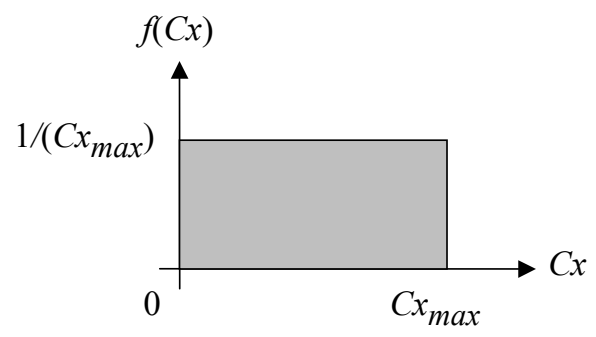

(a) - variável $C X$

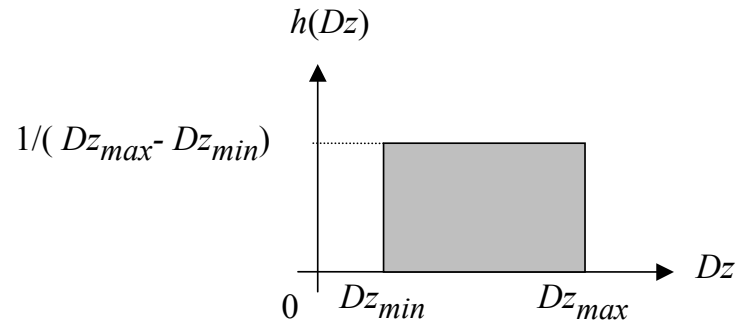

(b) - variável $D Z$

Figura 3.11 - FDP das variáveis $C X$ e $D Z$

De acordo com a referência [32], a FDP da variável $S$ deve ser obtida pela seguinte integral de convolução:

$$
h(s)=\int_{-\infty}^{+\infty} f(\omega) h(s-\omega) d \omega=\int_{-\infty}^{+\infty} \frac{1}{C x_{\max }} \cdot \frac{1}{D z_{\max }-D z_{\min }} d \omega=\left.\frac{1}{C D x_{\max }\left(z_{\max }-z_{\min }\right)} \cdot \omega\right|_{\mathrm{inf}} ^{\text {sup }}
$$

em que inf e sup indicam os limites inferior e superior de integração, respectivamente.

Observa-se que as funções $f(\omega)$ e $h(s-\omega)$ variam entre os seguintes limites:

1. $f(\omega): \quad 0 \leq \omega \leq C x_{\max }$

2. $h(s-\omega): D z_{\text {min }} \leq s-\omega \leq D z_{\text {max }} \Rightarrow s-D z_{\text {max }} \leq \omega \leq s-D z_{\text {min }}$.

Para a obtenção dos limites de integração inf e sup, os seguintes casos devem ser considerados:

Caso 1: $\quad C x_{\max }<D\left(z_{\max }-D z_{\min }\right) \mathrm{e}$

Caso 2: $\quad C x_{\max } \geq D\left(z_{\max }-D z_{\min }\right)$, 
os quais são abordados a seguir.

Caso 1: $\quad C x_{\max }<D\left(z_{\max }-D z_{\min }\right)$

A Figura 3.12 apresenta as 4 combinações possíveis $\left(C_{1}, C_{2}, C_{3}\right.$ e $\left.C_{4}\right)$ dos intervalos de integração das funções $f(\omega)$ e $h(s-\omega)$ para determinação do intervalo de integração da Equação (3.13). Os retângulos em preto indicam os intervalos de integração correspondentes a cada uma das funções.

$\mathrm{C}_{1}$

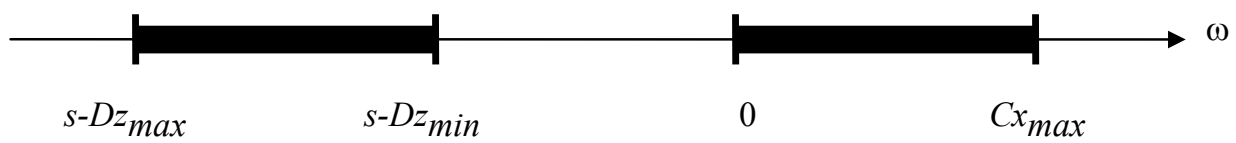

$\mathrm{C}_{2}$

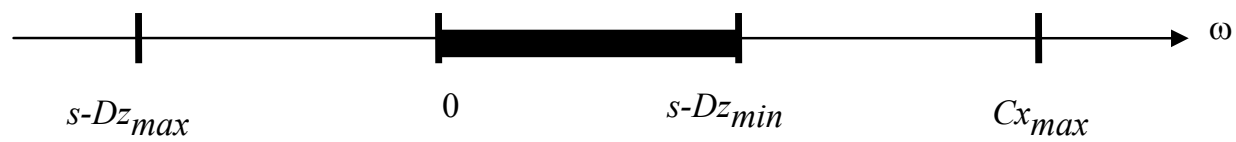

$\mathrm{C}_{3}$

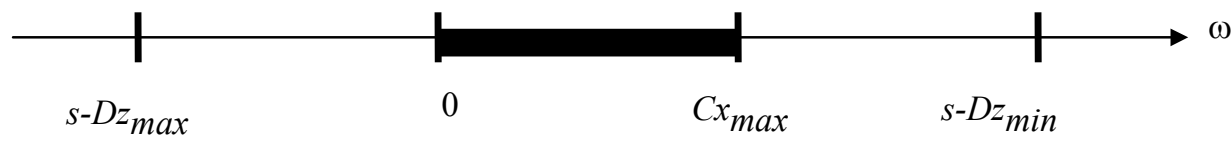

$\mathrm{C}_{4}$

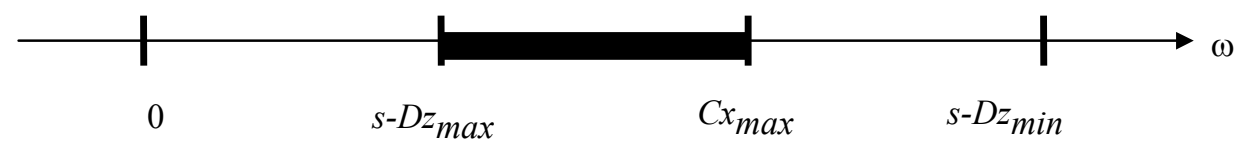

Figura 3.12 - Combinações possíveis para obtenção dos limites de integração - Caso 1

Da Figura 3.12, conclui-se que somente nas combinações $\mathrm{C}_{2}, \mathrm{C}_{3}$ e $\mathrm{C}_{4} \mathrm{o}$ integrando da Equação (3.13) é diferente de zero. Tais casos serão tratados separadamente a seguir.

a) - $\underline{\text { Combinação } \mathrm{C}_{2}}$

Neste caso, a função $h(s)$ (FDP da variável $S$ ) é dada por: 


$$
h(s)=\left.\frac{1}{C D x_{\max }\left(z_{\max }-z_{\min }\right)} \cdot \omega\right|_{0} ^{s-D z_{\min }}=\frac{s-D z_{\min }}{C D x_{\max }\left(z_{\max }-z_{\min }\right)},
$$

Com:

$$
\begin{aligned}
& s-D z_{\max }<0 \Rightarrow s<D z_{\max }, \\
& s-D z_{\min }>0 \Rightarrow s>D z_{\min }, \\
& \left.s-D z_{\min }<C x_{\max } \Rightarrow s<D z_{\min }+C x_{\max }<D z_{\max } \quad \text { (Caso } 1\right) .
\end{aligned}
$$

Das duas últimas condições acima, resulta para esta combinação:

$$
D z_{\min }<s<D z_{\min }+C x_{\max } .
$$

b) - $\underline{\text { Combinação } \mathrm{C}_{3}}$

Neste caso, função $h(s)$ é dada por:

$$
h(s)=\frac{1}{D\left(z_{\max }-z_{\min }\right)},
$$

Com:

$$
\begin{aligned}
& s-D z_{\max }<0 \Rightarrow s<D z_{\max } \\
& s-D z_{\min }>C x_{\max } \Rightarrow s>C x_{\max }+D z_{\min } .
\end{aligned}
$$

Assim, resulta:

$$
\begin{aligned}
& C x_{\max }+D z_{\min }<s<D z_{\text {max }} . \\
& \text { c) - Combinação } \mathrm{C}_{4}
\end{aligned}
$$

Neste caso, função $h(s)$ é dada por: 
$h(s)=\frac{C x_{\max }+D z_{\max }-s}{C D x_{\max }\left(z_{\max }-z_{\min }\right)}$,

com:

$s-D z_{\max }>0 \Rightarrow s>D z_{\max }$,

$s-D z_{\min }>C x_{\max } \Rightarrow s>C x_{\max }+D z_{\min }<D z_{\max } \quad$ (Caso 1$)$.

Assim, resulta:

$s \geq D z_{\max }$.

Na Figura 3.13 a função $h(s)$ é representada graficamente. Verifica-se facilmente que a área sob a curva da função é igual a 1.

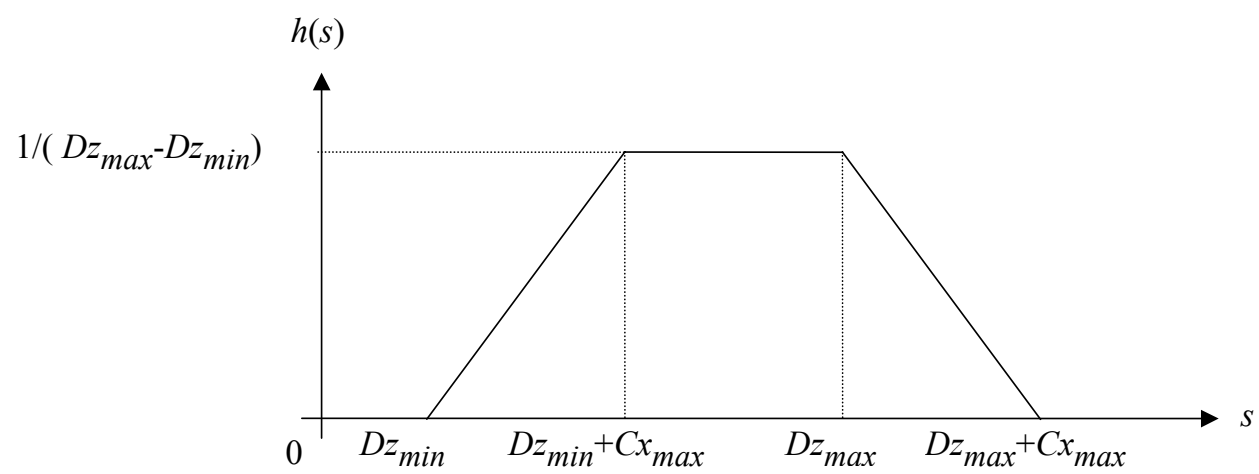

Figura 3.13 - Função $h(s)$ para o Caso 1

Caso 2: $\quad C x_{\max } \geq D\left(z_{\max }-D z_{\min }\right)$

O procedimento de obtenção de $h(s)$ neste caso é o mesmo do caso anterior. Na Figura 3.14 apresenta-se graficamente esta função. 


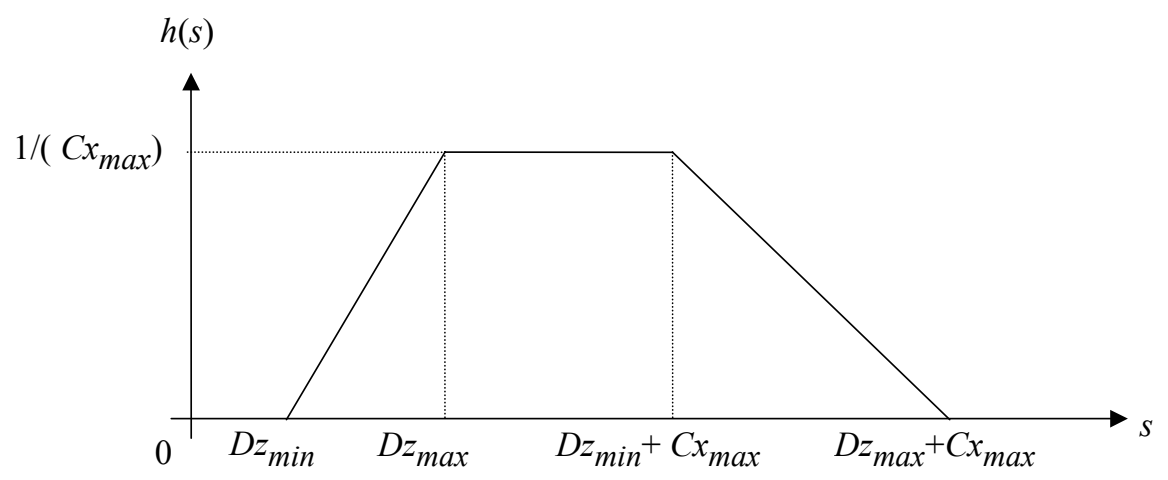

Figura 3.14 - Função $h(s)$ para o Caso 2

Para concluir, considerando-se os parâmetros $z_{\text {min }}$ e $z_{\text {max }}$ definidos na Figura 3.10, e ainda os parâmetros $x_{\max }, C$ e $D$ definidos pela Equação 3.12, a FDP da variável aleatória $S, h(s)$, é dada pelo gráfico da Figura 3.15. A expressão dos parâmetros $a, b, c$, $d, e$ nesta figura é apresentada na Tabela 3.3.

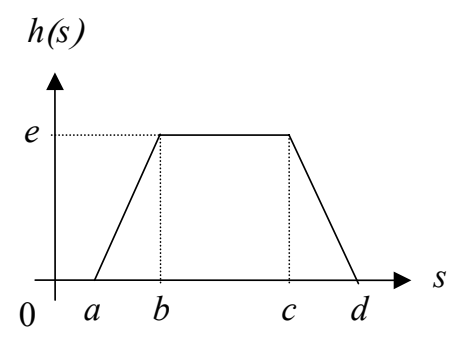

Figura 3.15 - Gráfico da função $h(s)$

\begin{tabular}{|c|c|c|}
\hline Parâmetro & $\begin{array}{c}\text { Caso } 1 \\
<x_{\text {max }}<\left(z_{\text {max }}-z_{\text {min }}\right)\end{array}$ & $\begin{array}{c}\text { Caso 2 } \\
C . x_{\text {max }} \geq D\left(z_{\text {max }}-z_{\text {min }}\right)\end{array}$ \\
\hline \hline$a$ & $D z_{\text {min }}$ & $D z_{\text {min }}$ \\
\hline$b$ & $D z_{\text {min }}+C x_{\text {max }}$ & $D z_{\text {max }}$ \\
\hline$c$ & $D z_{\text {max }}$ & $D z_{\text {min }}+C x_{\text {max }}$ \\
\hline$d$ & $D z_{\text {max }}+C x_{\text {max }}$ & $D z_{\text {max }}+C x_{\text {max }}$ \\
\hline$e$ & $1 /(\mathrm{c}-\mathrm{a})=1 /\left[D\left(z_{\text {max }}-z_{\text {min }}\right)\right]$ & $1 /(\mathrm{c}-\mathrm{a})=1 / C x_{\text {max }}$ \\
\hline
\end{tabular}

Tabela 3.3 - Parâmetros do gráfico da Figura 3.15 


\subsubsection{3 - Determinação da FDP da variável aleatória $\quad Y=\frac{A}{B+S}$}

O método para determinar a FDP da variável dependente $Y, g(y)$, uma vez conhecida a FDP da variável $S$, é exatamente o mesmo utilizado no caso de curto-circuito trifásico, o qual consiste nos seguintes passos:

a) Determinação de $H(s)$ (FPA de $S$ ) por integração de $h(s)$;

b) Determinação dos eventos $Y$ equivalentes aos eventos $S$, utilizando a relação funcional existente entre ambas as variáveis;

c) Determinação de $G(y)$ (FPA de $Y)$;

d) Determinação de $g(y)=\frac{d}{d y} G(y)$.

Integrando-se a função $h(s)$ da Figura 3.15 obtém-se a FPA da variável $S, H(s)$. A Figura 3.16 apresenta a correspondente forma geral da função $H(s)$.

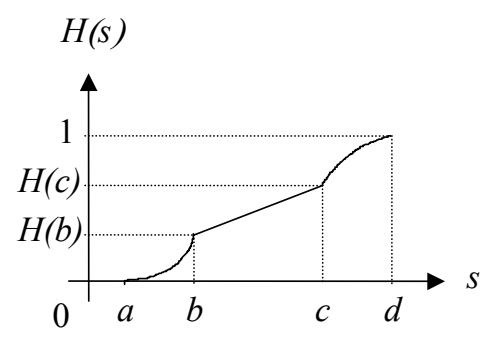

Figura 3.16 - Forma geral da função $H(s)$ (FPA de $S$ )

A expressão analítica da função $H(s)$ é determinada, observando que tanto no Caso 1 como no Caso 2 tem-se $(b-a)=(d-c)$, ou $(c-a)=(d-b)$ : 
1. $a \leq s \leq b: \quad H(s)=\frac{a^{2}+s^{2}}{2(d-b)(b-a)}-\frac{a}{(d-b)(b-a)} \cdot s$

$$
\begin{aligned}
& H(a)=0 \\
& H(b)=\frac{b-a}{2(d-b)}
\end{aligned}
$$

2. $\quad b \leq s \leq c: \quad H(s)=-\frac{a+b}{2(d-b)}+\frac{1}{d-b} \cdot s$

$$
\begin{aligned}
& H(b)=\frac{b-a}{2(d-b)} \\
& H(c)=\frac{2 c-a-b}{2(d-b)}
\end{aligned}
$$

3. $\quad c \leq s \leq d: \quad H(s)=\frac{-c^{2}+(a+b)(c-d)}{2(d-b)(d-c)}+\frac{d}{(d-b)(d-c)} \cdot s$

$$
\begin{aligned}
& -\frac{1}{2(d-b)(d-c)} \cdot s^{2} \\
H(c) & =\frac{2 c-a-b}{2(d-b)} \\
H(d) & =1
\end{aligned}
$$

A determinação dos eventos $Y$ equivalentes aos eventos $S$ é apresentada a seguir:

$$
\begin{gathered}
Y=\frac{A}{B+S} \quad \Leftrightarrow \quad S=\frac{A}{Y}-B . \\
G(y)=P(Y \leq y)=P(S \geq s)=P\left(S \geq \frac{A}{y}-B\right) \\
\quad=1-P\left(S \leq \frac{A}{y}-B\right)=1-H\left(\frac{A}{y}-B\right)
\end{gathered}
$$

Introduzindo a expressão analítica de $H(s)$ na Equação (3.14), obtém-se: 
1. $a \leq \frac{A}{y}-B \leq b \Leftrightarrow \frac{A}{b+B} \leq y \leq \frac{A}{a+B}$

$$
G(y)=1-\frac{a^{2}+\left(\frac{A}{y}-B\right)^{2}}{2(d-b)(b-a)}+\frac{a}{(d-b)(b-a)} \cdot\left(\frac{A}{y}-B\right)
$$

2. $b \leq \frac{A}{y}-B \leq c \Leftrightarrow \frac{A}{c+B} \leq y \leq \frac{A}{b+B}$

$$
G(y)=1+\frac{a+b}{2(d-b)}-\frac{1}{d-b} \cdot\left(\frac{A}{y}-B\right)
$$

3. $c \leq \frac{A}{y}-B \leq d \Leftrightarrow \frac{A}{d+B} \leq y \leq \frac{A}{c+B}$

$$
\begin{aligned}
G(y) & =1-\frac{-c^{2}+(a+b)(c-d)}{2(d-b)(d-c)}-\frac{d}{(d-b)(d-c)} \cdot\left(\frac{A}{y}-B\right) \\
& +\frac{1}{2(d-b)(d-c)} \cdot\left(\frac{A}{y}-B\right)^{2},
\end{aligned}
$$

Que é finalmente a FPA da variável $Y$ (correntes de curto-circuito fase-terra).

\subsection{7 - Exemplo de aplicação da metodologia}

Neste item será apresentado um exemplo de cálculo da distribuição das correntes de defeito fase-terra em um único trecho de rede, utilizando-se o método analítico baseado na metodologia apresentada anteriormente.

A Tabela 3.4 apresenta os dados do trecho de rede em consideração. 


\begin{tabular}{|c|c|}
\hline Parâmetro & Valor \\
\hline \hline Impedância de entrada de seq. positiva $(\mathrm{pu})$ & $0,5+\mathrm{j} 0$ \\
\hline Impedância de entrada de seq. zero $(\mathrm{pu})$ & $2+\mathrm{j} 0$ \\
\hline Impedância total do trecho de seq. positiva $(\mathrm{pu})$ & $0,8+\mathrm{j} 0$ \\
\hline Impedância total do trecho de seq. zero $(\mathrm{pu})$ & $3+\mathrm{j} 0$ \\
\hline Resistência mínima de defeito $(\mathrm{pu})$ & 0 \\
\hline Resistência máxima de defeito $(\mathrm{pu})$ & 2 \\
\hline
\end{tabular}

Tabela 3.4 - Dados para exemplo de trecho de rede

Considerando-se os dados da Tabela 3.4 e as Equações (3.11) e (3.12), obtém-se imediatamente o valor dos seguintes parâmetros:

$$
A=3 ; \quad B=3 ; \quad C=1 ; \quad x_{\max }=4,6 ; \quad D=3 ; \quad z_{\min }=0 ; \quad z_{\max }=2 .
$$

A Figura 3.17 apresenta a função densidade de probabilidade da variável aleatória $S$, $h(s)$ (FDP da variável aleatória $S$ ).

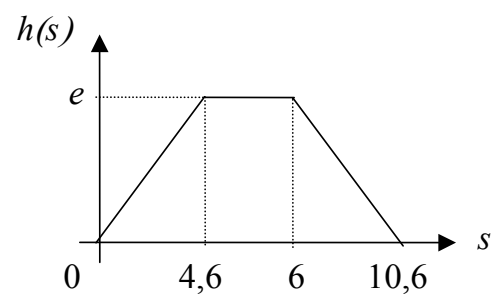

Figura 3.17 - Função $h(s)$

Nesta figura é possível observar o valor dos parâmetros:

$a=0 ; \quad b=4,6 ; \quad c=6 ; \quad d=10,6$

Substituindo-se o valor dos parâmetros acima na expressão da função $G(y)$, obtém-se:

a) $0,39474<y \leq 1$ 
$G(y)=1-\frac{\left(\frac{3}{y}-3\right)^{2}}{55,2}$

b) $0,33333<y \leq 0,39474$

$$
G(y)=1,88333-\frac{1}{2 y}
$$

c) $0,22059 \leq y \leq 0,39474$

$$
G(y)=2,03551-0,38406\left(\frac{3}{y}-3\right)+0,018116\left(\frac{3}{y}-3\right)^{2} .
$$

A Figura 3.18 apresenta o gráfico da função de probabilidade acumulada da corrente de defeito fase-terra com base nas expressões (3.15), (3.16) e (3.17).

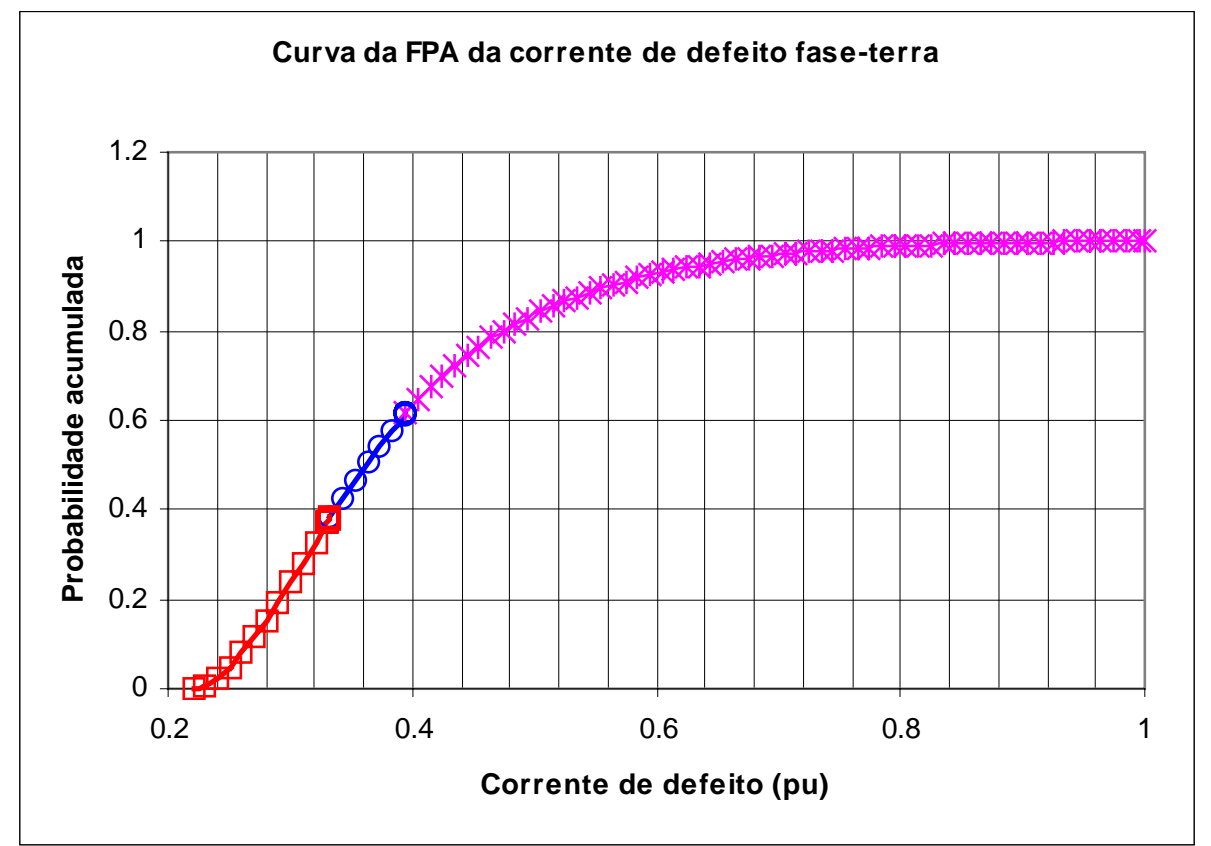

Figura 3.18 - Curva da FPA da corrente de defeito fase-terra 
Conforme pode ser observado no desenvolvimento ilustrado, a determinação da função de probabilidade acumulada da corrente de defeito (fase-terra no exemplo em questão) apresenta um grau de complexidade bastante elevado, mesmo para um caso simples como o do presente exemplo.

Nestas condições, será estudada na próxima seção uma outra metodologia cujo tratamento matemático seja mais simples e possa ser facilmente aplicada em uma rede de distribuição primaria de energia.

\section{4 - Determinação da distribuição das correntes de defeito através de simulação}

\subsection{1 - Considerações gerais}

Conforme visto anteriormente, a distribuição das correntes de defeito nos diversos trechos de uma rede elétrica depende dos seguintes fatores: localização do defeito, resistência de defeito (nos defeitos que envolvem a terra) e tipo do defeito (trifásico, fase-terra, etc.). Em princípio, os dois primeiros fatores (localização dos defeitos e resistência de defeito) podem ser melhor representados através de variáveis aleatórias contínuas, conduzindo ao método analítico abordado no item precedente. Entretanto, no sentido de poder determinar a distribuição das correntes de defeito em redes reais de distribuição (com centenas e até milhares de trechos), bem como no sentido de eliminar algumas das hipóteses restritivas adotadas no método analítico, torna-se necessário considerar todas as variáveis aleatórias como sendo discretas. Desta forma, executa-se cálculos de corrente de curto-circuito em um número finito de situações e a partir daí monta-se imediatamente o histograma de distribuição da corrente de defeito.

No presente caso, a transformação do problema contínuo em um problema discreto é obtida dividindo-se os trechos de rede em um número adequado de subtrechos. Em cada subtrecho executa-se um cálculo de curto-circuito considerando-se a existência de cada um dos quatro tipos de defeito, bem como todos os possíveis valores (discretos) de resistência defeito. Por outro lado, a partir dos valores de taxa de falha conhecidos para a rede em estudo, determina-se também a probabilidade de ocorrência de defeito em 
cada subtrecho. Com ambas informações (valores da corrente de defeito com as correspondentes probabilidades) obtém-se finalmente a distribuição da corrente de defeito.

É importante destacar que a divisão da rede em subtrechos fornece também um controle adequado sobre o compromisso entre precisão e tempo de execução dos cálculos. Para um número relativamente elevado de subtrechos (discretização elevada), os resultados obtidos estarão próximos dos resultados que seriam obtidos através do procedimento analítico contínuo. Para um número relativamente baixo de subtrechos (baixa discretização), o tempo de cálculo será baixo e os resultados apresentarão precisão menor.

Nos próximos subitens serão apresentados: a definição dos subtrechos, a metodologia para determinação da distribuição da corrente de defeito através de simulação, e finalmente um exemplo de aplicação da metodologia.

\subsection{2 - Definição de subtrechos}

Conforme visto no Capítulo 2, a coordenação de dispositivos de proteção parte do conceito fundamental de "zona de proteção primária", que define as porções da rede que ficarão sob responsabilidade de cada dispositivo. A definição das zonas de proteção está intimamente ligada ao conceito de bloco de carga. Um bloco de carga é composto por um conjunto conexo de trechos que são delimitados por dispositivos de proteção. Naturalmente, a um determinado bloco de carga pertencem também os nós que delimitam os trechos e as cargas (consumidores) conectados a esses nós. A Figura 3.19 ilustra o conceito de um bloco de carga genérico $\mathbf{b}$, composto por trechos $\mathbf{t}$ e subtrechos

s. Nesta figura, o bloco em evidência está delimitado pelos dispositivos de proteção D1, D2 e D3. 


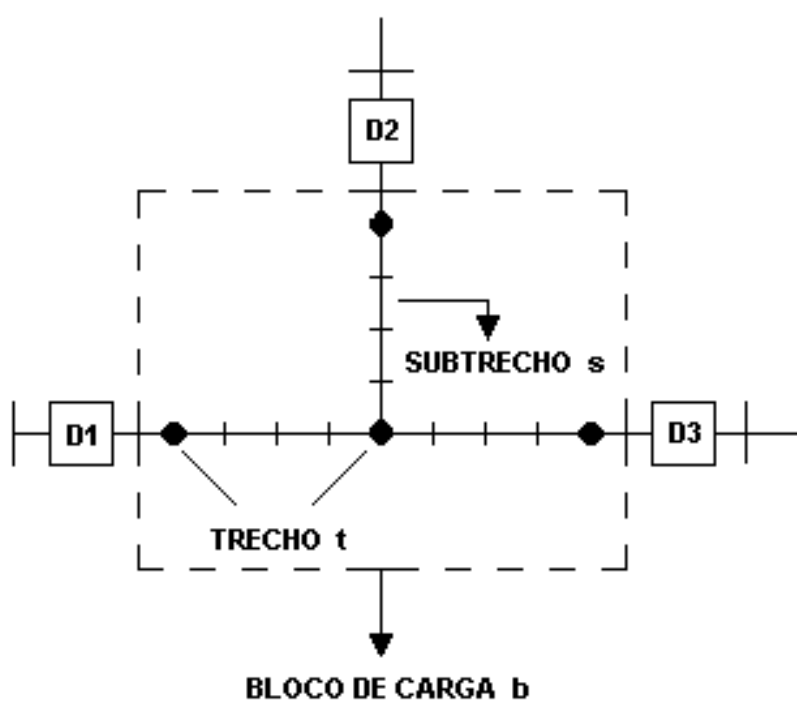

Figura 3.19 - Definição de bloco de carga, trecho e subtrecho

Neste trabalho, a distribuição da corrente de defeito será obtida para cada bloco de carga, de forma a poder considerar sempre a operação coordenada de dois dispositivos de proteção adjacentes (dispositivos protegido e protetor).

Um trecho genérico $\mathbf{t}$ pertencente a um bloco de carga genérico b será dividido em um certo número de subtrechos $\mathbf{s}$, todos de mesmo comprimento, conforme ilustra a Figura 3.20 .

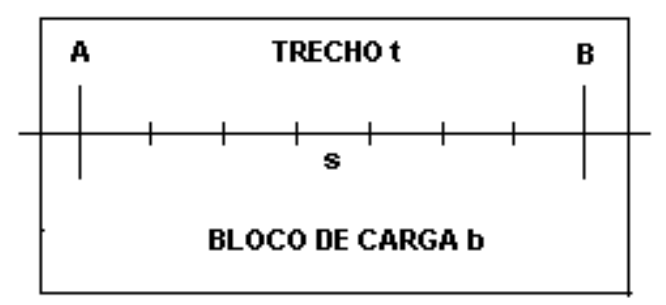

Figura 3.20 - Definição de subtrechos em um bloco de carga

\subsection{3 - Metodologia}

O objetivo principal desta seção é desenvolver uma metodologia que possibilite determinar a distribuição da variável aleatória “corrente de defeito no bloco de carga b". Para tanto, devem ser fornecidas as seguintes informações: 
- Impedância de entrada de seqüência positiva e de seqüência zero do bloco de carga $\mathbf{b}$

- Impedância de seqüência positiva e de seqüência zero de todos os trechos do bloco de carga $\mathbf{b}$;

- Distribuição da variável aleatória "tipo de defeito". Os defeitos podem ser do tipo trifásico $(3 \phi)$, dupla fase $(2 \phi)$, fase-terra $(\phi T)$ e dupla fase-terra $(2 \phi T)$;

- Distribuição da variável aleatória "resistência de defeito" (para defeitos que envolvem a terra);

- Taxa de falha dos trechos de rede que compõem o bloco de carga em tela.

Com estas informações, parte-se para a determinação da distribuição das correntes de defeito. Para tanto, devem ser executados os seguintes passos:

a) Determinar a probabilidade condicionada de ocorrência de defeito no trecho $\mathbf{t}$ do bloco de carga $\mathbf{b}$, dado que houve defeito no bloco $\mathbf{b}\left(P_{t}\right)$ :

$$
P_{t}=\frac{\lambda_{t}}{\sum_{i=1}^{n} \lambda_{i}}
$$

em que:

$\lambda_{t}$ é a taxa de falha do trecho t (falhas/ano);

$i$ é o índice dos trechos do bloco de carga $\mathbf{b}$;

$n$ é o número de trechos do bloco de carga $\mathbf{b}$.

b) Determinar a probabilidade condicionada de ocorrência de defeito no subtrecho s do trecho $\mathbf{t}$, dado que houve defeito no bloco $\mathbf{b}\left(P_{s}\right)$ : 


$$
P_{s}=\frac{P_{t}}{n_{s}}
$$

em que:

$n_{s}$ é o número de subtrechos do trecho $\mathbf{t}$.

c) Determinar a probabilidade condicionada de ocorrência de defeito no subtrecho s, dado que houve defeito no bloco de carga b, para cada um dos tipos de defeito $\left(P_{s_{3 \phi}}, P_{s_{2 \phi}}, P_{s_{\phi T}}, P_{s_{2 \phi T}}\right)$ :

$P_{s_{3 \phi}}=P_{s} \cdot P_{3 \phi}$

$P_{s_{2 \phi}}=P_{s} \cdot P_{2 \phi}$

$P_{s_{\phi T}}=P_{s} \cdot P_{\phi T}$

$P_{s_{2 \phi T}}=P_{s} \cdot P_{2 \phi T}$

em que:

$\mathrm{P}_{3 \phi}$ é a probabilidade de um defeito ser $3 \phi$;

$\mathrm{P}_{2 \phi}$ é a probabilidade de um defeito ser $2 \phi$;

$\mathrm{P}_{\phi T}$ é a probabilidade de um defeito ser $\phi T$;

$\mathrm{P}_{2 \phi T}$ é a probabilidade de um defeito ser $2 \phi T$,

e $P_{3 \phi}+P_{2 \phi}+P_{\phi T}+P_{2 \phi T}=1$.

d) Calcular as correntes de defeito trifásico, dupla-fase, dupla fase-terra e fase-terra para defeito no subtrecho s. No caso dos defeitos que envolvam a terra, considerar todos os possíveis valores da variável "resistência de defeito";

e) Executar os passos (b), (c) e (d) para todos os subtrechos do trecho t; 
f) Executar os passos (a) a (e) para todos os trechos do bloco de carga $\mathbf{b}$.

De posse dos pares de valores "corrente de defeito" e "probabilidade", monta-se a curva de distribuição da corrente de defeito no bloco de carga $\mathbf{b}$, considerando separadamente os tipos de defeito (trifásico, dupla-fase, dupla fase-terra e dupla fase-terra).

\subsection{4 - Exemplo de aplicação}

A Figura 3.21 apresenta uma rede simples que será utilizada para ilustrar a metodologia descrita no subitem precedente. Nesta figura, o bloco de carga A é delimitado pelos dispositivos de proteção D1, D2 e D3 e composto pelos trechos 1, 2 e 3. Já o bloco B é delimitado pelos dispositivos de proteção D3, D4 e D5 e composto pelos trechos 4, 5 e 6.

Neste exemplo será determinada a distribuição da corrente de defeito para o bloco de carga B. Por simplicidade, serão considerados somente os defeitos trifásicos, cuja probabilidade de ocorrência foi assumida igual a 0,1 .

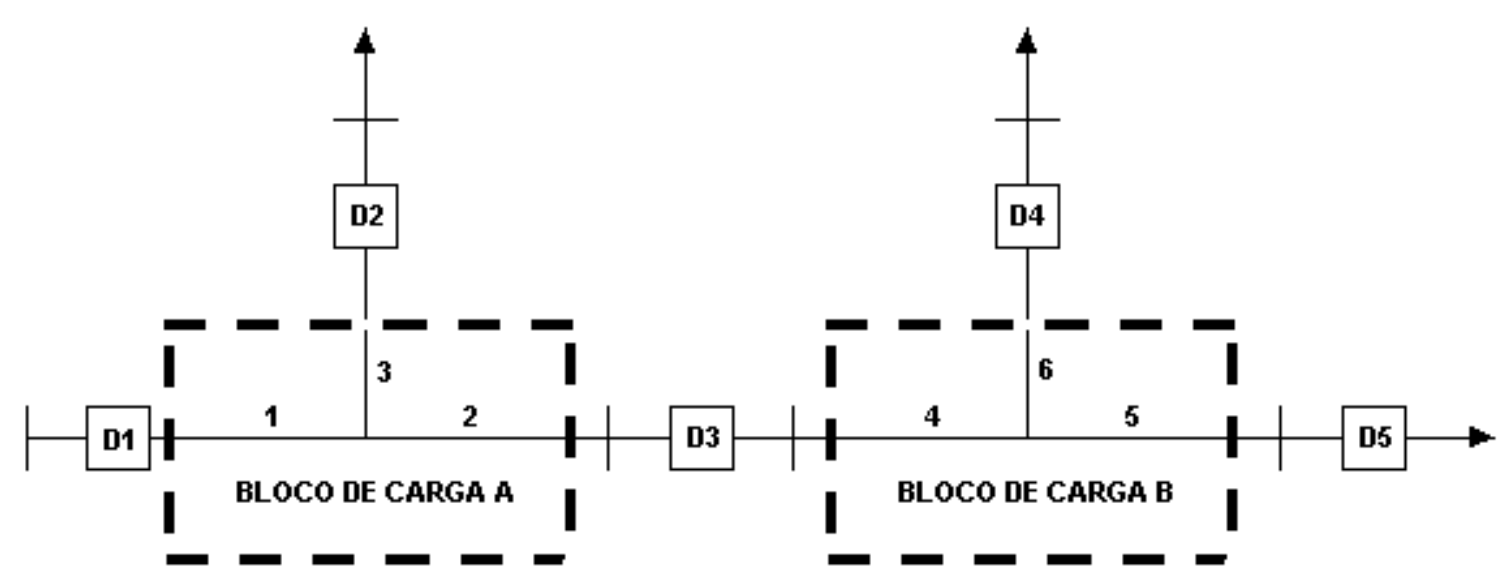

Figura 3.21 - Exemplo de aplicação 
A Tabela 3.5 indica o comprimento e número de subtrechos associados a cada trecho do bloco de carga B. Ela fornece também a taxa de falhas por ano, para cada trecho, obtida de um estudo anterior de confiabilidade.

\begin{tabular}{|c|c|c|c|}
\hline $\begin{array}{c}\text { Número do } \\
\text { trecho }\end{array}$ & $\begin{array}{c}\text { Comprimento } \\
\mathbf{( k m )}\end{array}$ & $\begin{array}{c}\text { Número de } \\
\text { subtrechos }\end{array}$ & $\begin{array}{c}\text { Taxa de } \\
\text { falhas/ano }(\lambda)\end{array}$ \\
\hline 4 & 0,6 & 3 & 2 \\
\hline 5 & 1,2 & 6 & 5 \\
\hline 6 & 0,8 & 4 & 3 \\
\hline Total & - & $\mathbf{1 3}$ & $\mathbf{1 0}$ \\
\hline
\end{tabular}

Tabela 3.5 - Dados do bloco de carga B (Figura 3.21)

A Tabela 3.6 fornece os dados elétricos necessários ao cálculo de curto-circuito trifásico no bloco de carga $\mathrm{B}$.

\begin{tabular}{|l|c|}
\hline \multicolumn{1}{|c|}{ Grandeza } & Valor \\
\hline Tensão nominal do circuito primário $(\mathrm{kV})$ & 13,8 \\
\hline $\begin{array}{l}\text { Potência de curto-circuito trifásico no início do alimentador } \\
(\mathrm{MVA})\end{array}$ & $0+\mathrm{j} 200$ \\
\hline $\begin{array}{l}\text { Impedância de seqüência positiva do cabo tronco que } \\
\text { interliga o início do alimentador e o bloco de carga B } \\
(\Omega / \text { km) }\end{array}$ & $0,2+\mathrm{j} 0,4$ \\
\hline $\begin{array}{l}\text { Comprimento do tronco que interliga o início do } \\
\text { alimentador e o bloco de carga B (km) }\end{array}$ & 1 \\
\hline $\begin{array}{l}\text { Impedância de seqüência positiva do cabo utilizado em } \\
\text { todos os trechos do bloco de carga B }\end{array}$ & $0,2+\mathrm{j} 0,4$ \\
\hline
\end{tabular}

Tabela 3.6 - Dados elétricos para cálculo das correntes de curto-circuito

A Tabela 3.7 fornece a corrente de defeito trifásico calculada para cada subtrecho pertencente ao bloco de carga B. 


\begin{tabular}{|c|c|c|}
\hline \multirow{3}{*}{ Trecho } & Subtrecho & $\begin{array}{c}\text { Corrente de defeito } \\
\text { trifásico (A) }\end{array}$ \\
\hline \hline \multirow{4}{*}{4} & 0 & 5829 \\
\cline { 2 - 3 } & 1 & 5487 \\
\cline { 2 - 3 } & 2 & 5181 \\
\cline { 2 - 3 } & 3 & 4906 \\
\hline \hline \multirow{4}{*}{5} & 0 & 4906 \\
\cline { 2 - 3 } & 1 & 4658 \\
\cline { 2 - 3 } & 2 & 4433 \\
\cline { 2 - 3 } & 3 & 4228 \\
\cline { 2 - 3 } & 4 & 4041 \\
\cline { 2 - 3 } & 5 & 3870 \\
\hline \hline \multirow{4}{*}{6} & 6 & 3712 \\
\cline { 2 - 3 } & 1 & 4906 \\
\cline { 2 - 3 } & 2 & 4658 \\
\cline { 2 - 3 } & 3 & 4433 \\
\cline { 2 - 3 } & 4 & 4228 \\
\hline
\end{tabular}

Tabela 3.7 - Correntes de defeito em cada subtrecho do bloco de carga B

A seguir calcula-se a probabilidade condicionada de ocorrência de defeito no trecho 4 conforme apresentado na Equação (3.18):

$P_{4}=\frac{2}{2+5+3}=0,2$.

Através da Equação (3.19) determina-se a probabilidade de ocorrência de um defeito em qualquer um dos subtrechos do trecho 4 :

$P_{s 4}=\frac{0,2}{3}=0,06667$. 
A probabilidade condicionada de ocorrência de defeito trifásico em qualquer um dos subtrechos do trecho 4 é calculada através da Equação (3.20):

$P_{s 4_{3 \phi}}=0,1 \cdot 0,06667=0,006667$.

Aplicando-se este procedimento a todos os trechos e subtrechos do bloco de carga B, obtém-se os resultados apresentados na Tabela 3.8.

\begin{tabular}{|c|c|c|c|}
\hline Trecho & Subtrecho & $\begin{array}{l}\text { Corrente de defeito } \\
\text { trifásico (A) }\end{array}$ & $\begin{array}{c}\text { Probabilidade de } \\
\text { ocorrer defeito } \\
\text { trifásico (pu) } \\
\end{array}$ \\
\hline \multirow{4}{*}{4} & 0 & 5829 & - \\
\hline & 1 & 5487 & 0,006667 \\
\hline & 2 & 5181 & 0,006667 \\
\hline & 3 & 4906 & 0,006667 \\
\hline \multirow{7}{*}{5} & 0 & 4906 & - \\
\hline & 1 & 4658 & 0,008333 \\
\hline & 2 & 4433 & 0,008333 \\
\hline & 3 & 4228 & 0,008333 \\
\hline & 4 & 4041 & 0,008333 \\
\hline & 5 & 3870 & 0,008333 \\
\hline & 6 & 3712 & 0,008333 \\
\hline \multirow{5}{*}{6} & 0 & 4906 & - \\
\hline & 1 & 4658 & 0.007500 \\
\hline & 2 & 4433 & 0.007500 \\
\hline & 3 & 4228 & 0.007500 \\
\hline & 4 & 4041 & 0.007500 \\
\hline & & Total do bloco & 0,100000 \\
\hline
\end{tabular}

Tabela 3.8 - Correntes de defeito e probabilidades para o bloco de carga B 
Conforme esperado, a soma das probabilidades condicionadas na Tabela 3.8 coincide com a probabilidade do defeito ser trifásico $(0,1)$, pois esse valor foi distribuído integralmente entre todos os subtrechos que compõem o bloco de carga.

Se os trechos apresentassem valores diferentes entre si da probabilidade de ocorrência de defeito trifásico (o que não ocorreu no exemplo acima), a soma de todas as probabilidades dos subtrechos seria igual à probabilidade média de ocorrer defeito trifásico no bloco de carga.

A obtenção da distribuição da corrente de defeito trifásico no bloco de carga B é imediata a partir dos valores nas duas colunas mais à direita na Tabela 3.8. Para a montagem do correspondente histograma considera-se normalmente um número reduzido de classes para a corrente, por exemplo, $n_{c}=10$. O intervalo de cada classe $(\Delta I)$ é calculado pela diferença entre o valor máximo $\left(I_{\max }\right)$ e o valor mínimo $\left(I_{\min }\right)$ da corrente de defeito trifásico no bloco de carga $\mathrm{B}$, dividido pelo número de classes adotado:

$$
\Delta I=\frac{I_{\max }-I_{\min }}{n_{c}}=\frac{5487-3712}{10}=177,5 \mathrm{~A} .
$$

Finalmente, a Tabela 3.9 apresenta o histograma da corrente de defeito trifásico para o bloco de carga B. 


\begin{tabular}{|c|c|c|}
\hline Classe de corrente (A) & Probabilidade (pu) & $\begin{array}{c}\text { Probabilidade acumulada } \\
\text { (pu) }\end{array}$ \\
\hline $3712,0-3889,5$ & 0,016667 & 0,016667 \\
\hline $3889,5-4067,0$ & 0,015833 & 0,032500 \\
\hline $4067,0-4244,5$ & 0,015833 & 0,048333 \\
\hline $4244,5-4422,0$ & 0 & 0,048333 \\
\hline $4422,0-4599,5$ & 0,015833 & 0,064167 \\
\hline $4599,5-4777,0$ & 0,015833 & 0,080000 \\
\hline $4777,0-4954,5$ & 0,006667 & 0,086667 \\
\hline $4954,5-5132,0$ & 0 & 0,086667 \\
\hline $5132,0-5309,5$ & 0,006667 & 0,093333 \\
\hline $5309,5-5487,0$ & 0,006667 & 0,100000 \\
\hline
\end{tabular}

Tabela 3.9 - Classes de freqüência

A Figura 3.22 apresenta a representação gráfica do histograma da Tabela 3.9.

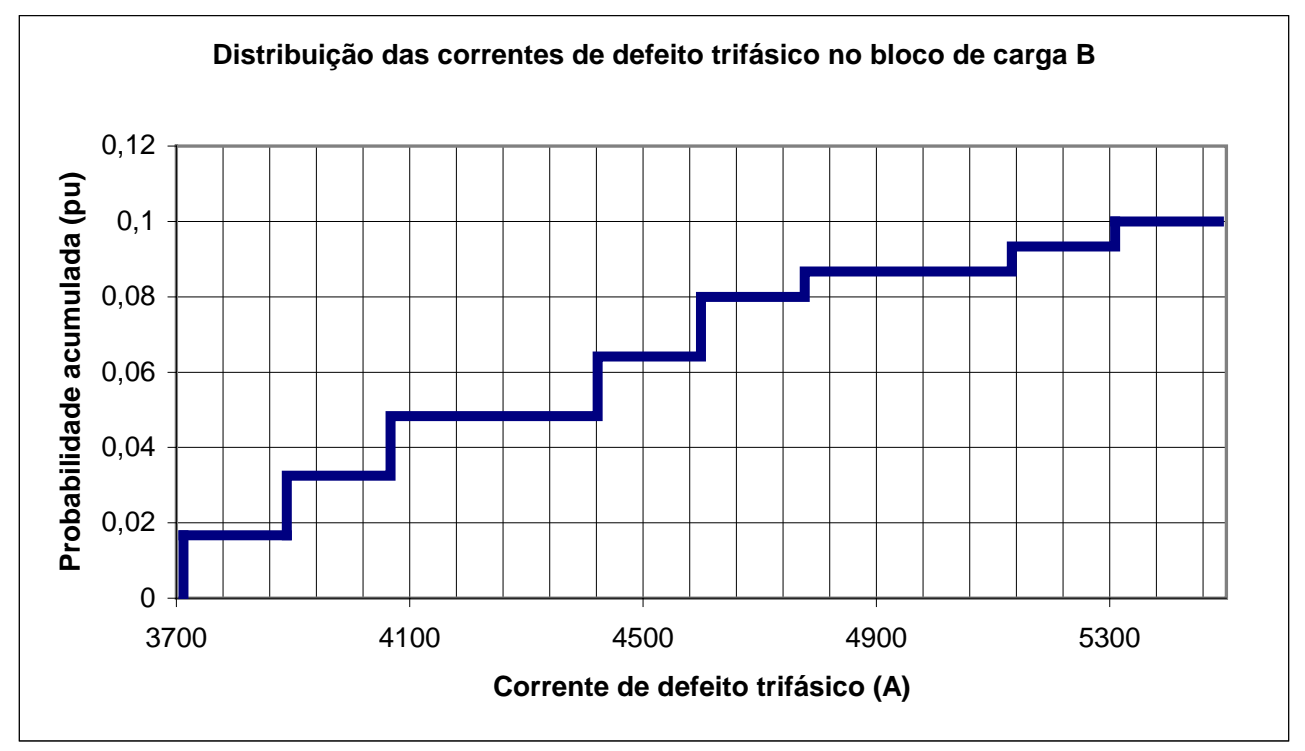

Figura 3.22 - Curva de distribuição da corrente de defeito trifásico para o bloco de carga B 


\section{5 - Discussão}

Nos itens 3.3 e 3.4 foram apresentadas, respectivamente, as metodologias para a determinação analítica e por simulação da distribuição das correntes de defeito em um bloco de carga.

O método de simulação apresenta duas importantes vantagens em relação ao método analítico, que são sua simplicidade de formulação e a possibilidade de generalização dos resultados obtidos no trecho de rede para um alimentador composto por centenas ou milhares de trechos.

$\mathrm{Na}$ trabalhosa dedução do método analítico não foram levadas em conta as impedâncias complexas envolvidas (as impedâncias de entrada, as impedâncias do trecho e a resistência de defeito foram representadas por números reais puros). A eliminação desta hipótese aumentaria consideravelmente o grau de dificuldade da solução do problema. Além disso, a generalização do método analítico para um alimentador com centenas de trechos apresenta dificuldade excepcional, pois seria necessário combinar a função $G(y)$ de cada trecho para obter uma função global.

O método de simulação, por outro lado, permite facilmente representar a rede através de suas impedâncias complexas, a partir das quais se obtém rapidamente o módulo das correntes de defeito. Em seguida, os trechos do bloco de carga são divididos em subtrechos e as suas respectivas probabilidades para a ocorrência de um determinado tipo de defeito são calculadas. De posse destas informações, parte-se para a montagem da curva de distribuição das correntes de defeito, sendo que quanto maior o número de subtrechos considerados, maior será a precisão do resultado obtido.

A generalização do método probabilístico para uma rede contendo centenas de trechos é imediata, bastando para isso acumular convenientemente todas as correntes de defeito calculadas e obter a curva de distribuição das mesmas de acordo com a metodologia analisada para o bloco de carga. 


\section{IMPLEMENTAÇÃO COMPUTACIONAL}

\section{1 - Introdução}

Conforme apresentado no capítulo anterior, existem duas metodologias (analítica e de simulação) que permitem determinar a distribuição de probabilidades das correntes de defeito em uma rede elétrica. Concluiu-se que o método de simulação é o mais adequado para redes complexas, uma vez que a aplicação do método analítico é inviável para redes reais de Distribuição.

Nestas condições foi desenvolvida no Centro de excelência em Distribuição de Energia Elétrica da Universidade de São Paulo (CED/USP) [33] uma ferramenta computacional que permitisse realizar estudos de casos, baseados no método de simulação apresentado em 3.4. Tal ferramenta se chama PROCOR e será descrita no presente capítulo.

\section{2 - Sistema PROCOR}

O Sistema PROCOR representa uma ferramenta computacional que tem por objetivo avaliar, para o intervalo das correntes de defeito (fase e terra) esperadas, a probabilidade de haver ou não a coordenação entre os diversos dispositivos de proteção de uma rede de distribuição primária de energia elétrica.

Dentro do Sistema PROCOR existem 7 módulos onde cada um deles é responsável por executar uma determinada tarefa. A Figura 4.1 ilustra em detalhe a tela inicial do sistema em questão. 


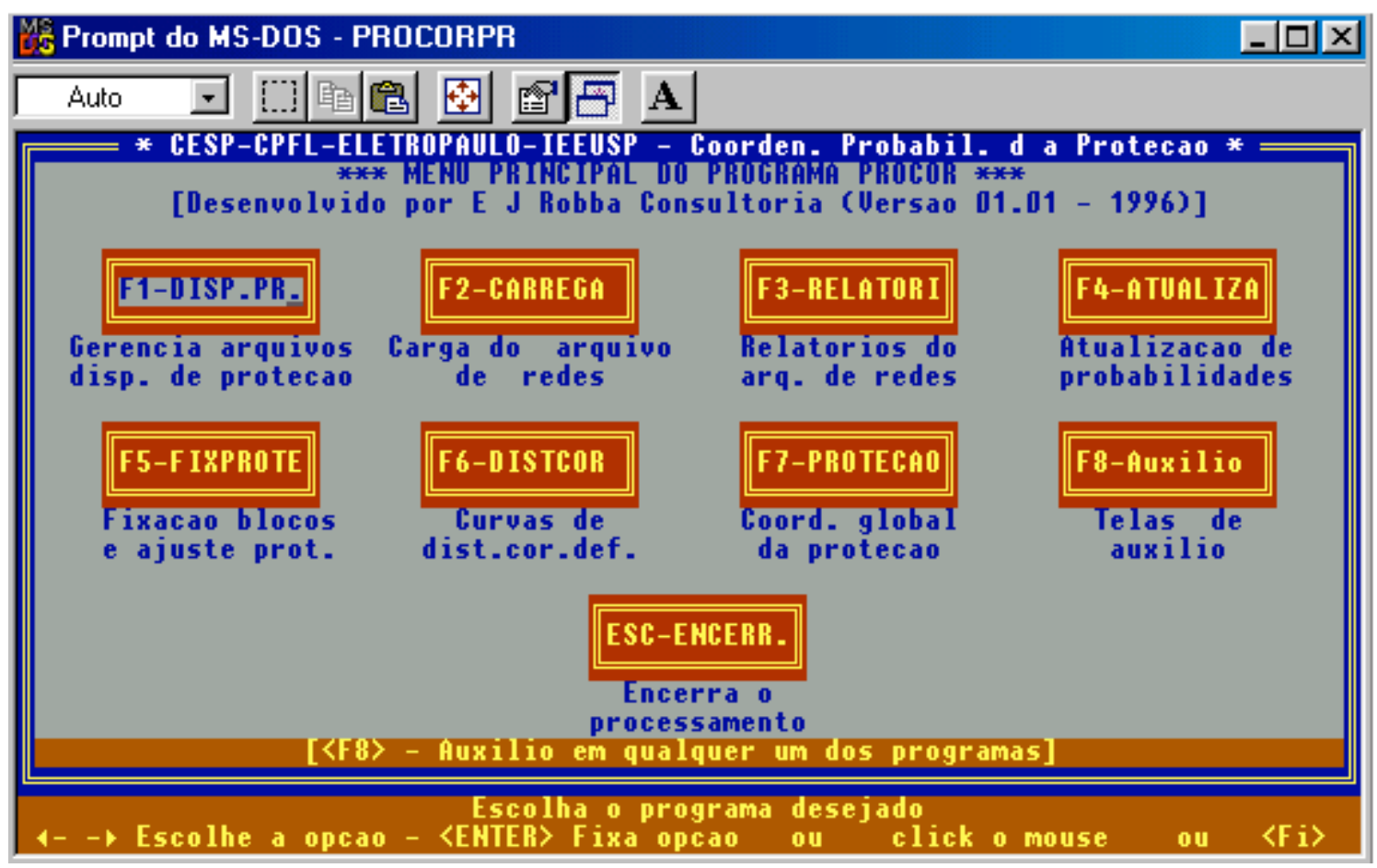

Figura 4.1 - Menu principal do sistema PROCOR

O sistema PROCOR é composto pelos seguintes módulos:

- GERDIS (Gerenciamento dos dispositivos de proteção).

Tem por finalidade gerenciar e catalogar todos os dispositivos de proteção comumente utilizados em redes de distribuição primária. Neste módulo, os dispositivos de proteção são cadastrados de acordo com as suas características elétricas baseados nos catálogos dos fabricantes.

\section{- CARREGA.}

Este módulo tem por finalidade efetuar a consistência dos dados e efetuar a montagem do arquivo de trabalho contendo os dados da topologia da rede elétrica de distribuição a ser estudada.

As concessionárias de distribuição possuem um banco de dados contendo as mais diversas características de uma rede elétrica, tais como; o número de barras, o número 
de trechos com os respectivos comprimentos, topologia, número de transformadores, entre outros. Para utilizar o sistema PROCOR, o interessado deverá efetuar a codificação destes dados em um arquivo texto com extensão SYS. Através dos dados armazenados neste arquivo texto é gerado o arquivo de redes com a extensão A11 em formato binário.

No menu CARREGA é também possível criar o arquivo binário de dados ARQDADOS.PRO. Neste arquivo são armazenadas informações relacionadas à rede elétrica, tais como:

- Os valores iniciais da probabilidade de ocorrência para cada tipo de defeito (Trifásico, dupla fase, dupla fase-terra e fase-terra) que serão atribuídos a todos os trechos da rede elétrica em estudo;

- Regras para instalação de elos fusíveis;

- Curvas de resistência de defeito (3 curvas padrões, mas podem ser criadas até 10 curvas com até no máximo 10 pontos);

- Dados dos condutores tais como o código e identificação da bitola, resistências e reatâncias de seqüência positiva e zero em $\Omega / \mathrm{km}$, capacidade de condução de corrente em A, taxa de falhas representando o número de falhas por ano e por km;

- Fatores multiplicativos para a corrente de inrush em função do número de transformadores instalados a jusante do dispositivo de proteção;

- Fator de assimetria da corrente que corresponde à relação entre a reatância $(\mathrm{X})$ e a resistência (R) vista no ponto de defeito. Para os defeitos trifásicos este valor é calculado pela divisão entre as parcelas $\mathrm{X}$ e $\mathrm{R}$ contidas na impedância de seqüência positiva $\left(Z_{1}\right)$, enquanto que para os defeitos fase-terra esta divisão corresponde às parcelas $\mathrm{X}$ e $\mathrm{R}$ da soma de duas vezes a impedância de seqüência positiva mais a impedância de seqüência zero $\left(Z_{0}\right)$; 
- Fator de segurança para ajuste de relés e religadores.

\section{- RELATORI}

Este módulo tem por função mostrar os relatórios na tela ou na impressora, das redes elétricas armazenadas no arquivo de redes (extensão A11). Para este arquivo, o módulo fornece as seguintes informações:

- Nome, código, demanda, número e potência dos transformadores instalados, número de dispositivos de proteção e de seccionamento, e taxas de falha das Subestações e dos circuitos existentes;

- Potências de curto-circuito (trifásica e fase-terra) e resistência de defeito, de todos os circuitos pertencentes ao arquivo de redes escolhido;

- Dados dos condutores e curvas de resistência de defeito, cadastradas previamente no arquivo de dados ARQDADOS.PRO;

- Tipo de chave ou dispositivo de proteção disponível na rede elétrica (Seccionalizadores, elos fusíveis, religadores, disjuntores com relés de proteção e chave faca).

Também são fornecidas informações detalhadas de todos os circuitos existentes no arquivo de redes. Tais informações são:

- Número total de barras, número de barras de carga, número de nós, número de chaves NA (Normalmente aberta), número de chaves NF (Normalmente fechada) de proteção e número de chaves NF de seccionamento; 
- Dados relativos às barras de carga tais como: número, coordenadas x e y, quantidade de transformadores de distribuição instalados, potência total instalada e demandas máximas (aparente, ativa e reativa);

- Dados dos trechos tais como; coordenadas da barra terminal, número interno das barras inicial e terminal, comprimento, código da bitola do cabo utilizado, código e estado (Aberto ou Fechado) da chave ou dispositivo de proteção, taxa de falha, código da curva de resistência de defeito (de acordo com o arquivo ARQDADOS.PRO) e probabilidade de ocorrência para os defeitos trifásico, dupla fase, dupla fase-terra e fase-terra.

As coordenadas x e y das barras de uma rede elétrica provêm do sistema de informações geográficas da empresa de distribuição de energia elétrica, sendo estas normalmente fornecidas de acordo com o sistema de projeção UTM (Universal Transversal Mercator).

\section{- ATUALIZA}

Este módulo permite que sejam modificados os seguintes parâmetros:

- Taxa de falha de cada trecho de rede;

- Probabilidade de ocorrência de cada tipo de defeito em cada trecho de rede;

- Curva de resistência de defeito em cada trecho de rede.

\section{- FIXPROTE}

Este módulo é responsável pela execução das seguintes tarefas:

- Montagem dos blocos de carga dos circuitos contidos no arquivo de redes. 
Esta ferramenta tem for finalidade efetuar a montagem dos blocos de carga de acordo com a metodologia estudada em 3.4.2. Após esta etapa, o módulo fornece um relatório contendo as seguintes informações:

- Número de cada um dos blocos de carga montados com a indicação das coordenadas UTM da barra inicial e da barra terminal de cada um deles. Além disto, também são fornecidos os números dos blocos de carga que se encontram a montante;

- Indicação do dispositivo de proteção instalado no início de cada bloco de carga em estudo e dos blocos que estão a sua montante;

- Número de transformadores instalados nos blocos em estudo e a jusante, bem como a potência total dos mesmos expressa em MVA;

- Indicação das probabilidades de ocorrência dos defeitos; trifásico, dupla fase, dupla fase-terra e fase-terra e do tipo de curva de resistência de defeito, para cada um dos trechos pertencentes ao bloco de carga. Para cada trecho são representadas as coordenadas UTM das barras inicial e terminal;

- Efetuar a modificação dos dispositivos de proteção que são instalados no início de cada bloco de carga.

Esta ferramenta permite efetuar a modificação do tipo de dispositivo de proteção utilizado em um determinado bloco de carga.

O programa efetua uma análise de consistência visando avaliar se não houve nenhuma violação dos critérios técnicos baseados na abordagem determinística. Tais critérios são classificados por ordem de importância em fundamentais e secundários.

São critérios de importância fundamental:

- Capacidade de interrupção do disjuntor menor do que a máxima corrente de curtocircuito assimétrica no ponto imediatamente posterior a sua instalação; 
- Existência de seccionalizador na rede sem que haja a montante deste um religador ou disjuntor dotado de relé de religamento;

- Existência de elos fusíveis instalados entre um religador e um seccionalizador;

- Existência de elos fusíveis instalados a montante de um religador.

São critérios de importância secundária:

- Número de elos fusíveis em série maior do que o número máximo definido no arquivo ARQDADOS.PRO;

- Número de transformadores existentes a jusante de um elo fusível inferior ao número mínimo definido no arquivo ARQDADOS.PRO;

- Comprimento de rede a jusante do elo fusível inferior ao comprimento mínimo definido no ARQDADOS.PRO.

Quando um critério de importância secundária é violado, o programa mostra uma mensagem de aviso, porém é permitido que o estudo seja prosseguido. Por outro lado, quando um critério de importância fundamental é violado uma mensagem de erro é gerada e não há condições de prosseguir com o estudo.

A Figura 4.2 mostra a tela gráfica de uma rede elétrica com os blocos de carga e os dispositivos de proteção que os definem. 


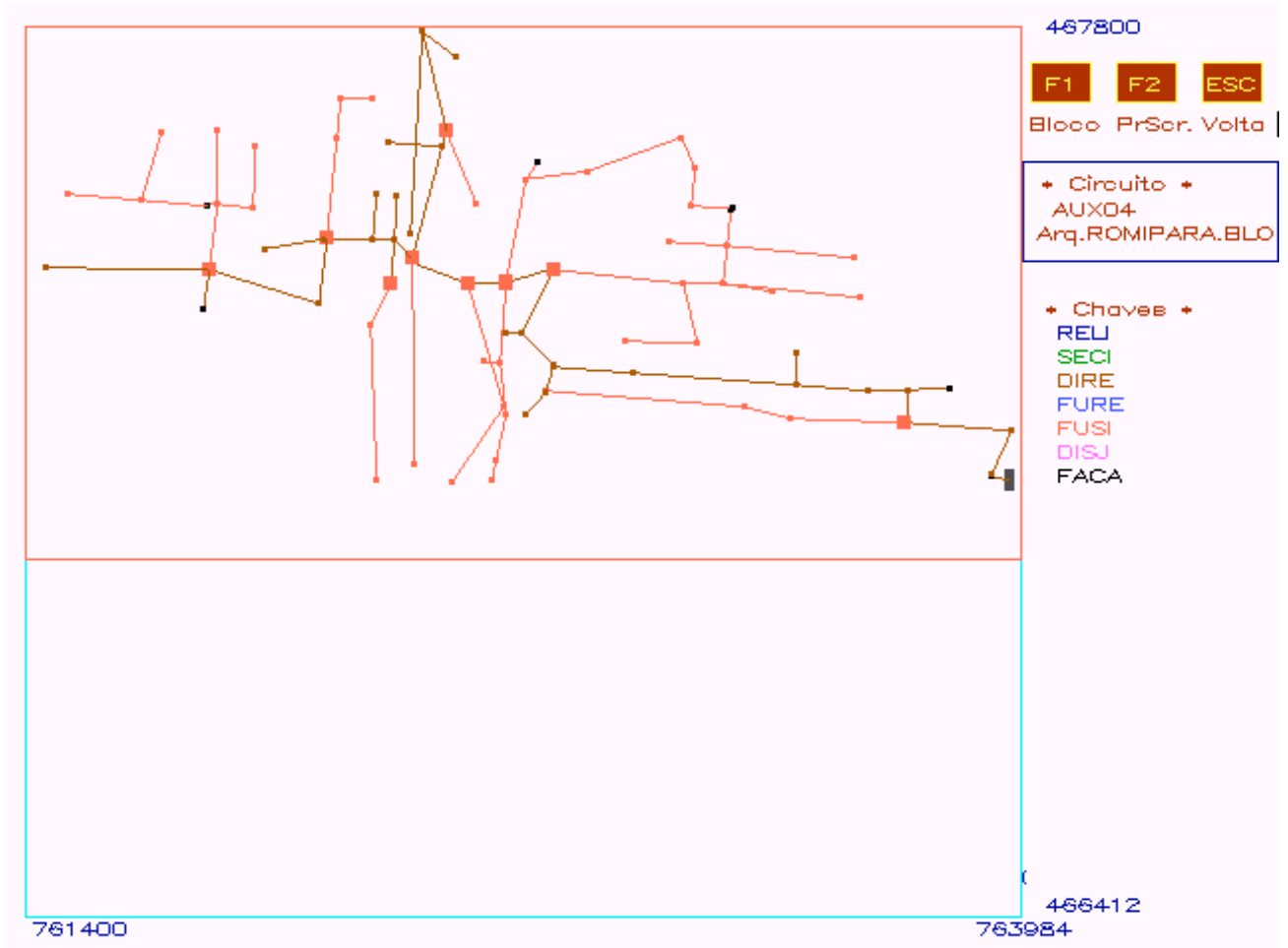

Figura 4.2 - Tela gráfica contendo a rede em estudo com os blocos de carga

- Estabelecer os ajustes dos dispositivos de proteção existentes

Nesta etapa é possível fixar os ajustes para todos os dispositivos de proteção existentes na rede elétrica em estudo.

Para cada um dos dispositivos de proteção dos respectivos blocos de carga, o módulo apresenta uma tela similar a ilustrada na Figura 4.3. Observa-se nesta figura que a tela para o ajuste do dispositivo de proteção é dividida em duas partes, sendo que no lado esquerdo são indicadas as informações sobre o bloco de carga, correntes de carga (no ano inicial e no horizonte de estudo) e de defeito, comprimento e blocos de carga situados a montante e a jusante do bloco em estudo com os seus respectivos dispositivos de proteção.

Já no lado direito da tela, são fixados os ajustes dos dispositivos de proteção para os blocos de carga que foram definidos na etapa anterior. São listados apenas os 
dispositivos de proteção cadastrados através do módulo GERDIS e que atendam aos critérios técnicos.

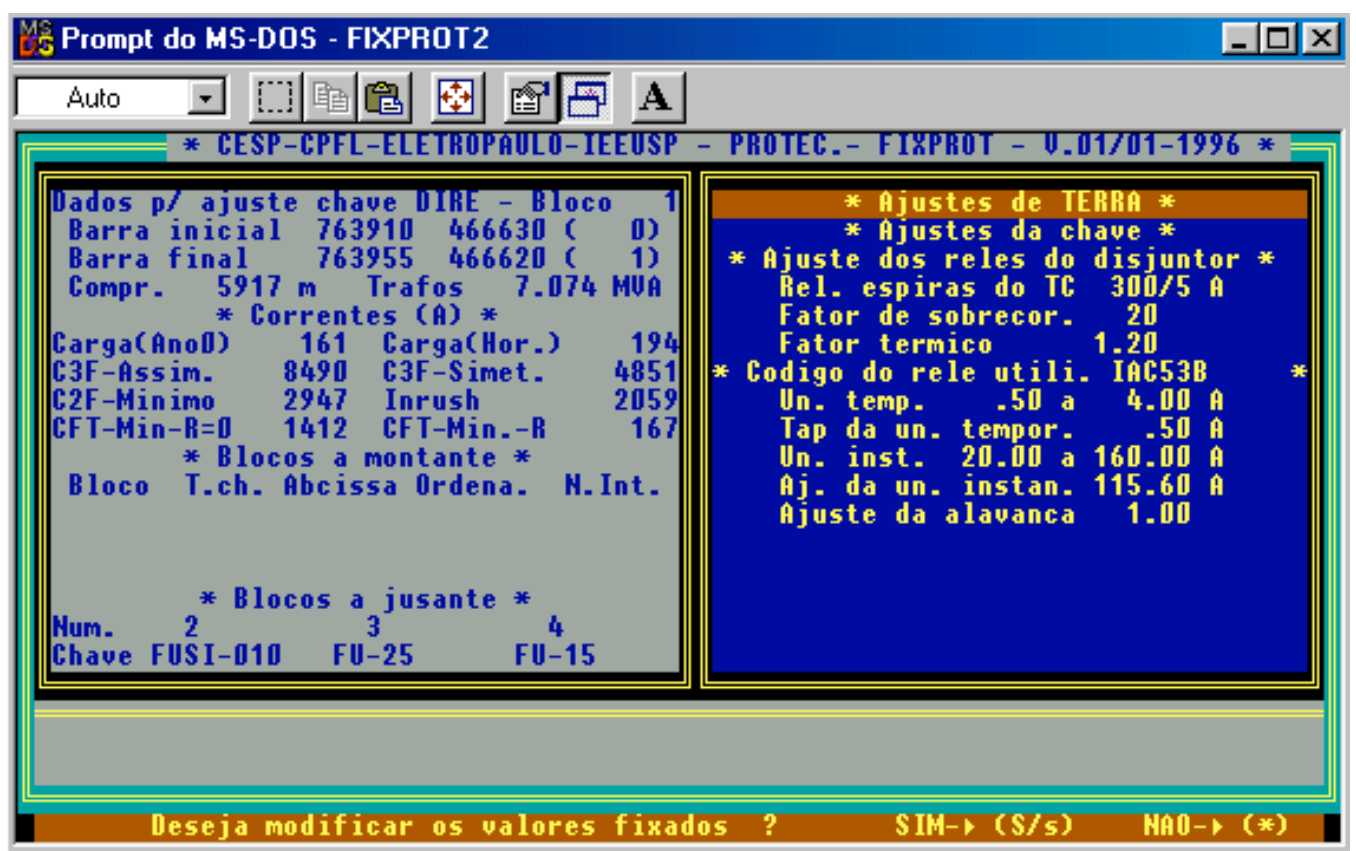

Figura 4.3 - Tela para ajuste dos dispositivos de proteção

Além das funções executadas por este módulo, existe a possibilidade do sistema em questão efetuar um estudo de fluxo de potência e calcular as correntes de curto-circuito para todos os trechos da rede elétrica em estudo.

\section{- DISTCOR}

Este módulo tem por finalidade determinar a curva de distribuição de probabilidades das correntes esperadas de defeito de fase e terra. A metodologia utilizada para se atingir tal objetivo foi discutida em detalhes no item 3.4.

Neste módulo é definido o número de classes de freqüência utilizado para a montagem dos histogramas das correntes de defeito bem como o comprimento máximo de cada trecho do bloco de carga que está sendo analisado.

A Figura 4.4 ilustra para um determinado bloco de carga, a distribuição de probabilidades das correntes de defeito esperadas de fase e neutro. Observa-se nesta 
figura que o intervalo das correntes de defeito esperadas de fase e terra foi dividido em 10 classes de freqüência. Para cada uma delas são fornecidas a sua respectiva probabilidade, além dos valores acumulados, conforme ilustrado no item 3.4.4. O processo acima descrito é repetido para todos os blocos de carga do circuito em estudo. As barras verticais na Figura 4.4 representam as probabilidades.

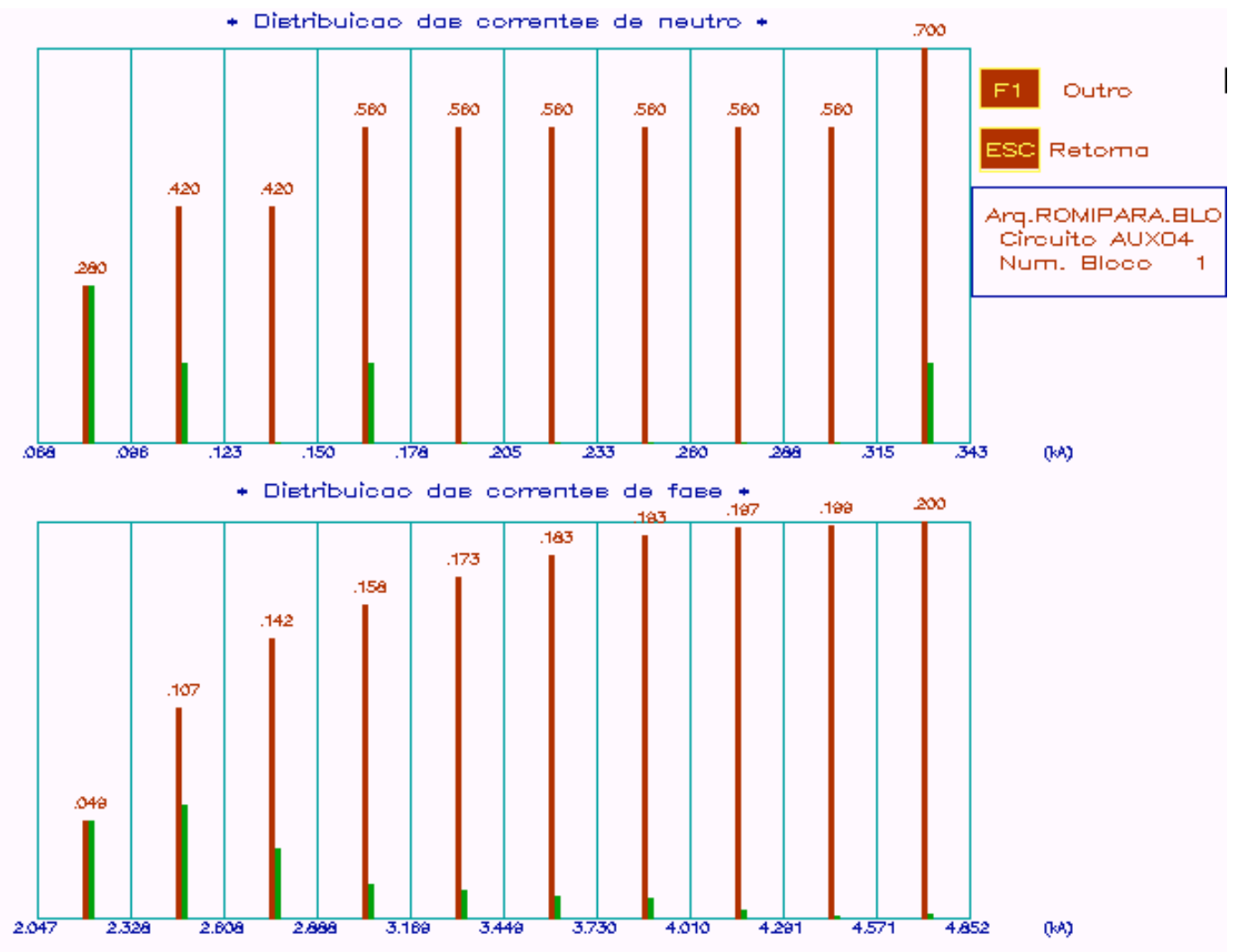

Figura 4.4 - Distribuição das correntes de fase e neutro de um bloco de carga

\section{- PROTECAO}

Este módulo também é conhecido por PROFATE e tem por finalidade determinar a probabilidade de haver ou não coordenação entre os dispositivos de proteção adjacentes, com base nos ajustes estabelecidos no módulo FIXPROTE e pelas curvas de distribuição de probabilidades das correntes de defeito obtidas através do módulo DISTCOR.

Na seqüência, o módulo ilustra para cada bloco em estudo as seguintes informações: 
- Número do bloco com o seu respectivo dispositivo de proteção;

- Coordenadas UTM das barras terminais do dispositivo de proteção;

- Número de transformadores que estão instalados no bloco em estudo e a sua jusante, com a respectiva potência total;

- Corrente de regime na chave e no horizonte de estudo (5 anos);

Para os blocos situados a montante são fornecidos os seguintes dados:

- Número do bloco;

- Coordenadas UTM da barra inicial e terminal;

- Dispositivo de proteção instalado.

Convém ressaltar que o módulo fornece as informações para todos os blocos instalados a montante do bloco em estudo, porém alguns deles aparecem em destaque na cor vermelha. Isto significa que apenas as curvas dos dispositivos de proteção dos blocos com esta marcação serão ilustradas em conjunto com as curvas do dispositivo de proteção do bloco em estudo. O módulo estabelece um critério para determinar quais curvas de dispositivos de proteção serão avaliadas em conjunto com o dispositivo instalado no bloco em estudo. Tal critério considera o dispositivo de proteção do bloco em estudo e até mais 4 blocos instalados a sua montante, sendo que entre estes últimos estão sempre incluídos:

- Dispositivo de proteção instalado na saída da Subestação de Distribuição;

- Religador instalado entre o início do alimentador e o bloco de carga em estudo;

- Seccionalizador instalado entre o religador e o bloco em estudo; 
- Um dispositivo de proteção instalado no bloco imediatamente a montante do bloco em estudo.

A Figura 4.5 ilustra um exemplo, contendo as curvas dos dispositivos de proteção para um defeito fase-terra com as respectivas probabilidades indicadas na linha abaixo da linha de correntes. Observa-se que na abscissa são indicadas as correntes de defeito esperadas de terra para o bloco de carga em estudo com as suas respectivas probabilidades acumuladas. Já na ordenada são indicados os tempos de atuação em milisegundos.

Esta tela gráfica permite efetuar uma avaliação da probabilidade de haver ou não coordenação entre os dispositivos de proteção para uma faixa de correntes de defeito esperadas no bloco de carga.

Caso nesta etapa seja verificado algum risco de não haver coordenação entre os dispositivos de proteção, é possível abrir o módulo FIXPROTE e efetuar as mudanças necessárias.

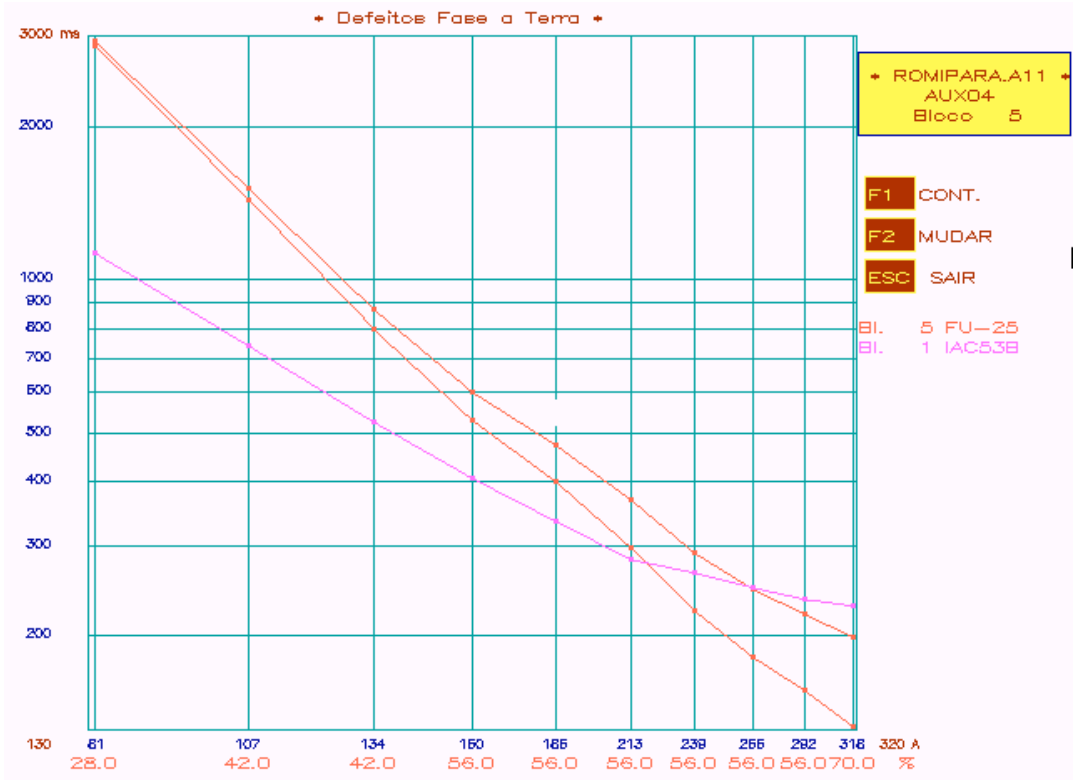

Figura 4.5 - Curvas dos dispositivos de proteção 


\section{APLICAÇÃO DA METODOLOGIA DE COORDENAÇÃO PROBABILÍSTICA DA PROTEÇÃO}

\section{1 - Introdução}

O objetivo do presente capítulo é mostrar a aplicação da metodologia proposta no capítulo 3 em uma rede de distribuição primária de energia elétrica.

Inicialmente foi escolhida uma rede elétrica e realizada a divisão da mesma em blocos de carga. Conhecendo-se as correntes de carga e curto-circuito em todos os trechos, parte-se para o dimensionamento dos respectivos dispositivos de proteção com base na metodologia clássica, amplamente difundida na literatura técnica [1]-[5].

Finalizada a etapa de dimensionamento dos dispositivos de proteção, parte-se para a simulação de casos, com o intuito de avaliar a sensibilidade dos parâmetros, probabilidade de ocorrência de um tipo de defeito, curva de resistência de defeito, taxa de falha, comprimento do subtrecho. Serão realizadas cinco simulações com as mais diversas combinações e para cada uma delas serão determinadas às probabilidades de coordenaação e de não coordenação entre os dispositivos de proteção.

\section{2 - Dados utilizados no estudo}

Será utilizada no presente estudo uma rede elétrica de distribuição primária radial com tensão nominal de $11,9 \mathrm{kV}$, contendo 15 blocos de carga, conforme ilustrado na Figura 5.1 . 


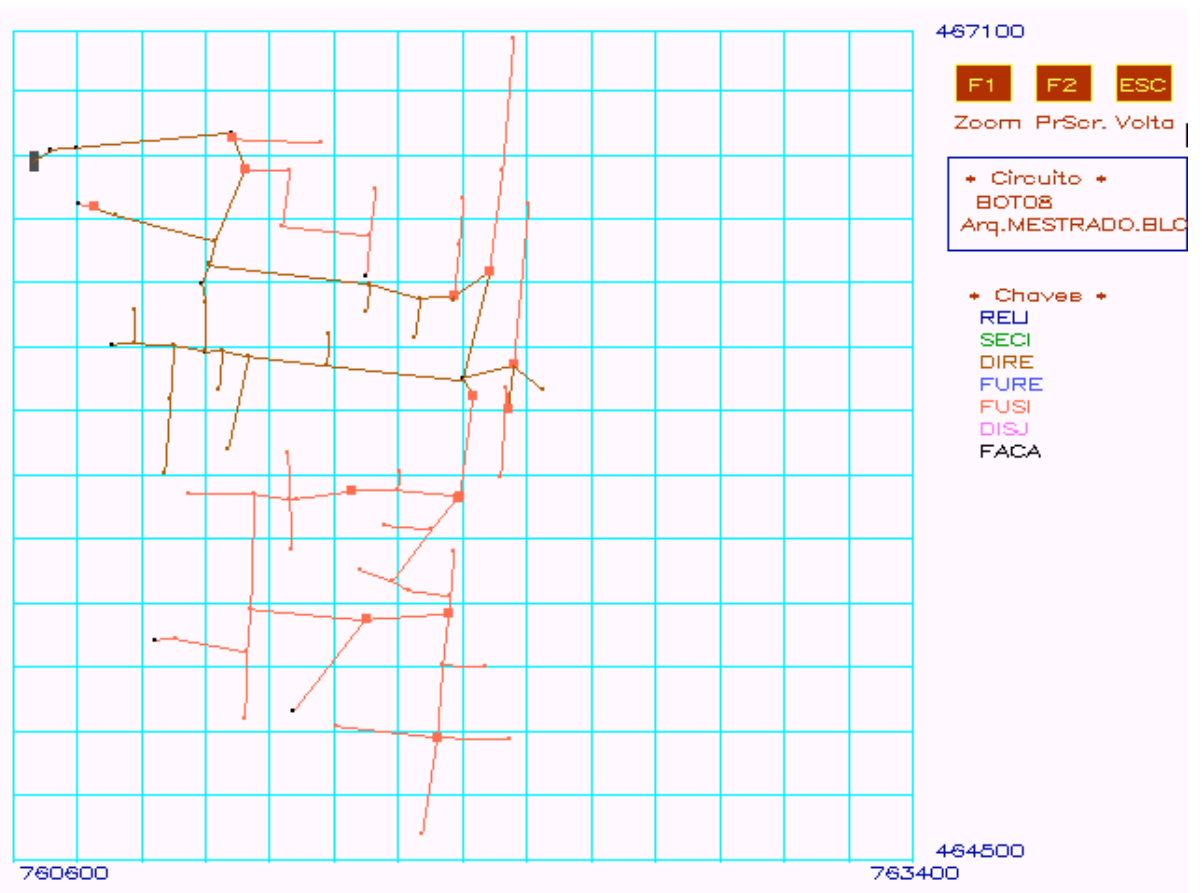

Figura 5.1 - Rede elétrica em estudo

Para melhor ilustrar o número de cada um dos blocos de carga e também para poder avaliar a conexão entre eles, segue na Figura 5.2 o diagrama de blocos da rede elétrica em estudo.

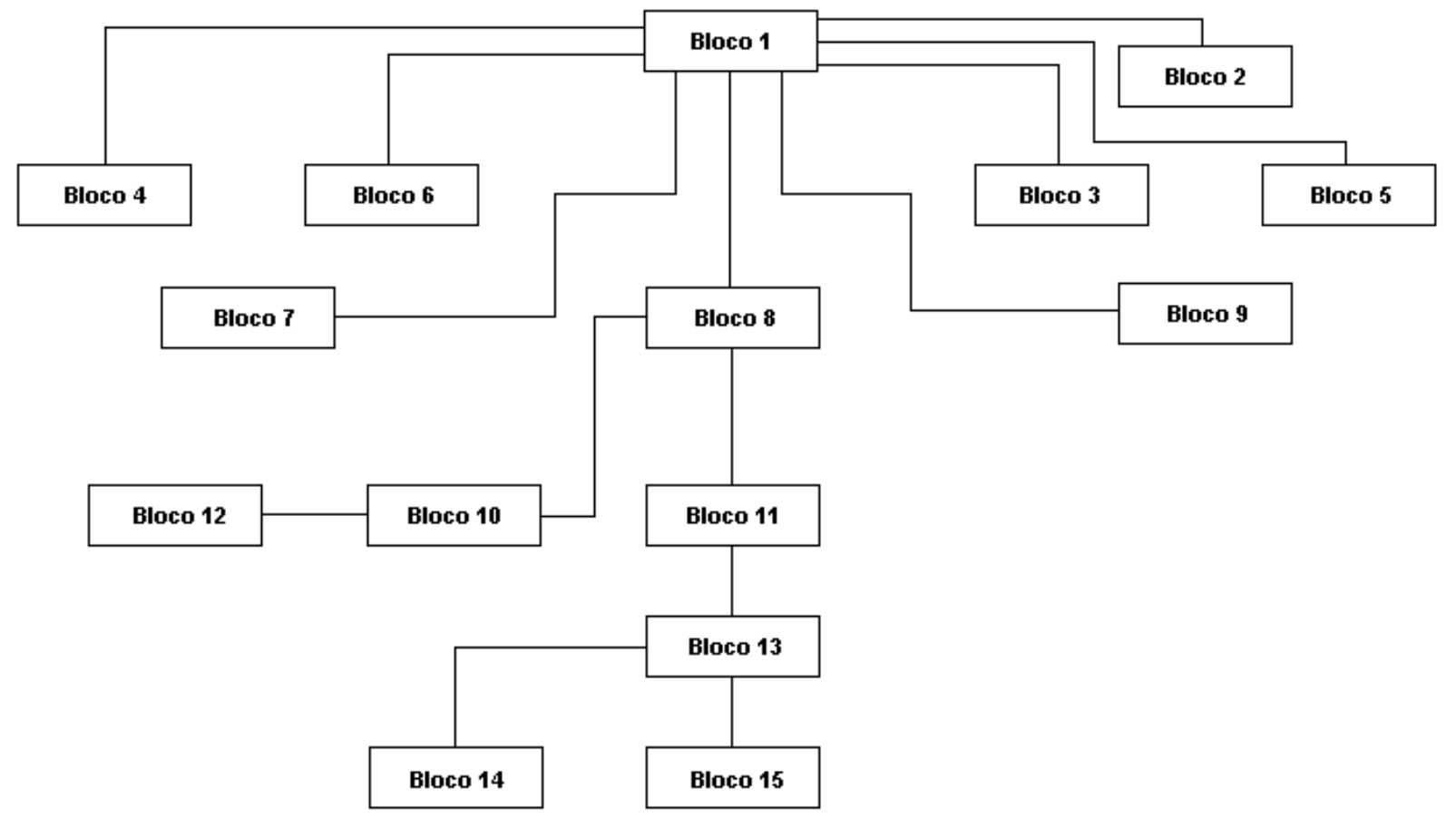

Figura 5.2 - Diagrama de blocos da rede elétrica em estudo 
Com base na Figura 5.2 é possível montar a Tabela 5.1 com o objetivo de visualizar quais blocos de carga se encontram a montante de um bloco específico.

\begin{tabular}{|c|c|}
\hline Bloco de carga & Blocos a montante \\
\hline 1 & 1 \\
\hline 2 & 1 \\
\hline 3 & 1 \\
\hline 4 & 1 \\
\hline 5 & 1 \\
\hline 6 & 1 \\
\hline 7 & 1 \\
\hline 8 & 1 \\
\hline 9 & 8,1 \\
\hline 10 & 8,1 \\
\hline 11 & $10,8,1$ \\
\hline 12 & $11,8,1$ \\
\hline 13 & $13,11,8,1$ \\
\hline 14 & $13,11,8,1$ \\
\hline 15 & \\
\hline
\end{tabular}

Tabela 5.1 - Blocos a montante

A Tabela 5.2 indica as características principais da rede elétrica em estudo, tais como o número de barras, número de transformadores, número de dispositivos de proteção, demanda total ativa e reativa, dentre outros. 


\begin{tabular}{|l|c|}
\hline \multicolumn{1}{|c|}{ Característica } & Valor \\
\hline \hline Número total de barras & 106 \\
\hline Número de barras de carga & 82 \\
\hline Número de dispositivos de proteção (chaves NF) & 15 \\
\hline Número de ligações & 106 \\
\hline Número de chaves NF de seccionamento & 4 \\
\hline Demanda ativa total (MW) & 2,340 \\
\hline Demanda reativa total (MVAr) & 1,136 \\
\hline Demanda aparente total (MVA) & 2,601 \\
\hline Número total de transformadores de distribuição & 112 \\
\hline Potência total dos transformadores de distribuição (kVA) & 5247,5 \\
\hline Taxa de falhas/ano & 5,62 \\
\hline
\end{tabular}

Tabela 5.2 - Características principais da rede elétrica em estudo

Os dados detalhados de cada um dos trechos da rede em estudo tais como; cargas, tipos de cabos utilizados, numeração das barras, dentre outros, podem ser visualizados no Anexo A. No Anexo C serão ilustrados os valores das correntes e tensões em pu no ano zero e no horizonte de estudo considerado ( 5 anos) e as correntes de defeito.

A Tabela 5.3 ilustra os dados gerais, definidos a priori para o início do estudo.

\begin{tabular}{|l|c|}
\hline \multicolumn{1}{|c|}{ Característica } & Valor \\
\hline Probabilidade de ocorrência de defeito trifásico & 0,050 \\
\hline Probabilidade de ocorrência de defeito dupla fase & 0,100 \\
\hline Probabilidade de ocorrência de defeito fase-terra & 0,700 \\
\hline Probabilidade de ocorrência de defeito dupla fase-terra & 0,150 \\
\hline Fator de segurança utilizado no ajuste dos religadores & 2,0 \\
\hline Resistência de defeito para terra & $40 \Omega$ \\
\hline Número máximo de elos fusíveis em série & 4 \\
\hline $\begin{array}{l}\text { Número mínimo de transformadores existentes a jusante para } \\
\text { inserção do elo fusível }\end{array}$ & 3 \\
\hline $\begin{array}{l}\text { Comprimento mínimo da rede a jusante do ponto de instalação do } \\
\text { elo fúsível (até o final do bloco de carga ou da rede, se for o caso) }\end{array}$ & $300 \mathrm{~m}$ \\
\hline
\end{tabular}

Tabela 5.3 - Dados gerais definidos a priori 


\section{3 - Coordenação da proteção através de abordagem convencional}

\subsection{1 - Considerações gerais}

O presente item está estruturado conforme segue:

a) Inicialmente são efetuados os dimensionamentos dos dispositivos de proteção instalados no início de cada um dos 15 blocos de carga existentes na rede elétrica em estudo, de acordo com os critérios básicos apresentados no capítulo 2 do presente trabalho;

b) Em seguida analisa-se em detalhes, as coordenações entre os dispositivos de proteção face aos ajustes definidos anteriormente. Observou-se alguns problemas de coordenação sendo que, após várias simulações, foram resolvidos instalando-se um religador na Subestação de distribuição (início do bloco de carga 1) e um seccionalizador no início do bloco de carga 8. Cabe ressaltar que a substituição destes dois dispositivos de proteção exigiu um novo estudo de coordenação da rede elétrica em análise, sendo que o mesmo também é apresentado em detalhes.

\subsection{2 - Dimensionamentos e ajustes dos dispositivos de proteção}

De acordo com a premissa inicial adotada, os blocos de carga de números 2 a 15 serão protegidos por elos fusíveis e o bloco 1 por um disjuntor associado a um relé de proteção de sobrecorrente (fase e neutro) mais a função de religamento.

Nestas condições, nas linhas subseqüentes será ilustrado o dimensionamento de cada um dos dispositivos de proteção acima citados, conforme segue:

\section{- Bloco de carga 15}

Para efetuar o dimensionamento do elo fusível instalado no início do bloco em estudo, é necessário conhecer a corrente de carga máxima, a corrente de curto-circuito fase-terra 
mínima (Com impedância de defeito igual a $40 \Omega$ ), calculada na barra mais afastada eletricamente e a corrente de magnetização $\left(I_{I N R U S H}\right)$. A corrente de carga máxima considerada no presente estudo leva em conta a previsão anual de crescimento da carga num período de 5 anos. O fator de crescimento da carga utilizado no período em questão é igual a 1,2 .

Para o correto dimensionamento são conhecidos os seguintes dados:

$I_{\text {CARGA (ANO 0) }}=0 \mathrm{~A} \quad I_{\text {CARGA (ANO 5) }}=0 \mathrm{~A} \quad I_{C C-F T-M i ́ n}=162 \mathrm{~A} \quad I_{\text {INRUSH }}=36 \mathrm{~A}$

De acordo com as regras apresentadas na seção 2.3.3, conclui-se que:

$$
\begin{aligned}
& I_{\text {CARGA ANO } 5} \leq I_{N-E L O} \leq \frac{I_{C C-F T-M i n}}{4} \\
& I_{F U S \tilde{O}(130 \mathrm{~ms})} \geq I_{\text {INRUSH }}
\end{aligned}
$$

em que:

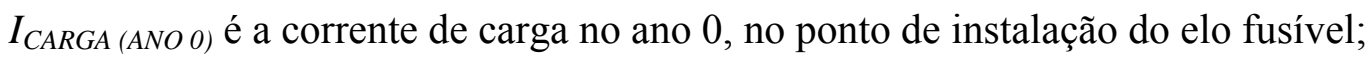

$I_{C A R G A(A N O \text { 5) }}$ é a corrente de carga no ano 5, no ponto de instalação do elo fusível;

$I_{C C}-F T$ - Mín é a corrente de curto-circuito fase-terra mínima na barra mais afastada eletricamente do bloco de carga em estudo;

$I_{I N R U S H)}$ é a corrente de magnetização do bloco de carga em estudo;

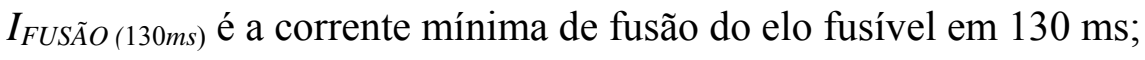

$I_{N-E L O}$ é a corrente nominal do elo fusível.

Aplicando nas expressões 5.1 e 5.2, os dados conhecidos, obtém-se:

$$
0 \leq I_{N-E L O} \leq \frac{162}{4} \quad \rightarrow \quad 0 \leq I_{N-E L O} \leq 40,5 \quad \rightarrow \quad \text { Elo } 10 K
$$


Para o Elo Fusível 10K:

$I_{\text {FUSÃO (130ms) }} \geq I_{\text {INRUSH }} \rightarrow \quad 115 \geq 36 \quad \rightarrow \quad$ Atende

Portanto, será utilizado no bloco 15 um Elo Fusível do tipo K de 10,0 A (10K).

\section{- Bloco de carga 14}

Analogamente ao caso anterior, obtém-se para o bloco em estudo os seguintes dados:

$I_{C A R G A(A N O))}=0 \mathrm{~A} \quad I_{C A R G A(A N O) 5)}=0 \mathrm{~A} \quad I_{C C-F T-M i ́ n}=163 \mathrm{~A} \quad I_{I N R U S H}=0 \mathrm{~A}$

De acordo com as expressões 5.1 e 5.2, conclui-se que:

$0 \leq I_{N-E L O} \leq \frac{163}{4} \quad \rightarrow \quad 0 \leq I_{N-E L O} \leq 40,75 \quad \rightarrow \quad$ Elo $10 K$

Para o Elo Fusível 10K:

$I_{\text {FUSÃO (130ms) }} \geq I_{\text {INRUSH }} \quad \rightarrow \quad 115 \geq 36 \quad \rightarrow \quad$ Atende

Portanto, será utilizado no bloco 14 um Elo Fusível do tipo K de 10,0 A (10K).

\section{- Bloco de carga 13}

Analogamente ao caso anterior, obtém-se para o bloco em estudo os seguintes dados:

$I_{\text {CARGA (ANO 0) }}=13 \mathrm{~A} \quad I_{\text {CARGA (ANO 5) }}=15 \mathrm{~A} \quad I_{C C-F T-M i ́ n}=163 \mathrm{~A} \quad I_{I N R U S H}=193 \mathrm{~A}$

De acordo com as expressões 5.1 e 5.2, conclui-se que: 
$15 \leq I_{N-E L O} \leq \frac{163}{4} \quad \rightarrow \quad 15 \leq I_{N-E L O} \leq 40,75 \quad \rightarrow \quad$ Elo $15 K$

Para o Elo Fusível 15K:

$I_{\text {FUSÃO (130ms) }} \geq I_{\text {INRUSH }} \rightarrow \quad 200 \geq 193 \quad \rightarrow \quad$ Atende

Portanto, será utilizado no bloco 13 um Elo Fusível do tipo K de 15,0 A (15K).

\section{- Bloco de carga 12}

Analogamente ao caso anterior, obtém-se para o bloco em estudo os seguintes dados:

$I_{C A R G A(A N O \text { ) })}=8 \mathrm{~A} \quad I_{C A R G A(A N O \text { 5) }}=9 \mathrm{~A} \quad I_{C C-F T-M i ́ n}=162 \mathrm{~A} \quad I_{I N R U S H}=105 \mathrm{~A}$

De acordo com as expressões 5.1 e 5.2, conclui-se que:

$9 \leq I_{N-E L O} \leq \frac{162}{4} \quad \rightarrow \quad 9 \leq I_{N-E L O} \leq 40,5 \quad \rightarrow \quad$ Elo $10 \mathrm{~K}$

Para o Elo Fusível 10K:

$I_{\text {FUSÃO (130ms) }} \geq I_{\text {INRUSH }} \rightarrow \quad 115 \geq 105 \quad \rightarrow \quad$ Atende

Portanto, será utilizado no bloco 12 um Elo Fusível do tipo K de 10,0 A (10K).

\section{- Bloco de carga 11}

Analogamente ao caso anterior, obtém-se para o bloco em estudo os seguintes dados:

$I_{C A R G A(A N O ~ 0)}=21 \mathrm{~A} \quad I_{C A R G A(A N O) 5)}=26 \mathrm{~A} \quad I_{C C-F T-M i ́ n}=164 \mathrm{~A} \quad I_{I N R U S H}=307 \mathrm{~A}$ 
De acordo com as expressões 5.1 e 5.2, conclui-se que:

$26 \leq I_{N-E L O} \leq \frac{164}{4} \quad \rightarrow \quad 26 \leq I_{N-E L O} \leq 41 \quad \rightarrow \quad$ Elo 40K

Para o Elo Fusível 40K:

$I_{\text {FUSÃO (130ms) }} \geq I_{\text {INRUSH }} \quad \rightarrow \quad 497 \geq 307 \quad \rightarrow \quad$ Atende

Portanto, será utilizado no bloco 11 um Elo Fusível do tipo K de 40,0 A (40K).

\section{- Bloco de carga 10}

Analogamente ao caso anterior, obtém-se para o bloco em estudo os seguintes dados:

$I_{\text {CARGA (ANO 0) }}=13 \mathrm{~A} \quad I_{\text {CARGA (ANO 5) }}=15 \mathrm{~A} \quad I_{C C-F T-M i ́ n}=165 \mathrm{~A} \quad I_{\text {INRUSH }}=139 \mathrm{~A}$

De acordo com as expressões 5.1 e 5.2, conclui-se que:

$15 \leq I_{N-E L O} \leq \frac{165}{4} \quad \rightarrow \quad 15 \leq I_{N-E L O} \leq 41,25 \quad \rightarrow \quad$ Elo 15K

Para o Elo Fusível 15K:

$I_{\text {FUSÃO (130ms) }} \geq I_{\text {INRUSH }} \quad \rightarrow \quad 200 \geq 139 \quad \rightarrow \quad$ Atende

Portanto, será utilizado no bloco 10 um Elo Fusível do tipo K de 15,0 A (15K).

\section{- Bloco de carga 9}

Analogamente ao caso anterior, obtém-se para o bloco em estudo os seguintes dados:

$I_{\text {CARGA (ANO 0) }}=12 \mathrm{~A} \quad I_{C A R G A(A N O) \text { ) }}=14 \mathrm{~A} \quad I_{C C-F T-M i ́ n}=167 \mathrm{~A} \quad I_{I N R U S H}=133 \mathrm{~A}$ 
De acordo com as expressões 5.1 e 5.2, conclui-se que:

$14 \leq I_{N-E L O} \leq \frac{167}{4} \quad \rightarrow \quad 14 \leq I_{N-E L O} \leq 41,75 \quad \rightarrow \quad$ Elo 15K

Para o Elo Fusível 15K:

$I_{\text {FUSÃO (130ms) }} \geq I_{I N R U S H} \quad \rightarrow \quad 200 \geq 133 \quad \rightarrow \quad$ Atende

Portanto, será utilizado no bloco 9 um Elo Fusível do tipo K de 15,0 A (15K).

\section{- $\underline{\text { Bloco de carga } 8}$}

Analogamente ao caso anterior, obtém-se para o bloco em estudo os seguintes dados:

$I_{\text {CARGA (ANO 0) }}=36 \mathrm{~A} \quad I_{\text {CARGA (ANO 5) }}=43 \mathrm{~A} \quad I_{C C-F T-M i ́ n}=167 \mathrm{~A} \quad I_{\text {INRUSH }}=468 \mathrm{~A}$

De acordo com as expressões 5.1 e 5.2, conclui-se que:

$43 \leq I_{N-E L O} \leq \frac{167}{4} \quad \rightarrow \quad 43 \leq I_{N-E L O} \leq 41,75$

Observa-se que não existe um elo fusível que atenda a condição acima. Nestas condições, o dimensionamento do mesmo será feito considerando apenas a corrente de carga ao final de 5 anos e a premissa descrita através da expressão 5.2.

$I_{N-E L O} \geq I_{\text {CARGA ANO } 5} \quad \rightarrow \quad I_{N-E L O} \geq 43 \quad \rightarrow \quad$ Elo 65K

Para o Elo Fusível 65K:

$I_{\text {FUSÃO (130ms) }} \geq I_{\text {INRUSH }} \quad \rightarrow \quad 789 \geq 468 \quad \rightarrow \quad$ Atende 
Portanto, será utilizado no bloco 8 um Elo Fusível do tipo K de 65,0 A (65K).

\section{- Bloco de carga 7}

Analogamente ao caso anterior, obtém-se para o bloco em estudo os seguintes dados:

$I_{C A R G A(A N O) \text { ) }}=8 \mathrm{~A} \quad I_{\text {CARGA (ANO 5) }}=10 \mathrm{~A} \quad I_{C C-F T-M i ́ n}=166 \mathrm{~A} \quad I_{I N R U S H}=120 \mathrm{~A}$

De acordo com as expressões 5.1 e 5.2, conclui-se que:

$10 \leq I_{N-E L O} \leq \frac{166}{4} \quad \rightarrow \quad 10 \leq I_{N-E L O} \leq 41,5 \quad \rightarrow \quad$ Elo $10 \mathrm{~K}$

Para o Elo Fusível 10K:

$I_{\text {FUSÃO (130ms) }} \geq I_{\text {INRUSH }} \quad \rightarrow \quad 115 \geq 120 \quad \rightarrow \quad$ Não atende

Nestas condições, o elo fusível $10 \mathrm{~K}$ não atende, pois a sua corrente mínima de fusão para um tempo de $130 \mathrm{~ms}$ (115 A) é menor do que a corrente de inrush no bloco de carga (120 A). Assim sendo, será utilizado o elo fusível de 15,0 A (15K), que atende a todos os critérios técnicos citados anteriormente.

\section{- Bloco de carga 6}

Analogamente ao caso anterior, obtém-se para o bloco em estudo os seguintes dados:

$I_{C A R G A(A N O) \text { ) }}=16 \mathrm{~A} \quad I_{\text {CARGA (ANO 5) }}=19 \mathrm{~A} \quad I_{C C-F T-M i ́ n}=165 \mathrm{~A} \quad I_{I N R U S H}=240 \mathrm{~A}$

De acordo com as expressões 5.1 e 5.2, conclui-se que:

$$
19 \leq I_{N-E L O} \leq \frac{165}{4} \quad \rightarrow \quad 19 \leq I_{N-E L O} \leq 41,25 \quad \rightarrow \quad \text { Elo 25K }
$$


Para o Elo Fusível 25K:

$I_{\text {FUSÃO (130ms) }} \geq I_{\text {INRUSH }} \quad \rightarrow \quad 320 \geq 240 \quad \rightarrow \quad$ Atende

Portanto, será utilizado no bloco 6 um Elo Fusível do tipo K de 25,0 A (25K).

\section{- Bloco de carga 5}

Analogamente ao caso anterior, obtém-se para o bloco em estudo os seguintes dados:

$I_{C A R G A(A N O))}=3 \mathrm{~A} \quad I_{C A R G A(A N O) 5)}=4 \mathrm{~A} \quad I_{C C-F T-M i ́ n}=168 \mathrm{~A} \quad I_{\text {INRUSH }}=38 \mathrm{~A}$

De acordo com as expressões 5.1 e 5.2, conclui-se que:

$4 \leq I_{N-E L O} \leq \frac{168}{4} \quad \rightarrow \quad 4 \leq I_{N-E L O} \leq 42 \quad \rightarrow \quad$ Elo 10K

Para o Elo Fusível 10K

$I_{\text {FUSÃO (130ms) }} \geq I_{\text {INRUSH }} \quad \rightarrow \quad 115 \geq 38 \quad \rightarrow \quad$ Atende

Portanto, será utilizado no bloco 5 um Elo Fusível do tipo K de 10,0 A (10K).

\section{- Bloco de carqa 4}

Analogamente ao caso anterior, obtém-se para o bloco em estudo os seguintes dados:

$I_{C A R G A(A N O) \text { ) }}=0 \mathrm{~A} \quad I_{C A R G A(A N O) 5)}=0 \mathrm{~A} \quad I_{C C-F T-M i ́ n}=168 \mathrm{~A} \quad I_{I N R U S H}=0 \mathrm{~A}$

De acordo com as expressões 5.1 e 5.2, conclui-se que: 
$0 \leq I_{N-E L O} \leq \frac{168}{4}$

Para o Elo Fusível 10K:

$I_{\text {FUSÃO (130ms) }} \geq I_{\text {INRUSH }}$ $\rightarrow \quad 0 \leq I_{N-E L O} \leq 42 \quad \rightarrow \quad$ Elo 10K

$\rightarrow \quad 125 \geq 0$

$\rightarrow \quad$ Atende

Portanto, será utilizado no bloco 4 um Elo Fusível do tipo K de 10,0 A (10K).

\section{- Bloco de carga 3}

Analogamente ao caso anterior, obtém-se para o bloco em estudo os seguintes dados:

$I_{C A R G A(A N O) \text { ) }}=11 \mathrm{~A} \quad I_{\text {CARGA (ANO 5) }}=14 \mathrm{~A} \quad I_{C C-F T-M i n}=167 \mathrm{~A} \quad I_{I N R U S H}=119 \mathrm{~A}$

De acordo com as expressões 5.1 e 5.2, conclui-se que:

$14 \leq I_{N-E L O} \leq \frac{167}{4} \quad \rightarrow \quad 14 \leq I_{N-E L O} \leq 41,75 \quad \rightarrow \quad$ Elo 15K

Para o Elo Fusível 15K:

$I_{\text {FUSÃO (130ms) }} \geq I_{\text {INRUSH }} \quad \rightarrow \quad 200 \geq 119 \quad \rightarrow \quad$ Atende

Portanto, será utilizado no bloco 3 um Elo Fusível do tipo K de 15,0 A (15K).

\section{- $\underline{\text { Bloco de carga } 2}$}

Analogamente ao caso anterior, obtém-se para o bloco em estudo os seguintes dados:

$I_{C A R G A(A N O) \text { ) }}=2 \mathrm{~A} \quad I_{C A R G A(A N O 5)}=3 \mathrm{~A} \quad I_{C C-F T-M i ́ n}=169 \mathrm{~A} \quad I_{I N R U S H}=24 \mathrm{~A}$ 
De acordo com as expressões 5.1 e 5.2, conclui-se que:

$3 \leq I_{N-E L O} \leq \frac{169}{4} \quad \rightarrow \quad 3 \leq I_{N-E L O} \leq 42,25 \quad \rightarrow \quad$ Elo 10K

Para o Elo Fusível 10K:

$I_{\text {FUSÃO (130ms) }} \geq I_{\text {INRUSH }} \quad \rightarrow \quad 115 \geq 24 \quad \rightarrow \quad$ Atende

Portanto, será utilizado no bloco 2 um Elo Fusível do tipo K de 10,0 A (10K).

\section{- Bloco de carga 1}

O dispositivo de proteção utilizado no bloco de carga em questão será um disjuntor com um relé de proteção, conforme descrito em 5.3.1.

O relé utilizado será do tipo eletromecânico, modelo IAC77B de fabricação GE cuja curva de atuação (com os diais de tempo 0,5, 2,0 e 5,0) de tempo em função da corrente está ilustrada no Anexo B. Foi escolhido este relé em virtude do mesmo apresentar curvas de atuação do tipo extremamente inversa, sendo que estas se assemelham mais com as curvas de mínima e máxima fusão dos elos fusíveis utilizados e, portanto, são mais adequadas para o estudo de coordenação da proteção.

Antes da determinação dos ajustes do relé em questão é necessário determinar a relação de transformação do TC utilizado (RTC). A determinação da RTC [12] deve levar em conta o consumo da entrada de corrente do relé (burden), a impedância dos cabos que interligam o secundário do TC ao relé e a impedância secundária do TC, para que seja possível avaliar as condições de saturação do mesmo, na ocorrência de um valor máximo de curto-circuito na zona de proteção no qual se encontra instalado.

Uma outra metodologia bastante utilizada para determinar a RTC, adotada pela maioria das concessionárias de Distribuição no Brasil, consiste em dividir a corrente de curto- 
circuito trifásica assimétrica, no ponto de instalação do dispositivo de proteção, pelo fator de sobrecorrente que de acordo com a NBR 6856 é igual a 20. Com isto obtém-se a corrente primária do $\mathrm{TC}$, sendo que o valor padrão geralmente adotado para a corrente secundária é igual a $5 \mathrm{~A}$.

Com base nas informações acima chega-se na Equação (5.3), conforme segue:

$$
I_{P T C}=\frac{I_{C C-3 F-A s s i m}}{f s}
$$

em que:

$I_{P T C}$ é a corrente nominal primária do TC expressa em A;

$I_{C C-3 F-A s s i m}$ é a corrente de curto-circuito trifásica assimétrica no ponto de instalação do conjunto disjuntor, relé de proteção e TC, expressa em A;

fs é o fator de sobrecorrente.

Pelo estudo de curto circuito ilustrado na seção C.4 do Anexo C, observa-se que o valor da corrente de curto-circuito trifásica assimétrica no ponto de instalação do conjunto disjuntor, relé de proteção e TC (barra 1) vale 8490 A. Aplicando este valor na Equação (5.3) chega-se em:

$$
I_{\text {PTC }}=\frac{8490}{20} \quad \rightarrow \quad I_{\text {PTC }}=424,5 \mathrm{~A}
$$

O valor comercial mais próximo da RTC é $500 / 5=100$, sendo esta adotada no presente estudo.

A determinação dos ajustes das proteções de sobrecorrente de fase, neutro e religamento do relé em questão pode ser feita conforme segue: 
- Unidade temporizada de fase

A determinação do tape da unidade temporizada de fase $\left(\operatorname{Tap}_{T f}\right)$ deve ser realizado de tal forma que o relé atue para o menor valor de corrente de defeito fase-fase na sua zona de proteção primária ( $\left.I_{C C-2 \phi-M i ́ n}\right)$ e que ainda o valor da corrente de carga máxima admissível ( $\left.I_{C \text { arga-Máx }}\right)$, levando em conta a taxa anual de crescimento da carga no horizonte de estudo (5 anos), no cabo do alimentador não seja ultrapassada.

Transformando as condições apresentadas no parágrafo anterior [3] em forma matemática, obtém as expressões (5.4) e (5.5).

$$
\begin{gathered}
\operatorname{Tap}_{T f}>\frac{I_{\text {Carga-Máx }}}{R T C} \\
\operatorname{Tap}_{T f}<\frac{I_{C C-2 \phi-M i ́ n}}{F_{s} \cdot F_{i n i} \cdot R T C}
\end{gathered}
$$

O parâmetro $F_{S}$ representa o fator de segurança definido na seção 2.3.4, enquanto que $F_{\text {ini }}$ corresponde ao fator de início da curva do relé, sendo este intrínseco de cada relé. Em linhas gerais este fator varia de 1,0 a 2,0 sendo que no presente estudo será considerado igual a 1,5 .

Para a determinação do tap da unidade temporizada de fase do relé de sobrecorrente instalado no início do bloco 1, são conhecidas as seguintes informações:

i) $I_{C \arg a-\text { Máx }}=153 \mathrm{~A}$;

ii) $R T C=500 / 5=100$;

iii) $I_{C C-2 \phi-M i n}=2353$ A. Corresponde ao menor valor da corrente de curto-circuito dupla fase, no ponto mais afastado eletricamente dos trechos dos blocos de carga situados 
imediatamente a jusante do bloco correspondente ao conjunto disjuntor mais relé de proteção. No caso em questão, o valor citado corresponde a esta corrente de defeito calculada ao final do bloco de carga número 8;

iv) $F_{S}=2,0$;

v) $F_{\text {ini }}=1,5$.

Aplicando estas informações nas expressões (5.4) e (5.5), obtém-se que:

$$
\begin{array}{lll}
\operatorname{Tap}_{T f}>\frac{153}{100} & \rightarrow & \operatorname{Tap}_{\text {Tf }}>1,53 \mathbf{A} \\
\operatorname{Tap}_{T f}<\frac{2353}{2 \cdot 1,5 \cdot 100} & \rightarrow & \boldsymbol{T a p}_{\text {Tf }}<\mathbf{7 , 8 4} \mathbf{A}
\end{array}
$$

Será escolhido para a unidade de sobrecorrente de fase o Tap de 2,0 A. Quanto ao dial de tempo, o mesmo será ajustado inicialmente em 0,5, que é o mínimo disponível no relé. Porém, caso haja algum problema de coordenação com os demais dispositivos de proteção, o mesmo será aumentado até que se consiga alcançar uma solução ótima.

\section{- Unidade instantânea de fase}

O ajuste do tap da unidade de sobrecorrente instantânea de fase $\left(\operatorname{Tap}_{I f}\right)$ deve levar em conta a corrente de magnetização dos transformadores de tal forma que não ocorra a abertura do circuito na energização do circuito. Analogamente a unidade temporizada de fase, o relé deve ser ajustado para que o relé atue para o menor valor da corrente de curto-circuito dupla fase, na zona de proteção primária do relé.

Transformando as condições apresentadas no parágrafo anterior [3] em forma matemática, obtém as expressões (5.6) e (5.7). 


$$
\begin{gathered}
\operatorname{Tap}_{\text {If }}>\frac{I_{I N R U S H}}{R T C} \\
\operatorname{Tap}_{\text {If }}<\frac{I_{C C-2 \phi-M i n}}{R T C}
\end{gathered}
$$

Com base nas informações disponíveis para a unidade temporizada de fase e sabendo que a corrente de magnetização é igual a 1527 A, conclui-se através das expressões (5.6) e (5.7) que:

$$
\begin{array}{lll}
\operatorname{Tap}_{\text {If }}>\frac{1527}{100} & \rightarrow & \text { Tap If }_{\text {If }} \mathbf{1 5 , 2 7} \mathrm{A} \\
\operatorname{Tap}_{\text {If }}<\frac{2353}{100} & \rightarrow & \text { Tap }_{\text {If }}<23,53 \mathrm{~A}
\end{array}
$$

A faixa de ajuste do tap da unidade de sobrecorrente instantânea de fase disponível no relé utilizado vai de 20 a 160 A. Com base nas condições obtidas acima, o ajuste escolhido inicialmente para esta unidade será de 20 A.

\section{- Unidade temporizada de neutro}

O tape da unidade temporizada de neutro $\left(\operatorname{Tap}_{T n}\right)$ pode ser determinado de acordo com a expressão (5.8)

$$
\operatorname{Tap}_{T n}<\frac{I_{C C-F T-M i n}}{R T C \cdot F_{i n i}}
$$

Para a determinação do tap da unidade temporizada de neutro $\left(\operatorname{Tap}_{T n}\right)$ são conhecidas as seguintes informações:

i) $R T C=500 / 5=100$; 
ii) $F_{\text {ini }}=1,5$;

iii) $I_{C C-F T-M i ́ n}=168$ A (Menor valor da corrente de curto-circuito fase-terra calculada com impedância de defeito igual a $40 \Omega$, no ponto mais eletricamente afastado dos trechos dos blocos de carga situados imediatamente a jusante do bloco correspondente ao conjunto disjuntor mais relé de proteção. No caso em questão, o valor citado corresponde a esta corrente de defeito calculada ao final do bloco de carga número 8);

Aplicando estas informações na expressão (5.8), obtém-se:

$$
\operatorname{Tap}_{T n}<\frac{168}{100 \cdot 1,5} \quad \rightarrow \quad \operatorname{Tap}_{T n}<\mathbf{1 , 1 2} \mathrm{A}
$$

Nestas condições, o ajuste do tap da unidade temporizada de neutro será inicialmente ajustado em seu valor mínimo que é igual a 0,5 A Quanto ao dial de tempo, o mesmo será ajustado inicialmente em 0,5 , que é o mínimo disponível no relé.

\section{- Unidade instantânea de neutro}

O tape da unidade instantânea de neutro $\left(\operatorname{Tap}_{I n}\right)$ pode ser determinado de acordo com a expressão (5.9)

$$
\operatorname{Tap}_{\text {IT }}<\frac{\mathrm{I}_{\mathrm{CC}-\phi \mathrm{T}-\mathrm{Assim}}}{\mathrm{RTC}}
$$

Para a determinação do tap da unidade instantânea de neutro (Tap In) são conhecidas as seguintes informações:

i) $R T C=500 / 5=100$;

ii) $I_{C C-\phi T-A s s i m}=2515 \mathrm{~A}$ (Menor valor da corrente de curto-circuito fase-terra assimétrica, calculada sem impedância de defeito, no ponto mais afastado eletricamente 
dos trechos dos blocos de carga situados imediatamente a jusante do bloco correspondente ao conjunto disjuntor mais relé de proteção. No caso em questão, o valor citado corresponde a esta corrente de defeito calculada ao final do bloco de carga número 8 ).

Aplicando estas informações na expressão (5.9), obtém-se:

$\operatorname{Tap}_{I n}<\frac{2515}{100} \quad \rightarrow \quad \operatorname{Tap}_{I n}<25,15 \mathrm{~A}$

A faixa de ajuste do tap da unidade de sobrecorrente instantânea de neutro disponível no relé utilizado vai de 20 a 160 A. Com base nas condições obtidas acima, o ajuste escolhido inicialmente para esta unidade será de 25 A.

- $\quad$ Unidade de religamento

Neste caso será considerado 3 ciclos de religamento com ajustes do tempo morto para o ciclo $1\left(t_{\mathrm{m} 1}\right)$ igual a $0,3 \mathrm{~s}$ e $\left(\mathrm{t}_{\mathrm{m} 2}\right)$ igual a $15 \mathrm{~s}$. A seqüência de operações do disjuntor utilizado é $\mathrm{O}-0,3 \mathrm{~s}-\mathrm{CO}-15 \mathrm{~s}-\mathrm{CO}$.

\subsection{3 - Coordenação entre os dispositivos de proteção}

Após a determinação prévia dos ajustes dos dispositivos de proteção parte-se para a análise da coordenação entre os mesmos.

\section{- Blocos de carga 15 e 13}

Neste caso, o problema a ser avaliado é a coordenação entre os elos fusíveis $10 \mathrm{~K}$ e $15 \mathrm{~K}$ e destes com o relé instalado na SE de distribuição.

Observa-se através da Figura 5.3 que existe coordenação entre os dois elos fusíveis para toda a faixa de correntes de defeito de terra, esperadas do bloco 15. Ainda de acordo com a Figura 5.3, observa-se que existe coordenação entre o elo fusível $10 \mathrm{~K}$ e o 
disjuntor da SE de distribuição para toda a faixa das correntes de defeito fase-terra esperadas no bloco de carga 15.

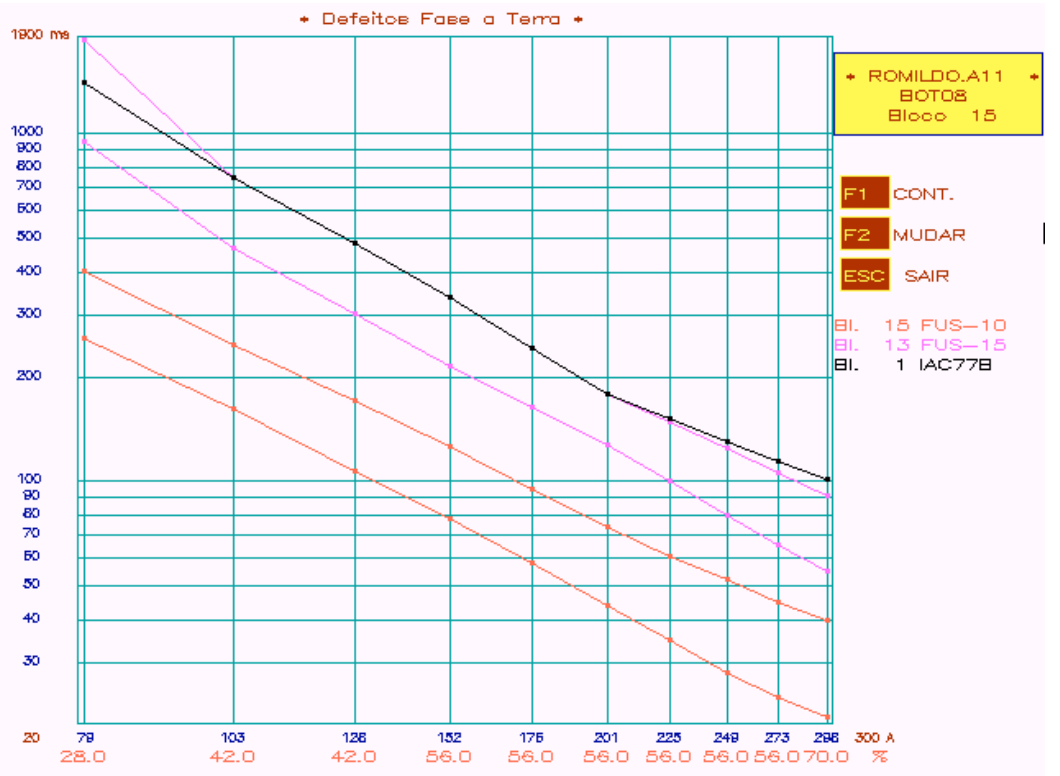

Figura 5.3 - Análise dos defeitos de terra para o bloco de carga 15

Já para os defeitos de fase existe coordenação entre o elo fusível e o relé para correntes de até no máximo 2010 A (aproximadamente), de acordo com a Figura 5.4.

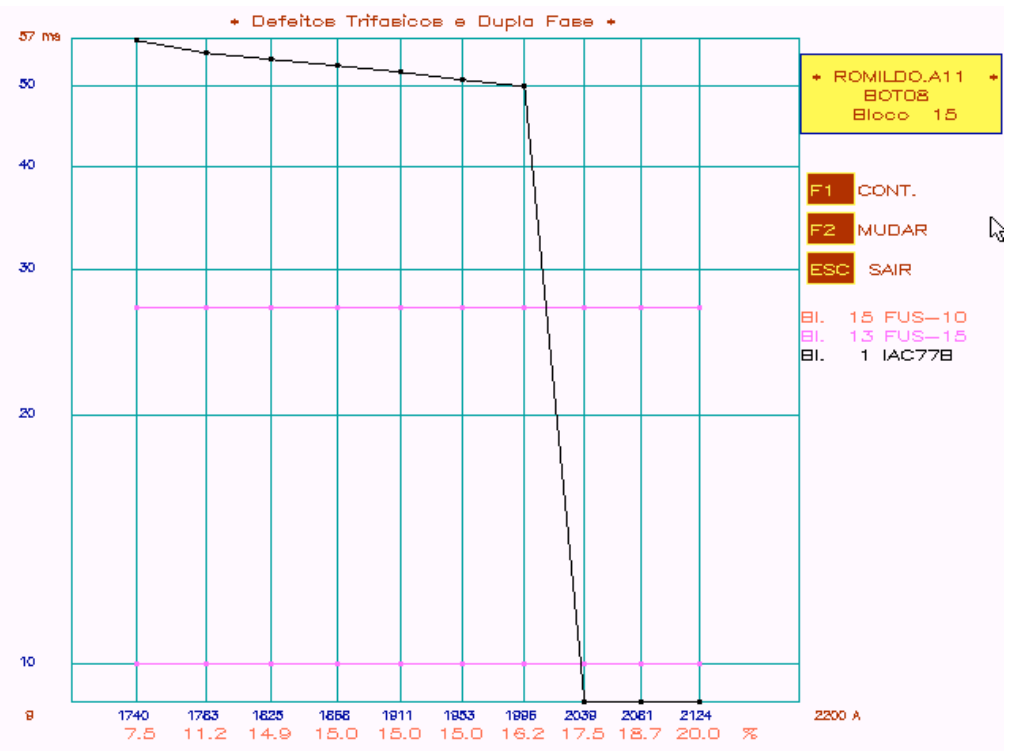

Figura 5.4 - Análise dos defeitos de fase para o bloco de carga 15 
Uma solução a ser testada para eliminar os problemas encontrados, consiste no aumento do tap e/ou o dial de tempo da curva da unidade de sobrecorrente de fase e aumentar o tap da unidade instantânea de fase.

Serão analisados os demais blocos de carga e ao final deste item será apresentada uma solução que seja mais adequada para o problema em questão.

\section{- Blocos de carga 14 e 13}

A análise e as conclusões são idênticas as apresentadas para os elos dos blocos 15 e 13 , exceto que a coordenação entre o elo do bloco 14 e o relé da SE para os defeitos de fase ocorre para correntes de até no máximo 1980 A.

\section{- Blocos de carga 13 e 11}

Neste caso, o problema a ser avaliado é a coordenação entre os elos fusíveis $15 \mathrm{~K}$ e $40 \mathrm{~K}$ e destes com o relé instalado na SE de distribuição.

Observa-se que existe coordenação entre os dois elos fusíveis para toda a faixa de correntes de defeito de fase e terra, esperadas do bloco 13.

Analisando a coordenação com o disjuntor da SE de distribuição, verifica-se de acordo com a Figura 5.5 que para as correntes esperadas de defeito de terra no bloco 13, a curva do relé fica em alguns pontos (faixa de 79 a 104 A) abaixo da curva de máxima interrupção do elo fusível 15K e em outros tangencia (faixa de 104 a 215 A). 


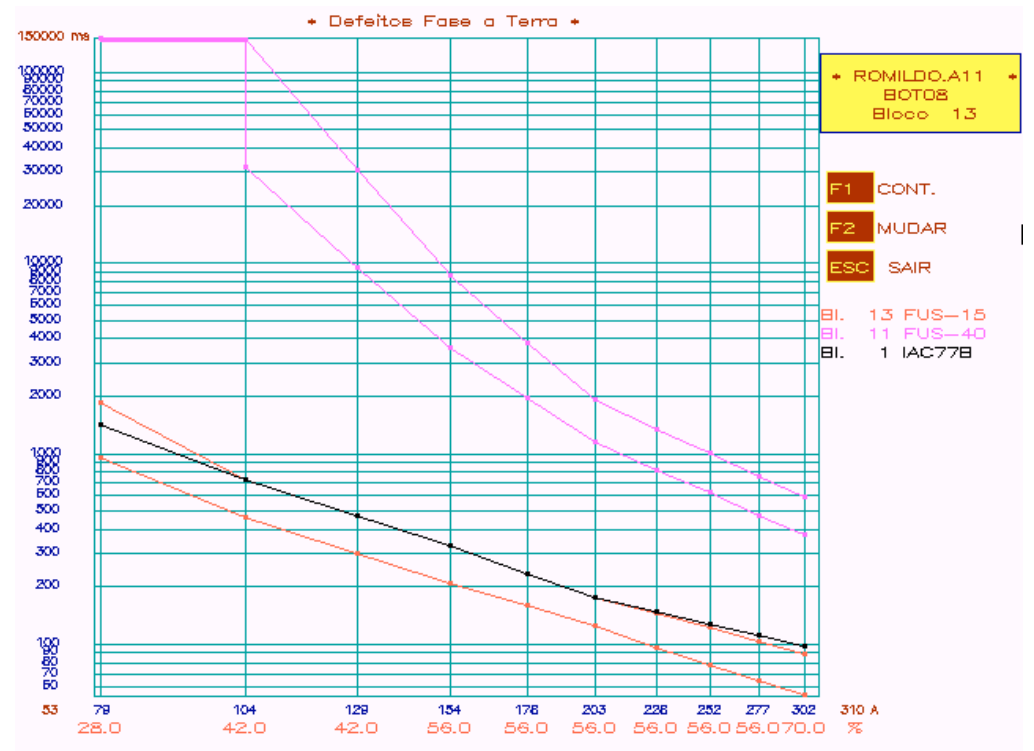

Figura 5.5 - Análise dos defeitos de terra para o bloco de carga 13

Já para os defeitos de fase, observa-se de acordo com a Figura 5.6 que para as correntes esperadas no intervalo de 1753 a 2020 A, existe um risco do elo fusível 40K fundir antes de haver a interrupção do arco do elo 15K. Para correntes maiores do que $2020 \mathrm{~A}$ (aproximadamente), haverá a atuação do relé antes da fusão dos elos fusíveis.

As soluções propostas visando eliminar o problema de descoordenação são análogas as apresentadas para os casos anteriores.

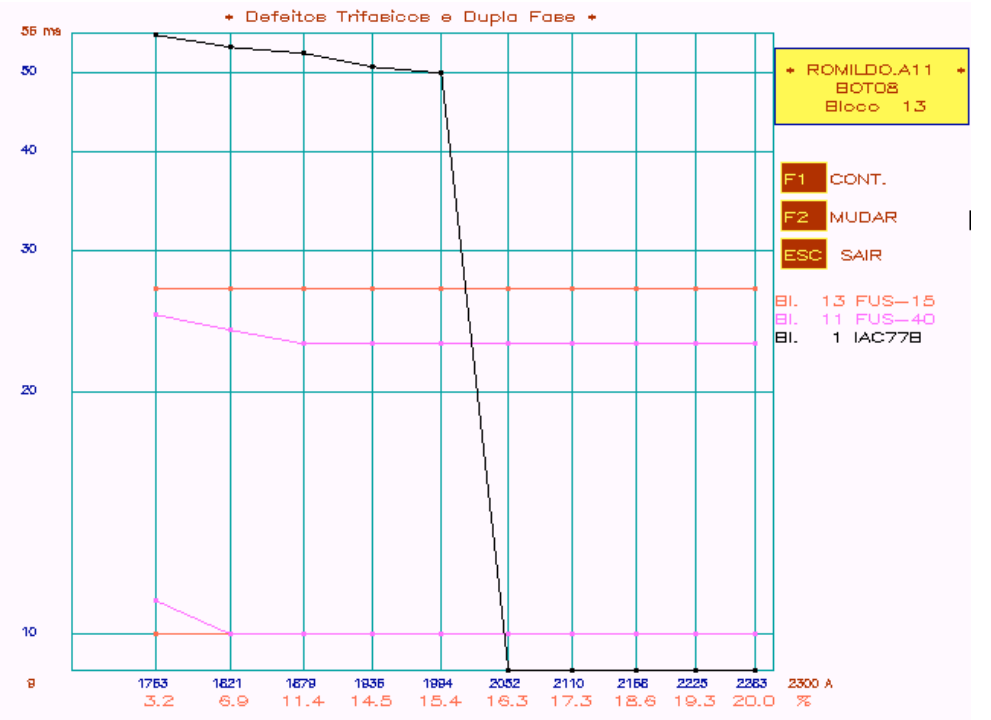

Figura 5.6 - Análise dos defeitos de fase para o bloco de carga 13 


\section{- Blocos de carga 12 e 10}

A análise e as conclusões são idênticas as apresentadas para os elos dos blocos 15 e 13, exceto que a coordenação entre o elo do bloco 10 e o relé da SE para os defeitos de fase ocorre para correntes de até no máximo 1970 A (aproximadamente).

\section{- Blocos de carga 11 e 8}

Neste caso, o problema a ser avaliado é a coordenação entre os elos fusíveis $40 \mathrm{~K}$ e $65 \mathrm{~K}$ e destes com o relé instalado na SE de distribuição.

Observa-se que existe coordenação entre os dois elos fusíveis para toda a faixa de correntes de defeito de fase e terra, esperadas do bloco 11.

Analisando a coordenação com o disjuntor da SE de distribuição, verifica-se que para os defeitos fase-terra a curva do relé fica abaixo das curvas dos elos fusíveis $40 \mathrm{~K}$ e $65 \mathrm{~K}$, indicando que existe descoordenação entre os dispositivos de proteção. A Figura 5.7 ilustra as condições acima descritas.

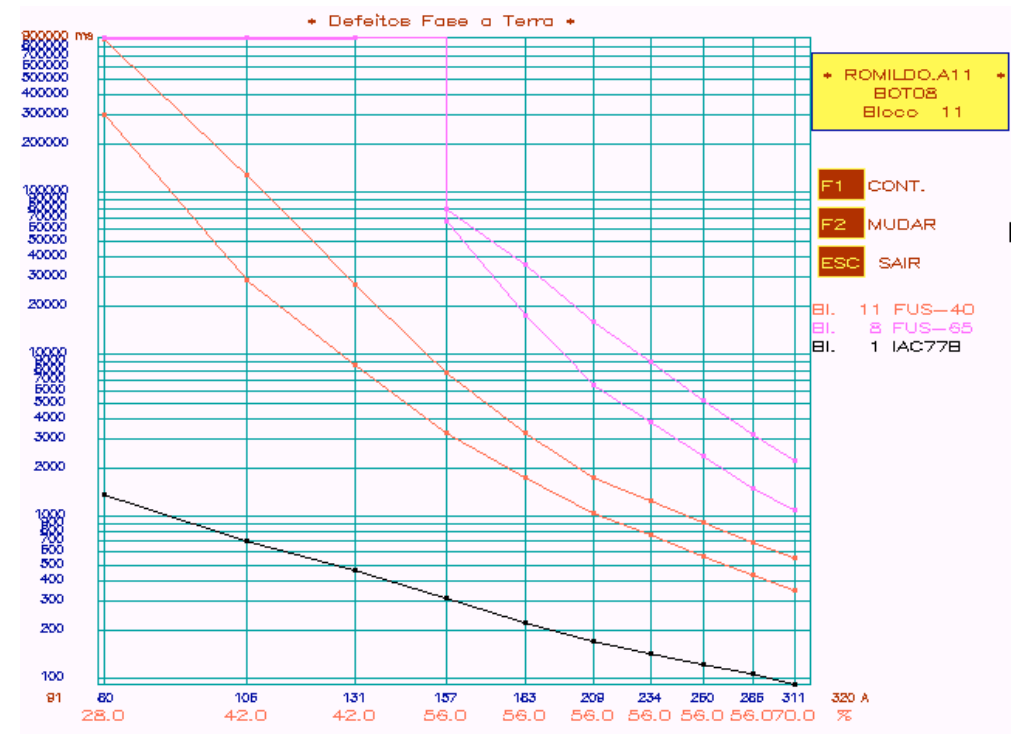

Figura 5.7 - Análise dos defeitos de terra para o bloco de carga 11 
Já para os defeitos de fase existe coordenação para correntes de até no máximo 2070 A (aproximadamente), conforme indicado na Figura 5.8.

Conclui-se neste caso que o ajuste das unidades de fase e terra do relé de proteção instalado na SE de distribuição deverá ser modificado para que haja coordenação entre este e o elo fusível.

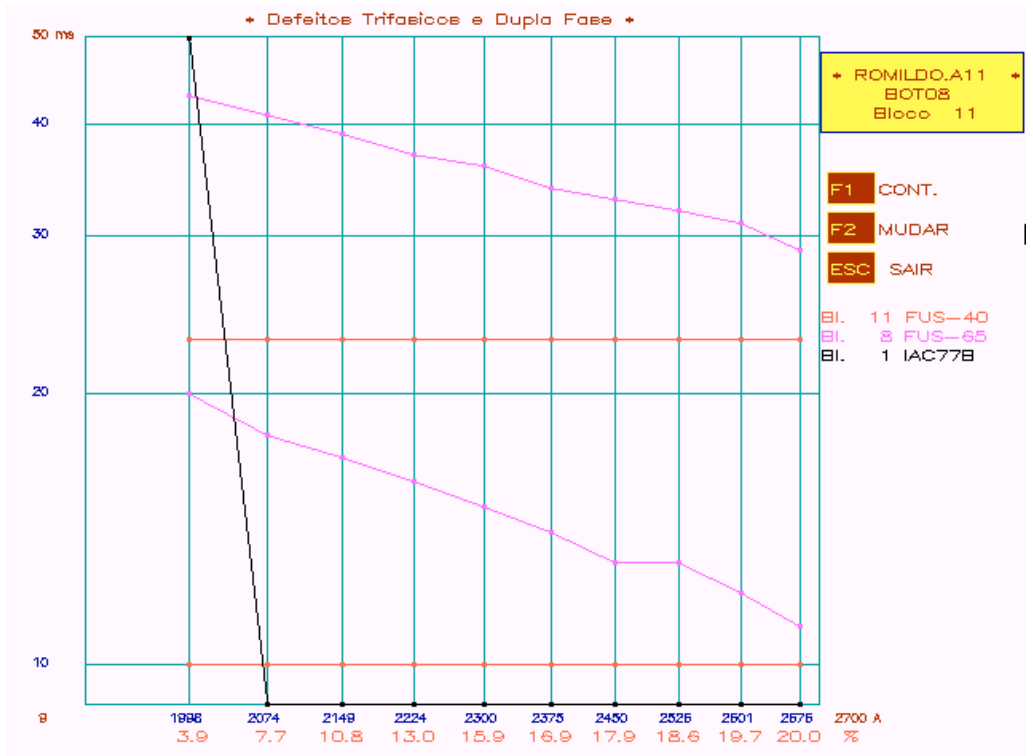

Figura 5.8 - Análise dos defeitos de fase para o bloco de carga 11

\section{- Blocos de carga 10 e 8}

Neste caso, o problema a ser avaliado é a coordenação entre os elos fusíveis $15 \mathrm{~K}$ e $65 \mathrm{~K}$ e destes com o relé instalado na SE de distribuição.

Observa-se que existe coordenação entre os dois elos fusíveis tanto para a faixa de correntes de defeito esperadas de fase quanto de terra no bloco 10.

No caso em estudo, observa-se que para os defeitos a terra no bloco de carga 10 a curva do relé fica em alguns pontos (faixa de 80 a 106 A) abaixo da curva de máxima interrupção do elo fusível 15K e em outros tangencia (faixa de 106 a 209 A). 
Já para os defeitos de fase, de acordo com a Figura 5.9, observa-se que ocorre a atuação do relé antes dos dois elos fusíveis, o que ocasionará a perda de todo o circuito na ocorrência de um defeito permanente a jusante do elo fusível instalado no bloco 10 , após o término da última tentativa de religamento.

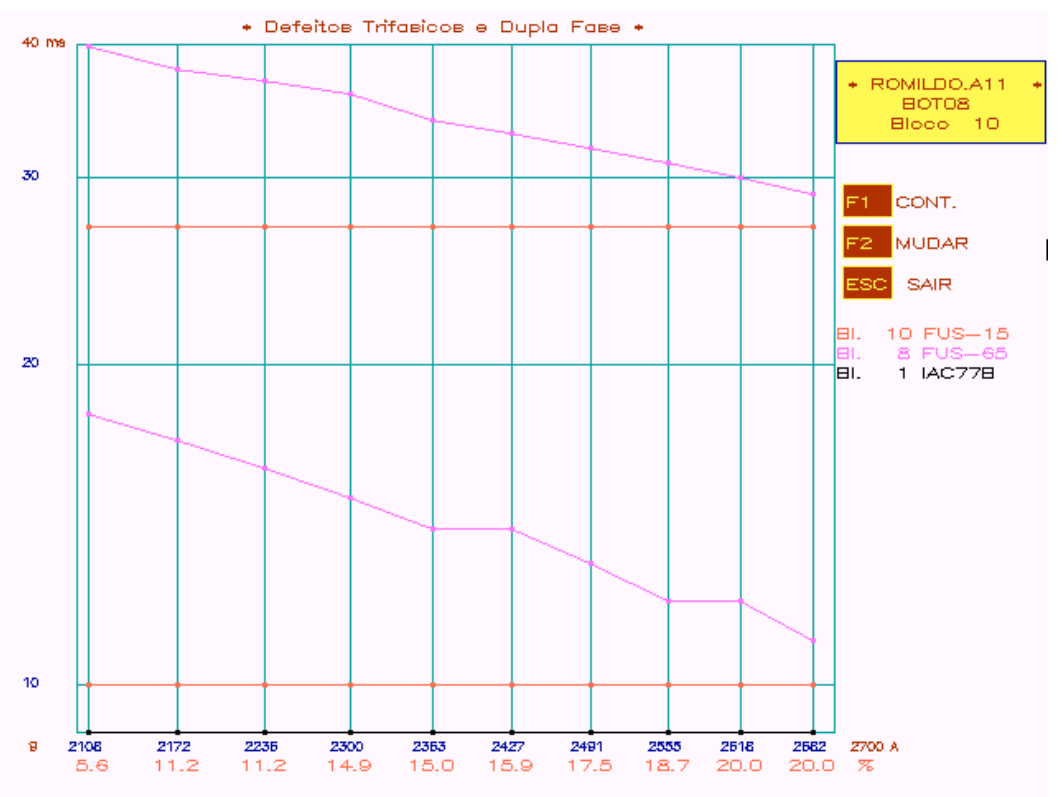

Figura 5.9 - Análise dos defeitos de fase para o bloco de carga 10

\section{- Blocos de carga 9 e 1}

Neste caso, o problema a ser avaliado é a coordenação entre o elo fusível $15 \mathrm{~K}$ instalado no início do bloco de carga 9, com o relé de proteção instalado na saída da SE de distribuição.

Para as correntes esperadas de defeito de terra no bloco 9, observa-se de acordo com a Figura 5.10 que a curva do relé fica em alguns pontos (faixa de 81 a 107 A) abaixo da curva de máxima interrupção do elo fusível 15K e em outros tangencia (faixa de 107 a $211 \mathrm{~A})$. 


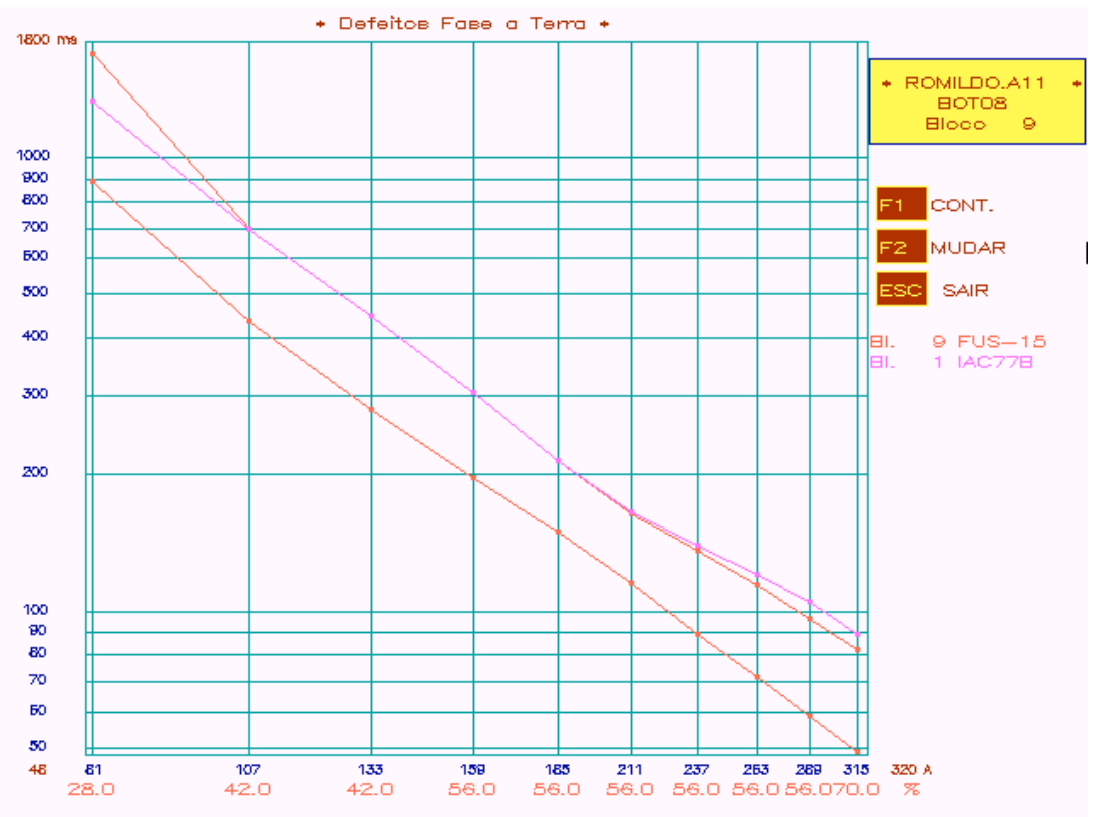

Figura 5.10 - Análise dos defeitos de terra para o bloco de carga 9

Já para toda a faixa de correntes esperadas de defeito de fase no bloco de carga 9 (de 2254 a 2792 A), a curva do relé está abaixo das curvas do elo fusível e cabe aqui o mesmo comentário feito para os elos dos blocos 10 e 8 .

\section{- Blocos de carga 8 e 1}

Neste caso, o problema a ser avaliado é a coordenação entre o elo fusível $65 \mathrm{~K}$ instalado no início do bloco de carga 8 e o relé de proteção instalado na SE de distribuição.

Observa-se que tanto para a faixa de correntes de defeito esperadas de fase e terra no bloco 8, o relé de proteção atua antes do elo fusível. Para os defeitos ocorridos a jusante do elo $65 \mathrm{~K}$ haverá primeiramente a atuação do relé e na seqüência a rede é religada via relé de religamento, conforme a seqüência pré-definida. Caso o defeito seja temporário, a rede é restabelecida normalmente sem ocorrer à fusão do elo fusível, mas se o defeito for permanente haverá a abertura do disjuntor da SE e toda a rede ficará desenergizada.

A Figura 5.11 ilustra a coordenação do elo fusível $65 \mathrm{~K}$ com o relé instalado na saída da SE de distribuição, para a faixa de correntes esperadas de terra no bloco de carga 8, enquanto que a Figura 5.12 ilustra o mesmo processo, porém para as correntes de fase. 


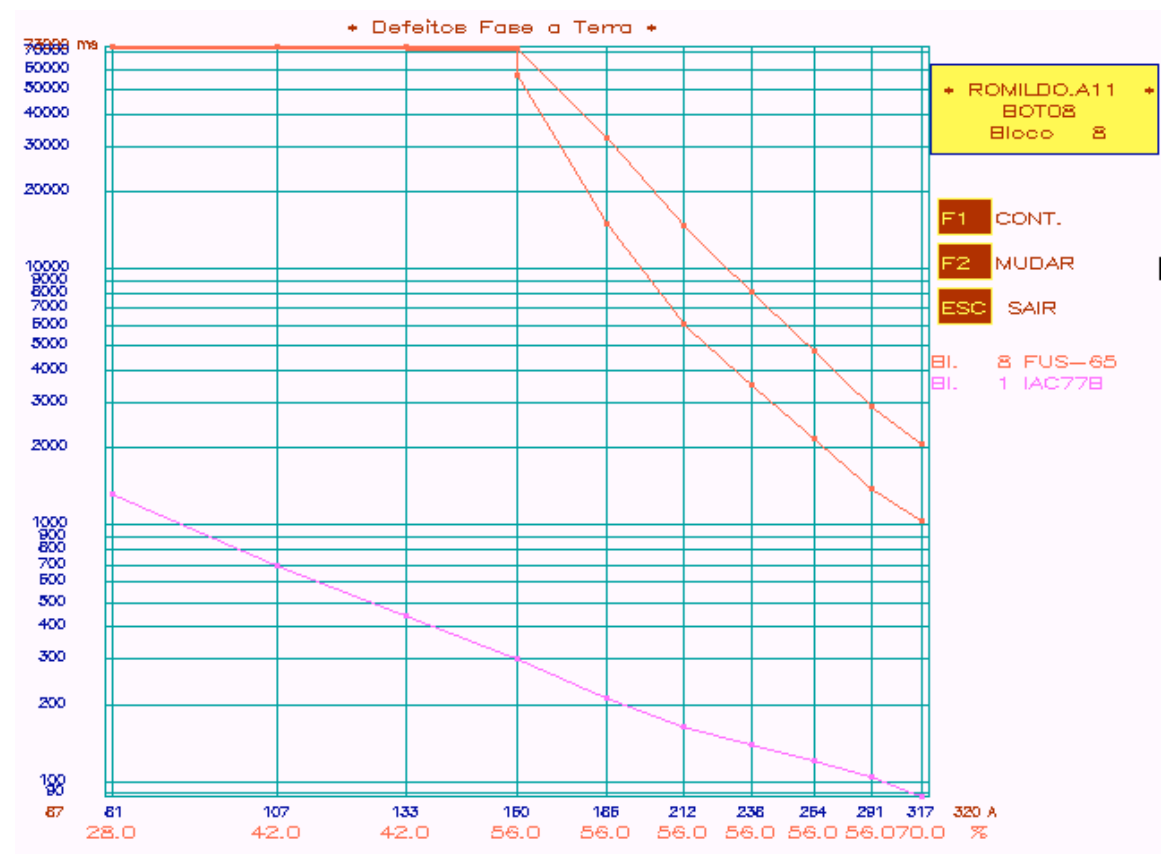

Figura 5.11 - Análise dos defeitos de terra para o bloco de carga 8

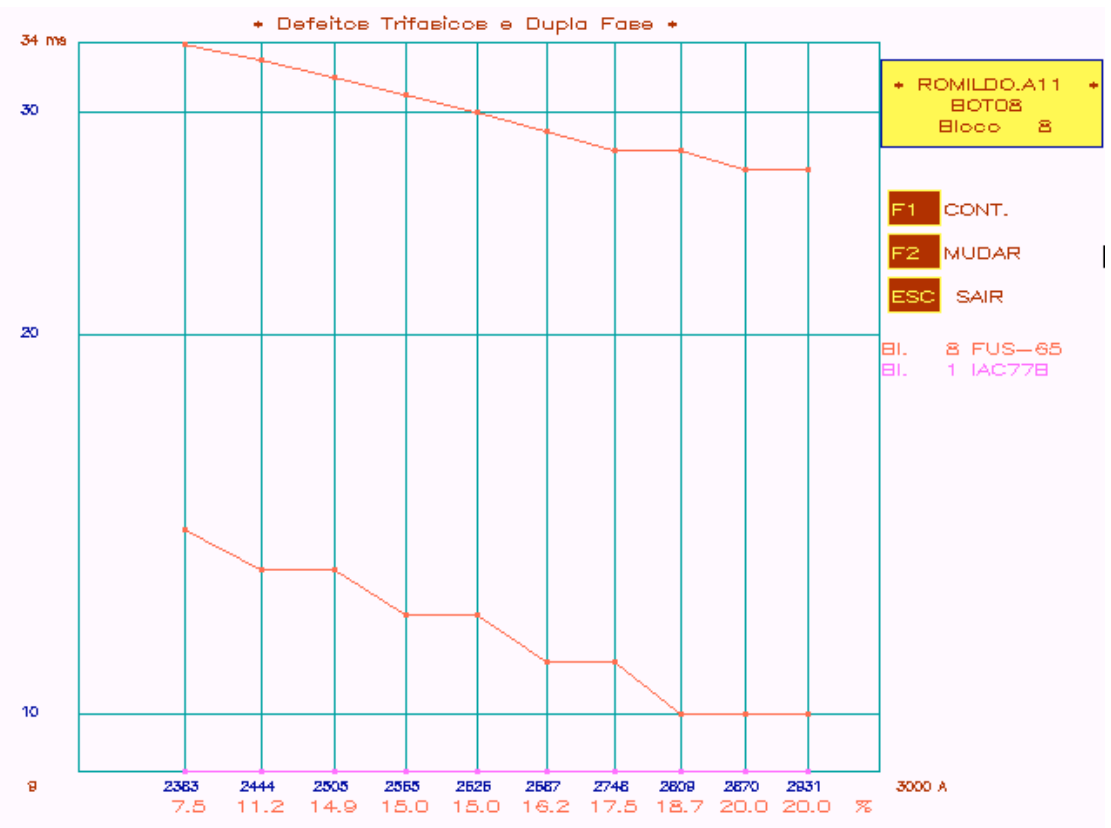

Figura 5.12 - Análise dos defeitos de fase para o bloco de carga 8 


\section{- Blocos de carga 7 e 1}

Este caso é similar ao estudado para os blocos de carga 9 e 1, exceto que a faixa das correntes esperadas de defeito de fase vai de 2251 a 2888 A.

\section{- Blocos de carga 6 e 1}

A análise a ser feita neste caso é a coordenação entre um elo fusível $25 \mathrm{~K}$ instalado no bloco de carga 6 com o relé instalado na saída da SE de distribuição.

De acordo com a Figura 5.13, observa-se que para toda a faixa de correntes de defeito esperadas de terra no bloco de carga 6 , o relé de proteção atua antes do elo fusível. Para os defeitos temporários em trechos situados a jusante do elo fusível 6 isto é bom devido ao fato de não haver a fusão do mesmo desnecessariamente. Já para os defeitos permanentes em trechos a jusante do elo fusível 6 isto é ruim, pois haverá a atuação permanente do disjuntor após serem esgotadas todas as tentativas de religamento e, portanto, todo o circuito ficará desenergizado.

Para as correntes de defeito esperadas de fase no bloco de carga 6 , observa-se através da Figura 5.14, que sempre haverá a atuação do disjuntor antes do elo fusível, seja o defeito temporário ou permanente.

Nestas condições será necessário modificar os ajustes do relé de proteção do disjuntor ou substitui-lo por um outro dispositivo de proteção que apresente melhores resultados de coordenação. 


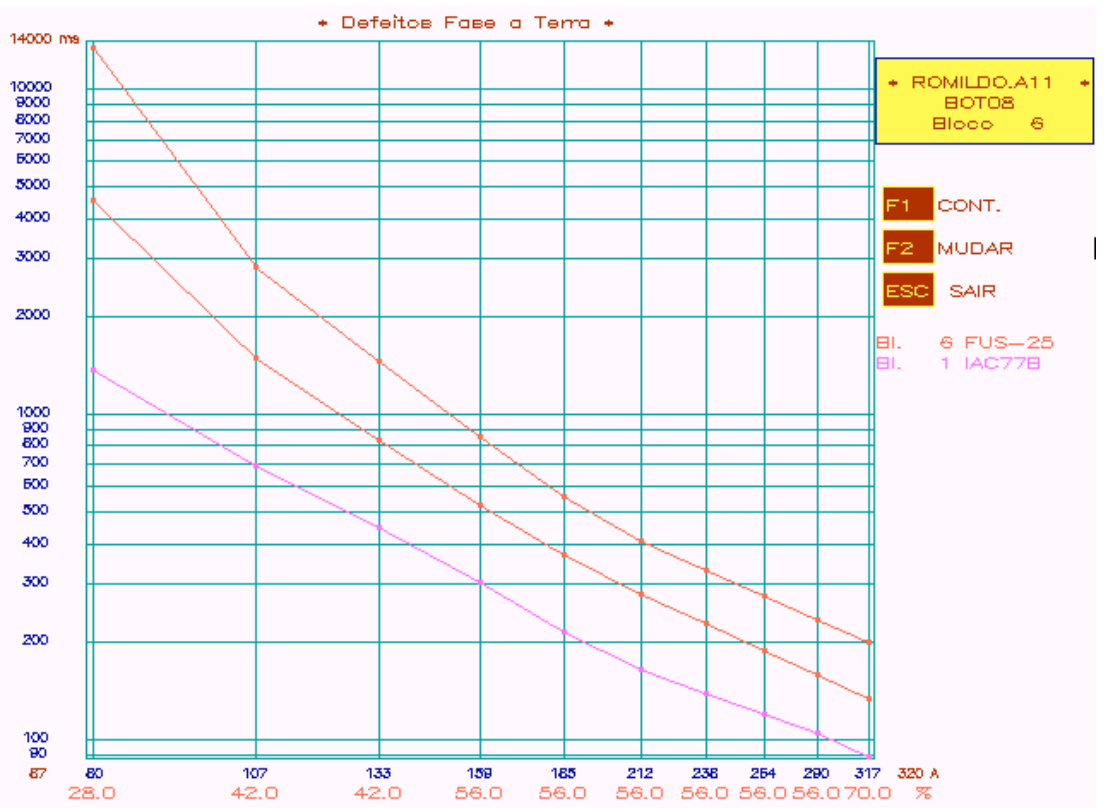

Figura 5.13 - Análise dos defeitos de terra para o bloco de carga 6

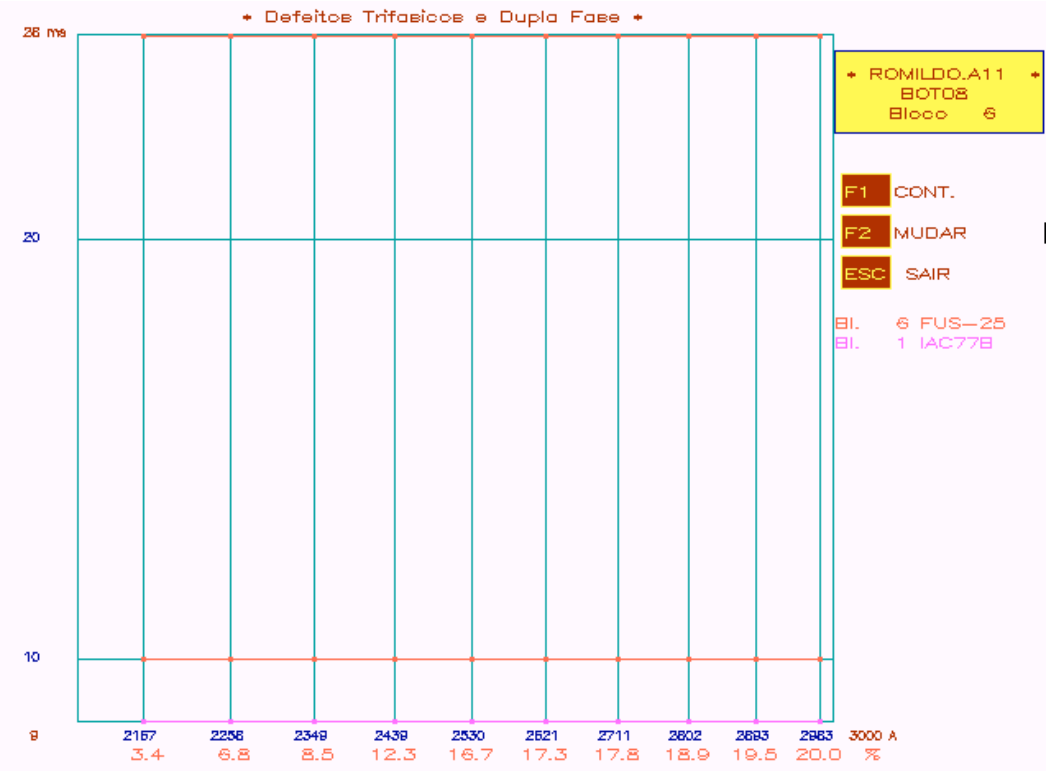

Figura 5.14 - Análise dos defeitos de fase para o bloco de carga 6

\section{- Blocos de carga 5 e 1}

Neste caso, o problema a ser avaliado é a coordenação entre o elo fusível 10K instalado no início do bloco de carga 5 e o relé de proteção instalado na SE de distribuição. 
Os comentários são similares aos apresentados para o estudo dos blocos de carga 6 e 1, exceto que a faixa das correntes de defeito esperadas de terra para o bloco de carga 6 varia de 81 a $318 \mathrm{~A}$, e a faixa para as correntes de defeito esperadas de fase para este mesmo bloco varia de 2533 a 3084 A.

\section{- Blocos de carga 4 e 1}

Este caso é similar ao estudado para os blocos de carga 5 e 1, exceto que a faixa de correntes de defeito de terra esperadas para o bloco de carga 5 varia de 81 a 317 A e a faixa das correntes de defeito de fase esperadas para este mesmo bloco varia de 2863 a 3305 A.

\section{- Blocos de carga 3 e 1}

Este caso é similar ao estudado para os blocos de carga 9 e 1, exceto que para as correntes esperadas de defeito de terra no bloco 3, observa-se que a curva do relé fica em alguns pontos (faixa de 81 a 106 A) abaixo da curva de máxima interrupção do elo fusível $15 \mathrm{~K}$ e em outros tangencia (faixa de 106 a 215 A).

Já para toda a faixa de correntes esperadas de defeito de fase no bloco de carga 3 (de 2758 a 3932 A), a curva do relé está abaixo das curvas do elo fusível e cabe aqui o mesmo comentário feito para os elos dos blocos 10 e 8 .

\section{- Blocos de carga 2 e 1}

Este caso é similar ao estudado para os blocos de carga 5 e 1, exceto que a faixa de correntes de defeito de terra esperadas para o bloco de carga 2 varia de 81 a $325 \mathrm{~A}$ e a faixa das correntes de defeito de fase esperadas para este mesmo bloco varia de 3291 a 4073 A. 
Com base nos resultados apresentados, observa-se que os elos fusíveis coordenam entre si, porém em alguns casos o relé da SE de distribuição atua definitivamente antes dos elos fusíveis para defeitos na zona de proteção primária destes últimos.

Concluiu-se em alguns casos que na ocorrência de um defeito temporário a solução apresentada é satisfatória, porém para os defeitos permanentes, observa-se que ela não é tão satisfatória, e conseqüentemente o sistema não será seletivo no ponto de vista da proteção. Para exemplificar esta condição, considerar a análise feita para os blocos de carga 11 e 8 em conjunto com o relé da SE, onde a curva deste último para os defeitos de terra se encontra abaixo das curvas dos dois elos fusíveis. Para defeitos temporários em trechos do bloco 11, o disjuntor atua antes do elo 11 e executa o restabelecimento da rede dentro da seqüência de religamento ajustada. Para os defeitos permanentes não haverá a fusão do elo fusível e, conseqüentemente, diversas cargas que nada tem a ver com o problema ocorrido, serão desnecessariamente desligadas.

Para resolver este problema foram executados diversos testes contendo configurações distintas de dispositivos de proteção na rede elétrica em estudo. A versão mais adequada que apresentou resultados satisfatórios consistiu na instalação de um religador na saída da SE de distribuição (início do bloco 1) no lugar do disjuntor com religamento e de uma seccionalizadora no início do bloco 8 no lugar do elo fusível $65 \mathrm{~K}$. Os ajustes dos novos dispositivos de proteção bem como as avaliações da coordenação entre eles serão avaliadas conforme segue:

\section{- Ajustes do religador instalado no início do bloco 1}

Os ajustes efetuados para o religador foram os seguintes:

Corrente de atuação da bobina de fase: $\quad 200$ A

Número de ciclos de religamento: $\quad 4$

Curvas escolhidas da unidade de fase: $\quad$ A, B, C e C (Conforme Anexo B)

Corrente de atuação da bobina de terra: $\quad 35 \mathrm{~A}$

Curvas escolhidas da unidade de terra: $\quad$ 1, 2, 9 e 9 (Conforme Anexo B)

Tempo morto do $1^{\circ}$ ciclo de religamento: $5000 \mathrm{~ms}$ 
Tempo morto do $2^{\circ}$ ciclo de religamento: $5000 \mathrm{~ms}$

Tempo morto do $3^{\circ}$ ciclo de religamento: $5000 \mathrm{~ms}$

\section{- Ajustes do seccionalizador instalado no início do bloco 8}

Os ajustes efetuados para o seccionalizador são:

Corrente de atuação da unidade de fase: 160 A

Número de ciclos: 3

Corrente de atuação da unidade de terra: $28 \mathrm{~A}$

O ajuste da corrente de atuação das unidades de fase e terra é igual a $80 \%$ do ajuste efetuado para o religador. O número de ciclos ajustado no seccionalizador é igual ao número de ciclos ajustado no religador menos 1 .

\subsection{4 - Novo estudo de coordenação}

Com base nas mudanças propostas para substituir o disjuntor com relé de religamento no início do bloco de carga 1 por um religador e também instalar um seccionalizador no início do bloco 8, segue uma análise resumida da coordenação entre os mesmos.

\section{- Blocos de carga 15 e 13}

Os elos fusíveis $10 \mathrm{~K}$ e $15 \mathrm{~K}$ estão coordenados para toda a faixa das correntes de defeito esperadas de fase e terra no bloco de carga 15.

Quanto à coordenação com o religador, observa-se de acordo com a Figura 5.15 que para as correntes de defeito de terra esperadas no bloco de carga 15 acima de $237 \mathrm{~A}$, existe uma possibilidade de fusão do elo 10K (instalado no início do bloco de carga 15) antes da atuação do religador. Para os demais valores da corrente de terra, ocorrerá a fusão do referido elo fusível após a operação da segunda curva rápida do religador. 


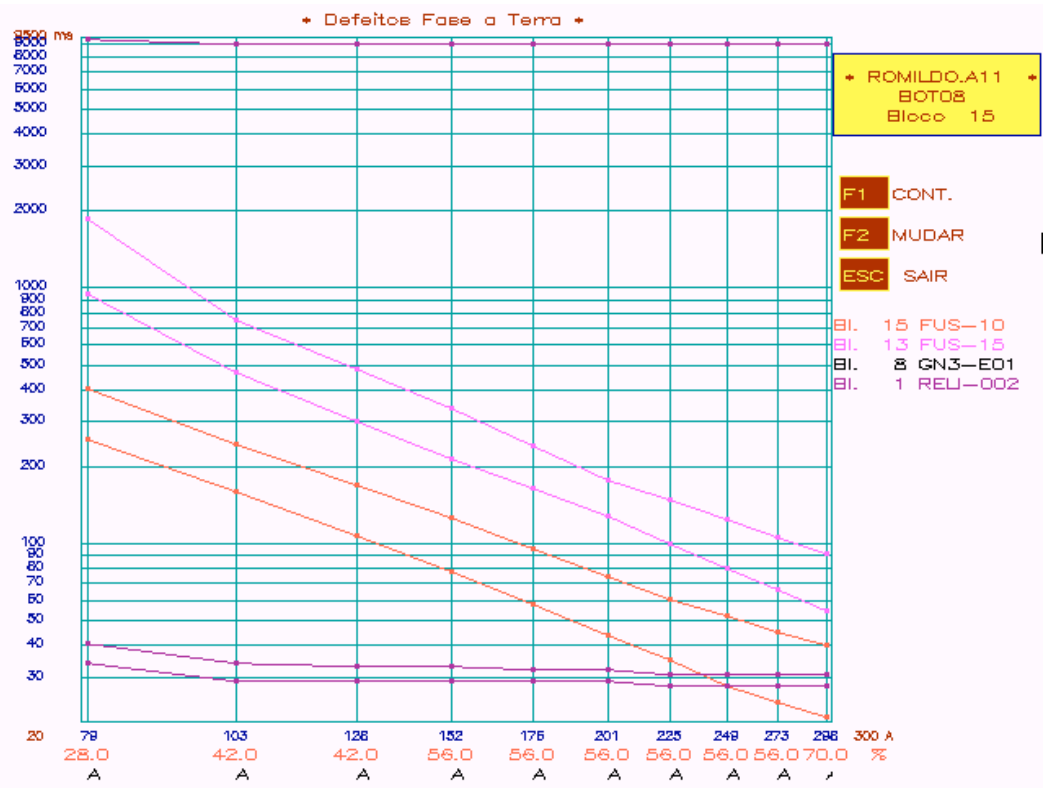

Figura 5.15 - Estudo dos defeitos de terra para o bloco de carga 15

Para as correntes de defeito de fase esperadas no bloco de carga 15 , de acordo com a Figura 5.16, sempre ocorrerá a fusão do respectivo elo fusível quer seja o defeito temporário ou permanente, uma vez que as curvas rápidas e lentas do religador se encontram acima da curva do elo fusível. As curvas do religador para os defeitos de fase também se encontram acima das curvas do elo a montante (15K do bloco de carga 13).

Foram realizadas diversas simulações com outros religadores visando contornar este problema de coordenação, porém em nenhuma delas encontrou-se uma solução melhor do que a apresentada. Por outro lado, a corrente de carga no bloco em questão no horizonte de 5 anos é nula, e portanto, o fato de haver a atuação do elo fusível antes do religador para os defeitos de fase não é um problema.

As probabilidades de não coordenação serão objeto do próximo item do presente capítulo. 


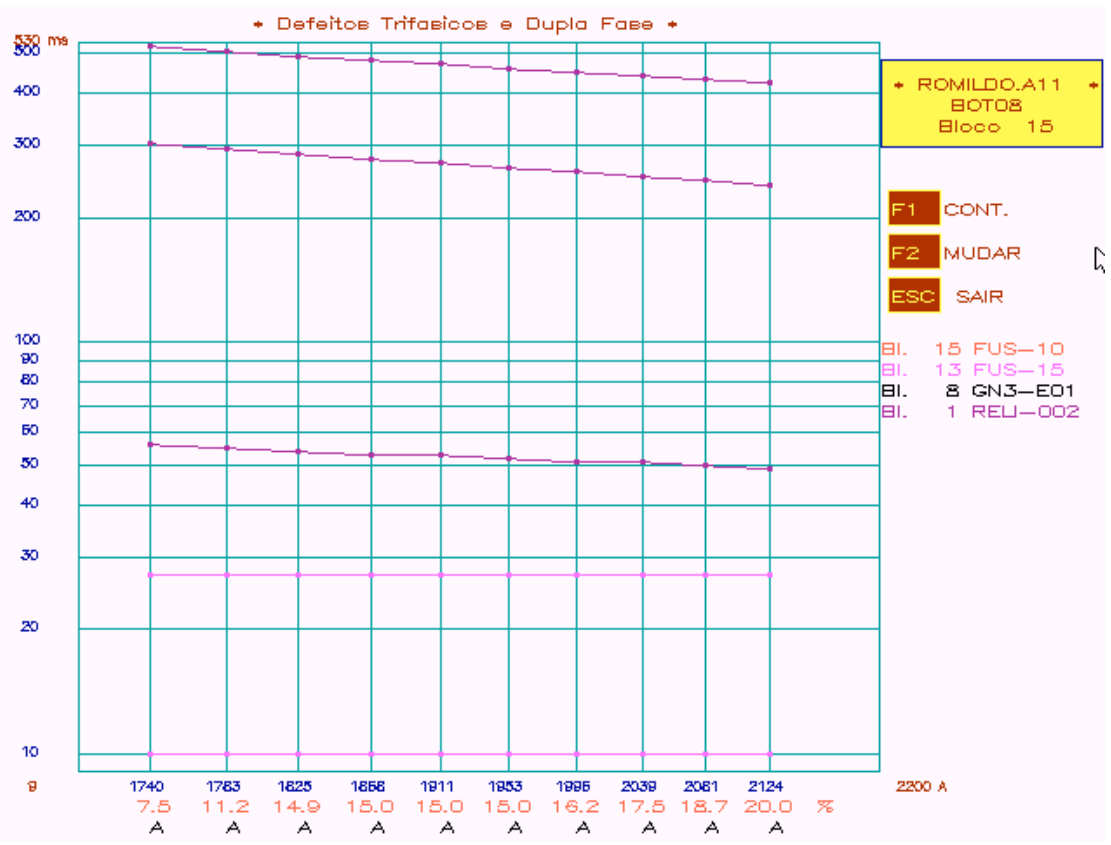

Figura 5.16 - Estudo dos defeitos de fase para o bloco de carga 15

\section{- Blocos de carga 14 e 13}

As análises e conclusões são similares ao caso anterior (blocos de carga 15 e 13), exceto que a faixa das correntes de defeito esperadas de fase vai de 1775 a 2202 A e a de terra vai de 79 a 300 A. Estes intervalos correspondem ao bloco de carga 14.

\section{- Blocos de carga 13 e 11}

Os elos fusíveis estão coordenados para as correntes esperadas de fase e terra no bloco de carga 13.

Quanto à coordenação com o religador, observa-se de acordo com a Figura 5.17 que para toda a faixa das correntes de defeito de terra esperadas no bloco de carga 13, ocorrerá a fusão do elo fusível 15K (instalado no início do bloco de carga 13) após a operação da segunda curva rápida do religador. 


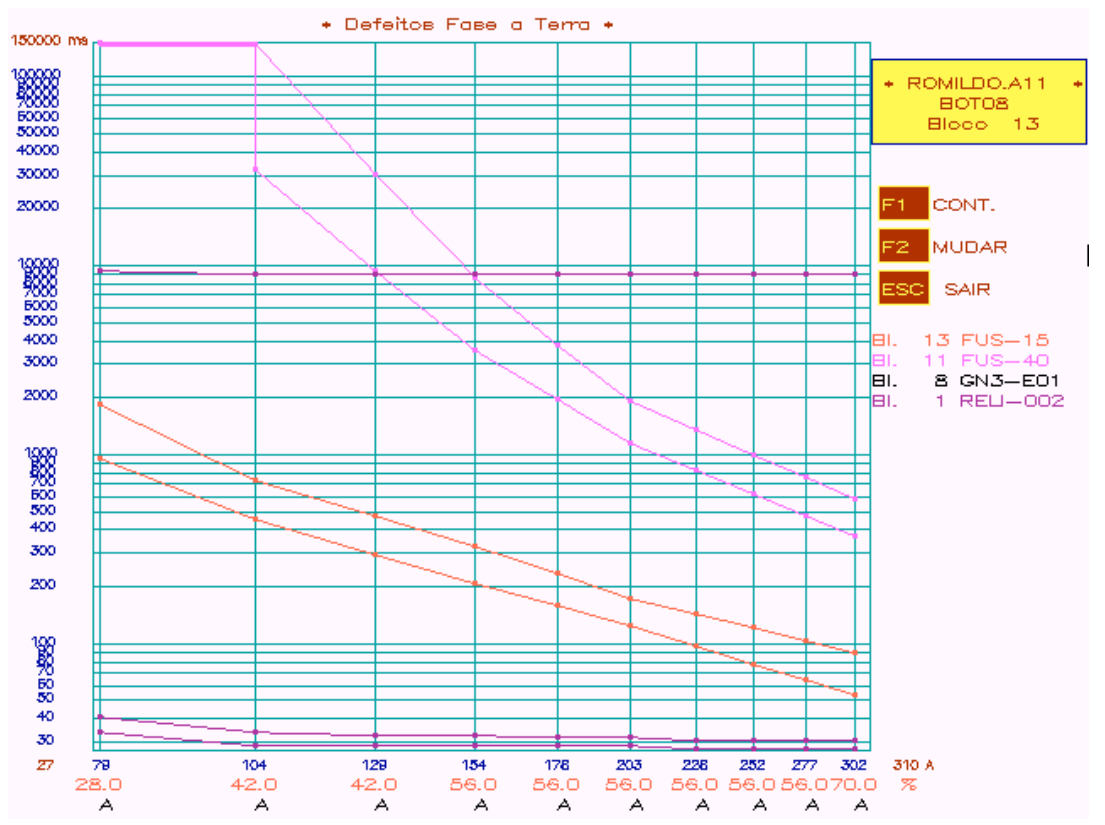

Figura 5.17 - Estudo dos defeitos de terra para o bloco de carga 13

Para toda a faixa das correntes de defeito de fase esperadas no bloco de carga 13, observa-se através da Figura 5.18 que sempre ocorrerá a fusão do respectivo elo fusível quer seja o defeito temporário ou permanente, uma vez que as curvas rápidas e lentas do religador se encontram acima da curva do elo fusível. As curvas do religador para os defeitos de fase também se encontram acima das curvas do elo a montante (40K do bloco de carga 13). Também observa-se através desta mesma figura que a curva de máxima interrupção do elo fusível $15 \mathrm{~K}$ encontra-se acima da curva de mínima fusão do elo fusível 40K, havendo, portanto, descoordenação. 


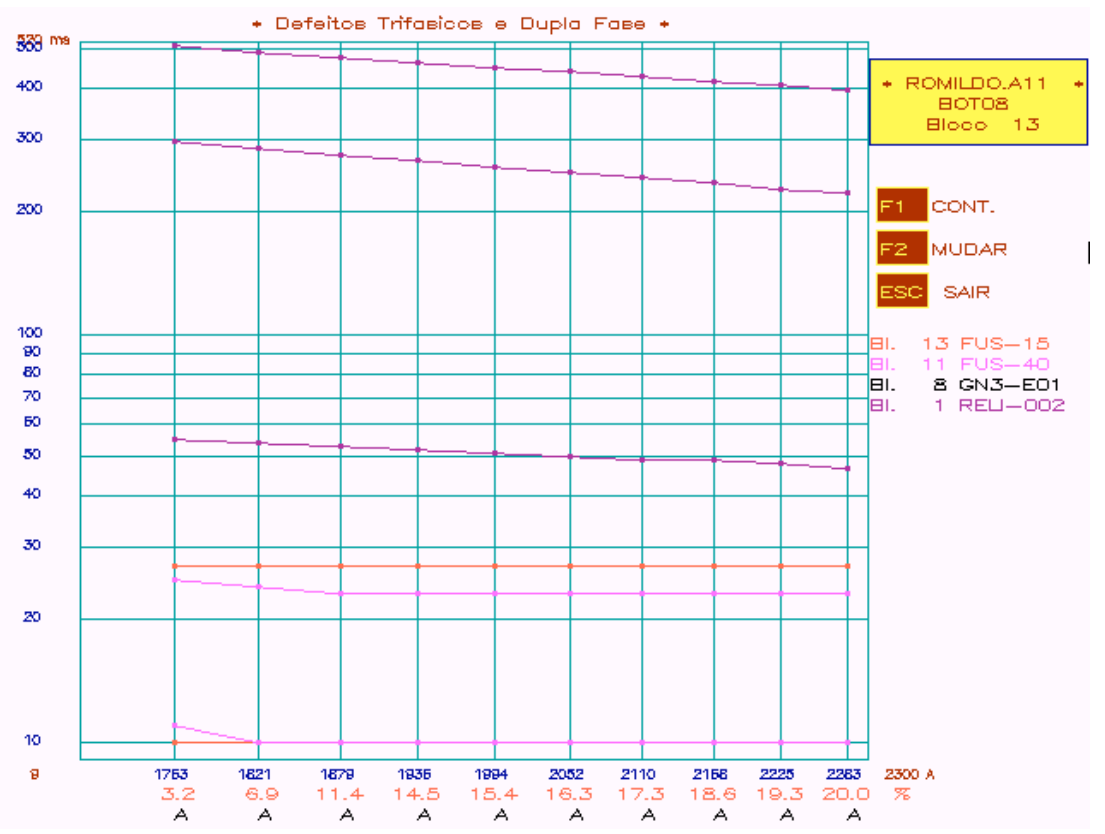

Figura 5.18 - Estudo dos defeitos de fase para o bloco de carga 13

\section{- Blocos de carga 12 e 10}

As análises e conclusões são similares as apresentadas para os blocos de carga 15-13 e 14-13, exceto que a faixa das correntes de defeito esperadas de fase varia de 1741 a 2361 A e a de terra vai de 79 a 303 A. Estes intervalos correspondem ao bloco de carga 12.

Observa-se neste caso diferentemente dos blocos de carga 14 e 15, que a corrente de carga no horizonte de estudo não é nula e, portanto, para defeitos temporários de fase no bloco 12, as suas respectivas cargas serão desligadas em decorrência da fusão do elo fusível 10K.

\section{- Blocos de carga 11 e 8}

Neste caso, existe um elo fusível $40 \mathrm{~K}$ instalado no início do bloco 11 e um seccionalizador instalado no início do bloco 8.

Quanto à coordenação do elo $40 \mathrm{~K}$ com o religador, observa-se de acordo com a Figura 5.19 que para os valores das correntes de terra esperadas no bloco de carga 11 no 
intervalo de 80 a 131 A, existe uma possibilidade de abertura do seccionalizador após a terceira operação do religador (primeira lenta). Isto se justifica devido ao fato de neste intervalo a curva do elo fusível $40 \mathrm{~K}$ estar acima da primeira curva lenta do religador e, portanto, após a operação desta, o seccionalizador registrará a sua terceira e última contagem, provocando assim a abertura de todos os blocos de carga instalados a sua jusante. No intervalo de 131 a 155 A, a primeira curva lenta do religador está acima da curva de mínima fusão do elo fusível, porém abaixo da sua curva de máxima interrupção. Assim sendo, para este intervalo também existe um risco do seccionalizador abrir, caso o elo não interrompa a corrente e extinga o arco, antes da atuação da primeira curva lenta do religador.

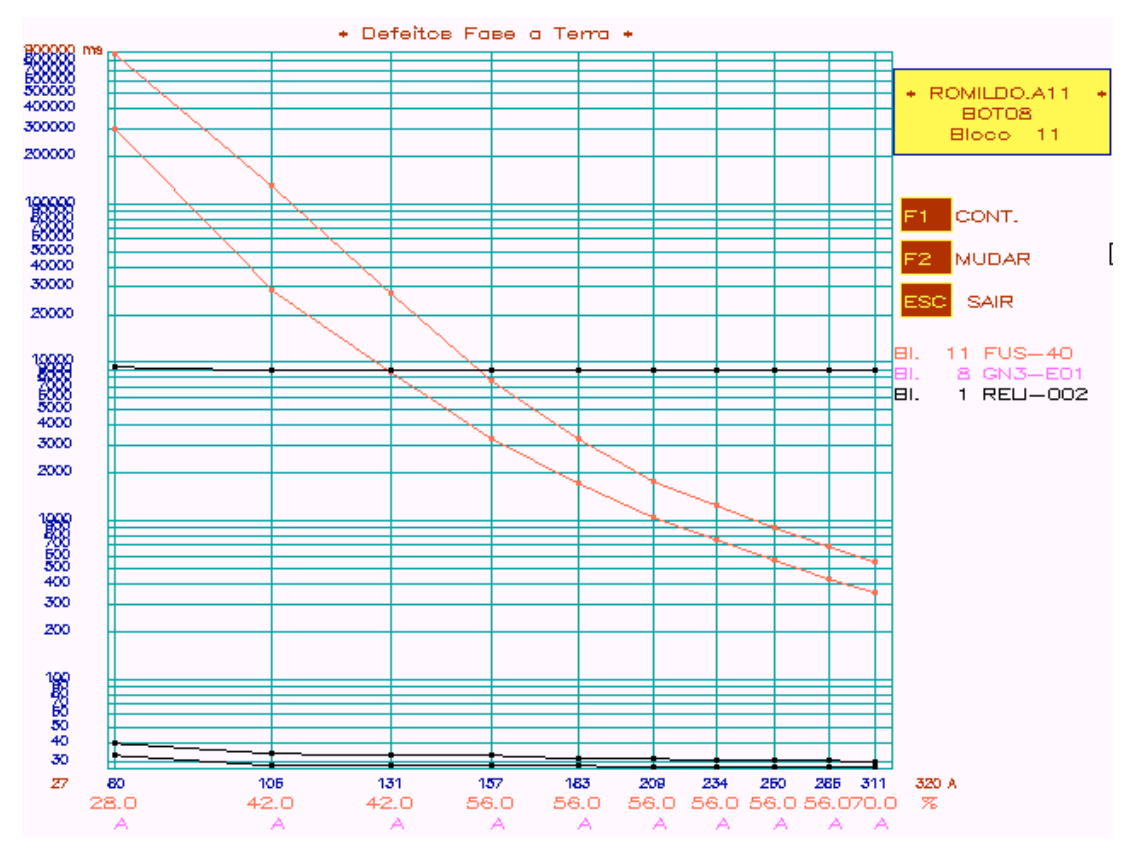

Figura 5.19 - Estudo dos defeitos de terra para o bloco de carga 11

Para as correntes de defeito de fase esperadas no bloco de carga 11, sempre ocorrerá a fusão do respectivo elo fusível quer seja o defeito temporário ou permanente, uma vez que as curvas rápidas e lentas do religador se encontram acima da curva do elo fusível.

As probabilidades de não coordenação serão objeto do próximo item do presente capítulo. 


\section{- Blocos de carga 10 e 8}

Neste caso, existe um elo fusível $15 \mathrm{~K}$ instalado no início do bloco 10 e um seccionalizador instalado no início do bloco 8 .

Quanto à coordenação com o religador, observa-se através da Figura 5.20 que para toda a faixa das correntes de defeito de terra esperadas no bloco de carga 10, ocorrerá a fusão do elo fusível 15K (instalado no início do bloco de carga 10) após a operação da segunda curva rápida do religador.

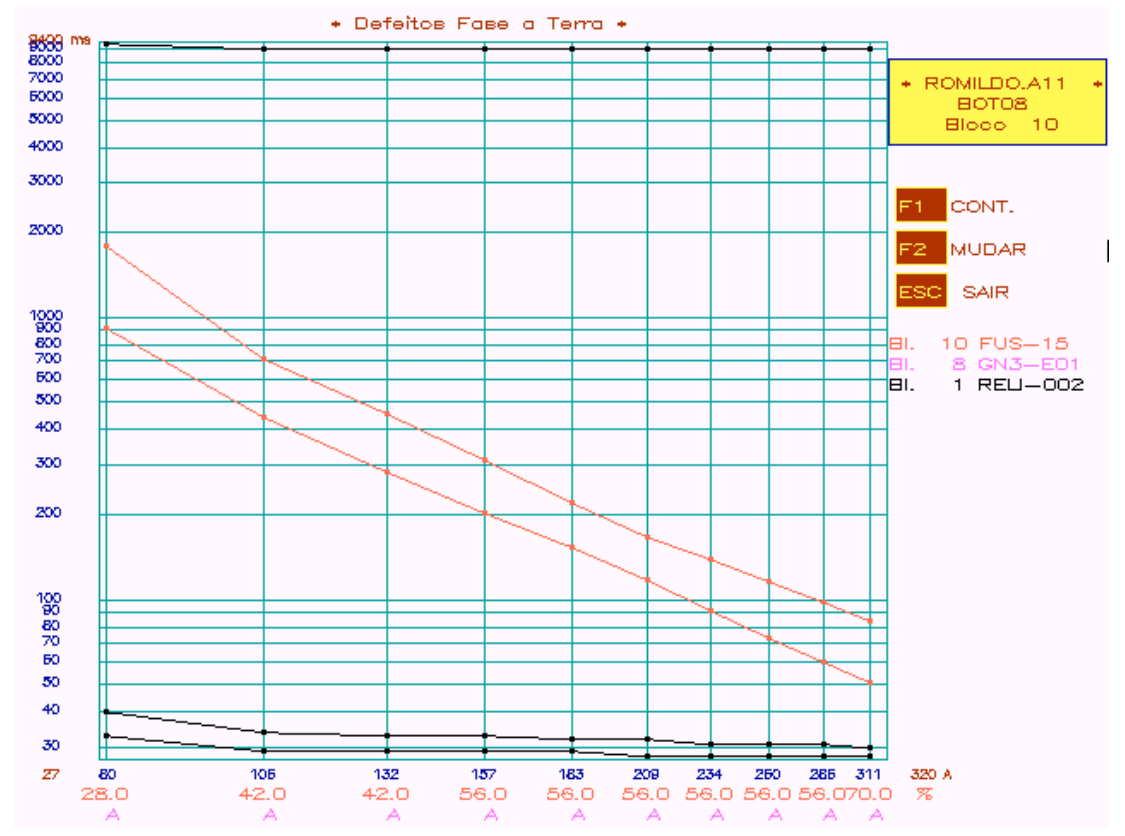

Figura 5.20 - Estudo dos defeitos de terra para o bloco de carga 10

Para toda a faixa das correntes de defeito de fase esperadas no bloco de carga 10 , sempre ocorrerá a fusão do respectivo elo fusível quer seja o defeito temporário ou permanente, uma vez que as curvas rápidas e lentas do religador se encontram acima da curva do elo fusível. 


\section{- Blocos de carga 9 e 1}

Neste caso, existe um elo fusível $15 \mathrm{~K}$ instalado no início do bloco 9 e um religador instalado no início do bloco 1 (saída da SE de distribuição).

Quanto à coordenação com o religador, observa-se com base na Figura 5.21 que para toda a faixa das correntes de defeito de terra esperadas no bloco de carga 9, ocorrerá a fusão do elo fusível 15K instalado no início deste (bloco de carga 9) após a operação da segunda curva rápida do religador.

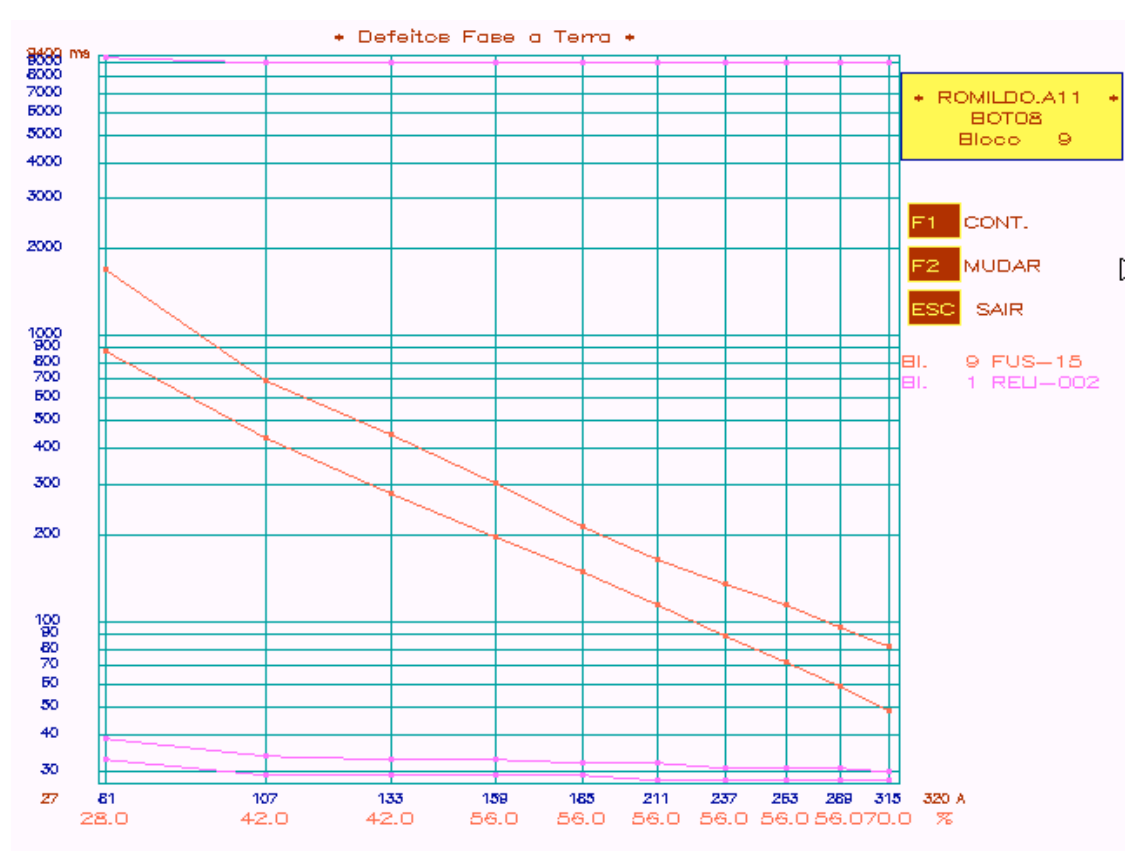

Figura 5.21 - Estudo dos defeitos de terra para o bloco de carga 9

Para toda a faixa das correntes de defeito de fase esperadas no bloco de carga 9 são válidos os mesmos comentários ilustrados para os blocos 10 e 8 .

\section{- Blocos de carga 8 e 1}

Neste caso, existe no início do bloco de carga 8 um seccionalizador e no início do bloco 1 , um religador. 
Para as correntes esperadas de fase e de terra no bloco de carga 8, ocorrerá as 2 operações rápidas do religador. Caso após a ocorrência das mesmas, os defeitos de fase ou de terra ainda estejam presentes em algum ponto do bloco em estudo, o religador irá atuar em sua primeira operação lenta e após isto, o seccionalizador registrará a sua terceira e última contagem abrindo, portanto, todos os trechos de rede instalados a jusante do dispositivo de proteção instalado no início do bloco de carga 8 .

\section{- Blocos de carga 7 e 1}

As análises e conclusões são similares as apresentadas para os blocos de carga 10 e 8 , exceto que a faixa das correntes de defeito esperadas de fase vai de 2251 a 2888 A e a de terra vai de 81 a 317 A. Estes intervalos correspondem ao bloco de carga 7.

\section{- Blocos de carga 6 e 1}

Neste caso, existe no início do bloco de carga 6 um elo fusível $25 \mathrm{~K}$ e no início do bloco 1 , um religador.

Para a faixa das correntes de defeito esperadas de terra no bloco de carga 6 conforme a Figura 5.22, observa-se que no intervalo de 80 a $87 \mathrm{~A}$, a primeira curva lenta do religador está acima da curva de mínima fusão do elo fusível, mas abaixo da sua curva de máxima interrupção. Nestas condições, existe o risco do elo fusível fundir após o restabelecimento do circuito através da última tentativa de religamento.

Para resolver este problema as curvas de atuação da unidade de terra serão modificadas para 1,2,9,10, e isto não prejudicará a coordenação do religador com os demais dispositivos de proteção instalados na rede elétrica em estudo. 


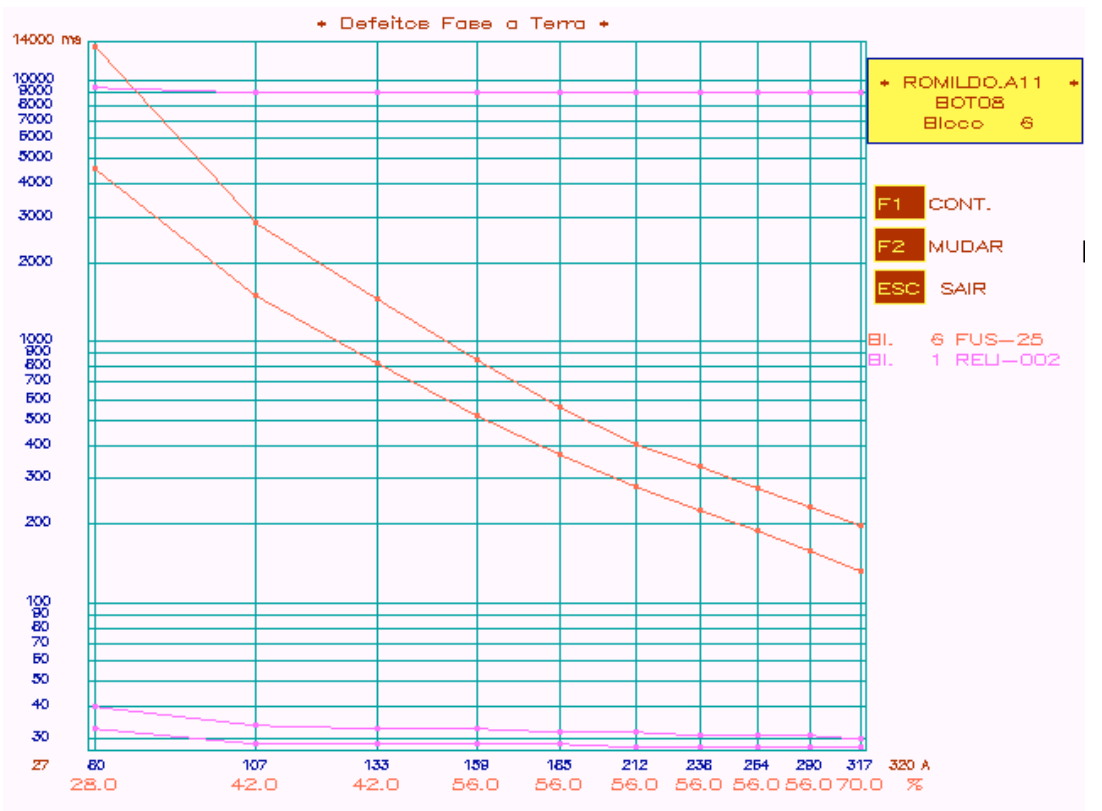

Figura 5.22 - Estudo dos defeitos de terra para o bloco de carga 6

Para toda a faixa das correntes de defeito de fase esperadas no bloco de carga 6 são válidos os mesmos comentários ilustrados para os blocos 9 e 1.

\section{- Blocos de carga 5 e 1}

Neste caso, existe no início do bloco de carga 5 um elo fusível $10 \mathrm{~K}$ e no início do bloco 1 , um religador.

De acordo com a Figura 5.23, para a faixa das correntes de defeito esperadas de terra maiores do que $237 \mathrm{~A}$, ocorre a fusão do elo fusível antes da atuação do religador. Assim, para esta faixa, mesmo que o defeito seja temporário haverá a fusão do elo fusível.

Para toda a faixa das correntes de defeito de fase esperadas no bloco de carga 5 são válidos os mesmos comentários ilustrados para os demais blocos de carga até então estudados. 


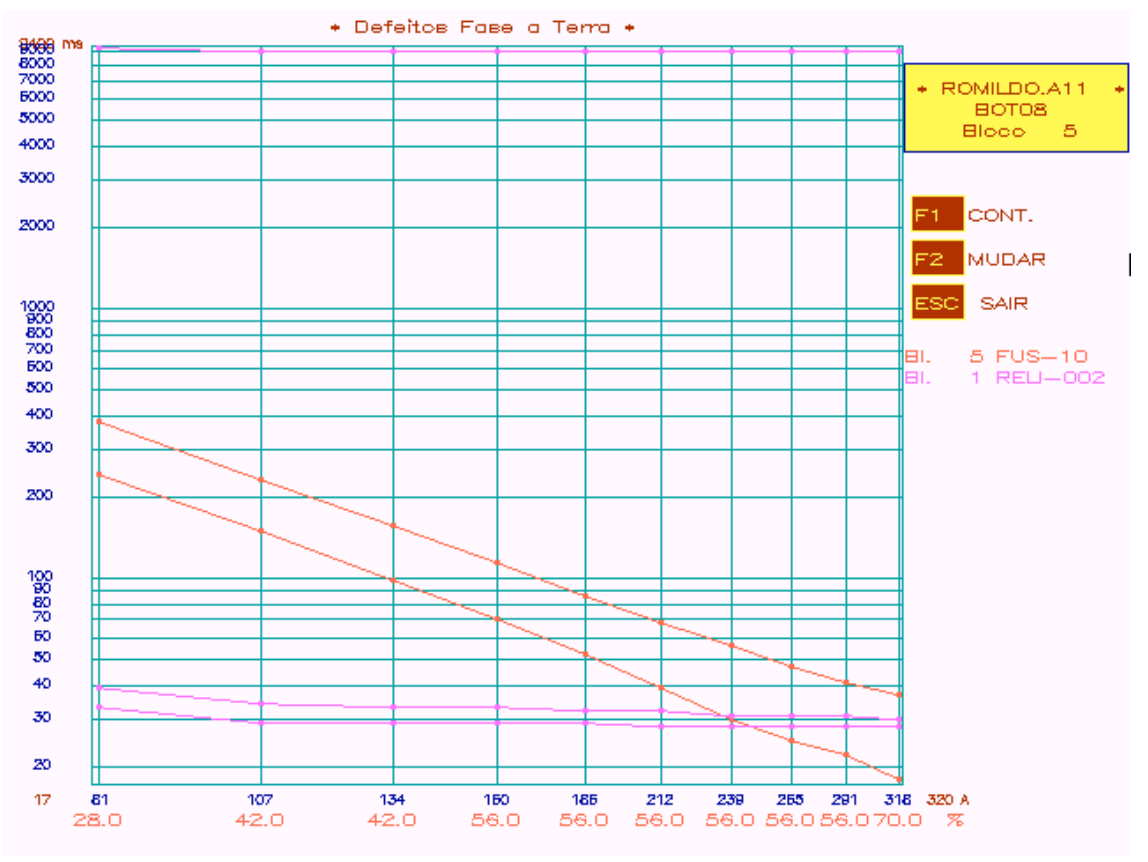

Figura 5.23 - Estudo dos defeitos de terra para o bloco de carga 5

\section{- Blocos de carga 4 e 1}

As análises e conclusões são similares as apresentadas para os blocos de carga 5 e 1, exceto que a faixa das correntes de defeito esperadas de fase vai de 2863 a $3305 \mathrm{~A}$ e a de terra vai de 81 a 317 A. Estes intervalos correspondem ao bloco de carga 4.

\section{- Blocos de carga 3 e 1}

As análises e conclusões são similares as apresentadas para os blocos de carga 7 e 1, exceto que a faixa das correntes de defeito esperadas de fase vai de 2756 a 3932 A e a de terra vai de 81 a 325 A. Estes intervalos correspondem ao bloco de carga 3.

\section{- Blocos de carga 2 e 1}

As análises e conclusões são similares as apresentadas para os blocos de carga 5 e 1, exceto que a faixa das correntes de defeito esperadas de fase vai de 3291 a 4073 A e a de terra vai de 82 a 325 A. Estes intervalos correspondem ao bloco de carga 2. 
Neste segundo estudo constatou-se que para defeitos fase-terra existe uma possibilidade pequena do religador atuar em sua operação lenta antes do elo fusível. Para resolver este problema as curvas de atuação da unidade de terra serão modificadas para 1,2,9,10, e isto não prejudicará a coordenação do religador com os demais dispositivos de proteção instalados na rede elétrica em estudo.

Após o dimensionamento dos ajustes dos dispositivos de proteção e na análise da coordenação entre eles, segue na Figura 5.24 o diagrama de blocos da rede elétrica final, com a indicação dos equipamentos instalados no início de cada um deles.

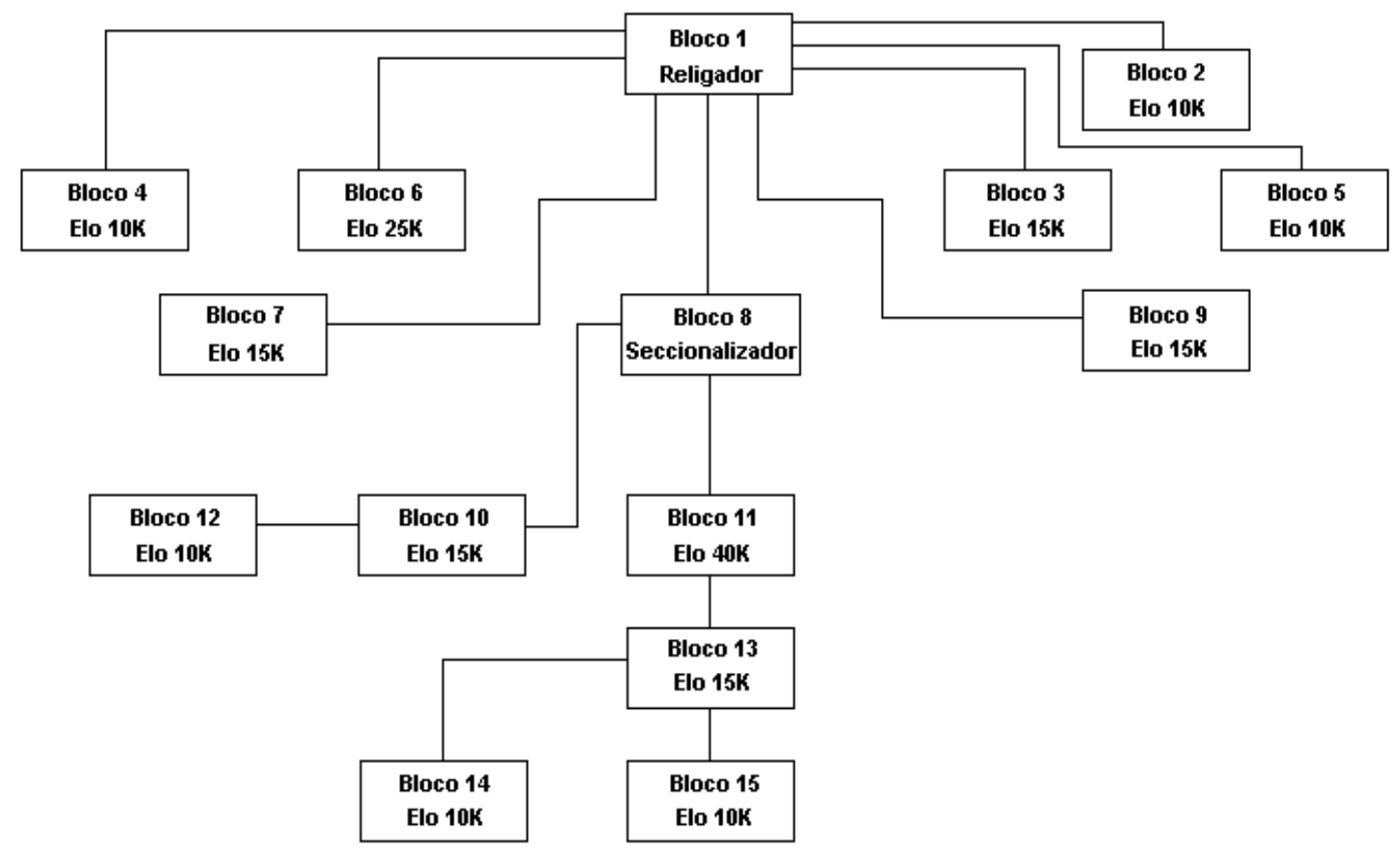

Figura 5.24 - Diagrama de blocos da rede elétrica final contendo os dispositivos de proteção

\section{4 - Avaliação da probabilidade de existir coordenação}

\subsection{1 - Considerações gerais}

Após o dimensionamento dos dispositivos de proteção e estudo de coordenação entre os mesmos com enfoque determinístico, parte-se agora para a análise probabilística do problema. 
Tal análise consiste basicamente em estimar a probabilidade de haver ou não coordenação entre os dispositivos de proteção para o intervalo de correntes esperadas de defeito de fase e de terra para cada um dos blocos de carga. Para tanto será realizada uma simulação de um caso base com o intuito de apresentar a metodologia probabilística de coordenação da proteção.

\subsection{2 - Simulações e análises}

\subsubsection{1 - Introdução}

Para o estudo em questão foram inicialmente definidos para cada trecho da rede elétrica em estudo e implementados na ferramenta computacional utilizada os seguintes parâmetros:

a) A taxa de falhas por ano, conforme ilustrado no Anexo A;

b) Curva de resistência de defeito com os valores de 20, 40, 60, 80 e 100 $\Omega$. Para cada um destes valores foi assumida uma probabilidade de ocorrência igual a 0,2;

c) A probabilidade de ocorrência de um defeito trifásico $\left(\mathrm{P}_{3 \phi}\right)$ igual a 0,05 ;

d) A probabilidade de ocorrência de um defeito dupla fase $\left(\mathrm{P}_{2 \phi}\right)$ igual a 0,15 ;

e) A probabilidade de ocorrência de um defeito fase-terra $\left(\mathrm{P}_{\phi T}\right)$ igual a 0,70 ;

Com estas três probabilidades definidas, obtém-se a probabilidade de ocorrência de um defeito dupla fase-terra $\left(\mathrm{P}_{2 \phi T}\right)$ igual a 0,10 . Tal valor é obtido pelo complemento da soma das probabilidades de ocorrência dos defeitos: trifásico, dupla fase e fase-terra.

$\mathrm{Na}$ seqüência, foram adotados os seguintes parâmetros para o cálculo de fluxo de potência na rede, conforme segue:

- Tensão na barra da SE igual a 1,0 pu, que no caso em questão equivale a 11,9 kV; 
- Fator multiplicativo da carga para o horizonte de 5 anos igual a 1,2;

- Número de classes de freqüência da corrente de defeito, consideradas para a montagem do histograma igual a 10 ;

- Comprimento máximo de cada subtrecho para o cálculo das correntes de curtocircuito igual a $100 \mathrm{~m}$.

Com os ajustes efetuados até então, parte-se para a análise probabilística visando avaliar os riscos de que haja ou não coordenação entre os dispositivos de proteção utilizados, para uma determinada faixa de correntes esperadas de fase e terra no bloco de carga em estudo.

A explicação dos resultados obtidos será apresentada em detalhes para um bloco de carga. Como a metodologia utilizada é similar para os demais blocos, os resultados destes serão indicados em tabelas e comentados sucintamente.

\subsubsection{2 - Exemplo de aplicação}

Como exemplo de aplicação, será considerado o bloco de carga número 11 , sendo que no início deste está instalado um elo fusível 40K. O bloco de carga instalado imediatamente a montante deste é o de número 8 que conta com um seccionalizador, conforme apresentado anteriormente. Os gráficos também ilustram as curvas do religador instalado na saída da SE de distribuição (início do bloco de carga 1).

As análises serão feitas em separado para os defeitos fase-terra e para os defeitos de fase.

- Defeitos fase-terra: 
Conforme apresentado no item 5.3.4, observa-se que para os valores das correntes de defeito de terra esperadas no bloco de carga em estudo no intervalo de 80 a $131 \mathrm{~A}$, existe uma possibilidade de abertura do seccionalizador após a terceira operação do religador (primeira lenta).

A Figura 5.25 fornece a característica tempo de atuação em função da corrente dos dispositivos de proteção instalados no bloco em estudo e a montante conforme apresentado anteriormente. O gráfico ilustra no eixo das ordenadas, o tempo de atuação dos dispositivos de proteção, e no eixo das abscissas são indicadas as correntes de defeito de terra esperadas para o bloco de carga em tela. Para cada um destes valores de corrente, são indicadas: a probabilidade acumulada e o estado do seccionalizador, onde A significa que para aquele valor de corrente o mesmo atuou. Caso isto não ocorra, aparecerá a letra $\mathrm{N}$ que significa que o dispositivo de proteção não atuou para $\mathrm{o}$ correspondente valor de corrente.

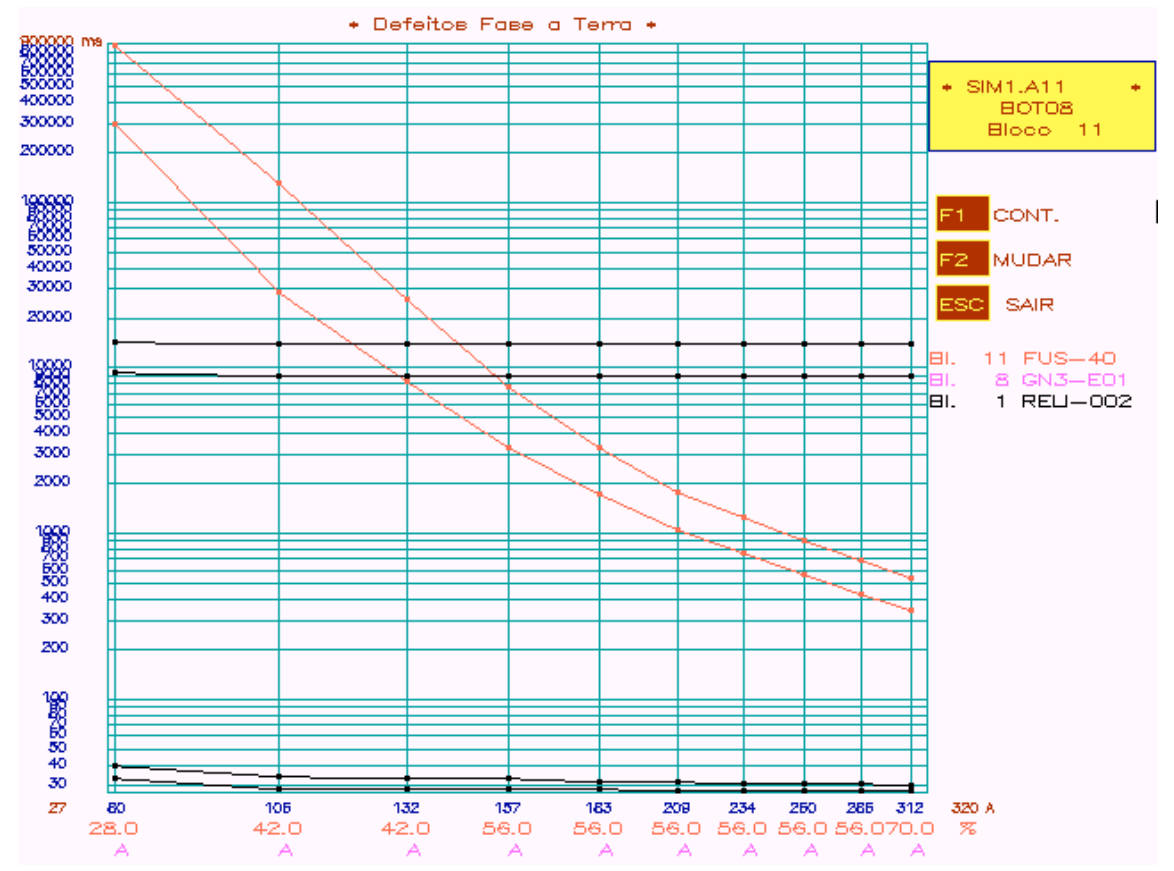

Figura 5.25 - Análise das probabilidades para os defeitos a terra no bloco de carga 11

Analisando a Figura 5.25, conclui-se que a probabilidade acumulada correspondente à corrente de defeito fase-terra menor ou igual a 131 A é igual a $42 \%$. (Na base de $70 \%$ que corresponde a probabilidade do defeito ser fase-terra). 
Como o valor encontrado está em uma base diferente de $100 \%$, deverá ser feita uma normalização para esta base, da probabilidade obtida, de acordo com a Equação 5.10.

$$
P^{\prime}=(P) \cdot \frac{100}{P_{\phi T}}
$$

em que:

$P^{\prime}$ representa a probabilidade acumulada normalizada na base de $100 \%$;

$P$ representa a probabilidade percentual acumulada obtida para uma determinada corrente;

$\mathrm{P}_{\phi T}$ é a probabilidade de um defeito ser fase-terra.

Substituindo na Equação 5.10 os valores de $P$ igual a $42 \%$ e $\mathrm{P}_{\phi T}$ igual a $70 \%$, obtém-se o valor da probabilidade acumulada normalizada na base de $100 \%$ para as correntes esperadas de defeito fase-terra menores do que 131 A no bloco de carga 11.

$$
P^{\prime}=(42) \cdot \frac{100}{70} \quad \rightarrow \quad P^{\prime}=60,0 \%
$$

Portanto, conclui-se que para a ocorrência de um defeito fase-terra no bloco de carga 11, no intervalo de correntes considerado, existe uma probabilidade de $60 \%$ da seccionalizadora instalada no início do bloco 8 abrir após a atuação da primeira curva lenta do religador, havendo, portanto, uma não coordenação. Deste ponto em diante serão considerados em todos os estudos as probabilidades normalizadas na base de $100 \%$.

Um outro ponto a ser analisado, corresponde ao intervalo de correntes de 131 a $155 \mathrm{~A}$, onde a primeira curva lenta do religador está acima da curva de mínima fusão do elo fusível, porém abaixo da sua curva de máxima interrupção. Assim sendo, para este intervalo também existe um risco do seccionalizador abrir, caso o elo não interrompa a corrente e extinga o arco, antes da atuação da primeira curva lenta do religador. 
Analisando a Figura 5.25 e aplicando a Equação 5.10, conclui-se que a probabilidade acumulada correspondente a corrente de defeito fase-terra esperada no bloco de carga 11 menor ou igual a 155 A vale $80 \%$.

Estas duas análises descritas nos parágrafos anteriores representam uma condição de não coordenação. Fazendo uma sobreposição dos dois intervalos avaliados, conclui-se que a probabilidade de não coordenação entre o elo fusível $40 \mathrm{~K}$ e o religador, para correntes menores do que $155 \mathrm{~A}$, equivale a $80 \%$.

Verifica-se ainda que para a faixa de correntes de defeito fase-terra superiores a $155 \mathrm{~A}$ ocorre a atuação das 2 operações rápidas do religador e caso o defeito ainda persista, haverá a fusão do elo fusível $40 \mathrm{~K}$, havendo, portanto, coordenação. Se para a corrente de 155 A, a FPA correspondente é igual a $80 \%$ e para 312 A ela vale $100 \%$, conclui-se que neste intervalo houve uma variação de $20 \%$ que representa a probabilidade de coordenação entre os dispositivos de proteção considerados.

Portanto, a probabilidade de coordenação é igual a $20 \%$ e a de não coordenação é $80 \%$, para toda a faixa de correntes esperadas de defeito fase-terra no bloco de carga 11.

- Defeitos de fase

A Figura 5.26 ilustra a análise das correntes de defeito de fase esperadas no bloco de carga 11, com as curvas de tempo em função da corrente dos dispositivos de proteção, além do estado do seccionalizador.

Para a normalização das probabilidades é válida a Equação 5.10, substituindo apenas a probabilidade de um defeito ser fase-terra pela probabilidade do defeito ser fase-fase. 


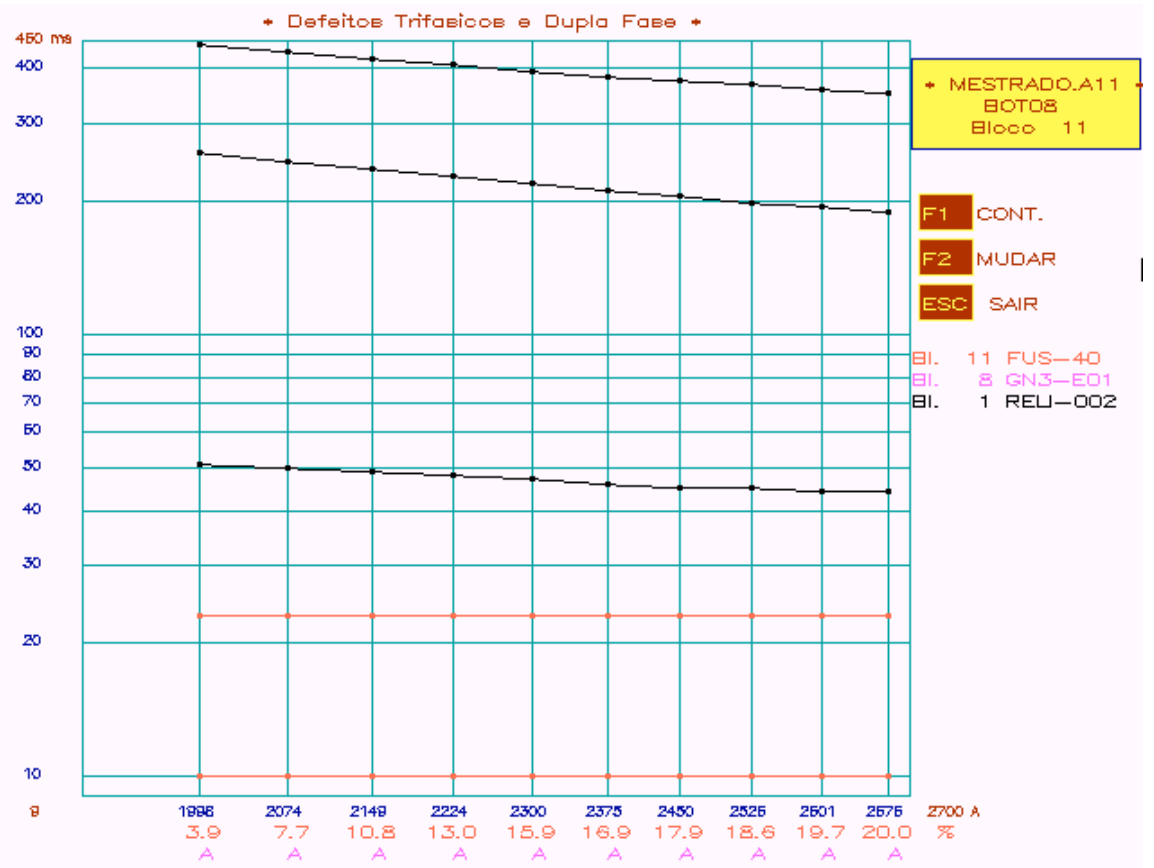

Figura 5.26 - Análise das probabilidades para os defeitos de fase no bloco de carga 11

Conforme citado anteriormente, sempre ocorrerá a fusão do elo fusível instalado no início do bloco 11 para as correntes esperadas de fase, quer seja o defeito temporário ou permanente, uma vez que as curvas rápidas e lentas do religador se encontram acima das curvas do elo fusível.

Será adotada como premissa para a solução do problema que na ocorrência de defeitos de fase temporários ou permanentes, haverá sempre a atuação do elo fusível antes do religador e que tal condição representa coordenação da proteção. Foram realizadas diversas simulações e observa-se nas curvas dos elos fusíveis que o respectivo tempo de operação para as faixas das correntes esperadas de defeito de fase em todos os blocos de carga é menor ou igual a $50 \mathrm{~ms}$. Mesmo que o religador fosse ajustado com 2 curvas rápidas com tempo zero, não haveria a seletividade com o elo fusível, pois o tempo de abertura e extinção do arco elétrico dos religadores é na ordem de $65 \mathrm{~ms}$, e portanto, maior do que o tempo mínimo de fusão do elo fusível. 


\subsubsection{3 - Resultados para os demais blocos de carga}

A discussão feita no item anterior teve por objetivo ilustrar como se determinam as probabilidades de haver ou não coordenação para as correntes de fase e terra esperadas no bloco de carga 11 da rede elétrica em estudo. Na seqüência serão feitas as observações e as análises para os demais blocos de carga, conforme segue:

- Bloco de carga 15

Observa-se que existe uma probabilidade de haver a fusão do elo fusível instalado no início do bloco antes da atuação das curvas rápidas do religador da SE. Este evento ocorre para correntes esperadas de terra maiores do que $237 \mathrm{~A}$.

Utilizando a mesma metodologia discutida na seção 5.4.2.2, conclui-se que a probabilidade de não coordenação para toda a faixa de correntes esperadas de terra no bloco de carga 15 vale $20,0 \%$ e a probabilidade de haver coordenação para estas mesmas condições, vale $80,0 \%$.

Para toda a faixa de correntes esperadas de fase no bloco de carga 15 , a probabilidade de haver a fusão do elo fusível antes da atuação do religador é igual a 100,0\%.

- Bloco de carga 14

As análises, comentários e conclusões são similares ao que foi apresentado para o bloco de carga 15.

- Bloco de carga 13

Para as correntes esperadas de defeito fase-terra no bloco de carga 13 a probabilidade de haver coordenação é igual a 100,0\%. 
Para as correntes esperadas de defeito de fase neste bloco, a probabilidade de haver coordenação é igual a zero, conforme ilustrado em 5.3.4.

- Bloco de carga 12

As análises, comentários e conclusões são similares ao que foi apresentado para os blocos de carga 14 e 15 .

- Bloco de carga 11

Vide apresentação no item 5.4.2.2.

- Bloco de carga 10

Para as correntes esperadas de terra no bloco de carga em questão, a probabilidade de haver coordenação entre o elo fusível $15 \mathrm{~K}$, o seccionalizador e o religador é igual a $100 \%$.

Para toda a faixa de correntes esperadas de fase no bloco de carga 10, a probabilidade de haver a fusão do elo fusível antes da atuação do religador é igual a 100,0\%.

- Bloco de carga 9

Para as correntes esperadas de terra no bloco de carga em questão, a probabilidade de haver coordenação entre o elo fusível $15 \mathrm{~K}$ e o religador é igual a $100 \%$. Ou seja, a probabilidade que o elo fusível funda antes da atuação da primeira curva lenta do religador é igual a $100 \%$.

Para toda a faixa de correntes esperadas de fase no bloco de carga 9, a probabilidade de haver a fusão do elo fusível antes da atuação do religador é igual a 100,0\%. 
- Bloco de carga 8

Para toda a faixa das correntes esperadas de fase e terra no bloco de carga em estudo, a probabilidade do seccionalizador abrir após a atuação do religador em sua primeira curva lenta é igual a $100 \%$.

- Bloco de carga 7

As análises, comentários e conclusões são similares ao que foi apresentado para o bloco de carga 9.

- Bloco de carga 6

Observa-se que para as correntes esperadas de defeito fase-terra no bloco em estudo, a probabilidade de haver coordenação entre o elo fusível e o religador é 100\%.

Para as correntes esperadas de defeito de fase neste bloco, a probabilidade de haver a fusão do elo fusível antes da atuação do religador é igual a 100\%.

- Bloco de carga 5

As análises, comentários e conclusões são similares ao que foi apresentado para o bloco de carga 15 .

- Bloco de carga 4

As análises, comentários e conclusões são similares ao que foi apresentado para o bloco de carga 5.

- Bloco de carga 3

As análises, comentários e conclusões são similares ao que foi apresentado para o bloco de carga 9. 
- Bloco de carga 2

As análises, comentários e conclusões são similares ao que foi apresentado para o bloco de carga 4.

Para o bloco de carga 1 não tem sentido fazer análise, uma vez que não existe nenhum dispositivo de proteção, nem bloco de carga situado a montante.

Com base neste estudo segue na Tabela 5.4 os resultados globais relativos a esta simulação (Simulação 1), onde são indicadas as probabilidades de haver coordenação ou não entre os dispositivos de proteção para as correntes esperadas de defeito de fase e terra.

\begin{tabular}{|c|c|c|c|c|c|c|}
\hline \multirow{2}{*}{$\begin{array}{c}\text { Bloco } \\
\text { de } \\
\text { carga }\end{array}$} & \multicolumn{3}{|c|}{ Defeitos de Terra } & \multicolumn{3}{|c|}{ Defeitos de Fase } \\
\hline & $\begin{array}{c}\text { Faixa de correntes } \\
\text { esperadas (A) } \\
\end{array}$ & $\begin{array}{c}\mathbf{P}_{\mathbf{C}} \\
(\%) \\
\end{array}$ & $\begin{array}{l}\mathbf{P}_{\mathrm{NC}} \\
(\%) \\
\end{array}$ & $\begin{array}{c}\text { Faixa de correntes } \\
\text { esperadas (A) }\end{array}$ & $\begin{array}{c}\mathbf{P}_{\mathbf{C}} \\
(\%) \\
\end{array}$ & $\begin{array}{l}\mathbf{P}_{\mathrm{NC}} \\
(\%) \\
\end{array}$ \\
\hline 15 & 79 a 299 & 80 & 20 & 1459 a 1831 & 100 & 0 \\
\hline 14 & 79 a 301 & 80 & 20 & 1505 a 1937 & 100 & 0 \\
\hline 13 & 80 a 303 & 100 & 0 & 1574 a 1996 & 0 & 100 \\
\hline 12 & 80 a 304 & 80 & 20 & 1402 a 2040 & 100 & 0 \\
\hline 11 & 80 a 312 & 20 & 80 & 1743 a 2562 & 100 & 0 \\
\hline 10 & 80 a 312 & 100 & 0 & 1840 a 2567 & 100 & 0 \\
\hline 9 & 81 a 314 & 100 & 0 & 2154 a 2881 & 100 & 0 \\
\hline 8 & 81 a 317 & 100 & 0 & 2320 a 3062 & 100 & 0 \\
\hline 7 & 81 a 317 & 100 & 0 & 2152 a 3101 & 100 & 0 \\
\hline 6 & 81 a 316 & 100 & 0 & 1906 a 3006 & 100 & 0 \\
\hline 5 & 81 a 317 & 80 & 20 & 2466 a 3126 & 100 & 0 \\
\hline 4 & 81 a 318 & 80 & 20 & 2599 a 3030 & 100 & 0 \\
\hline 3 & 81 a 325 & 100 & 0 & 2366 a 4016 & 100 & 0 \\
\hline 2 & 82 a 326 & 80 & 20 & 3094 a 4187 & 100 & 0 \\
\hline
\end{tabular}

Tabela 5.4 - Probabilidades de haver ou não coordenação entre os dispositivos de proteção (Simulação 1) 
Nas Tabelas 5.4, 5.6, 5.8 e 5.10, os símbolos $\mathbf{P}_{\mathbf{C}} \mathbf{e} \mathbf{P}_{\mathrm{NC}}$ significam, respectivamente:

- A probabilidade de haver coordenação entre os dispositivos de proteção na ocorrência de defeitos de fase ou de terra;

- A probabilidade de não haver coordenação entre os dispositivos de proteção na ocorrência de defeitos de fase ou de terra.

\section{5 - Análise de sensibilidade a parâmetros}

Após a análise probabilística de coordenação da proteção efetuada no item anterior, parte-se para a análise de sensibilidade de alguns parâmetros com o intuito de verificar a influência dos mesmos, na obtenção das probabilidades de haver ou não coordenação entre os dispositivos de proteção instalados na rede elétrica em estudo.

Para uma melhor avaliação do problema, cinco simulações foram realizadas, conforme segue:

\section{- Simulação 1:}

Esta simulação corresponde ao caso base, apresentado no item anterior como exemplo de aplicação da metodologia proposta.

\section{- Simulação 2:}

Para esta simulação, foram modificadas em relação ao caso base, as probabilidades de ocorrência dos defeitos, conforme indicado na Tabela 5.5. 


\begin{tabular}{|c|c|c|}
\hline Variável & Simulação 1 & Simulação 2 \\
\hline \hline $\mathbf{P}_{\mathbf{3} \boldsymbol{\phi}}$ & 0,05 & 0,08 \\
\hline $\mathbf{P}_{\mathbf{2} \boldsymbol{\phi}}$ & 0,15 & 0,25 \\
\hline $\mathbf{P}_{\phi \mathbf{T}}$ & 0,70 & 0,62 \\
\hline $\mathbf{P}_{\mathbf{2} \boldsymbol{T} \mathbf{T}}$ & 0,10 & 0,05 \\
\hline
\end{tabular}

Tabela 5.5 - Comparação das variáveis modificadas em relação a Simulação 1

Observou-se nesta simulação que as FPAs para os defeitos de fase e de terra mudaram em relação ao caso base pelo fato das probabilidades de ocorrência de cada um dos tipos de defeito ter sido modificada.

Analogamente a metodologia apresentada no item anterior, calcula-se as probabilidades de haver coordenação entre os dispositivos de proteção instalados, bem como as de não haver.

Embora tenham ocorrido estas mudanças nas FPAs, observa-se que as probabilidades normalizadas de coordenação e de não coordenação, na base de $100 \%$ não mudaram. Exemplificando, para os defeitos fase-terra, na normalização do caso base $70 \%$ equivale a 1 enquanto que na normalização da simulação 2, 62\% equivale a 1 . Os outros valores da FPA também mudaram na mesma proporção, o que leva a concluir que as probabilidades normalizadas são iguais em ambos os casos. Assim sendo, são válidos os mesmos dados apresentados na Tabela 5.4.

\section{- Simulação 3:}

No caso em questão foram mantidas as mesmas condições da simulação 1 , mudando apenas o comprimento de cada subtrecho de 100 metros para 1,0 metro.

Observa-se através da Figura 5.27, que para os defeitos de terra no bloco de carga 11 não houve nenhuma modificação significativa, em relação a simulação 1 , nas correntes 
nem nas suas respectivas probabilidades conforme ilustram as Tabelas C.1 e C.3 do Anexo C.

Devido ao comprimento do subtrecho ser 100 vezes menor, ocorreu uma maior discretização no processamento das FPAs, uma vez que cada trecho de rede foi subdividido em partes menores. Por este motivo, as FPAs para os defeitos de fase e terra desta simulação são mais precisas do que as da simulação 1 .

Para os defeitos de fase, houve uma mudança de alguns pontos da função de probabilidade acumulada. A título ilustrativo, a Figura 5.28 ilustra as FPAs das correntes de defeito de fase do bloco de carga 11 das simulações 1 e 3 .

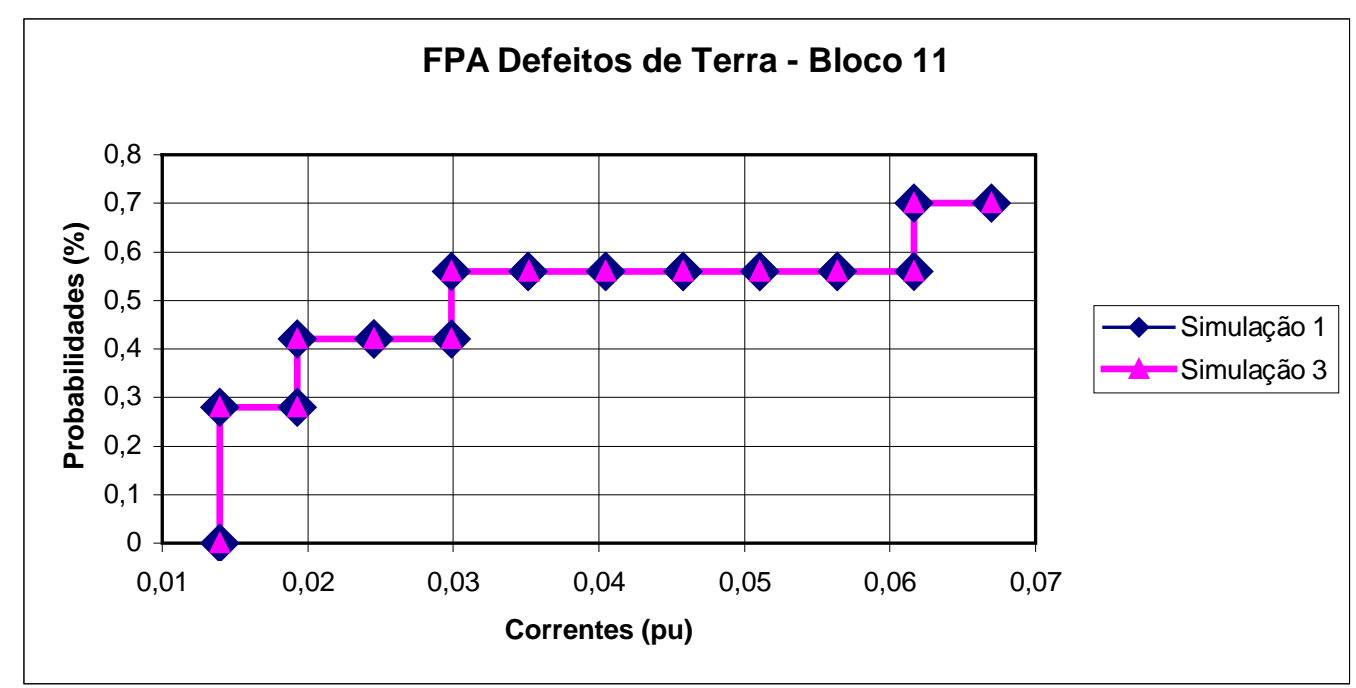

Figura 5.27 - FPA relativa as simulações 1 e 3 para os defeitos de terra - bloco 11 


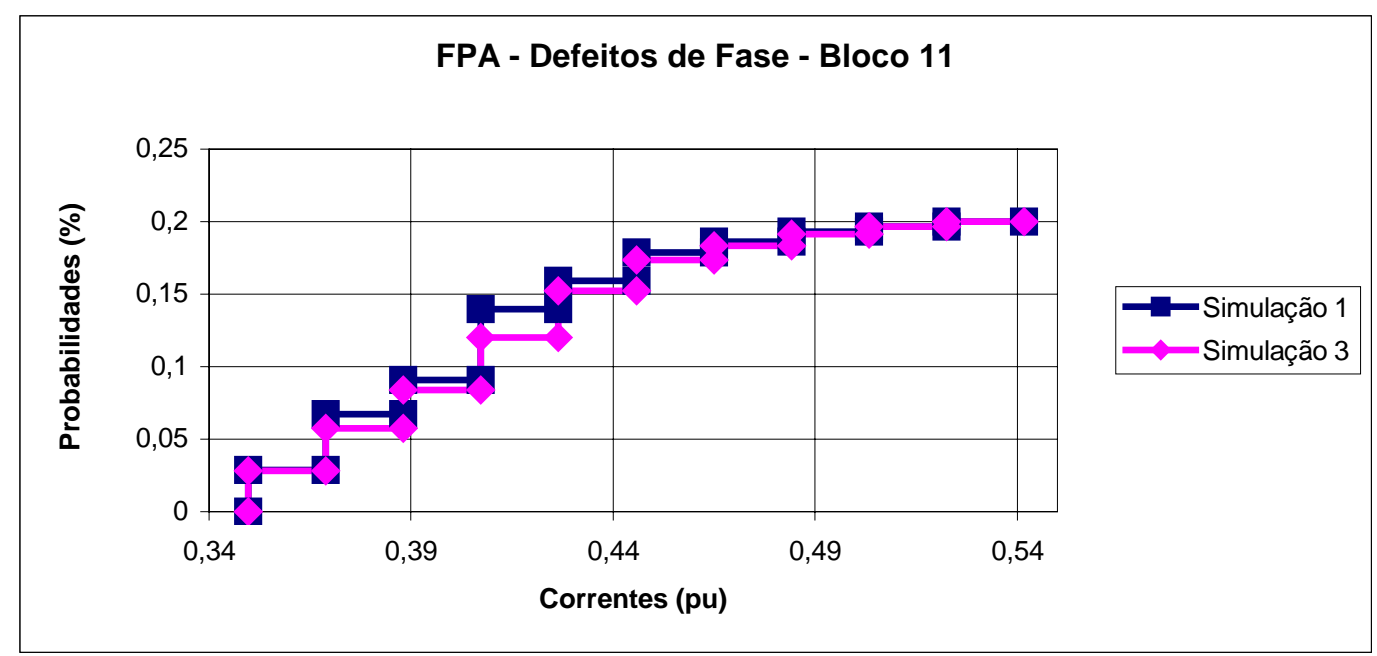

Figura 5.28 - FPA relativa as simulações 1 e 3 para os defeitos de fase - bloco 11

Com as FPAs dos defeitos de fase e terra e conhecendo-se as curvas dos dispositivos de proteção utilizados, monta-se analogamente a simulação 1 a Tabela 5.6, na qual são avaliadas as probabilidades de haver ou não coordenação entre os dispositivos de proteção instalados nos blocos de carga em estudo. 


\begin{tabular}{|c|c|c|c|c|c|c|}
\hline \multirow{2}{*}{$\begin{array}{c}\text { Bloco } \\
\text { de } \\
\text { carga } \\
\end{array}$} & \multicolumn{3}{|c|}{ Defeitos de Terra } & \multicolumn{3}{|c|}{ Defeitos de Fase } \\
\hline & $\begin{array}{c}\text { Faixa de correntes } \\
\text { esperadas }(\mathrm{A})\end{array}$ & $\begin{array}{c}\mathbf{P}_{\mathbf{C}} \\
(\%) \\
\end{array}$ & $\begin{array}{l}\mathbf{P}_{\mathrm{NC}} \\
(\%) \\
\end{array}$ & $\begin{array}{c}\text { Faixa de correntes } \\
\text { esperadas }(\mathrm{A})\end{array}$ & $\begin{array}{c}\mathbf{P}_{\mathbf{C}} \\
(\%) \\
\end{array}$ & $\begin{array}{l}\mathbf{P}_{\mathrm{NC}} \\
(\%) \\
\end{array}$ \\
\hline 15 & 79 a 299 & 80 & 20 & 1459 a 1832 & 100 & 0 \\
\hline 14 & 79 a 301 & 80 & 20 & 1505 a 1937 & 100 & 0 \\
\hline 13 & 80 a 303 & 100 & 0 & 1574 a 1999 & 0 & 100 \\
\hline 12 & 80 a 304 & 80 & 20 & 1402 a 2041 & 100 & 0 \\
\hline 11 & 80 a 312 & 20 & 80 & 1743 a 2563 & 100 & 0 \\
\hline 10 & 80 a 312 & 100 & 0 & 1840 a 2568 & 100 & 0 \\
\hline 9 & 81 a 314 & 100 & 0 & 2154 a 2883 & 100 & 0 \\
\hline 8 & 81 a 317 & 100 & 0 & 2320 a 3063 & 100 & 0 \\
\hline 7 & 81 a 317 & 100 & 0 & 2152 a 3102 & 100 & 0 \\
\hline 6 & 81 a 316 & 100 & 0 & 1906 a 3006 & 100 & 0 \\
\hline 5 & 81 a 317 & 80 & 20 & 2466 a 3130 & 100 & 0 \\
\hline 4 & 81 a 318 & 80 & 20 & 2599 a 3032 & 100 & 0 \\
\hline 3 & 81 a 325 & 100 & 0 & 2366 a 4020 & 100 & 0 \\
\hline 2 & 82 a 326 & 80 & 20 & 3094 a 4191 & 100 & 0 \\
\hline
\end{tabular}

Tabela 5.6 - Probabilidades de haver ou não coordenação entre os dispositivos de proteção (Simulação 3)

Embora para os defeitos de fase tenha havido uma mudança nos valores da FPA em relação a simulação 1 (Conforme Tabelas C.6 e C.8), o valor das probabilidades de coordenação e de não coordenação não sofreu alteração face a discretização do parâmetro comprimento do subtrecho.

\section{- Simulação 4:}

No caso em questão foram mantidas as mesmas condições da simulação 1, mudando a curva de resistência de defeito de A para C. Os valores de resistência de defeito com a sua respectiva probabilidade são indicados na Tabela 5.7. 


\begin{tabular}{|c|c|c|}
\hline Curva & Resistência de defeito ( $\mathbf{(})$ & Probabilidade \\
\hline \hline A & 20 & 0,2 \\
\hline & 40 & 0,2 \\
\hline & 60 & 0,2 \\
\hline & 80 & 0,2 \\
\hline & 100 & 0,2 \\
\hline $\mathbf{C}$ & 0 & 0,3 \\
\hline & 50 & 0,2 \\
\hline & 100 & 0,2 \\
\hline & 400 & 0,2 \\
\hline & 1000 & 0,1 \\
\hline
\end{tabular}

Tabela 5.7 - Pontos das curvas de resistência de defeito A e C

A metodologia utilizada na obtenção dos resultados é análoga a aplicada para as simulações anteriores. Os resultados globais desta simulação são indicados na Tabela 5.8 .

\begin{tabular}{|c|c|c|c|c|c|c|}
\hline \multirow{2}{*}{$\begin{array}{c}\text { Bloco } \\
\text { de } \\
\text { carga }\end{array}$} & $\begin{array}{c}\text { Faixa de correntes } \\
\text { esperadas }(\mathbf{A})\end{array}$ & $\begin{array}{c}\mathbf{P}_{\mathbf{C}} \\
\mathbf{( \% )}\end{array}$ & $\begin{array}{c}\mathbf{P}_{\mathbf{N C}} \\
\mathbf{( \% )}\end{array}$ & $\begin{array}{c}\text { Faixa de correntes } \\
\text { esperadas (A) }\end{array}$ & $\begin{array}{c}\mathbf{P}_{\mathbf{C}} \\
(\mathbf{\%})\end{array}$ & $\begin{array}{c}\mathbf{P}_{\mathbf{N C}} \\
(\mathbf{\%})\end{array}$ \\
\hline \hline 15 & 70 a 1212 & 70 & 30 & 1459 a 1831 & 100 & 0 \\
\hline 14 & 73 a 1264 & 70 & 30 & 1505 a 1937 & 100 & 0 \\
\hline 13 & 76 a 1329 & 70 & 30 & 1574 a 1996 & 0 & 100 \\
\hline 12 & 79 a 1382 & 70 & 30 & 1402 a 2040 & 100 & 0 \\
\hline 11 & 92 a 1637 & 0 & 100 & 1743 a 2562 & 100 & 0 \\
\hline 10 & 92 a 1637 & 70 & 30 & 1840 a 2567 & 100 & 0 \\
\hline 9 & 98 a 1740 & 70 & 30 & 2154 a 2881 & 100 & 0 \\
\hline 8 & 105 a 1874 & 100 & 0 & 2320 a 3062 & 100 & 0 \\
\hline 7 & 103 a 1844 & 70 & 30 & 2152 a 3101 & 100 & 0 \\
\hline 6 & 106 a 1945 & 70 & 30 & 1906 a 3006 & 100 & 0 \\
\hline 5 & 113 a 2030 & 70 & 30 & 2466 a 3126 & 100 & 0 \\
\hline 4 & 123 a 2215 & 70 & 30 & 2599 a 3030 & 100 & 0 \\
\hline 3 & 169 a 3094 & 70 & 30 & 2366 a 4016 & 100 & 0 \\
\hline 2 & 178 a 3274 & 70 & 30 & 3094 a 4187 & 100 & 0 \\
\hline
\end{tabular}

Tabela 5.8 - Probabilidades de haver ou não coordenação entre os dispositivos de proteção (Simulação 4) 
Observa-se nesta simulação que a faixa das correntes de defeito esperadas de terra aumentou em virtude da diminuição do valor da resistência de defeito. Mesmo assim, observa-se que na maioria dos blocos de carga a probabilidade de coordenação não caiu tão drasticamente quando comparada à simulação 1 .

O bloco de carga 11 apresentou uma probabilidade de coordenação nula. A Figura 5.29 ilustra três intervalos que serão melhor analisados nas linhas subseqüentes.

\section{- Faixa de 92 a 207 A:}

Para este intervalo, o religador atua inicialmente em suas duas curvas rápidas e em seguida opera na primeira curva lenta. Logo após isto, o seccionalizador instalado no início do bloco de carga 8 abre os seus pólos e, portanto, não há coordenação. A probabilidade acumulada neste intervalo corresponde a $70 \%$.

\section{- Faixa de 207 a 1050 A:}

Neste intervalo ocorre inicialmente a atuação do religador em suas curvas rápidas e na seqüência haverá a fusão do elo fusível. Isto representa que há coordenação entre os dispositivos de proteção (Elo fusível, Seccionalizador e religador), porém a probabilidade da corrente de defeito fase terra estar neste intervalo é nula. Portanto, será um caso que nunca ocorrerá razão pela qual não será considerado no presente estudo.

\section{- Faixa de 1050 a 1637 A:}

Neste intervalo, a curva de mínima fusão do elo fusível $40 \mathrm{~K}$ se encontra abaixo das curvas rápidas dos religadores, não havendo, portanto, coordenação. A probabilidade acumulada neste intervalo corresponde a $30 \%$.

Fazendo a sobreposição dos intervalos acima, demonstra-se que a probabilidade de não coordenação entre o elo fusível, o seccionalizador e o religador, para toda a faixa de correntes esperadas de terra é igual a 100\% não sendo, portanto, uma solução tecnicamente viável. 


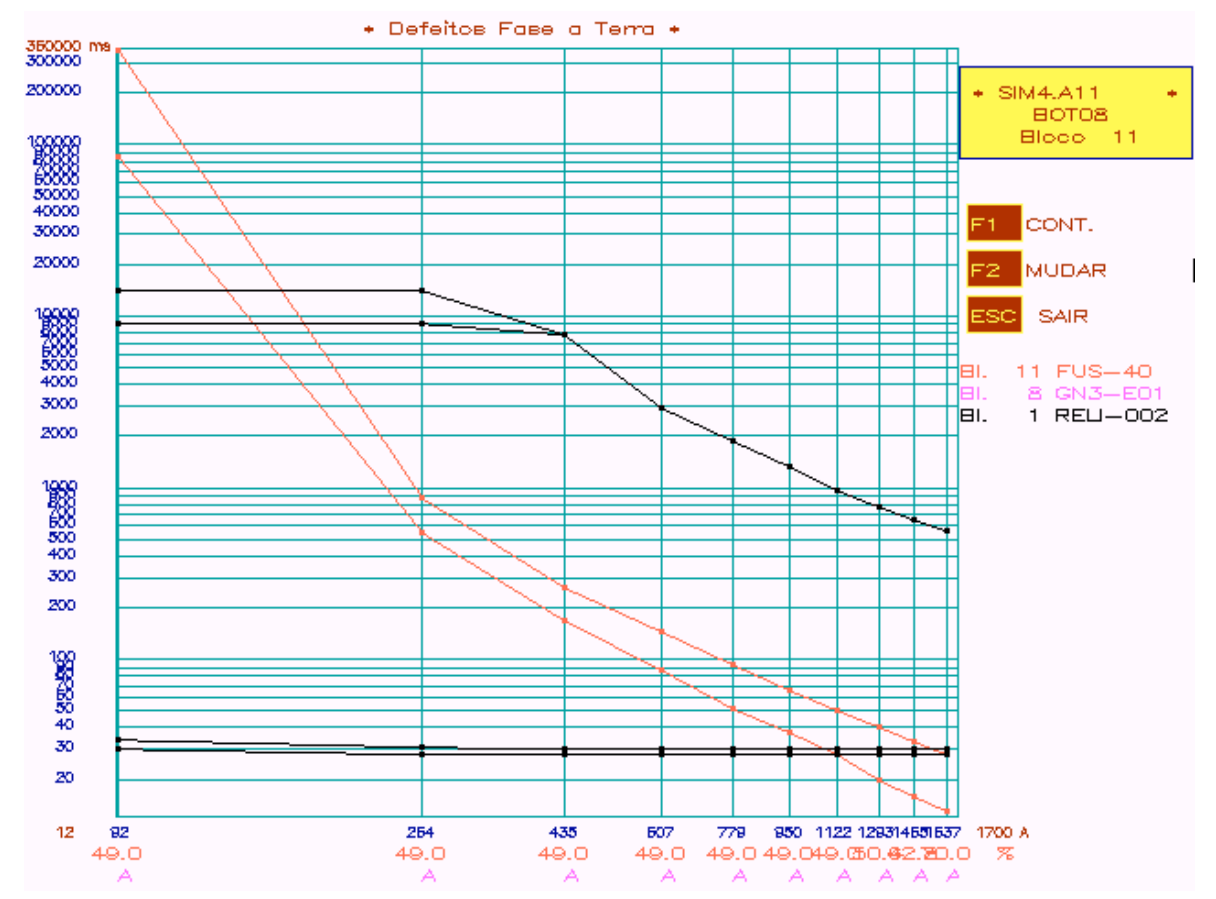

Figura 5.29 - Análise para os defeitos a terra no bloco de carga 11

A ação corretiva proposta para eliminar o problema de não coordenação encontrado consiste em instalar no início do bloco de carga 11 um elo fusível $65 \mathrm{~K}$.

Observa-se de acordo com a Figura 5.30 que existe coordenação para praticamente toda a faixa das correntes esperadas de defeito fase-terra no bloco de carga 11, exceto para valores superiores a $1608 \mathrm{~A}$. No intervalo de correntes compreendido entre 92 e 264 A, o religador operará inicialmente em suas duas operações rápidas. Caso o defeito seja permanente poderá tanto ocorrer a fusão do elo fusível $65 \mathrm{~K}$, quanto a operação do religador em sua primeira curva lenta. Caso esta última condição ocorra poderá haver a fusão do elo fusível ou a abertura do seccionalizador instalado no início do bloco de carga 8 . Na presente análise esta eventual abertura do seccionalizador será adotada como uma condição de coordenação, uma vez que não dá para prever se o elo fundirá ou não após a primeira operação lenta do religador.

Aplicando analogamente a metodologia apresentada em 5.4.2.2, conclui-se que a probabilidade de coordenação é igual a $96,0 \%$ e, portanto a de não coordenação vale $4,0 \%$. 


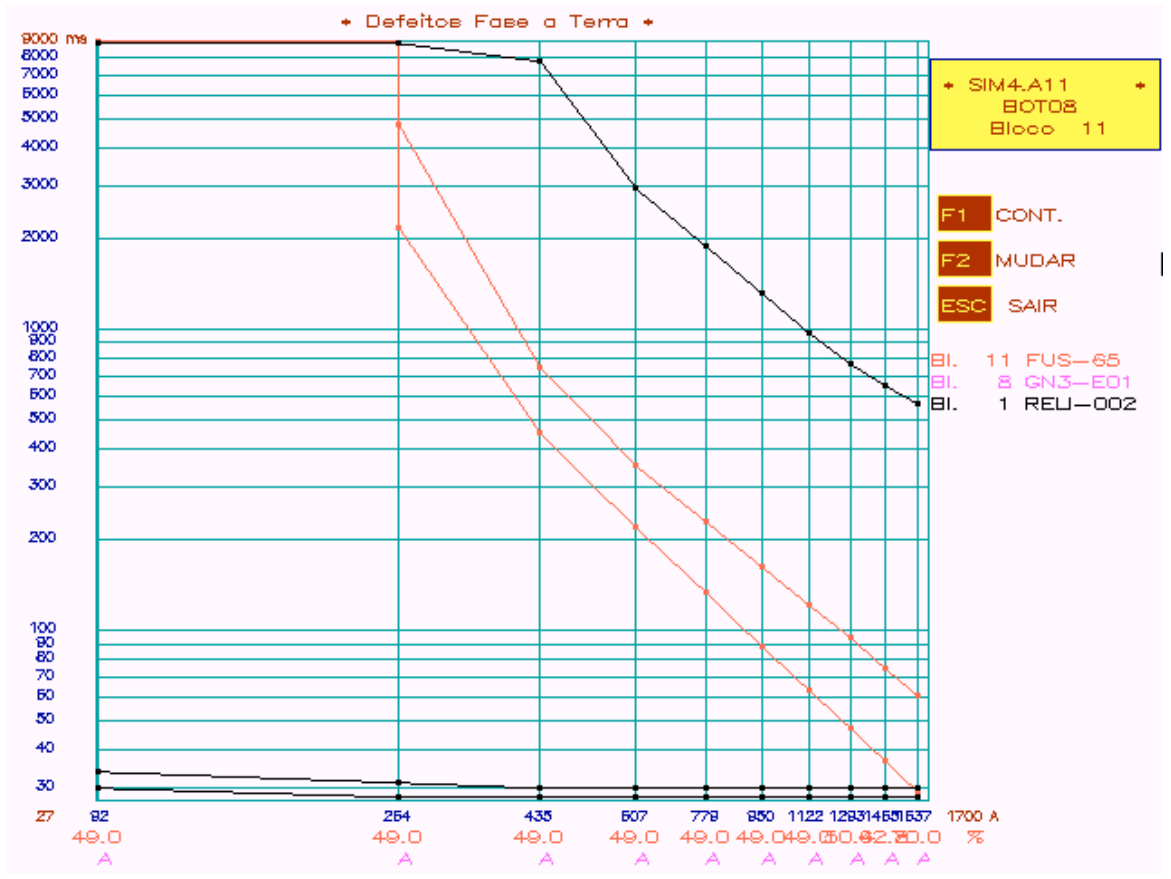

Figura 5.30 - Ação corretiva proposta para os defeitos a terra no bloco de carga 11

O investimento realizado pela concessionária de distribuição para a troca de um elo fusível fornece um retorno bastante significativo para a mesma, pois na ocorrência de um defeito fase-terra no bloco de carga em análise, a probabilidade de haver coordenação será maior e por conseqüência, apenas os consumidores situados a jusante deste elo fusível serão afetados, sendo que na solução encontrada inicialmente todos os consumidores ligados a rede elétrica sofreriam uma interrupção no fornecimento de energia elétrica.

\section{- Simulação 5:}

Nesta simulação alguns parâmetros foram alterados arbitrariamente nos diversos trechos da rede elétrica em estudo. A Tabela 5.9 ilustra o número de trechos que sofreram modificações dos parâmetros: taxa de falha, probabilidade de ocorrência de defeito (trifásico, fase-terra, dupla fase e dupla fase-terra) e resistência de defeito.

O caso base desta análise corresponde a simulação 3, na qual o comprimento dos subtrechos adotado é igual a 1,0m. 


\begin{tabular}{|c|c|c|c|c|}
\hline \multirow{2}{*}{$\begin{array}{c}\text { Bloco } \\
\text { de } \\
\text { Carga } \\
\end{array}$} & \multicolumn{4}{|c|}{ Número de trechos modificados por parâmetro } \\
\hline & $\begin{array}{c}\text { Taxa de } \\
\text { falha }\end{array}$ & $\begin{array}{c}\text { Probabilidade } \\
\text { de defeito }\end{array}$ & $\begin{array}{c}\text { Resistência de } \\
\text { defeito }\end{array}$ & $\begin{array}{c}\text { Total por bloco } \\
\text { de carga }\end{array}$ \\
\hline 1 & 6 & 3 & 2 & 11 \\
\hline 2 & 0 & 0 & 1 & 1 \\
\hline 3 & 0 & 0 & 0 & $\mathbf{0}$ \\
\hline 4 & 0 & 0 & 0 & $\mathbf{0}$ \\
\hline 5 & 0 & 0 & 0 & $\mathbf{0}$ \\
\hline 6 & 0 & 0 & 2 & 2 \\
\hline 7 & 0 & 0 & 0 & $\mathbf{0}$ \\
\hline 8 & 2 & 2 & 2 & 6 \\
\hline 9 & 0 & 0 & 0 & 0 \\
\hline 10 & 0 & 1 & 0 & 1 \\
\hline 11 & 1 & 1 & 3 & 5 \\
\hline 12 & 0 & 1 & 0 & 1 \\
\hline 13 & 0 & 0 & 0 & $\mathbf{0}$ \\
\hline 14 & 0 & 0 & 0 & 0 \\
\hline 15 & 0 & 0 & 0 & 0 \\
\hline Total & 9 & 8 & 10 & 27 \\
\hline
\end{tabular}

Tabela 5.9 - Número de trechos modificados por parâmetro

Após a ilustração dos trechos cujos parâmetros foram modificados, segue abaixo um detalhamento para cada um dos blocos de carga da rede elétrica em estudo, do que efetivamente mudou em relação ao caso base considerado.

\section{- Bloco de carga 1:}

Para o bloco de carga em questão, foram modificados os seguintes parâmetros:

\section{Taxa de falha:}

Entre as barras 3-4, 4-5 e 5-6, corresponde ao dobro do valor de referência;

Entre as barras 16-20, 20-25, corresponde a metade do valor;

Entre as barras 58-60, corresponde a 10 vezes o valor. 
Probabilidades:

Entre as barras 0-1:

$\mathrm{P}_{3 \phi}=0,05 \quad \mathrm{P}_{2 \phi}=0,10 \quad \mathrm{P}_{\phi T}=0,70 \quad \mathrm{P}_{2 \phi T}=0,15$

Entre as barras 7-9 e 9-12:

$\mathrm{P}_{3 \phi}=0,08 \quad \mathrm{P}_{2 \phi}=0,25 \quad \mathrm{P}_{\phi T}=0,62 \quad \mathrm{P}_{2 \phi T}=0,05$

Resistência de defeito:

Entre as barras 3-4 e 4-5 - curva C

- Bloco de carga 2:

Para o bloco de carga em questão, foi modificado o seguinte parâmetro:

Resistência de defeito:

Entre as barras 6-8 - curva C

- Bloco de carga 6:

Para o bloco de carga em questão, foi modificado o seguinte parâmetro:

Resistência de defeito:

Entre as barras 40-49 e 49-53 - curva C 


\section{- Bloco de carga 8:}

Para o bloco de carga em questão, foram modificados os seguintes parâmetros:

\section{Taxa de falha:}

Entre as barras 60-64 e 64-67, corresponde a 10 vezes o valor padrão.

\section{Probabilidades:}

Entre as barras 60-64 e 64-67:

$\mathrm{P}_{3 \phi}=0,08 \quad \mathrm{P}_{2 \phi}=0,25 \quad \mathrm{P}_{\phi T}=0,62 \quad \mathrm{P}_{2 \phi T}=0,05$

Resistência de defeito:

Entre as barras 60-64 e 64-67 - curva C

\section{- Bloco de carga 10:}

Para o bloco de carga em questão, foi modificado o seguinte parâmetro:

\section{Probabilidades:}

Entre as barras 67-69:

$$
\mathrm{P}_{3 \phi}=0,08 \quad \mathrm{P}_{2 \phi}=0,25 \quad \mathrm{P}_{\phi T}=0,62 \quad \mathrm{P}_{2 \phi T}=0,05
$$




\section{- Bloco de carga 11:}

Para o bloco de carga em questão, foram modificados os seguintes parâmetros:

\section{Taxa de falha:}

Entre as barras $67-70$, corresponde a 10 vezes o valor padrão.

\section{Probabilidades:}

Entre as barras 82-84:

$$
\mathrm{P}_{3 \phi}=0,08 \quad \mathrm{P}_{2 \phi}=0,25 \quad \mathrm{P}_{\phi T}=0,62 \quad \mathrm{P}_{2 \phi T}=0,05
$$

\section{Resistência de defeito:}

Entre as barras $67-70,70-73,73-76$ - curva C.

\section{- Bloco de carga 12:}

Para o bloco de carga em questão, foi modificado o seguinte parâmetro:

\section{Probabilidades:}

Entre as barras 83-88:

$$
\mathrm{P}_{3 \phi}=0,08 \quad \mathrm{P}_{2 \phi}=0,25 \quad \mathrm{P}_{\phi T}=0,62 \quad \mathrm{P}_{2 \phi T}=0,05
$$

Os demais trechos não sofreram modificação nos parâmetros, taxa de falha, probabilidades de ocorrência dos tipos de defeito e resistência de defeito. 
A metodologia utilizada na obtenção dos resultados é análoga a aplicada para as simulações anteriores. Os resultados globais desta simulação são indicados na Tabela 5.10 .

\begin{tabular}{|c|c|c|c|c|c|c|}
\hline \multirow{2}{*}{$\begin{array}{c}\text { Bloco } \\
\text { de } \\
\text { carga }\end{array}$} & $\begin{array}{c}\text { Faixa de correntes } \\
\text { esperadas (A) }\end{array}$ & $\begin{array}{c}\mathbf{P}_{\mathbf{C}} \\
\mathbf{( \% )}\end{array}$ & $\begin{array}{c}\mathbf{P}_{\mathbf{N C}} \\
\mathbf{( \% )}\end{array}$ & $\begin{array}{c}\text { Faixa de correntes } \\
\text { esperadas (A) }\end{array}$ & $\begin{array}{c}\mathbf{P}_{\mathbf{C}} \\
(\mathbf{\%})\end{array}$ & $\begin{array}{c}\mathbf{P}_{\mathbf{N C}} \\
(\mathbf{\%})\end{array}$ \\
\hline 15 & 79 a 299 & 80 & 20 & 1459 a 1832 & 100 & 0 \\
\hline 14 & 79 a 301 & 80 & 20 & 1505 a 1937 & 100 & 0 \\
\hline 13 & 80 a 303 & 100 & 0 & 1574 a 1999 & 0 & 100 \\
\hline 12 & 80 a 304 & 80 & 20 & 1402 a 2041 & 100 & 0 \\
\hline 11 & 92 a 1636 & 4,3 & 95,7 & 1743 a 2583 & 100 & 0 \\
\hline 10 & 80 a 312 & 100 & 0 & 1840 a 2588 & 100 & 0 \\
\hline 9 & 81 a 314 & 100 & 0 & 2154 a 2883 & 100 & 0 \\
\hline 8 & 105 a 1876 & 100 & 0 & 2320 a 3083 & 100 & 0 \\
\hline 7 & 81 a 317 & 100 & 0 & 2152 a 3102 & 100 & 0 \\
\hline 6 & 109 a 1947 & 87,1 & 12,9 & 1906 a 3006 & 100 & 0 \\
\hline 5 & 81 a 317 & 80 & 20 & 2466 a 3130 & 100 & 0 \\
\hline 4 & 81 a 318 & 80 & 20 & 2599 a 3032 & 100 & 0 \\
\hline 3 & 81 a 325 & 100 & 0 & 2366 a 4020 & 100 & 0 \\
\hline 2 & 179 a 3280 & 99,8 & 0,02 & 3094 a 4191 & 100 & 0 \\
\hline
\end{tabular}

Tabela 5.10 - Probabilidades de haver ou não coordenação entre os dispositivos de proteção (Simulação 5)

Comparando os resultados obtidos com a simulação 3, observa-se com base nas Tabelas 5.6 e 5.10, que houve uma mudança nas probabilidades de coordenação e de não coordenação para os defeitos de terra nos blocos 2,6 e 11. Isto ocorre em decorrência da mudança da curva de resistência de defeito que mudou consideravelmente a faixa das correntes de defeito esperadas de terra nos blocos de carga em questão.

No bloco de carga 11 houve uma piora em relação à simulação 3, em que a probabilidade de coordenação para os defeitos fase-terra caiu de $20 \%$ para $4,3 \%$. Analogamente a solução adotada na simulação 4, a ação corretiva neste caso consiste em substituir o elo fusível $40 \mathrm{~K}$ instalado no início do bloco de carga por um elo $65 \mathrm{~K}$. Com esta modificação a probabilidade de coordenação entre os dispositivos de 
proteção, para a faixa de correntes de defeito fase-terra esperadas no bloco de carga 11, caiu para $2 \%$ não sendo, portanto, viável.

No bloco de carga 6 houve uma queda da probabilidade de coordenação de 100 para $87,1 \%$. Como solução inicial procurou-se substituir o elo fusível $25 \mathrm{~K}$ por um $40 \mathrm{~K}$, porém de acordo com a Figura 5.31 observou-se que no intervalo de 109 a 210 A haverá o risco do religador operar definitivamente antes a fusão do elo fusível e que para correntes maiores do que $1100 \mathrm{~A}$, existe a possibilidade do elo fundir antes das curvas rápidas do religador na ocorrência de defeitos temporários.

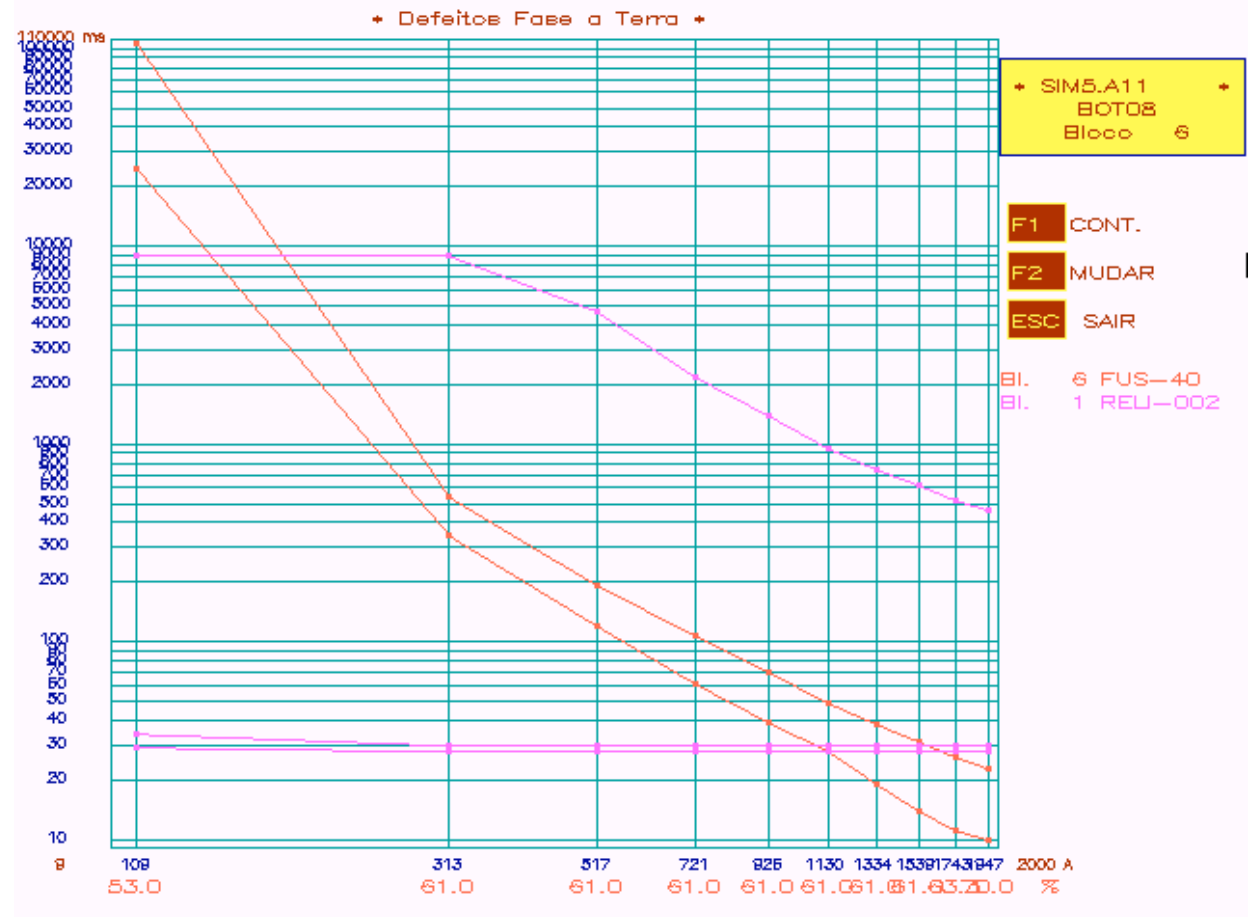

Figura 5.31 - Análise para o bloco de carga 6 com a troca do elo fusível

Analisando ainda a Figura 5.31 e com base na Equação 5.10, conclui-se que a probabilidade de não coordenação para os defeitos de terra no bloco de carga 6 com a substituição do elo fusível $25 \mathrm{~K}$ pelo $40 \mathrm{~K}$ aumentou de $12,9 \%$ para $88,6 \%$, não sendo, portanto, viável a substituição.

O bloco de carga 2 apresentou uma melhoria significativa na probabilidade de coordenação aumentando de $80 \%$ na simulação 3 para 99,8\% na simulação 5 . 
Já o bloco de carga 8 não teve nenhuma modificação em relação ao caso base considerado.

\section{6 - Discussão}

O presente capítulo abordou detalhadamente o estudo de proteção de uma rede elétrica de distribuição primária onde foi possível aplicar todos os conceitos e metodologias propostas nos capítulos anteriores.

Inicialmente foi apresentada a topologia da rede em estudo bem como as suas principais características elétricas, tais como: tensão nominal, número de trechos, número de transformadores de distribuição, demandas ativa, reativa e aparente, dentre outras.

De posse destes dados partiu-se para o dimensionamento e ajustes dos dispositivos de proteção, com base na metodologia convencional, bem estabelecida e difundida na área de proteção de redes elétricas. Adotou-se como premissa inicial a instalação de elos fusíveis no início de todos os blocos de carga e de um disjuntor associado com relé de religamento na saída da SE de distribuição.

Após esta etapa avaliou-se a coordenação entre os equipamentos de proteção aplicando a metodologia probabilística proposta. Isto possibilitou incluir na análise do problema, as probabilidades de coordenação e de não coordenação entre estes equipamentos, e dimensiona-los e ajusta-los de tal forma que não sejam consideradas situações de pior caso, cuja probabilidade é muito pequena ou nula. Esta nova metodologia contempla, portanto, uma avaliação extremamente importante, coisa que a abordagem convencional não permite.

O único problema encontrado foi com relação aos defeitos de fase em que na ocorrência de um defeito temporário não foi possível fazer com que o religador atuasse antes da fusão do elo fusível. Para solucionar este problema a solução mais segura consiste em utilizar relés digitais com disjuntores no início de todos os blocos de carga, porém isto é 
inviável no ponto de vista econômico. Por outro lado a probabilidade de ocorrência dos defeitos de fase é muito inferior aos defeitos de terra razão esta que permite com que a solução proposta apresente uma relação custo benefício bastante significativa.

Finalizando o presente capítulo, partiu-se para a simulação de cinco casos com o intuito de avaliar a sensibilidade dos parâmetros: probabilidade de ocorrência dos defeitos de fase e de terra, comprimento do subtrecho, curva de resistência de defeito e taxa de falha, no problema de coordenação da proteção. 


\section{CONCLUSÕES}

\section{1 - Considerações Gerais}

O estudo de proteção representa uma das etapas mais importantes no projeto de uma rede elétrica de distribuição primária.

As abordagens convencionais amplamente difundidas na literatura técnica são as mais utilizadas nos projetos de redes de distribuição, porém esta análise leva muitas vezes o projetista a considerar situações de pior caso, cuja probabilidade de ocorrência é nula ou muito pequena.

O presente trabalho procurou avaliar a abordagem probabilística da proteção de sobrecorrente em redes de distribuição primária onde foi possível efetuar o dimensionamento e o ajuste dos equipamentos de proteção avaliando a probabilidade de haver ou não coordenação entre todos eles.

Como ponto de partida para o presente estudo, procurou-se no capítulo 2 apresentar em detalhe as principais características de cada um dos dispositivos de proteção utilizados bem como as principais regras de dimensionamento e coordenação entre os mesmos, utilizando a abordagem convencional.

No capítulo 3 foi apresentado o estado da arte da proteção probabilística com as duas metodologias utilizadas (analítica e de simulação), apresentando as vantagens e as desvantagens de cada uma delas. Concluiu-se que o método de simulação é o mais adequado. Para melhor ilustrar as metodologias propostas, foram incluídos no texto dois exemplos básicos de aplicação.

Tendo sido desenvolvido todo o estudo sobre os equipamentos utilizados e as metodologias propostas, foi apresentada no capítulo 4 a ferramenta computacional utilizada que ainda contribuiu para efetuar os cálculos de curto-circuito e fluxo de potência. 
Completando o presente trabalho, foi desenvolvida no capítulo 5 a aplicação de todos os conceitos discutidos nos capítulos anteriores. Com base na topologia da rede e suas características elétricas foi possível efetuar a divisão da mesma em blocos de carga, calcular as correntes de curto-circuito, e verificar o fluxo de potência. Tendo isto definido partiu-se para o estudo de proteção com base nos critérios técnicos convencionais, sendo que a primeira solução não se mostrou tão adequada, razão pela qual realizou-se um segundo estudo e a partir deste efetuou-se a análise de sensibilidade a parâmetros.

Todos os estudos e análises efetuadas no presente trabalho levaram em conta redes de distribuição primária radiais. O Estudo para redes em uma configuração distinta desta (redes em anel) torna o trabalho muito mais complexo, pois relés de sobrecorrente direcionais devem ser acrescentados, visando avaliar o sentido da corrente elétrica.

\section{2 - Contribuições do Trabalho}

A análise do problema de coordenação da proteção em uma rede elétrica qualquer tem por objetivo principal fazer com que, na ocorrência de um defeito, o menor trecho de rede seja desligado.

Com a topologia da rede elétrica em análise, bem como o conhecimento de suas características elétricas, parte-se para o estudo da proteção em que são dimensionados os equipamentos e a coordenação entre eles. Tal coordenação é baseada em critérios convencionais amplamente difundidos na literatura técnica e apresentados resumidamente no capítulo 2.

O presente trabalho contribuiu significativamente em apresentar uma nova abordagem para problema de coordenação da proteção em redes radiais de distribuição primária de energia elétrica. Tal abordagem permitiu avaliar a influência de algumas variáveis aleatórias independentes, tais como taxa de falha, resistência de defeito, comprimento do subtrecho e probabilidades de ocorrência de cada um dos tipos de defeito, no estudo de proteção, possibilitando identificar para uma determinada faixa de correntes 
esperadas de defeito de fase e terra em um bloco de carga, a probabilidade de haver ou não coordenação entre os equipamentos de proteção, instalados na rede elétrica de distribuição primária.

Por outro lado a metodologia apresentada serve como ponto de partida para que a abordagem probabilística seja também aplicada para outras topologias de redes elétricas, como por exemplo, linhas de alta tensão e redes em anel.

Na análise clássica, para a avaliação da influência de modificação de um determinado parâmetro na coordenação entre os equipamentos instalados em uma rede elétrica, haverá a necessidade de ser realizado um novo estudo de proteção da mesma, o que exige um trabalho bastante árduo do projetista.

Por outro lado, a abordagem probabilística apresenta uma maior flexibilidade na análise de sensibilidade a parâmetros, em que consegue-se com extrema facilidade e rapidez verificar o impacto da mudança de uma variável aleatória no problema de coordenação da proteção.

Com base em tudo o que foi discutido, conclui-se que a metodologia probabilística de estudo da coordenação da proteção apresenta vantagens importantes em relação à abordagem clássica, uma vez que o engenheiro de proteção consegue ter uma melhor idéia das probabilidades de coordenação em função das variáveis aleatórias citadas e amplamente discutidas ao longo do texto. Disto resulta em um projeto de proteção mais lógico e racional de forma que haja o compromisso entre custo e atendimento de todos os critérios técnicos, evitando considerar situações nas quais a probabilidade de ocorrência é muito baixa ou inexistente.

\section{3 - Tópicos para desenvolvimento futuro}

Para encerrar o presente trabalho, segue uma discussão resumida de alguns tópicos que merecem análise em estudos futuros. São eles: 
a) Proteção de sobrecorrente de terra de alta impedância

O assunto em questão tem sido alvo de inúmeras pesquisas na área de engenharia elétrica, pois é muito difícil definir com exatidão um valor para a resistência de defeito, sendo que a mesma varia de região para região e está diretamente relacionada com as características geográficas e climáticas. No presente trabalho foram realizadas algumas simulações observando o impacto da variação da resistência de defeito, porém existem outras metodologias que foram ou estão sendo estudadas para melhor avaliar os defeitos de alta impedância.

Para a elaboração do presente trabalho foram realizadas pesquisas sobre defeitos de alta impedância em artigos técnicos, conforme as referências bibliográficas [8], [9] e [22]. A descrição destes artigos foi apresentada resumidamente no capítulo 2, item 2.2.5.4.

Nestas condições a implementação destas novas metodologias dos defeitos de alta impedância, pode contribuir para a obtenção de resultados mais precisos que permitirão com que o Engenheiro de proteção projete a rede elétrica de maneira segura com o menor custo possível.

b) Aplicação da metodologia em redes de distribuição em Anel

Conforme citado anteriormente, a metodologia probabilística proposta considerou apenas redes radiais de distribuição primária de energia elétrica. Uma segunda análise consiste em propor uma metodologia para avaliar a coordenação entre os dispositivos de proteção em redes em anel e na seqüência implementá-la em uma ferramenta computacional capaz de efetuar o processamento dos dados necessários para a avaliação do problema.

Além das proteções de sobrecorrente de fase e terra aplicadas nas redes radiais, utilizam em redes em anel as proteções de sobrecorrente direcionais de fase e terra, representadas, respectivamente, pelas funções ANSI 67 e 67N. As proteções de sobrecorrente direcionais avaliam o valor da corrente em módulo e fase, o que 
possibilita a proteção enxergar o sentido da corrente. Para esta avaliação todos os relés direcionais devem ser polarizados por uma outra grandeza de referência que, no caso em questão, corresponde à tensão entre fases para a função 67 e a tensão residual (somatória das tensões fase-neutro) para a função 67N.

Os ajustes efetuados nas proteções direcionais são: Corrente de disparo, curva característica de atuação, dial de tempo e ângulo de conjugado máximo [1], [2], [13] e [14].

c) Implementação do conceito de seletividade lógica na metodologia probabilística da proteção

Esta metodologia é amplamente utilizada nos relés digitais e foi desenvolvida para solucionar um problema que ocorre em um estudo de coordenação convencional. Tal problema se refere ao tempo de operação dos relés situados mais próximos da fonte que é muito alto em decorrência dos critérios estudados pela seletividade convencional.

O princípio de seletividade lógica consiste na troca de sinais lógicos entre o relé instalado na zona de proteção primária e aquele que se encontra na sua respectiva zona de retaguarda. O elemento de sobrecorrente destinado para a seletividade lógica é sensibilizado quando a corrente que passa pelo alimentador for maior do que o seu valor de atuação. Nesta condição, um relé auxiliar da unidade de proteção instalada na zona de proteção primária onde ocorreu o defeito, atuará um de seus contatos auxiliares previamente programado para esta função, enviando um sinal lógico para uma entrada digital específica do relé instalado na zona de retaguarda (a montante). Este relé ao receber este sinal lógico fica bloqueado por um intervalo de tempo de aproximadamente 200 ms [7, 14]. Após este período, se a unidade de proteção da zona primária na qual ocorreu o defeito não enviar uma ordem de abertura para o respectivo disjuntor, o equipamento de proteção da zona de retaguarda, sem a ordem de bloqueio lógico, atuará e abrirá o circuito. Neste caso o trecho de rede desenergizado será maior e o sistema não será seletivo. 
Com esta técnica, não é necessário ter uma diferença de tempo de 300 ms (aproximadamente) entre o relé da zona primária e o dispositivo que está a sua montante. $\mathrm{O}$ ajuste da temporização destes dois dispositivos geralmente é igual a do relé a montante. A grande vantagem disto é que todos os relés situados a montante do dispositivo instalado mais próximo da carga têm os seus respectivos tempos de atuação diminuídos e caso ocorra uma falta nas suas respectivas zonas de proteção primária, o tempo no qual cada trecho de rede ficará submetido a condições anormais, será menor do que se estivesse sendo utilizado os critérios de coordenação convencionais.

Com base no princípio de funcionamento apresentado nos parágrafos anteriores, toda esta metodologia deve ser implementada em um sistema computacional para avaliar as probabilidades de coordenação entre os equipamentos de proteção. A única desvantagem desta metodologia é que em todos os blocos de carga devem ser instalados equipamentos dotados de relés digitais que contemplem esta função de seletividade lógica e, portanto, o custo de implantação se torna extremamente alto face a solução com elos fusíveis, religadores e seccionalizadores.

d) Aplicação da metodologia proposta em Sistema de Transmissão de Energia Elétrica:

Uma outra proposta de pesquisa futura diz respeito a aplicação da metodologia proposta e estudos de casos em sistemas de transmissão de energia elétrica, tanto radiais quanto em anel, avaliando as probabilidades de coordenação entre os equipamentos de proteção associados. 


\section{REFERÊNCIAS BIBLIOGRÁFICAS}

[1] Mamede Filho, J. Manual de Equipamentos Elétricos, Ed. LTC - Livros Técnicos e Científicos, Rio de Janeiro: Vol. 1, 2ª edição, pp 53-74, 173-219, 309-521, 1994.

[2] Giguer, S. Proteção de Sistemas de Distribuição, Ed. Sagra, Porto Alegre: $1^{\mathrm{a}}$ edição, 1988.

[3] Robba, E.J. Nota técnica NT01 - Critérios para o Desenvolvimento do Estudo de Proteção contra Sobrecorrentes, Escola Politécnica da USP, 1996.

[4] Mamede Filho, J. Manual de Equipamentos Elétricos, Ed. LTC - Livros Técnicos e Científicos, Rio de Janeiro: Vol. 2, 2ª edição, pp 347-415, 1994.

[5] Coleção Distribuição de Energia Elétrica, Ed. Campus/Eletrobrás, Rio de Janeiro: Vol. 2: Proteção de Sistemas Aéreos de Distribuição, 1982.

[6] Senger, E.C. Notas de aula da disciplina PEA 5778 - Proteção Digital das redes Elétricas de Potência, Escola Politécnica da USP, 2003.

[7] Schneider Electric Industries SAS. Sepam Series 40 - Merlin Gerin - Installation and User's Manual - Ref - PCRED301006EN/2 - ART. 08556, Grenoble, França, 2003.

[8] Wester, C.G. High Impedance Fault Detection on Distribution Systems. Rural Electric Power Conference, 1998. Papers Presented at the 42nd Annual Conference, 26-28 April 1998, pp c5 - 1-5.

[9] Senger, E.C; Kaiser, W; Santos, J.C; Burt P.M.S; Malagodi, C.V.S. Broken Conductors Protection System Using Carrier Communication. IEEE Transactions on Power Systems, Vol. 15, № 2, April 2000, pp 525-530. 
[10] Kindermann, G. Curto Circuito, Ed. Sagra-DC Luzzatto, Porto Alegre: $1^{\mathrm{a}}$ edição, 1992.

[11] Oliveira, C.C.B; Schmidt, H.P; Kagan, N; Robba, E.J. Introdução a Sistemas Elétricos de Potência - Componentes Simétricas, Ed. Edgard Blücher, São Paulo: 2a edição, 1996.

[12] Senger, E.C. Notas de aula da disciplina PEA 5729 - Proteção de Sistemas Elétricos de Potência, Escola Politécnica da USP, 2003.

[13] Kindermann, G. Proteção de Sistemas Elétricos de Potência - Volume I, Universidade Federal de Santa Catarina - UFSC, Florianópolis: $1^{\text {a }}$ edição, 1999.

[14] Schneider Electric Industries SAS. Protection Guide - Ref Art 065193, Grenoble, França, 2003.

[15] Costa Neto, P.L.O; Cymbalista, M. Probabilidades: resumos teóricos, exercícios resolvidos, exercícios propostos, Ed. Edgard Blücher, São Paulo, 1974.

[16] Sato, F; Garcia, A.V; Monticelli, A. Parallel Implementation of Probabilistic ShortCircuit Analysis by the Monte Carlo approach. IEEE Transactions on Power Systems, Vol. 9, N² 2, May 1994, pp 826-832.

[17] Robba, E.J; Kagan, N; Oliveira, C.C.B; Schmidt, H.P. Proteção de Redes de Distribuição de Energia Elétrica com Enfoque Probabilístico. In: Congresso Latino Americano de Distribuição de Energia Elétrica - CONLADIS, 3., São Paulo, 1998. pp 256-260.

[18] Sá, J.P; Afonso, J; Rodrigues, R. A Probabilistic Approach to Setting Distance Relays in Transmission Networks. IEEE Transactions on Power Delivery, Volume: 12 , Issue: 2, April 1997 pp 681 - 686. 
[19] Zhu, J; Lubkeman, D.L; Fellow, A.A.G. Automated Fault Location and Diagnosis on Electric Power Distribution Feeders. IEEE Transactions on Power Systems, Vol. 12, $\mathrm{N}^{\circ} 2$, April 1997, pp 801-809.

[20] Kangvansaichol, K; Pittayapat, P; Eua-arporn, B. Routine Test Interval Decision for Protective Systems Based on Probabilistic Approach. International Conference on Power System Technology, 2000. Proceedings. PowerCon 2000. Volume: 2 , 4-7 Dec. 2000 pp 977 - 982 vol.2.

[21] Souza, C.G. Identificação e Localização de Faltas em Redes de Distribuição de Energia Elétrica Baseadas nos Níveis de Seqüência Zero e Negativa Pré e Pós Falta. Dissertação de Mestrado, Universidade Federal de Juiz de Fora - UFJF, Maio 2003.

[22] Lazkano, A; Ruiz, J; Aramendi, E; Leturiondo, L.A; González, J.A. Study of High Impedance Fault Detection in Levante Area in Spain. Ninth International Conference on Harmonics and Quality of Power, 2000. Proceedings. Volume: 3, 1-4 Oct. 2000 pp 1011 - 1016 vol.3.

[23] Dudor, J.S; Padden, L.K. Protective Relaying on Medium and High Voltage Systems. IEEE Industry Applications Magazine, March/April 1996, pp 27-34.

[24] Kojovic, Lj.A; Witte, J.F. A New Method in Reducing the Overcurrent Protection Response Times at High Fault Currents to Protect Equipment from Extended Stress. Transmission and Distribution Conference and Exposition, 2001 IEEE/PES, Volume: 1, 28 Oct.-2 Nov. 2001 pp 65 - 70 vol.1.

[25] Leão, R.P.S; Medeiros, E.B; Silveira, J.G; Medeiros, M.S; Pinheiro, T.M.M. Avaliação do Compromisso no Uso de Religadores em Alimentadores com Cargas Sensíveis. V SBQEE - Seminário Brasileiro sobre Qualidade da Energia Elétrica, Agosto 2003, Aracaju - Sergipe - Brasil, pp 303-308. 
[26] M, S. Protection of Distribution Systems using Electronic Devices. The Institution of Electrical Engineers - IEE, 1999, pp 1/1-1/4.

[27] Associação Brasileira de Normas Técnicas - ABNT. Elos Fusíveis de Distribuição NBR 5359, Dezembro, 1989.

[28] International Electrotechnical Commission. IEC 255-3 - Electrical Relays - Part 3Single Input Energizing Quantity Measuring Relays With Dependent or Independent Time. September, 1992.

[29] McGraw Edison Company, Power System Division. Distribution System Protection Manual.

[30] Associação Brasileira de Normas Técnicas - ABNT. Transformador de Corrente - NBR 6856, Abril, 1992.

[31] Schneider Electric Brasil Ltda - Distribuição MT - Gama de aparelhagem, guia de escolha Ref MT/004/Br - rev 3, São Paulo - Brasil, Outubro, 2000.

[32] Meyer, P. L.: Probabilidade - Aplicações à Estatística, LTC - Livros Técnicos e Científicos, São Paulo, 1983.

[33] Robba, E.J; Kagan, N; Oliveira, C.C.B; Schmidt, H.P. - Sistema PROCOR Especificação de programas, Relatório técnico CED/IEE-USP, São Paulo, 1997. 
ANEXO A

TABELAS COM INFORMAÇÕES GERAIS DA REDE ELÉTRICA EM ESTUDO 
Segue abaixo os dados e características físicas e elétricas de todos os trechos e blocos de carga da rede elétrica utilizada no presente trabalho.

As Tabelas estão organizadas como se segue:

- Tabela A.1 ilustra as características elétricas dos condutores;

- As Tabela A.2, A.3, A.4 e A.5 indicam as curvas das resistências de defeito A, B, C e D, respectivamente;

- A Tabela A.6 mostra o fator de assimetria da corrente em função da relação X/R;

- A Tabela A.7 representa o número de transformadores instalados com a sua respectiva potência aparente $(\mathrm{S})$ e demandas ativa, reativa e aparente das cargas;

- A Tabela A.8 ilustra os dados de cada trecho de rede, tais como o tipo de cabo utilizado, comprimento, taxa de falha por ano e dispositivo de proteção instalado;

- Finalmente nas Tabelas A.9 até A.23 são indicadas as probabilidades de ocorrência de defeito trifásico, dupla fase, dupla fase-terra e fase-terra e a curva de resistência de defeito para os trechos dos blocos 1 até 15 , respectivamente. 


\begin{tabular}{|c|c|c|c|c|c|c|}
\hline Tipo de cabo & $\begin{array}{c}\text { Resistência de } \\
\text { seqüência } \\
\text { positiva } \\
\text { (ohms/km) }\end{array}$ & $\begin{array}{c}\text { Reatância de } \\
\text { seqüência } \\
\text { positiva } \\
\text { (ohms/km) }\end{array}$ & $\begin{array}{c}\text { Resistência de } \\
\text { seqüência zero } \\
\text { (ohms/km) }\end{array}$ & $\begin{array}{c}\text { Reatância de } \\
\text { seqüência } \\
\text { zero } \\
\text { (ohms/km) }\end{array}$ & $\begin{array}{c}\text { Corrente } \\
\text { (A) }\end{array}$ & $\begin{array}{c}\text { Taxa de } \\
\text { falhas } \\
\text { /ano/ km }\end{array}$ \\
\hline \hline 477MCMCA & 0,1330 & 0,3901 & 0,3093 & 2,0526 & 485,0 & 0,200 \\
\hline 336MCMCA & 0,1876 & 0,4033 & 0,3639 & 2,0658 & 395,0 & 0,200 \\
\hline 4/0AWGCA & 0,2977 & 0,4249 & 0,4740 & 2,0874 & 293,0 & 0,200 \\
\hline 1/0AWGCA & 0,5954 & 0,4513 & 0,7717 & 2,1138 & 184,0 & 0,400 \\
\hline 2AWGCA & 0,9477 & 0,4687 & 1,1240 & 2,1312 & 138,0 & 0,500 \\
\hline 4AWGCA & 1,5040 & 0,4861 & 1,6803 & 2,1486 & 100,0 & 0,600 \\
\hline 477ACSR & 0,1342 & 0,3793 & 0,3105 & 2,0417 & 500,0 & 0,200 \\
\hline 336ACSR & 0,1902 & 0,3923 & 0,3665 & 2,0547 & 410,0 & 0,200 \\
\hline 4/0ACSR & 0,3679 & 0,4750 & 0,5442 & 2,1374 & 308,0 & 0,500 \\
\hline 1/0ACSR & 0,6960 & 0,5209 & 0,8723 & 2,1833 & 200,0 & 0,400 \\
\hline 2ACSR & 1,0503 & 0,5255 & 1,2266 & 2,1879 & 152,0 & 0,500 \\
\hline 4ACSR & 1,5972 & 0,5220 & 1,7735 & 2,1844 & 114,0 & 0,600 \\
\hline 1/0CU & 0,3766 & 0,4513 & 0,5529 & 2,1138 & 242,0 & 0,400 \\
\hline 2CU & 0,5935 & 0,4671 & 0,7698 & 2,1296 & 188,0 & 0,500 \\
\hline 4CU & 0,9341 & 0,4904 & 1,1104 & 2,1529 & 130,0 & 0,600 \\
\hline 6CU & 1,4854 & 0,5078 & 1,6617 & 2,1703 & 97,0 & 0,600 \\
\hline
\end{tabular}

Tabela A.1 - Características elétricas dos condutores

\begin{tabular}{|c|c|}
\hline Resistência de defeito (ohms) & Probabilidade de ocorrência \\
\hline \hline 20,0 & 0,200 \\
\hline 40,0 & 0,200 \\
\hline 60,0 & 0,200 \\
\hline 80,0 & 0,200 \\
\hline 100,0 & 0,200 \\
\hline
\end{tabular}

Tabela A.2 - Curva da resistência de defeito A 


\begin{tabular}{|c|c|}
\hline Resistência de defeito (ohms) & Probabilidade de ocorrência \\
\hline \hline 100,0 & 0,100 \\
\hline 200,0 & 0,100 \\
\hline 300,0 & 0,100 \\
\hline 400,0 & 0,200 \\
\hline 500,0 & 0,100 \\
\hline 600,0 & 0,100 \\
\hline 700,0 & 0,100 \\
\hline 800,0 & 0,100 \\
\hline 900,0 & 0,050 \\
\hline 1000,0 & 0,050 \\
\hline
\end{tabular}

Tabela A.3 - Curva da resistência de defeito B

\begin{tabular}{|c|c|}
\hline Resistência de defeito (ohms) & Probabilidade de ocorrência \\
\hline 0 & 0,300 \\
\hline 50,0 & 0,200 \\
\hline 100,0 & 0,200 \\
\hline 400,0 & 0,200 \\
\hline 1000,0 & 0,100 \\
\hline
\end{tabular}

Tabela A.4 - Curva da resistência de defeito C

\begin{tabular}{|c|c|}
\hline Resistência de defeito (ohms) & Probabilidade de ocorrência \\
\hline \hline 0 & 0,500 \\
\hline 10,0 & 0,200 \\
\hline 20,0 & 0,300 \\
\hline
\end{tabular}

Tabela A.5 - Curva da resistência de defeito D 


\begin{tabular}{|c|c|}
\hline Relação X/R & Fator de Assimetria \\
\hline 0,10 & 1,04 \\
\hline 0,20 & 1,00 \\
\hline 0,30 & 1,00 \\
\hline 0,40 & 1,00 \\
\hline 0,50 & 1,00 \\
\hline 0,60 & 1,00 \\
\hline 0,70 & 1,00 \\
\hline 0,80 & 1,02 \\
\hline 0,90 & 1,04 \\
\hline 1,00 & 1,05 \\
\hline 2,00 & 1,17 \\
\hline 3,00 & 1,30 \\
\hline 4,00 & 1,37 \\
\hline 5,00 & 1,44 \\
\hline 6,00 & 1,47 \\
\hline 7,00 & 1,50 \\
\hline 8,00 & 1,54 \\
\hline 9,00 & 1,57 \\
\hline 10,0 & 1,60 \\
\hline 20,0 & 1,68 \\
\hline 30,0 & 1,70 \\
\hline 40,0 & 1,71 \\
\hline 50,0 & 1,72 \\
\hline 60,0 & 1,74 \\
\hline 70,0 & 1,74 \\
\hline 80,0 & 1,74 \\
\hline 90,0 & 1,75 \\
\hline
\end{tabular}

Tabela A.6 - Fatores de assimetria em função da relação X/R 


\begin{tabular}{|c|c|c|c|c|c|}
\hline \multirow{2}{*}{$\begin{array}{c}\text { Número } \\
\text { interno da } \\
\text { barra }\end{array}$} & $\begin{array}{c}\text { Transformadores } \\
\text { de Distribuição }\end{array}$ & \multicolumn{3}{|c|}{ Demanda máxima } \\
\cline { 2 - 6 } & $\boldsymbol{N}^{\boldsymbol{o}}$ & $\boldsymbol{S}$ (KVA) & $\boldsymbol{k V A}$ & $\boldsymbol{k} \boldsymbol{W}$ & $\boldsymbol{k V A r}$ \\
\hline \hline 0007 & 1 & 30,0 & 19,416 & 19,000 & 4,000 \\
\hline 0008 & 1 & 30,0 & 25,495 & 23,000 & 11,000 \\
\hline 0009 & 2 & 60,0 & 55,362 & 52,000 & 19,000 \\
\hline 0010 & 1 & 30,0 & 18,868 & 16,000 & 10,000 \\
\hline 0011 & 1 & 30,0 & 25,495 & 23,000 & 11,000 \\
\hline 0012 & 1 & 30,0 & 14,560 & 14,000 & 4,000 \\
\hline 0013 & 2 & 150,0 & 21,471 & 19,000 & 10,000 \\
\hline 0014 & 1 & 75,0 & 56,080 & 48,000 & 29,000 \\
\hline 0016 & 1 & 45,0 & 35,171 & 34,000 & 9,000 \\
\hline 0018 & 2 & 105,0 & 52,355 & 46,000 & 25,000 \\
\hline 0020 & 2 & 75,0 & 42,450 & 41,000 & 11,000 \\
\hline 0021 & 1 & 15,0 & 10,000 & 8,000 & 6,000 \\
\hline 0022 & 1 & 45,0 & 65,924 & 61,000 & 25,000 \\
\hline 0024 & 1 & 30,0 & 7,280 & 7,000 & 2,000 \\
\hline 0025 & 1 & 15,0 & 14,765 & 13,000 & 7,000 \\
\hline 0026 & 1 & 30,0 & 10,000 & 8,000 & 6,000 \\
\hline 0028 & 3 & 135,0 & 48,847 & 45,000 & 19,000 \\
\hline 0030 & 1 & 30,0 & 14,765 & 13,000 & 7,000 \\
\hline 0032 & 1 & 30,0 & 15,652 & 14,000 & 7,000 \\
\hline 0033 & 1 & 30,0 & 16,553 & 15,000 & 7,000 \\
\hline 0035 & 1 & 10,0 & 5,385 & 5,000 & 2,000 \\
\hline 0036 & 1 & 30,0 & 28,018 & 23,000 & 16,000 \\
\hline 0037 & 1 & 30,0 & 18,788 & 17,000 & 8,000 \\
\hline 0038 & 1 & 45,0 & 16,553 & 15,000 & 7,000 \\
\hline 0039 & 1 & 30,0 & 18,358 & 16,000 & 9,000 \\
\hline 0040 & 1 & 75,0 & 48,600 & 39,000 & 29,000 \\
\hline 0041 & 1 & 15,0 & 13,601 & 11,000 & 8,000 \\
\hline 0042 & 1 & 30,0 & 5,385 & 5,000 & 2,000 \\
\hline 0043 & 1 & 75,0 & 48,754 & 44,000 & 21,000 \\
\hline 0045 & 1 & 75,0 & 20,248 & 17,000 & 11,000 \\
\hline & & & & & \\
\hline & 1 & 1 & 1 & 1500 \\
\hline
\end{tabular}




\begin{tabular}{|c|c|c|c|c|c|}
\hline 0046 & 1 & 30,0 & 10,817 & 9,000 & 6,000 \\
\hline 0047 & 1 & 45,0 & 18,358 & 16,000 & 9,000 \\
\hline 0048 & 2 & 90,0 & 48,600 & 39,000 & 29,000 \\
\hline 0049 & 1 & 150,0 & 112,730 & 102,000 & 48,000 \\
\hline 0050 & 1 & 45,0 & 35,468 & 33,000 & 13,000 \\
\hline 0051 & 2 & 75,0 & 34,482 & 30,000 & 17,000 \\
\hline 0052 & 1 & 45,0 & 73,763 & 71,000 & 20,000 \\
\hline 0053 & 5 & 495,0 & 166,436 & 151,000 & 70,000 \\
\hline 0054 & 1 & 45,0 & 21,587 & 21,000 & 5,000 \\
\hline 0055 & 1 & 45,0 & 19,416 & 19,000 & 4,000 \\
\hline 0056 & 4 & 180,0 & 40,522 & 39,000 & 11,000 \\
\hline 0057 & 3 & 155,0 & 52,393 & 48,000 & 21,000 \\
\hline 0059 & 1 & 30,0 & 17,493 & 15,000 & 9,000 \\
\hline 0061 & 1 & 112,5 & 85,235 & 73,000 & 44,000 \\
\hline 0063 & 1 & 45,0 & 17,493 & 15,000 & 9,000 \\
\hline 0064 & 1 & 30,0 & 15,652 & 14,000 & 7,000 \\
\hline 0065 & 3 & 232,5 & 85,235 & 73,000 & 44,000 \\
\hline 0066 & 1 & 112,5 & 88,814 & 72,000 & 52,000 \\
\hline 0067 & 1 & 45,0 & 15,652 & 14,000 & 7,000 \\
\hline 0068 & 1 & 150,0 & 122,874 & 103,000 & 67,000 \\
\hline 0069 & 1 & 15,0 & 13,416 & 12,000 & 6,000 \\
\hline 0071 & 2 & 120,0 & 34,438 & 31,000 & 15,000 \\
\hline 0072 & 1 & 30,0 & 48,847 & 45,000 & 19,000 \\
\hline 0073 & 1 & 45,0 & 36,674 & 33,000 & 16,000 \\
\hline 0074 & 1 & 45,0 & 19,235 & 17,000 & 9,000 \\
\hline 0075 & 1 & 45,0 & 16,492 & 16,000 & 4,000 \\
\hline 0076 & 1 & 30,0 & 33,106 & 30,000 & 14,000 \\
\hline 0077 & 2 & 105,0 & 24,698 & 23,000 & 9,000 \\
\hline 0079 & 1 & 30,0 & 10,770 & 10,000 & 4,000 \\
\hline 0080 & 1 & 30,0 & 14,560 & 14,000 & 4,000 \\
\hline 0081 & 1 & 75,0 & 13,601 & 13,000 & 4,000 \\
\hline 0082 & 2 & 45,0 & 27,514 & 26,000 & 9,000 \\
\hline 0083 & 1 & 30,0 & 42,720 & 40,000 & 15,000 \\
\hline
\end{tabular}




\begin{tabular}{|c|c|c|c|c|c|}
\hline 0085 & 2 & 105,0 & 24,352 & 23,000 & 8,000 \\
\hline 0086 & 1 & 30,0 & 12,649 & 12,000 & 4,000 \\
\hline 0087 & 1 & 45,0 & 14,866 & 14,000 & 5,000 \\
\hline 0088 & 1 & 45,0 & 41,146 & 37,000 & 18,000 \\
\hline 0089 & 1 & 30,0 & 15,264 & 13,000 & 8,000 \\
\hline 0090 & 1 & 30,0 & 8,544 & 8,000 & 3,000 \\
\hline 0091 & 2 & 90,0 & 32,650 & 29,000 & 15,000 \\
\hline 0092 & 2 & 45,0 & 37,696 & 35,000 & 14,000 \\
\hline 0093 & 1 & 10,0 & 2,236 & 2,000 & 1,000 \\
\hline 0094 & 1 & 45,0 & 13,601 & 13,000 & 4,000 \\
\hline 0095 & 1 & 45,0 & 55,946 & 51,000 & 23,000 \\
\hline 0096 & 2 & 60,0 & 18,028 & 15,000 & 10,000 \\
\hline 0098 & 1 & 30,0 & 13,416 & 12,000 & 6,000 \\
\hline 0099 & 1 & 10,0 & 1,414 & 1,000 & 1,000 \\
\hline 0100 & 3 & 105,0 & 32,650 & 29,000 & 15,000 \\
\hline 0101 & 1 & 75,0 & 46,648 & 40,000 & 24,000 \\
\hline 0103 & 2 & 90,0 & 1,414 & 1,000 & 1,000 \\
\hline 0104 & 1 & 45,0 & 15,652 & 14,000 & 7,000 \\
\hline 0105 & 2 & 75,0 & 14,765 & 13,000 & 7,000 \\
\hline \hline Total & $\mathbf{1 1 2}$ & 5247,5 & $\mathbf{2 6 0 1 , 1 7}$ & $\mathbf{2 3 4 0 , 0 0}$ & $\mathbf{1 1 3 6 , 0 0}$ \\
\hline & & & & & \\
\hline
\end{tabular}

Tabela A.7 - Dados das cargas da rede elétrica em estudo 


\begin{tabular}{|c|c|c|c|c|c|}
\hline \multicolumn{2}{|c|}{$\begin{array}{l}\text { Número } \\
\text { da barra }\end{array}$} & \multirow{2}{*}{$\begin{array}{l}\text { Tipo } \\
\text { de } \\
\text { Cabo }\end{array}$} & \multirow{2}{*}{$\begin{array}{c}\text { Compri- } \\
\text { mento } \\
\text { (m) }\end{array}$} & \multirow{2}{*}{$\begin{array}{c}\text { Código } \\
\text { da } \\
\text { chave }\end{array}$} & \multirow{2}{*}{$\begin{array}{c}\text { Taxa } \\
\text { de } \\
\text { falha/ano }\end{array}$} \\
\hline Atual & $\begin{array}{c}\text { Anterio } \\
r\end{array}$ & & & & \\
\hline 0001 & 0000 & & 0 & RELI & 0 \\
\hline 0002 & 0001 & 477MCMCA & 65 & & 0,013 \\
\hline 0003 & 0002 & 477MCMCA & 5 & FACA & 0,001 \\
\hline 0004 & 0003 & 477MCMCA & 80 & & 0,016 \\
\hline 0005 & 0004 & 477MCMCA & 483 & & 0,097 \\
\hline 0006 & 0005 & 477MCMCA & 5 & FACA & 0,001 \\
\hline 0007 & 0006 & 4/0AWGCA & 112 & & 0,022 \\
\hline 0008 & 0006 & 477MCMCA & 5 & FUSI & 0,001 \\
\hline 0009 & 0007 & 477MCMCA & 247 & & 0,049 \\
\hline 0010 & 0007 & 477MCMCA & 5 & FUSI & 0,001 \\
\hline 0011 & 0008 & 2AWGCA & 280 & & 0,140 \\
\hline 0012 & 0009 & 2AWGCA & 321 & & 0,161 \\
\hline 0013 & 0009 & 477MCMCA & 73 & & 0,015 \\
\hline 0014 & 0010 & 2AWGCA & 140 & & 0,070 \\
\hline 0015 & 0012 & 2AWGCA & 73 & & 0,036 \\
\hline 0016 & 0013 & 477MCMCA & 5 & FACA & 0,001 \\
\hline 0017 & 0013 & 477MCMCA & 63 & & 0,013 \\
\hline 0018 & 0014 & 2AWGCA & 171 & & 0,086 \\
\hline 0019 & 0015 & 477MCMCA & 5 & FUSI & 0,001 \\
\hline 0020 & 0016 & 4/0AWGCA & 503 & & 0,101 \\
\hline 0021 & 0017 & 477MCMCA & 61 & & 0,012 \\
\hline 0022 & 0018 & 2AWGCA & 272 & & 0,136 \\
\hline 0023 & 0019 & 2AWGCA & 46 & & 0,023 \\
\hline 0024 & 0020 & 4/0AWGCA & 167 & & 0,033 \\
\hline 0025 & 0020 & 2AWGCA & 5 & & 0,002 \\
\hline 0026 & 0021 & 477MCMCA & 150 & & 0,030 \\
\hline 0027 & 0022 & 2AWGCA & 130 & & 0,065 \\
\hline 0028 & 0022 & 2AWGCA & 146 & & 0,073 \\
\hline 0029 & 0024 & 477MCMCA & 5 & FACA & 0,001 \\
\hline
\end{tabular}




\begin{tabular}{|c|c|c|c|c|c|}
\hline 0030 & 0025 & 2AWGCA & 86 & & 0,043 \\
\hline 0031 & 0026 & 477MCMCA & 5 & & 0,001 \\
\hline 0032 & 0026 & 336MCMCA & 100 & & 0,020 \\
\hline 0033 & 0029 & 2AWGCA & 5 & & 0.002 \\
\hline 0034 & 0029 & 4/0AWGCA & 100 & & 0,020 \\
\hline 0035 & 0031 & 477MCMCA & 50 & & 0,010 \\
\hline 0036 & 0032 & 2AWGCA & 121 & & 0,060 \\
\hline 0037 & 0032 & 2AWGCA & 170 & & 0,085 \\
\hline 0038 & 0033 & 2AWGCA & 121 & & 0,060 \\
\hline 0039 & 0034 & 2AWGCA & 5 & & 0,002 \\
\hline 0040 & 0034 & 4/0AWGCA & 133 & & 0,027 \\
\hline 0041 & 0034 & 477MCMCA & 5 & FUSI & 0,001 \\
\hline 0042 & 0035 & 2AWGCA & 125 & & 0,063 \\
\hline 0043 & 0035 & 477MCMCA & 87 & & 0,017 \\
\hline 0044 & 0036 & 336MCMCA & 70 & & 0,014 \\
\hline 0045 & 0036 & 2AWGCA & 108 & & 0,054 \\
\hline 0046 & 0037 & 2AWGCA & 232 & & 0,116 \\
\hline 0047 & 0039 & 2AWGCA & 10 & & 0,005 \\
\hline 0048 & 0040 & 4/0AWGCA & 340 & & 0,068 \\
\hline 0049 & 0040 & 477MCMCA & 5 & FUSI & 0,001 \\
\hline 0050 & 0041 & 2AWGCA & 156 & & 0,078 \\
\hline 0051 & 0043 & 2AWGCA & 297 & & 0,148 \\
\hline 0052 & 0043 & 477MCMCA & 241 & & 0,048 \\
\hline 0053 & 0049 & 2AWGCA & 313 & & 0,156 \\
\hline 0054 & 0050 & 4/0AWGCA & 145 & & 0,029 \\
\hline 0055 & 0052 & 2AWGCA & 96 & & 0,048 \\
\hline 0056 & 0052 & 477MCMCA & 428 & & 0,086 \\
\hline 0057 & 0053 & 2AWGCA & 417 & & 0,208 \\
\hline 0058 & 0056 & 477MCMCA & 5 & & 0,001 \\
\hline 0059 & 0058 & 477MCMCA & 161 & & 0,032 \\
\hline 0060 & 0058 & 2AWGCA & 58 & & 0,029 \\
\hline 0061 & 0059 & 477MCMCA & 5 & FUSI & 0,001 \\
\hline 0062 & 0059 & 2AWGCA & 136 & & 0,068 \\
\hline
\end{tabular}




\begin{tabular}{|c|c|c|c|c|c|}
\hline 0063 & 0059 & 477MCMCA & 121 & & 0,024 \\
\hline 0064 & 0060 & 477MCMCA & 5 & SECI & 0,001 \\
\hline 0065 & 0061 & 2AWGCA & 502 & & 0,251 \\
\hline 0066 & 0062 & 477MCMCA & 5 & FUSI & 0,001 \\
\hline 0067 & 0064 & 2AWGCA & 318 & & 0,159 \\
\hline 0068 & 0066 & 2AWGCA & 70 & & 0,035 \\
\hline 0069 & 0067 & 477MCMCA & 5 & FUSI & 0,001 \\
\hline 0070 & 0067 & 477MCMCA & 5 & FUSI & 0,001 \\
\hline 0071 & 0068 & 2AWGCA & 281 & & 0,140 \\
\hline 0072 & 0069 & $6 \mathrm{CU}$ & 196 & & 0,118 \\
\hline 0073 & 0070 & 2AWGCA & 131 & & 0,065 \\
\hline 0074 & 0072 & $6 \mathrm{CU}$ & 145 & & 0,087 \\
\hline 0075 & 0072 & 2AWGCA & 56 & & 0,028 \\
\hline 0076 & 0073 & 2AWGCA & 200 & & 0,100 \\
\hline 0077 & 0073 & 2AWGCA & 146 & & 0,073 \\
\hline 0078 & 0074 & 477MCMCA & 5 & FUSI & 0,001 \\
\hline 0079 & 0076 & $6 \mathrm{CU}$ & 106 & & 0,064 \\
\hline 0080 & 0076 & 2AWGCA & 63 & & 0,032 \\
\hline 0081 & 0078 & $6 \mathrm{CU}$ & 167 & & 0,100 \\
\hline 0082 & 0080 & 2AWGCA & 126 & & 0,063 \\
\hline 0083 & 0081 & 2AWGCA & 25 & & 0,013 \\
\hline 0084 & 0082 & 2AWGCA & 55 & & 0,027 \\
\hline 0085 & 0082 & 2AWGCA & 135 & & 0,068 \\
\hline 0086 & 0083 & 2AWGCA & 145 & & 0,072 \\
\hline 0087 & 0083 & 2AWGCA & 155 & & 0,078 \\
\hline 0088 & 0083 & 2AWGCA & 111 & & 0,056 \\
\hline 0089 & 0084 & 477MCMCA & 5 & FUSI & 0,001 \\
\hline 0090 & 0088 & 2AWGCA & 355 & & 0,177 \\
\hline 0091 & 0088 & 2AWGCA & 200 & & 0,100 \\
\hline 0092 & 0089 & 2AWGCA & 156 & & 0,078 \\
\hline 0093 & 0089 & 336MCMCA & 255 & & 0,051 \\
\hline 0094 & 0092 & 2AWGCA & 130 & & 0,065 \\
\hline 0095 & 0092 & 336MCMCA & 226 & & 0,045 \\
\hline
\end{tabular}




\begin{tabular}{|c|c|c|c|c|c|}
\hline 0096 & 0093 & 336MCMCA & 361 & & 0,072 \\
\hline 0097 & 0093 & 477MCMCA & 5 & FUSI & 0,001 \\
\hline 0098 & 0095 & 336MCMCA & 225 & & 0,045 \\
\hline 0099 & 0095 & 477MCMCA & 5 & FUSI & 0,001 \\
\hline 0100 & 0095 & 336MCMCA & 317 & & 0,063 \\
\hline 0101 & 0096 & 336MCMCA & 130 & & 0,026 \\
\hline 0102 & 0097 & 2AWGCA & 367 & & 0,184 \\
\hline 0103 & 0099 & 2AWGCA & 303 & & 0,152 \\
\hline 0104 & 0101 & 336MCMCA & 224 & & 0,045 \\
\hline 0105 & 0101 & 336MCMCA & 210 & & 0,042 \\
\hline 0106 & 0104 & 336ACSR & 65 & & 0,013 \\
\hline
\end{tabular}

Tabela A.8 - Dados dos trechos da rede elétrica em estudo

Na coluna da Tabela A.8, relativa aos dispositivos de proteção, as nomenclaturas apresentadas significam:

- RELI - Chave religadora ou simplesmente, Religador;

- SECI - Seccionalizador;

- FUSI - Chave fusível;

- FACA - Chave Faca.

\begin{tabular}{|c|c|c|c|c|c|c|}
\hline \multicolumn{2}{|c|}{$\begin{array}{c}\text { Número } \\
\text { da barra }\end{array}$} & \multicolumn{4}{c|}{$\begin{array}{c}\text { Probabilidades dos } \\
\text { defeitos }\end{array}$} & $\begin{array}{c}\text { Curva da } \\
\text { Resistência } \\
\text { de defeito }\end{array}$ \\
\hline \hline Inicial & Terminal & $3 \boldsymbol{\phi}$ & $2 \boldsymbol{\phi}$ & $\boldsymbol{\phi} \boldsymbol{T}$ & $\mathbf{2} \boldsymbol{T}$ & \\
\hline \hline 0001 & 0000 & 0,05 & 0,10 & 0,70 & 0,15 & $\mathrm{~A}$ \\
\hline 0002 & 0001 & 0,05 & 0,15 & 0,70 & 0,10 & $\mathrm{~A}$ \\
\hline 0003 & 0002 & 0,05 & 0,15 & 0,70 & 0,10 & $\mathrm{~A}$ \\
\hline 0004 & 0003 & 0,05 & 0,15 & 0,70 & 0,10 & $\mathrm{~A}$ \\
\hline 0005 & 0004 & 0,05 & 0,15 & 0,70 & 0,10 & $\mathrm{~A}$ \\
\hline 0006 & 0005 & 0,05 & 0,15 & 0,70 & 0,10 & $\mathrm{~A}$ \\
\hline 0007 & 0006 & 0,05 & 0,15 & 0,70 & 0,10 & $\mathrm{~A}$ \\
\hline 0009 & 0007 & 0,05 & 0,15 & 0,70 & 0,10 & $\mathrm{~A}$ \\
\hline
\end{tabular}




\begin{tabular}{|c|c|c|c|c|c|c|}
\hline 0012 & 0009 & 0,05 & 0,15 & 0,70 & 0,10 & A \\
\hline 0013 & 0009 & 0,05 & 0,15 & 0,70 & 0,10 & A \\
\hline 0015 & 0012 & 0,05 & 0,15 & 0,70 & 0,10 & A \\
\hline 0016 & 0013 & 0,05 & 0,15 & 0,70 & 0,10 & A \\
\hline 0017 & 0013 & 0,05 & 0,15 & 0,70 & 0,10 & A \\
\hline 0020 & 0016 & 0,05 & 0,15 & 0,70 & 0,10 & A \\
\hline 0021 & 0017 & 0,05 & 0,15 & 0,70 & 0,10 & A \\
\hline 0024 & 0020 & 0,05 & 0,15 & 0,70 & 0,10 & A \\
\hline 0025 & 0020 & 0,05 & 0,15 & 0,70 & 0,10 & A \\
\hline 0026 & 0021 & 0,05 & 0,15 & 0,70 & 0,10 & A \\
\hline 0029 & 0024 & 0,05 & 0,15 & 0,70 & 0,10 & $\mathrm{~A}$ \\
\hline 0030 & 0025 & 0,05 & 0,15 & 0,70 & 0,10 & A \\
\hline 0031 & 0026 & 0,05 & 0,15 & 0,70 & 0,10 & A \\
\hline 0032 & 0026 & 0,05 & 0,15 & 0,70 & 0,10 & A \\
\hline 0033 & 0029 & 0,05 & 0,15 & 0,70 & 0,10 & A \\
\hline 0034 & 0029 & 0,05 & 0,15 & 0,70 & 0,10 & A \\
\hline 0035 & 0031 & 0,05 & 0,15 & 0,70 & 0,10 & A \\
\hline 0036 & 0032 & 0,05 & 0,15 & 0,70 & 0,10 & A \\
\hline 0037 & 0032 & 0,05 & 0,15 & 0,70 & 0,10 & $\mathrm{~A}$ \\
\hline 0038 & 0033 & 0,05 & 0,15 & 0,70 & 0,10 & A \\
\hline 0039 & 0034 & 0,05 & 0,15 & 0,70 & 0,10 & A \\
\hline 0040 & 0034 & 0,05 & 0,15 & 0,70 & 0,10 & A \\
\hline 0042 & 0035 & 0,05 & 0,15 & 0,70 & 0,10 & A \\
\hline 0043 & 0035 & 0,05 & 0,15 & 0,70 & 0,10 & A \\
\hline 0044 & 0036 & 0,05 & 0,15 & 0,70 & 0,10 & A \\
\hline 0045 & 0036 & 0,05 & 0,15 & 0,70 & 0,10 & A \\
\hline 0046 & 0037 & 0,05 & 0,15 & 0,70 & 0,10 & A \\
\hline 0047 & 0039 & 0,05 & 0,15 & 0,70 & 0,10 & A \\
\hline 0048 & 0040 & 0,05 & 0,15 & 0,70 & 0,10 & A \\
\hline 0051 & 0043 & 0,05 & 0,15 & 0,70 & 0,10 & A \\
\hline 0052 & 0043 & 0,05 & 0,15 & 0,70 & 0,10 & A \\
\hline 0055 & 0052 & 0,05 & 0,15 & 0,70 & 0,10 & A \\
\hline 0056 & 0052 & 0,05 & 0,15 & 0,70 & 0,10 & $\mathrm{~A}$ \\
\hline
\end{tabular}




\begin{tabular}{|l|l|l|l|l|l|l|}
\hline 0058 & 0056 & 0,05 & 0,15 & 0,70 & 0,10 & A \\
\hline 0059 & 0058 & 0,05 & 0,15 & 0,70 & 0,10 & A \\
\hline 0060 & 0058 & 0,05 & 0,15 & 0,70 & 0,10 & A \\
\hline 0062 & 0059 & 0,05 & 0,15 & 0,70 & 0,10 & A \\
\hline 0063 & 0059 & 0,05 & 0,15 & 0,70 & 0,10 & A \\
\hline
\end{tabular}

Tabela A.9 - Trechos do bloco de carga 1 com as respectivas probabilidades de ocorrência dos defeitos e tipo da curva de resistência de defeito.

\begin{tabular}{|c|c|c|c|c|c|c|}
\hline \multicolumn{2}{|c|}{$\begin{array}{c}\text { Número } \\
\text { da barra }\end{array}$} & \multicolumn{4}{c|}{$\begin{array}{c}\text { Probabilidades dos } \\
\text { defeitos }\end{array}$} & \multirow{2}{*}{$\begin{array}{c}\text { Curva da } \\
\text { Resistência } \\
\text { de defeito }\end{array}$} \\
\hline \hline Inicial & Terminal & $3 \boldsymbol{\phi}$ & $\mathbf{2 \phi}$ & $\boldsymbol{\phi} \boldsymbol{T}$ & $\mathbf{2 \phi T}$ & \\
\hline \hline 0008 & 0006 & 0,05 & 0,15 & 0,70 & 0,10 & A \\
\hline 0011 & 0008 & 0,05 & 0,15 & 0,70 & 0,10 & A \\
\hline
\end{tabular}

Tabela A.10 - Trechos do bloco de carga 2 com as respectivas probabilidades de ocorrência dos defeitos e tipo da curva de resistência de defeito.

\begin{tabular}{|c|c|c|c|c|c|c|}
\hline \multicolumn{2}{|c|}{$\begin{array}{c}\text { Número } \\
\text { da barra }\end{array}$} & \multicolumn{4}{c|}{$\begin{array}{c}\text { Probabilidades dos } \\
\text { defeitos }\end{array}$} & $\begin{array}{c}\text { Curva da } \\
\text { Resistência } \\
\text { de defeito }\end{array}$ \\
\hline \hline Inicial & Terminal & $\mathbf{3 \phi}$ & $\mathbf{2 \phi}$ & $\boldsymbol{\phi} \boldsymbol{T}$ & $\mathbf{2} \boldsymbol{T}$ & \\
\hline 0010 & 0007 & 0,05 & 0,15 & 0,70 & 0,10 & $\mathrm{~A}$ \\
\hline 0014 & 0010 & 0,05 & 0,15 & 0,70 & 0,10 & $\mathrm{~A}$ \\
\hline 0018 & 0014 & 0,05 & 0,15 & 0,70 & 0,10 & $\mathrm{~A}$ \\
\hline 0022 & 0018 & 0,05 & 0,15 & 0,70 & 0,10 & $\mathrm{~A}$ \\
\hline 0027 & 0022 & 0,05 & 0,15 & 0,70 & 0,10 & $\mathrm{~A}$ \\
\hline 0028 & 0022 & 0,05 & 0,15 & 0,70 & 0,10 & $\mathrm{~A}$ \\
\hline
\end{tabular}

Tabela A.11 - Trechos do bloco de carga 3 com as respectivas probabilidades de ocorrência dos defeitos e tipo da curva de resistência de defeito. 


\begin{tabular}{|c|c|c|c|c|c|c|}
\hline \multicolumn{2}{|c|}{$\begin{array}{c}\text { Número } \\
\text { da barra }\end{array}$} & \multicolumn{4}{c|}{$\begin{array}{c}\text { Probabilidades dos } \\
\text { defeitos }\end{array}$} & \multirow{2}{*}{$\begin{array}{c}\text { Curva da } \\
\text { Resistência } \\
\text { de defeito }\end{array}$} \\
\hline \hline Inicial & Terminal & $3 \boldsymbol{\phi}$ & $\mathbf{2 \phi}$ & $\boldsymbol{\phi} \mathbf{T}$ & $\mathbf{2} \boldsymbol{\phi}$ & \\
\hline 0019 & 0015 & 0,05 & 0,15 & 0,70 & 0,10 & A \\
\hline 0023 & 0019 & 0,05 & 0,15 & 0,70 & 0,10 & A \\
\hline
\end{tabular}

Tabela A.12 - Trechos do bloco de carga 4 com as respectivas probabilidades de ocorrência dos defeitos e tipo da curva de resistência de defeito.

\begin{tabular}{|c|c|c|c|c|c|c|}
\hline \multicolumn{2}{|c|}{$\begin{array}{c}\text { Número } \\
\text { da barra }\end{array}$} & \multicolumn{4}{c|}{$\begin{array}{c}\text { Probabilidades dos } \\
\text { defeitos }\end{array}$} & \multirow{2}{*}{$\begin{array}{c}\text { Curva da } \\
\text { Resistência } \\
\text { de defeito }\end{array}$} \\
\hline \hline Inicial & Terminal & $3 \boldsymbol{\phi}$ & $\mathbf{2 \phi}$ & $\boldsymbol{\phi} \boldsymbol{T}$ & $\mathbf{2} \boldsymbol{\phi}$ & \\
\hline 0041 & 0034 & 0,05 & 0,15 & 0,70 & 0,10 & $\mathrm{~A}$ \\
\hline 0050 & 0041 & 0,05 & 0,15 & 0,70 & 0,10 & $\mathrm{~A}$ \\
\hline 0054 & 0050 & 0,05 & 0,15 & 0,70 & 0,10 & $\mathrm{~A}$ \\
\hline
\end{tabular}

Tabela A.13 - Trechos do bloco de carga 5 com as respectivas probabilidades de ocorrência dos defeitos e tipo da curva de resistência de defeito.

\begin{tabular}{|c|c|c|c|c|c|c|}
\hline \multicolumn{2}{|c|}{$\begin{array}{c}\text { Número } \\
\text { da barra }\end{array}$} & \multicolumn{4}{c|}{$\begin{array}{c}\text { Probabilidades dos } \\
\text { defeitos }\end{array}$} & $\begin{array}{c}\text { Curva da } \\
\text { Resistência } \\
\text { de defeito }\end{array}$ \\
\hline \hline Inicial & Terminal & $3 \boldsymbol{\phi}$ & $\mathbf{2 \phi}$ & $\boldsymbol{\phi} \boldsymbol{T}$ & $\mathbf{2} \boldsymbol{\phi}$ & \\
\hline \hline 0049 & 0040 & 0,05 & 0,15 & 0,70 & 0,10 & $\mathrm{~A}$ \\
\hline 0053 & 0049 & 0,05 & 0,15 & 0,70 & 0,10 & $\mathrm{~A}$ \\
\hline 0057 & 0053 & 0,05 & 0,15 & 0,70 & 0,10 & $\mathrm{~A}$ \\
\hline
\end{tabular}

Tabela A.14 - Trechos do bloco de carga 6 com as respectivas probabilidades de ocorrência dos defeitos e tipo da curva de resistência de defeito. 


\begin{tabular}{|c|c|c|c|c|c|c|}
\hline \multicolumn{2}{|c|}{$\begin{array}{c}\text { Número } \\
\text { da barra }\end{array}$} & \multicolumn{4}{c|}{$\begin{array}{c}\text { Probabilidades dos } \\
\text { defeitos }\end{array}$} & \multirow{2}{*}{$\begin{array}{c}\text { Curva da } \\
\text { Resistência } \\
\text { de defeito }\end{array}$} \\
\hline \hline Inicial & Terminal & $3 \boldsymbol{\phi}$ & $\mathbf{2 \phi}$ & $\boldsymbol{\phi} \boldsymbol{T}$ & $\mathbf{2} \boldsymbol{\phi}$ & \\
\hline \hline 0061 & 0059 & 0,05 & 0,15 & 0,70 & 0,10 & A \\
\hline 0065 & 0061 & 0,05 & 0,15 & 0,70 & 0,10 & A \\
\hline
\end{tabular}

Tabela A.15 - Trechos do bloco de carga 7 com as respectivas probabilidades de ocorrência dos defeitos e tipo da curva de resistência de defeito.

\begin{tabular}{|c|c|c|c|c|c|c|}
\hline \multicolumn{2}{|c|}{$\begin{array}{c}\text { Número } \\
\text { da barra }\end{array}$} & \multicolumn{4}{c|}{$\begin{array}{c}\text { Probabilidades dos } \\
\text { defeitos }\end{array}$} & $\begin{array}{c}\text { Curva da } \\
\text { Resistência } \\
\text { de defeito }\end{array}$ \\
\hline \hline Inicial & Terminal & $3 \boldsymbol{\phi}$ & $2 \boldsymbol{\phi}$ & $\boldsymbol{\phi} \boldsymbol{T}$ & $\mathbf{2} \boldsymbol{\phi}$ & \\
\hline \hline 0064 & 0060 & 0,05 & 0,15 & 0,70 & 0,10 & A \\
\hline 0067 & 0064 & 0,05 & 0,15 & 0,70 & 0,10 & A \\
\hline
\end{tabular}

Tabela A.16 - Trechos do bloco de carga 8 com as respectivas probabilidades de ocorrência dos defeitos e tipo da curva de resistência de defeito.

\begin{tabular}{|c|c|c|c|c|c|c|}
\hline \multicolumn{2}{|c|}{$\begin{array}{c}\text { Número } \\
\text { da barra }\end{array}$} & \multicolumn{4}{c|}{$\begin{array}{c}\text { Probabilidades dos } \\
\text { defeitos }\end{array}$} & \multirow{2}{*}{$\begin{array}{c}\text { Curva da } \\
\text { Resistência } \\
\text { de defeito }\end{array}$} \\
\hline \hline Inicial & Terminal & $3 \boldsymbol{\phi}$ & $\mathbf{2 \phi}$ & $\boldsymbol{\phi} \mathbf{T}$ & $\mathbf{2} \boldsymbol{\phi} \mathbf{n}$ & \\
\hline \hline 0066 & 0062 & 0,05 & 0,15 & 0,70 & 0,10 & $\mathrm{~A}$ \\
\hline 0068 & 0066 & 0,05 & 0,15 & 0,70 & 0,10 & $\mathrm{~A}$ \\
\hline 0071 & 0068 & 0,05 & 0,15 & 0,70 & 0,10 & $\mathrm{~A}$ \\
\hline
\end{tabular}

Tabela A.17 - Trechos do bloco de carga 9 com as respectivas probabilidades de ocorrência dos defeitos e tipo da curva de resistência de defeito. 


\begin{tabular}{|c|c|c|c|c|c|c|}
\hline \multicolumn{2}{|c|}{$\begin{array}{c}\text { Número } \\
\text { da barra }\end{array}$} & \multicolumn{4}{c|}{$\begin{array}{c}\text { Probabilidades dos } \\
\text { defeitos }\end{array}$} & \multirow{2}{*}{$\begin{array}{c}\text { Curva da } \\
\text { Resistência } \\
\text { de defeito }\end{array}$} \\
\hline \hline Inicial & Terminal & $3 \boldsymbol{\phi}$ & $2 \boldsymbol{\phi}$ & $\boldsymbol{\phi} \boldsymbol{T}$ & $\mathbf{2} \boldsymbol{\phi}$ & \\
\hline \hline 0069 & 0067 & 0,05 & 0,15 & 0,70 & 0,10 & $\mathrm{~A}$ \\
\hline 0072 & 0069 & 0,05 & 0,15 & 0,70 & 0,10 & $\mathrm{~A}$ \\
\hline 0074 & 0072 & 0,05 & 0,15 & 0,70 & 0,10 & $\mathrm{~A}$ \\
\hline 0075 & 0072 & 0,05 & 0,15 & 0,70 & 0,10 & $\mathrm{~A}$ \\
\hline
\end{tabular}

Tabela A.18 - Trechos do bloco de carga 10 com as respectivas probabilidades de ocorrência dos defeitos e tipo da curva de resistência de defeito.

\begin{tabular}{|c|c|c|c|c|c|c|}
\hline \multicolumn{2}{|c|}{$\begin{array}{c}\text { Número } \\
\text { da barra }\end{array}$} & \multicolumn{4}{c|}{$\begin{array}{c}\text { Probabilidades dos } \\
\text { defeitos }\end{array}$} & $\begin{array}{c}\text { Curva da } \\
\text { Resistência } \\
\text { de defeito }\end{array}$ \\
\hline \hline Inicial & Terminal & $3 \boldsymbol{\phi}$ & $2 \boldsymbol{\phi}$ & $\boldsymbol{\phi} \boldsymbol{T}$ & $\mathbf{2} \boldsymbol{\phi T}$ & $\mathrm{A}$ \\
\hline \hline 0070 & 0067 & 0,05 & 0,15 & 0,70 & 0,10 & $\mathrm{~A}$ \\
\hline 0073 & 0070 & 0,05 & 0,15 & 0,70 & 0,10 & $\mathrm{~A}$ \\
\hline 0076 & 0073 & 0,05 & 0,15 & 0,70 & 0,10 & $\mathrm{~A}$ \\
\hline 0077 & 0073 & 0,05 & 0,15 & 0,70 & 0,10 & $\mathrm{~A}$ \\
\hline 0079 & 0076 & 0,05 & 0,15 & 0,70 & 0,10 & $\mathrm{~A}$ \\
\hline 0080 & 0076 & 0,05 & 0,15 & 0,70 & 0,10 & $\mathrm{~A}$ \\
\hline 0082 & 0080 & 0,05 & 0,15 & 0,70 & 0,10 & $\mathrm{~A}$ \\
\hline 0084 & 0082 & 0,05 & 0,15 & 0,70 & 0,10 & $\mathrm{~A}$ \\
\hline 0085 & 0082 & 0,05 & 0,15 & 0,70 & 0,10 & \\
\hline
\end{tabular}

Tabela A.19 - Trechos do bloco de carga 11 com as respectivas probabilidades de ocorrência dos defeitos e tipo da curva de resistência de defeito. 


\begin{tabular}{|c|c|c|c|c|c|c|}
\hline \multicolumn{2}{|c|}{$\begin{array}{c}\text { Número } \\
\text { da barra }\end{array}$} & \multicolumn{4}{c|}{$\begin{array}{c}\text { Probabilidades dos } \\
\text { defeitos }\end{array}$} & $\begin{array}{c}\text { Curva da } \\
\text { Resistência } \\
\text { de defeito }\end{array}$ \\
\hline \hline Inicial & Terminal & $3 \phi$ & $2 \phi$ & $\phi T$ & $2 \phi \boldsymbol{T}$ & A \\
\hline \hline 0078 & 0074 & 0,05 & 0,15 & 0,70 & 0,10 & A \\
\hline 0081 & 0078 & 0,05 & 0,15 & 0,70 & 0,10 & A \\
\hline 0083 & 0081 & 0,05 & 0,15 & 0,70 & 0,10 & A \\
\hline 0086 & 0083 & 0,05 & 0,15 & 0,70 & 0,10 & A \\
\hline 0087 & 0083 & 0,05 & 0,15 & 0,70 & 0,10 & A \\
\hline 0088 & 0083 & 0,05 & 0,15 & 0,70 & 0,10 & A \\
\hline 0090 & 0088 & 0,05 & 0,15 & 0,70 & 0,10 & A \\
\hline 0091 & 0088 & 0,05 & 0,15 & 0,70 & 0,10 & \\
\hline
\end{tabular}

Tabela A.20 - Trechos do bloco de carga 12 com as respectivas probabilidades de ocorrência dos defeitos e tipo da curva de resistência de defeito.

\begin{tabular}{|c|c|c|c|c|c|c|}
\hline \multicolumn{2}{|c|}{$\begin{array}{l}\text { Número } \\
\text { da barra }\end{array}$} & \multicolumn{4}{|c|}{$\begin{array}{l}\text { Número } \\
\text { da barra }\end{array}$} & \multirow{2}{*}{$\begin{array}{c}\text { Curva da } \\
\text { Resistência } \\
\text { de defeito }\end{array}$} \\
\hline Inicial & Terminal & $3 \phi$ & $2 \phi$ & $\phi T$ & $2 \phi T$ & \\
\hline 0089 & 0084 & 0,05 & 0,15 & 0,70 & 0,10 & A \\
\hline 0092 & 0089 & 0,05 & 0,15 & 0,70 & 0,10 & A \\
\hline 0093 & 0089 & 0,05 & 0,15 & 0,70 & 0,10 & A \\
\hline 0094 & 0092 & 0,05 & 0,15 & 0,70 & 0,10 & A \\
\hline 0095 & 0092 & 0,05 & 0,15 & 0,70 & 0,10 & A \\
\hline 0096 & 0093 & 0,05 & 0,15 & 0,70 & 0,10 & A \\
\hline 0098 & 0095 & 0,05 & 0,15 & 0,70 & 0,10 & A \\
\hline 0100 & 0095 & 0,05 & 0,15 & 0,70 & 0,10 & A \\
\hline 0101 & 0096 & 0,05 & 0,15 & 0,70 & 0,10 & A \\
\hline 0104 & 0101 & 0,05 & 0,15 & 0,70 & 0,10 & A \\
\hline 0105 & 0101 & 0,05 & 0,15 & 0,70 & 0,10 & A \\
\hline 0106 & 0104 & 0,05 & 0,15 & 0,70 & 0,10 & A \\
\hline
\end{tabular}

Tabela A.21 - Trechos do bloco de carga 13 com as respectivas probabilidades de ocorrência dos defeitos e tipo da curva de resistência de defeito. 


\begin{tabular}{|c|c|c|c|c|c|c|}
\hline \multicolumn{2}{|c|}{$\begin{array}{c}\text { Número } \\
\text { da barra }\end{array}$} & \multicolumn{4}{c|}{$\begin{array}{c}\text { Probabilidades dos } \\
\text { defeitos }\end{array}$} & \multirow{2}{*}{$\begin{array}{c}\text { Curva da } \\
\text { Resistência } \\
\text { de defeito }\end{array}$} \\
\hline \hline Inicial & Terminal & $3 \boldsymbol{\phi}$ & $\mathbf{2 \phi}$ & $\boldsymbol{\phi} \boldsymbol{T}$ & $\mathbf{2} \boldsymbol{\phi}$ & \\
\hline \hline 0097 & 0093 & 0,05 & 0,15 & 0,70 & 0,10 & A \\
\hline 0102 & 0097 & 0,05 & 0,15 & 0,70 & 0,10 & A \\
\hline
\end{tabular}

Tabela A.22 - Trechos do bloco de carga 14 com as respectivas probabilidades de ocorrência dos defeitos e tipo da curva de resistência de defeito.

\begin{tabular}{|c|c|c|c|c|c|c|}
\hline \multicolumn{2}{|c|}{$\begin{array}{c}\text { Número } \\
\text { da barra }\end{array}$} & \multicolumn{4}{c|}{$\begin{array}{c}\text { Probabilidades dos } \\
\text { defeitos }\end{array}$} & \multirow{2}{*}{$\begin{array}{c}\text { Curva da } \\
\text { Resistência } \\
\text { de defeito }\end{array}$} \\
\hline \hline Inicial & Terminal & $3 \boldsymbol{\phi}$ & $\mathbf{2 \phi}$ & $\boldsymbol{\phi} \mathbf{T}$ & $\mathbf{2} \boldsymbol{\phi}$ & \\
\hline \hline 0099 & 0095 & 0,05 & 0,15 & 0,70 & 0,10 & A \\
\hline 0103 & 0099 & 0,05 & 0,15 & 0,70 & 0,10 & A \\
\hline
\end{tabular}

Tabela A.23 - Trechos do bloco de carga 15 com as respectivas probabilidades de ocorrência dos defeitos e tipo da curva de resistência de defeito. 


\section{ANEXO B \\ CURVAS DE TEMPO X CORRENTE \\ DOS DISPOSTIVOS \\ DE PROTEÇÃO UTILIZADOS}




\section{B.1 - Introdução}

Para melhor análise e entendimento dos estudos realizados, seguem as curvas de tempo em função da corrente dos dispositivos de proteção utilizados no trabalho em questão.

Tais curvas foram devidamente cadastradas na ferramenta computacional utilizada, conforme referências bibliográficas [1], [2], [4] e [5].

\section{B.2 - Curvas dos elos fusíveis}

Serão ilustradas nas Figuras B.1, B.2, B.3, B.4, B.5, as curvas dos tempos mínimos de fusão e de máxima interrupção, em função da corrente passante, para os elos fusíveis $10 \mathrm{~K}, 15 \mathrm{~K}, 25 \mathrm{~K}, 40 \mathrm{~K}, 65 \mathrm{~K}$, respectivamente.

- Elo Fusível 10K

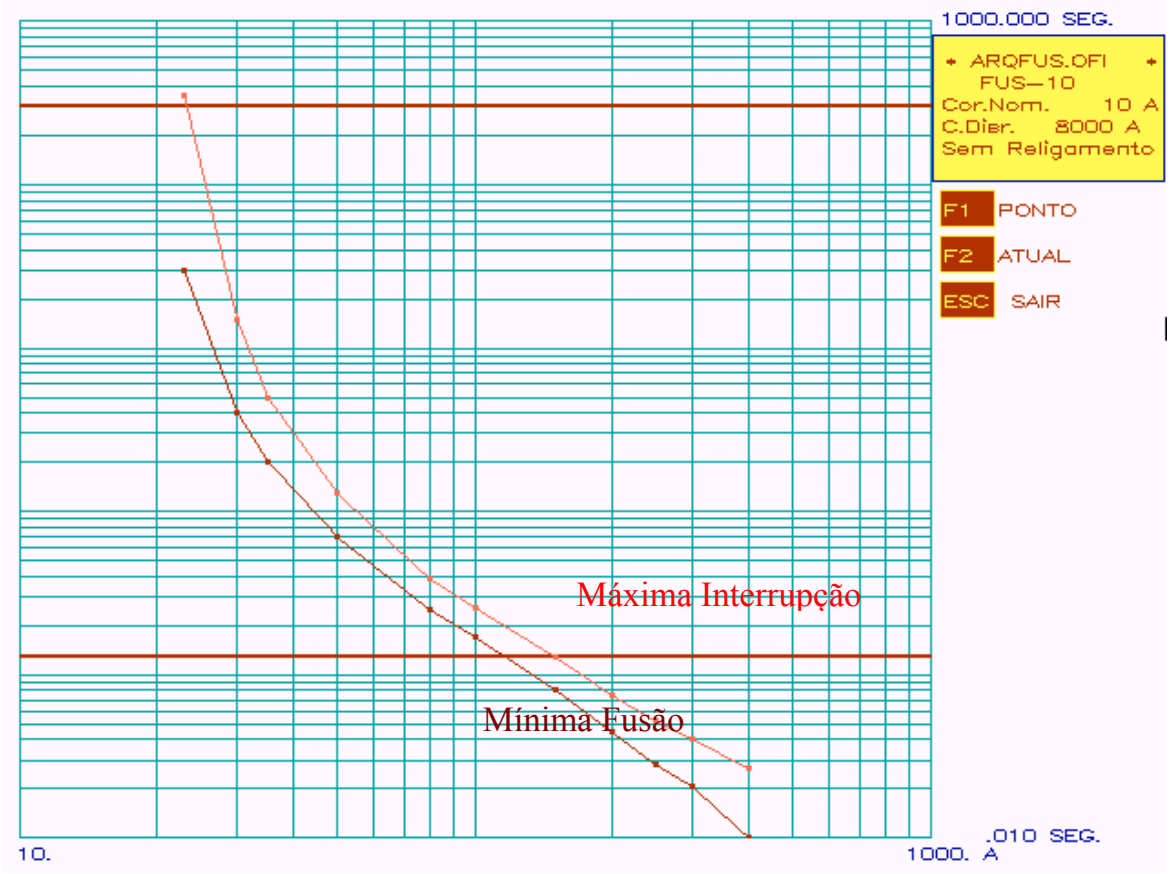

Figura B.1 - Curvas do elo fusível 10K 
- Elo Fusível 15K

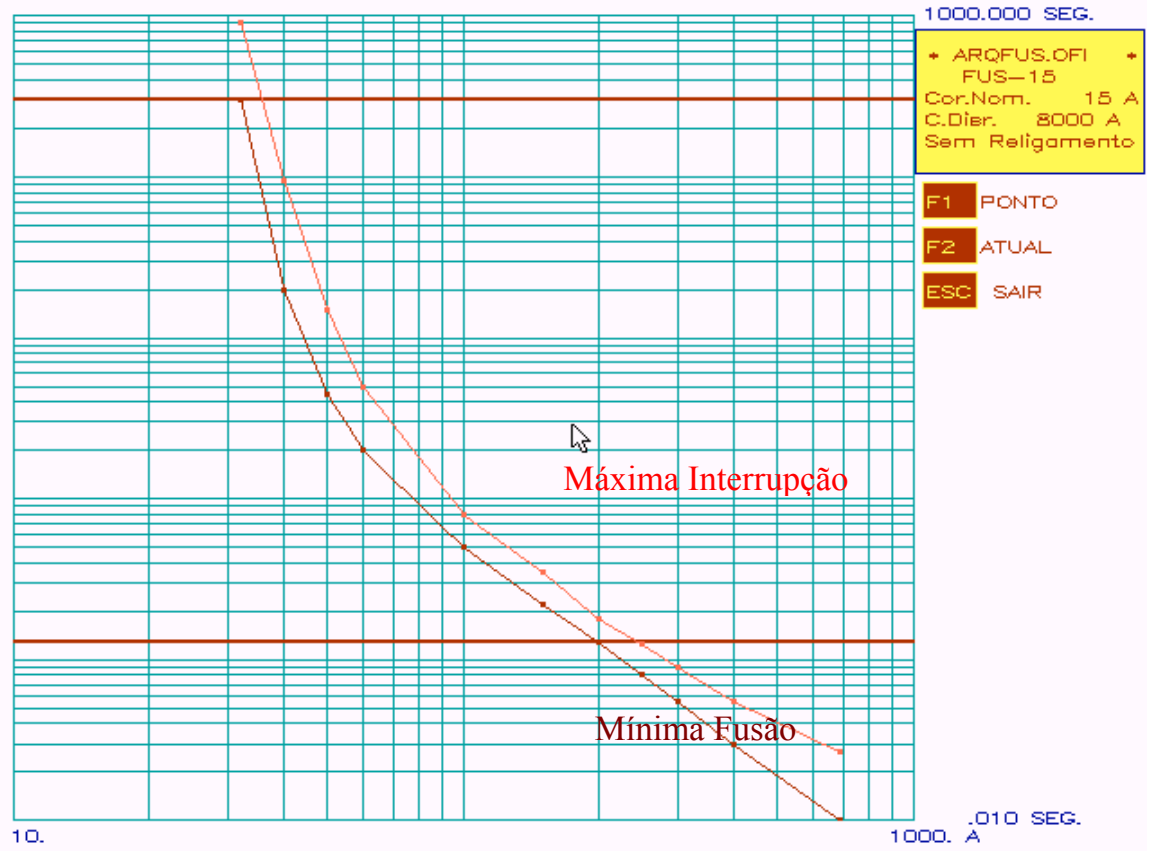

Figura B.2 - Curvas do elo fusível 15K

- Elo Fusível 25K

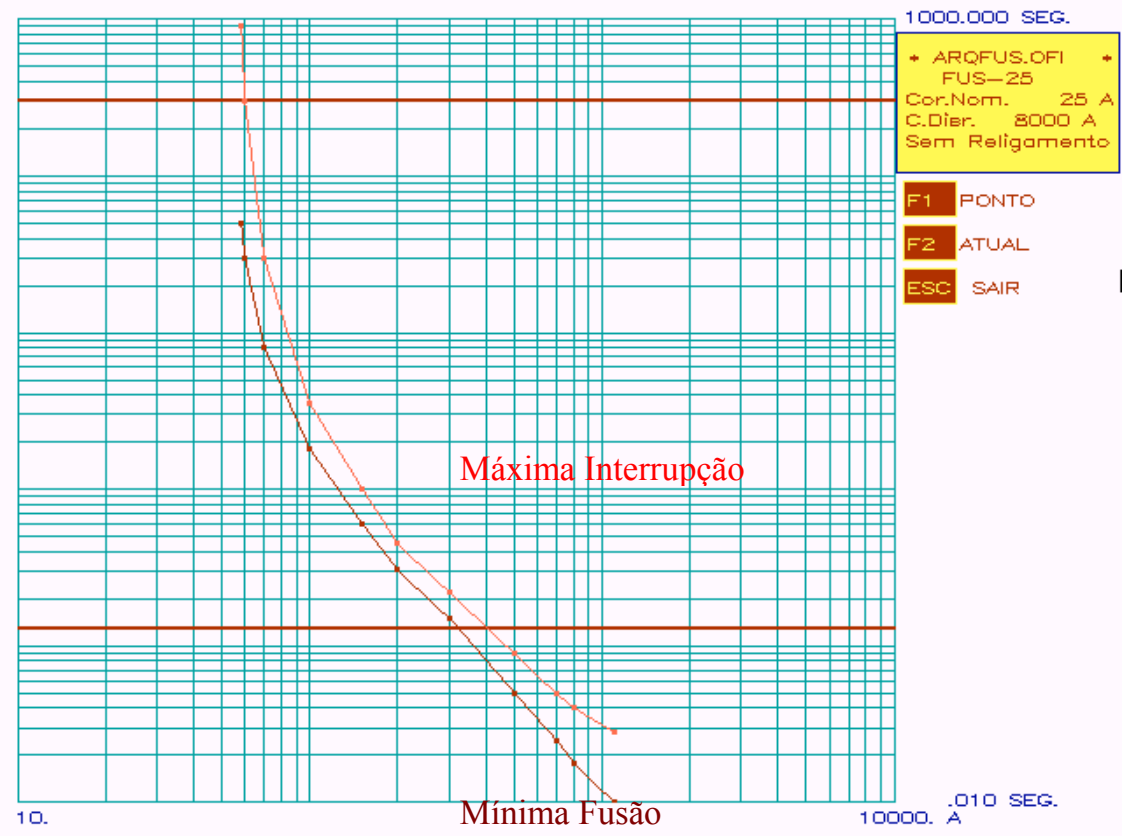

Figura B.3 - Curvas do elo fusível 25K 


\section{- Elo Fusível 40K}

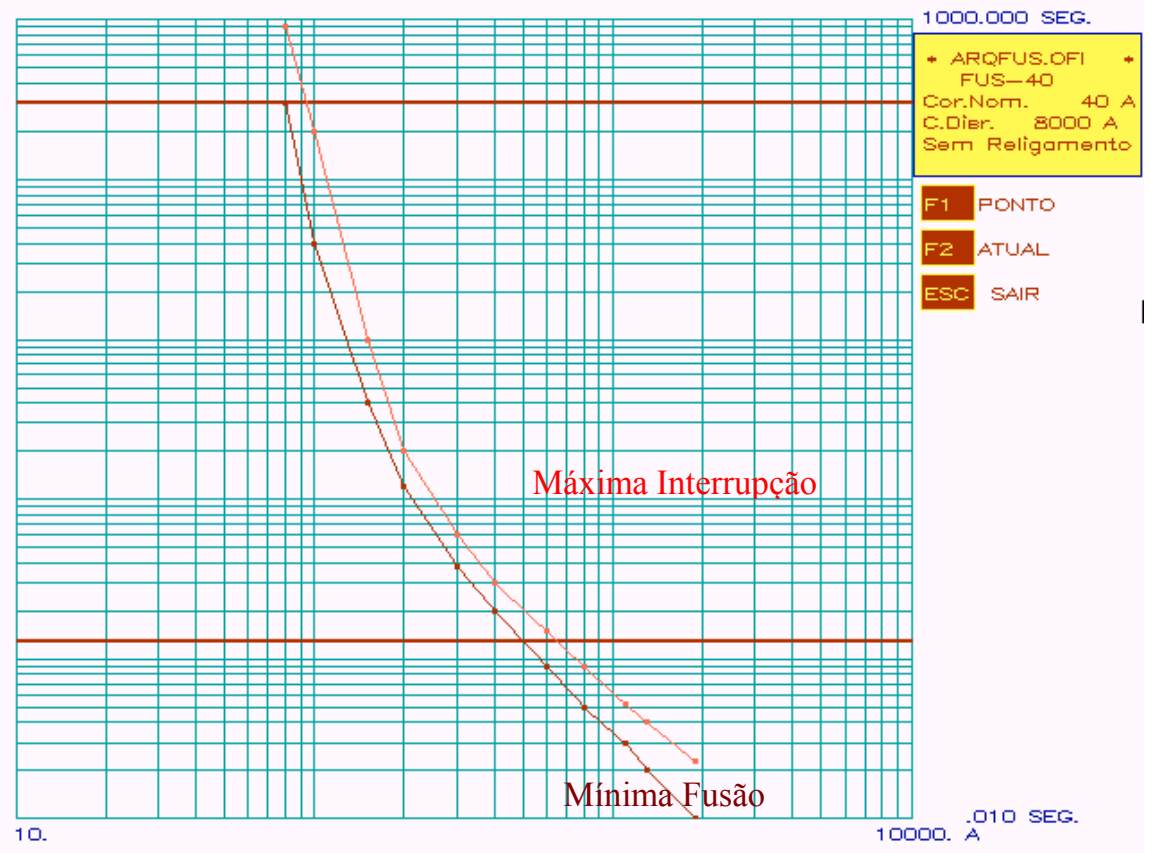

Figura B.4 - Curvas do elo fusível 40K

\section{- Elo Fusível 65K}

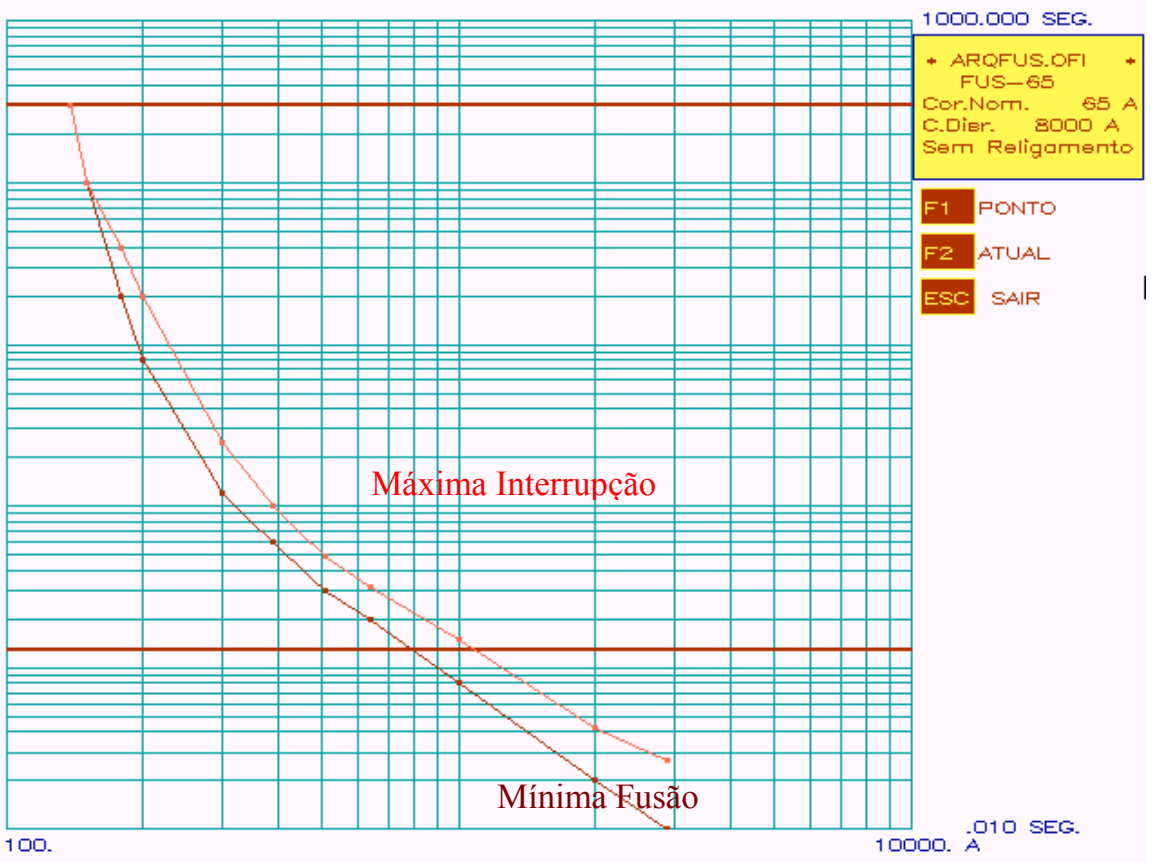

Figura B.5 - Curvas do elo fusível $65 \mathrm{~K}$ 


\section{B.3 - Curvas do religador}

Serão ilustradas nas Figuras B.6 e B.7 as curvas das unidades de sobrecorrente de fase e terra do religador utilizado no presente estudo.

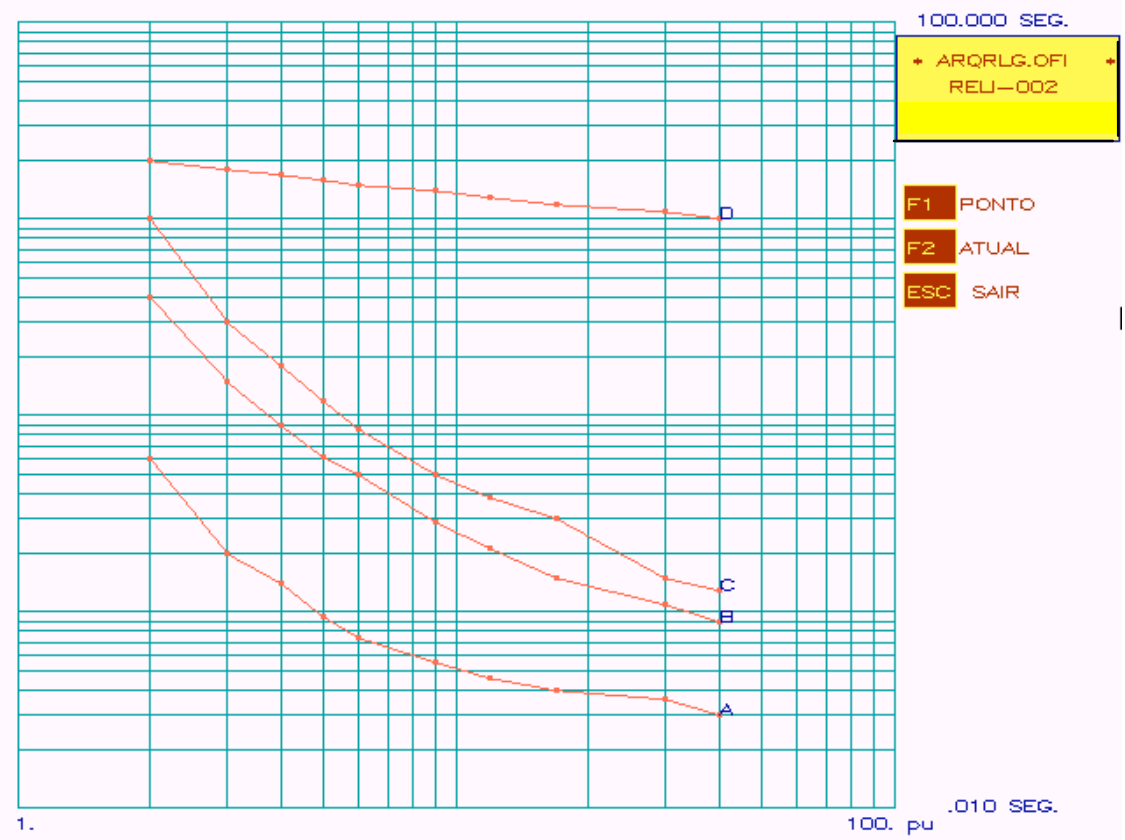

Figura B.6 - Curvas da unidade de sobrecorrente de fase do religador

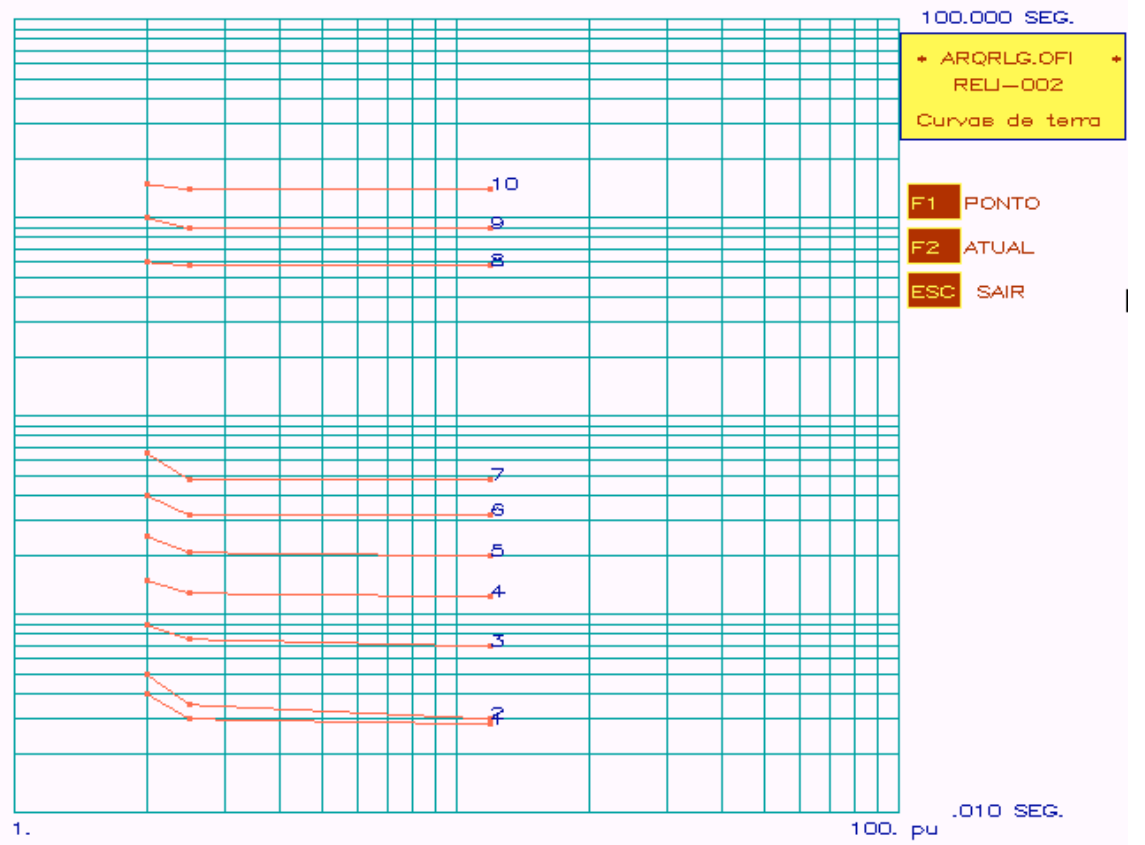

Figura B.7 - Curvas da unidade de sobrecorrente de terra do religador 


\section{B.4 - Curvas do relé}

A Figura B.8 indica as curvas de fase e terra do relé de proteção, com os diais de tempo $0,5,2,0$ e 5,0 .

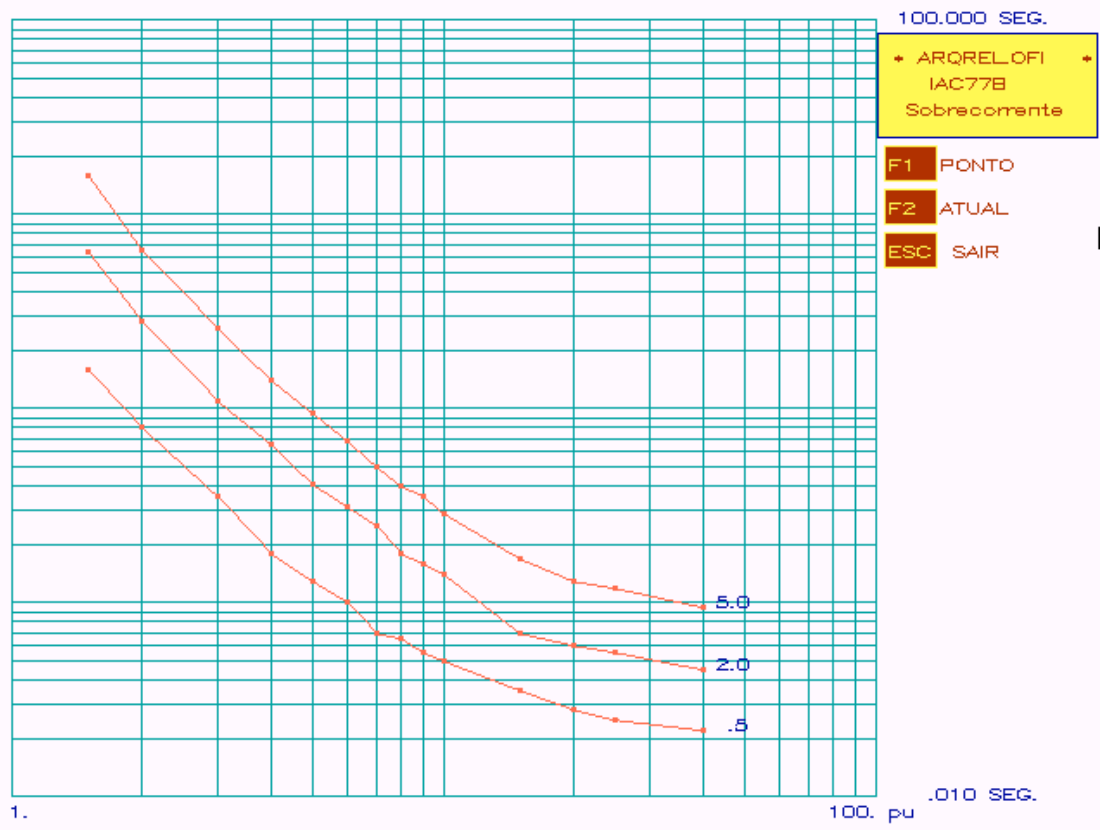

Figura B.8 - Curvas da unidade de sobrecorrente de fase e terra do relé 
ANEXO C

RESULTADOS GLOBAIS DAS SIMULAÇÕES REALIZADAS 


\section{C.1 - Introdução}

O presente Anexo tem por finalidade indicar os resultados detalhados das simulações realizadas.

Inicialmente serão indicados para cada simulação realizada, os valores das correntes de defeito de fase e de terra (fase-terra) para os todos os trechos da rede em estudo, com os respectivos valores das FPAs.

Para finalizar, serão ilustrados os valores das tensões e correntes em cada barra bem como os valores das correntes de defeito; trifásico, dupla fase, fase terra e fase terra mínimo.

\section{C.2 - Resultados das simulações}

O presente tópico tem por objetivo ilustrar em detalhes todos os valores das FPAs, com os respectivos valores de corrente de defeito fase-terra e fase-fase para cada um dos blocos de carga da rede elétrica em estudo.

A Tabelas estão estruturadas, conforme segue:

- Tabela C.1 - FPA das correntes de defeito fase - terra - Simulação 1;

- Tabela C.2 - FPA das correntes de defeito fase - terra - Simulação 2;

- Tabela C.3 - FPA das correntes de defeito fase - terra - Simulação 3;

- Tabela C.4 - FPA das correntes de defeito fase - terra - Simulação 4;

- Tabela C.5 - FPA das correntes de defeito fase - terra - Simulação 5;

- Tabela C.6 - FPA das correntes de defeito fase - fase - Simulação 1; 
- Tabela C.7 - FPA das correntes de defeito fase - fase - Simulação 2;

- Tabela C.8 - FPA das correntes de defeito fase - fase - Simulação 3;

- Tabela C.9 - FPA das correntes de defeito fase - fase - Simulação 4;

- Tabela C.10 - FPA das correntes de defeito fase - fase - Simulação 5. 


\begin{tabular}{|c|c|c|c|c|c|c|c|c|c|c|c|c|c|c|c|c|c|c|c|c|c|c|c|c|c|c|c|c|c|}
\hline $11(\mathrm{pu})$ & P1 (\%) & $\mathrm{I2}(\mathrm{pu})$ & P2 $(\%)$ & $\mathrm{I3}(\mathrm{pu})$ & P3 $3(\%)$ & ${ }^{14}(\mathrm{pu})$ & P4 $4 \%$ & $15(\mathrm{pu})$ & P5 (\%) & If(pur) & $\mathrm{P} 6(\%)$ & $17(\mathrm{pu})$ & P7(\%) & I8(pu) & $\mathrm{PB}(\%)$ & 19(pu) & $\mathbf{p 9}(\%)$ & $\mathrm{I10}(\mathrm{pu})$ & P10(\%) & ${ }^{I 11(p u)}$ & P11(\%) & $112(\mathrm{pu})$ & P12(\%) & ${ } 113(\mathrm{pu})$ & $\mathrm{P} 13(\%)$ & ${ }_{114(\mathrm{pu})}$ & P14(\%) & $\mathrm{I11}(\mathrm{pu})$ & P15 \\
\hline 0,014057 & 0 & 141066 & 0 & 0,014048 & 0 & 0,014073 & 0 & 0,014056 & 0 & 0,013989 & 0 & 0,01402 & 0 & 0.01404 & 0 & 0,014022 & 0 & 0,013982 & 0 & 0,013963 & 0 & 0,013895 & 0 & 0,013929 & 0 & 0,013918 & 0 & ,013908 & 0 \\
\hline 0,014057 & 0,279999 & 14106 & 0,28 & 014048 & 0,28 & 0,014073 & 0,28 & 0,014056 & 0,28 & .013989 & 0,28 & 0,01402 & 0,28 &, 01404 & 0,28 & 0,014022 & 0,28 & 0,013982 & 0,28 & 0,013963 & 0,28 & 0,013895 & 0,28 & 0,013929 & 0,28 & 0,013918 & 0,28 & 0,013908 & 0,28 \\
\hline 0,019714 & 0,279999 & 0,019692 & 0,28 & 0,019623 & 0,28 & 0,019492 & 0,28 & 0,019473 & 0,28 & 0,019391 & 0,28 & 0,01942 & 0,28 & 0,019438 & 0,28 & 0,019376 & 0,28 & 0,01928 & 0,28 & 0,019263 & 0,28 & 0,019043 & 0,28 & 0,019042 & 0,28 & 0,018997 & 0,28 & 0,018942 & 0,28 \\
\hline 0,019714 & 0,419999 & 0,019692 & 0,42 & 0,019623 & 0,42 & 0,019492 & 0,42 & 0,019473 & 0,42 & 0,019391 & 0,42 & 0,01942 & 0,42 & 0,019438 & 0,42 & 0,019376 & 0,42 & 0,01928 & 0,42 & 0,019263 & 0,42 & 0,019043 & 0,42 & 0,019042 & 0,42 & 0,018997 & 0,42 & 0,018942 & 0,42 \\
\hline 0,023371 & 0,419999 & 0,025279 & 0,42 & 0,025199 & 0,42 & 0,02491 & 0,42 & 0,024889 & 0,42 & 0,024793 & 0,42 & 0,02482 & 0,42 & 0,024836 & 0,42 & 0,024731 & 0,42 & 0,024577 & 0,42 & 0,024562 & 0,42 & 0,024191 & 0,42 & 0,024156 & 0,42 & 0,024077 & 0,42 & 0,023976 & 0,42 \\
\hline 0,025371 & 0,419999 & 0,025279 & 0,42 & 0,025199 & 0,42 & 0,02491 & 0,42 & 0,024889 & 0,42 & 0,024773 & \begin{tabular}{|l|l|}
0,42 \\
\end{tabular} & 0,02482 & 0,42 & 0,024836 & \begin{tabular}{|l|l|}
0,42 \\
\end{tabular} & 0,024731 & 0,42 & 0,022577 & 0,42 & 0,024562 & 0,42 & 0,024191 & 0,42 & 0,024156 & 0,42 & 0,0240777 & 0,42 & 0,023976 & 0,42 \\
\hline 0,031028 & 0,419999 & 0,0308655 & 0,42 & 0,030774 & 0,42 & 0,030329 & 0,42 & 0,030306 & 0,42 & 0,030195 & 0,42 & 0,03022 & 0,42 & 0,030234 & 0,42 & 0,030085 & 0,42 & 0,029875 & 0,42 & 0,029862 & 0,42 & 0,029339 & 0,42 & 0,02927 & 0,42 & 0,029156 & 0,42 & 0,029009 & 0,42 \\
\hline 0,031028 & 0,559998 & 0,030865 & 0,56 & 0,030774 & 0,56 & 0,030329 & 0,56 & 0,030306 & 0,56 & 0,030195 & 0,56 & 0,030222 & 0,56 & 0,030234 & 0,56 & 0,030085 & 0,56 & 0,029875 & 0,560001 & 0,029862 & 0,559999 & 0,029339 & 0,560001 & 0,02927 & 0,559999 & 0,029156 & 0,56 & 0,029009 & 0,56 \\
\hline 0,036686 & 0,559998 & 0,036452 & 0,56 & 0,036349 & 0,56 & 0,035747 & 0,56 & 0,035723 & 0,56 & 0,035597 & 0.56 & 0,03662 & 0,56 & 0,035632 & 0,56 & 0,03544 & 0,56 & 0,035173 & 0,560001 & 0,035161 & 0,559999 & 0,034877 & 0,560001 & 0,0343844 & 0,559999 & 0,0342355 & 0,56 & 0,034043 & 0,56 \\
\hline 0,036886 & 0,559998 & 0,036452 & 0,56 & 0,0363649 & 0,56 & 0,035747 & 0,56 & 0,035723 & 0,56 & 0,035597 & 0,56 & 0,03562 & 0,56 & 0,035632 & 0,56 & 0,03544 & 0,56 & 0,035173 & 0,560001 & 0,035161 & 0,559999 & 0,034487 & 0,560001 & 0,034384 & 0,559999 & 0,0342353 & 0,56 & 0,033043 & 0,56 \\
\hline 0,042343 & 0,559998 & 0,042038 & 0,56 & 0,041924 & 0,56 & 0,041166 & 0,56 & 0,04114 & 0,56 & 0,040999 & 0,56 & 0,041021 & 0,56 & 0,04103 & 0,56 & 0,040795 & 0,56 & 0,04047 & 0,560001 & 0,0404661 & 0,559999 & 0,039635 & 0,560001 & 0,039498 & 0,559999 & 0,039315 & 0,56 & 0,039077 & 0,56 \\
\hline 0,042343 & 0,559998 & 0,042038 & 0,56 & 0,041924 & 0,56 & 0,041166 & 0,56 & 0,04114 & 0,56 & 0,040999 & 0,56 & 0,041021 & 0,56 & 0,04103 & 0,56 & 0,040795 & 0,56 & 0,04047 & 0,560001 & $0,0,4046161$ & 0,559999 & 0,039635 & 0,560001 & 0,0334489 & 0,559999 & 0,039315 & 0,56 & 0,039077 & 0,56 \\
\hline 0,048 & $0, \frac{559998}{0.0}$ & 0,047625 & 0,56 & 0,0475 & 0.56 & $\begin{array}{r}0,046584 \\
\end{array}$ & 0,56 & 0,046556 & 0,56 & 0,046401 & 0.56 & 0,046421 & $0,0,56$ & 0,046428 & 0.56 & 0,046149 & 0,56 & 0,045768 & 0,560001 & 0,04576 & 0,559999 & 0,047782 & 0,560001 & $\begin{array}{r}0,044611 \\
\end{array}$ & $\begin{array}{r}0,559999 \\
0\end{array}$ & 0,044394 & 0,56 & 0,04411 & 0,56 \\
\hline 0,048 & 0.559998 & 0,047625 & 0,56 & 0,0475 & 0,56 & 0,046584 & 0,56 & 0,046556 & 0,56 & 0,046401 & 0,56 & 0,046421 & 0,56 & 0,046428 & 0,56 & 0,046149 & 0,56 & 0,045768 & 0,560001 & 0,04576 & 0,559999 & 0,047782 & 0,560001 & 0,044611 & 0,559999 & 0,044394 & 0,56 & 0,04411 & 0,56 \\
\hline 0,053657 & 0,559998 & 0,053211 & 0,56 & 0,0533075 & 0,56 & 0,052003 & 0,56 & 0,051973 & 0,56 & 0,051803 & 0,56 & 0,051821 & 0,56 & 0,051826 & 0,56 & 0,051504 & 0,56 & 0,051066 & 0,560001 & 0,05106 & 0,559999 & 0,04993 & 0,560001 & 0,049725 & 0,559999 & 0,049473 & 0,56 & 0,049144 & 0,56 \\
\hline 0,053657 & 0,559998 & 0,053211 & 0,56 & 0,0533075 & 0,56 & 0,052003 & 0,56 & 0,051973 & 0,56 & 0,051803 & 0,56 & 0,051821 & 0,56 & 0,051826 & 0,56 & 0,051504 & 0,56 & 0,051066 & 0,560001 & 0,05106 & 0,559999 & 0,04993 & 0,560001 & 0,049725 & 0,559999 & 0,049473 & 0,56 & 0,049144 & 0,56 \\
\hline 0,059314 & $0 ., 559988$ & 0,058798 & 0.56 & 0,05865 & 0.56 & $\begin{array}{r}0,057721 \\
\end{array}$ & 0,56 & $\begin{array}{l}0,05739 \\
\end{array}$ & 0.56 & 0,057204 & 0.56 & 0,057221 & 0.56 & 0,057223 & 0,56 & 0,056858 & 0,56 & 0,056363 & 0.560001 & $\begin{array}{l}0,0566359 \\
\end{array}$ & 0,559999 & 0,055078 & $0,0,560001$ & p.0.044839 & 0,559999 & , 0.044552 & 0,56 & 0,054177 & 0,56 \\
\hline 0,059314 & 0,559998 & 0,058798 & 0,56 & 0,05865 & 0,56 & 0,057421 & 0,56 & 0,05739 & 0,56 & 0,057204 & 0,56 & 0,057221 & 0,56 & 0,057223 & 0,56 & 0,056858 & 0,56 & 0,056363 & 0,560001 & 0,056359 & 0,559999 & 0,055078 & 0,560001 & 0,054839 & 0,559999 & 0,054552 & 0,56 & 0,054177 & 0,56 \\
\hline 0,064971 & 0,559998 & 0,064384 & 0,56 & $0,0,642225$ & 0,56 & 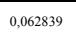 & 0,56 & $\begin{array}{l}0,062807 \\
\end{array}$ & 0,56 & 0,0626066 & $\begin{array}{l}0.56 \\
\end{array}$ & 0,062621 & 0,56 & 0,0626221 & \begin{tabular}{ll|l}
0,56 \\
\end{tabular} & 0,062213 & 0,56 & 0,0611661 & 0,560001 & $\begin{array}{l}0,061659 \\
\end{array}$ & 0,559999 & 0,060226 & 0.560001 & 0,059953 & 0,559999 & 0,059632 & 0,56 & 0,059211 & 0,56 \\
\hline 0,064971 & 0,699998 & 0,064384 & 0,7 & 0,064225 & 0,7 & 0,0628399 & 0,7 & 0,062807 & 0,7 & 0,0626066 & 0,7 & 0,062621 & 0,7 & 0,062621 & 0,7 & 0,062213 & 0,7 & 0,061661 & 0,700001 & 0,061659 & 0,6999999 & 0,060226 & 0,700001 & ,059953 & ,699999 & 0.096632 & 0,7 & ,059211 & 0,7 \\
\hline 0,070628 & 0,6999988 & 069971 & 0,7 & $0,0,0988$ & 0,7 & 0,068258 & 0,7 & 0,068223 & 0,7 & 0,068008 & 0,7 & 0,068021 & 0,7 & 0,068019 & 0,7 & 0,067568 & 0,7 & 0,066959 & 0,700000 & 0,066959 & 0,699999 & 0,065374 & 0,700001 & 0,065066 & $0,0.699999$ & 0,064711 & 0,7 & 0,064245 & 0,7 \\
\hline
\end{tabular}

Tabela C.1 - FPA das correntes de defeito fase - terra - Simulação 1 
FPA - CURTO FASE TERRA - SIMULAÇ̧̃̃o

\begin{tabular}{|c|c|c|c|c|c|c|c|c|c|c|c|c|c|c|c|c|c|c|c|c|c|c|c|c|c|c|c|c|c|}
\hline $\mathrm{I1}(\mathrm{pu})$ & $\mathbf{P 1}(\%)$ & $12(\mathrm{pu})$ & P2 $2 \%$ & $\mathrm{I3}$ (pu) & P3 (\%) & $14(\mathrm{pu})$ & $\mathrm{P} 4(\%)$ & $15(\mathrm{pu})$ & P5 (\%) & I6(put) & P6 $6 \%$ & $17(\mathrm{pu})$ & \begin{tabular}{|l|l|}
$\mathrm{P} 7(\%)$ \\
\end{tabular} & $\mathrm{II}(\mathrm{pu})$ & $\mathrm{P8}(\%)$ & 19(pu) & \begin{tabular}{|l|}
$\mathrm{P9}(\%)$ \\
\end{tabular} & $\mathrm{H11(pu)}$ & P10(\%) & $\mathrm{II1(p)}$ & P11(\%) & $111(\mathrm{pu})$ & $\mathrm{P} 12(\%)_{2}$ & ${ }_{\mathrm{I13}(\mathrm{pu})}$ & P13(\%) & I14(pu) & $\begin{array}{l}\mathbf{P} 14(\%) \\
\end{array}$ & ${ }^{115(\mathrm{pu})}$ & P15(\%) \\
\hline 0,014057 & 0 & 0,014106 & 0 & 0,0114048 & 0 & 0,014073 & 0 & 0,014056 & 0 & 0,013989 & 0 & 0,01402 & 0 & 0,011404 & 0 & 0,014022 & 0 & 0,013982 & 0 & 0,013963 & 0 & 0,013895 & 0 & 0,013929 & 0 & 0,013918 & 0 & 0,013908 & 0 \\
\hline 0,014057 & 0,248 & 0,014106 & 0,248 & 0,014048 & 0,248 & 0,014073 & 0,248 & 0,014056 & 0,248 & 0,013989 & 0,248 & 0,01402 & \begin{tabular}{|l|l|}
0,248 \\
\end{tabular} & 0,01404 & 0,248 & $0,0,14022$ & \begin{tabular}{|l|l|}
0,248 \\
\end{tabular} & 0,013982 & 0,248 & 0,013963 & 0,248 & 0,013895 & 0,248 & 0,013929 & 0,248 & 0,013918 & 0 & 0,013908 & 0,248 \\
\hline 0,019714 & 0,248 & 0,019692 & 0,248 & 0,019623 & 0,248 & 0,019492 & 0,248 & 0,019473 & 0,248 & 0,019391 & 0,248 & 0,01942 & \begin{tabular}{|l|l|}
0,248 \\
\end{tabular} & 0,019438 & 0,248 & 0,019376 & \begin{tabular}{|l|l|} 
\\
\end{tabular} & 0,01928 & 0,248 & 0,019263 & 0,248 & 0,019043 & 0,248 & 0,019042 & 0,248 & 0,018997 & 0,248 & 0,018942 & 0,248 \\
\hline 0,019714 & 0,371999 & 0,019692 & 0,372 & 0,019623 & 0,372 & 0,019492 & 0,372 & 0,019473 & 0,372 & 0,019391 & 0,372 & 0,01942 & \begin{tabular}{|l|l} 
& 0,372 \\
\end{tabular} & 0,019438 & 0,372 & 0,019376 & \begin{tabular}{|l} 
\\
0,372
\end{tabular} & 0,01928 & 0,372 & 0,019263 & 0,372 & 0,019043 & 0,372 & 0,019042 & 0,372 & 0,018997 & 0,372 & 0,018942 & 0,372 \\
\hline 0,025371 & 0,371999 & 0,025279 & 0,372 & 0,025199 & 0,372 & 0,02491 & 0,372 & 0,024889 & 0,372 & 0,024793 & 0,372 & 0,02482 & \begin{tabular}{|l}
0,372 \\
\end{tabular} & 0,024836 & 0,372 & 0,024731 & \begin{tabular}{|l}
0,372 \\
\end{tabular} & 0,024577 & 0,372 & 0,024462 & 0,372 & 0,024191 & 0,372 & 0,024156 & 0,372 & 0,024077 & 0,372 & 0,023976 & 0,372 \\
\hline 0,025371 & 0,371999 & 0,025279 & 0,372 & $\begin{array}{l}0,025199 \\
\end{array}$ & 0,372 & 0,02491 & 0,372 & 0,024889 & 0,372 & 0,024793 & 0,372 & 0,02482 & \begin{tabular}{|l|l} 
& 0,372 \\
\end{tabular} & 0,024836 & 0,372 & 0,024731 & \begin{tabular}{|l} 
\\
0,372
\end{tabular} & $\begin{array}{l}0,024577 \\
\end{array}$ & 0,372 & 0,024562 & 0,372 & 0,024191 & 0,372 & 0,024156 & 0,372 & 0,024077 & 0,372 & $\begin{array}{l}0,023976 \\
\end{array}$ & 0,372 \\
\hline 0,031028 & 0,371999 & 0,030865 & 0,372 & 0,030774 & 0,372 & 0,0303299 & 0,372 & 0,030300 & 0,372 & 0,030195 & 0,372 & 0,03022 & \begin{tabular}{|l|l} 
& 0,372 \\
\end{tabular} & 0,030234 & 0,372 & $0,0,030085$ & 0,372 & 0,029875 & 0,372 & 0,029862 & 0,372 & 0,029339 & 0,372 & 0,02927 & 0,372 & 0,029156 & 0,372 & 0,029009 & 0,372 \\
\hline 0,031028 & 0,495999 & 0,0308655 & 0,496 & 0,030774 & 0,496 & $\begin{array}{l}0,030329 \\
\end{array}$ & 0,496 & 0,030306 & 0,496 & 0,030195 & 0,496 & 0,03022 & \begin{tabular}{|l|l|} 
& 0,496 \\
\end{tabular} & 0,030234 & 0,496 & $0,0,030855$ & \begin{tabular}{|l|l|} 
& 0,496 \\
\end{tabular} & 0,029875 & 0,496 & 0,029862 & 0,496 & 0,029339 & 0,496 & 0,02927 & 0,496 & 0,029156 & 0,496 & 0,029009 & 0,496 \\
\hline 0,036686 & 0,495999 & ${ }_{0,036452}$ & 0,496 & 0,036349 & 0,496 & 0,035747 & 0,496 & 0,035723 & 0,496 & 0,035597 & 0,496 & 0,03562 & \begin{tabular}{|l|l|} 
& 0,496 \\
\end{tabular} & 0,035632 & 0,496 & 0,03544 & \begin{tabular}{|l|l|} 
& 0,496 \\
\end{tabular} & 0,035173 & 0,496 & 0,035161 & 0,496 & 0,034487 & 0,496 & 0,0344344 & 0,496 & 0,034235 & 0,496 & $0,0,034043$ & 0,496 \\
\hline 0,036686 & 0,495999 & 0,036452 & 0,496 & 0,036349 & 0,496 & 0,035747 & 0,496 & 0,035723 & 0,496 & 0,035597 & 0,496 & 0,03562 & \begin{tabular}{|l|l|} 
& 0,496 \\
\end{tabular} & 0,035632 & 0,496 & 0,03544 & \begin{tabular}{|l|l|} 
& 0,496 \\
\end{tabular} & 0,035173 & 0,496 & 0,035161 & 0,496 & 0,034487 & 0,496 & 0,034434 & 0,496 & 0,034235 & 0,496 & 0,039077 & 0,496 \\
\hline 0,042343 & 0,495999 & 0,042038 & 0,496 & 0,041924 & 0,496 & 0,041166 & 0,496 & 0,04114 & 0,496 & 0,040999 & 0,496 & 0,041021 & \begin{tabular}{|l|l|} 
& 0,496 \\
\end{tabular} & 0,04103 & 0,496 & \begin{tabular}{|l}
0,040795 \\
\end{tabular} & \begin{tabular}{|l|l|} 
& 0,496 \\
\end{tabular} & 0,04047 & 0,496 & 0,040461 & 0,496 & 0,039635 & 0,496 & 0,039498 & 0,496 & 0,039315 & 0,496 & 0,039077 & 0,496 \\
\hline 0,042343 & 0,495999 & 0,042038 & 0,496 & 0,041924 & 0,496 & 0,041166 & 0,496 & 0,04114 & 0,496 & 0,040999 & 0,496 & 0,041021 & \begin{tabular}{|l|l|}
0,496 \\
\end{tabular} & 0,04103 & 0,496 & 0,040795 & \begin{tabular}{|l|l|}
0,496 \\
\end{tabular} & 0,04047 & 0,496 & 0,040461 & 0,496 & 0,039635 & 0,496 & 0,039498 & 0,496 & 0,039315 & 0,496 & 0,04411 & 0,496 \\
\hline 0,048 & 0,495999 & 0,047625 & 0,496 & 0,0475 & 0,496 & 0,0465844 & 0,496 & 0,046556 & 0,496 & 0,046401 & 0,496 & 0,0464621 & \begin{tabular}{|l}
0,496 \\
\end{tabular} & 0,046428 & 0,496 & $0,0,046149$ & \begin{tabular}{|l|l|} 
\\
\end{tabular} & 0,45768 & 0,496 & 0,04576 & 0,496 & 0,044782 & 0,496 & 0,044611 & 0,496 & 0,044394 & 0,496 & 0,04411 & 0,496 \\
\hline 0,048 & 0,495999 & 0,047625 & 0,496 & 0,0475 & 0,496 & 0,0465844 & 0,496 & 0,046556 & 0,496 & 0,046401 & 0,496 & 0,0464621 & \begin{tabular}{|l|l|}
0,496 \\
\end{tabular} & 0,046428 & 0,496 & 0,046149 & \begin{tabular}{|l|l|}
0,496 \\
\end{tabular} & 0,45768 & 0,496 & 0,04576 & 0,496 & 0,044782 & 0,496 & 0,044611 & 0,496 & 0,044394 & 0,496 & 0,0491144 & 0,496 \\
\hline 0,053657 & 0,495999 & 0,053211 & 0,496 & 0,053075 & 0,496 & 0,052003 & 0,496 & 0,051973 & 0,496 & 0,051803 & 0,496 & 0,051821 & \begin{tabular}{|l|l|}
0,496 \\
\end{tabular} & 0,051826 & 0,496 & $0,0,051504$ & \begin{tabular}{|l|l|}
0,496 \\
\end{tabular} & 0,051066 & 0,496 & 0,05106 & 0,496 & 0,04993 & 0,496 & 0,049725 & 0,496 & 0,049473 & 0,496 & 0,049144 & 0,496 \\
\hline 0,053657 & 0,495999 & 0,053211 & 0,496 & 0,003075 & 0,496 & 0,052003 & 0,496 & 0,051973 & 0,496 & 0,051800 & 0,496 & 0,0551821 & \begin{tabular}{|l|l|}
0,496 \\
\end{tabular} & 0,051826 & 0,496 & 0,051504 & \begin{tabular}{|l|l|}
0,496 \\
\end{tabular} & 0,051066 & 0,496 & 0,05106 & 0,496 & 0,04993 & 0,496 & 0,049722 & 0,496 & 0,049473 & 0,496 & 0,054177 & 0,496 \\
\hline 0,059314 & 0,495999 & 0,058798 & 0,496 & 0,05865 & 0,496 & 0,057721 & 0,496 & 0,05739 & 0,496 & 0,057204 & 0,496 & 0,057221 & \begin{tabular}{|l}
0,496 \\
\end{tabular} & 0,057223 & 0,496 & 0,0568588 & \begin{tabular}{|l|l|} 
& 0,496 \\
\end{tabular} & 0,0566363 & 0,496 & 0,056359 & 0.496 & 0,055078 & 0,496 & 0,054839 & 0,496 & 0,054552 & 0,496 & 0,054177 & 0,496 \\
\hline 0,059314 & 0,495999 & 0,058798 & 0,496 & 0,05866 & 0,496 & 0,057721 & 0,496 & 0,05739 & 0,496 & 0,057204 & 0,496 & 0,057221 & \begin{tabular}{|l|l|} 
& 0,496 \\
\end{tabular} & 0,057223 & 0,496 & 0,056858 & \begin{tabular}{|l|l|} 
& 0,496 \\
\end{tabular} & 0,0566363 & 0,496 & 0,056359 & 0.496 & 0,055078 & 0,496 & 0,054839 & 0,496 & 0,054552 & 0,496 & 0,059211 & 0,496 \\
\hline 0,064971 & 0,495999 & 0,064384 & 0,496 & 0,064225 & 0,496 & 0,062839 & 0,496 & 0,062807 & 0,496 & 0,062606 & 0,496 & 0,062621 & \begin{tabular}{|l|l|}
0,496 \\
\end{tabular} & 0,0626221 & 0,496 & 0,062213 & \begin{tabular}{|l|l|}
0,496 \\
\end{tabular} & 0,061661 & 0,496 & 0,061659 & 0.496 & 0,060226 & 0,496 & 0,059953 & 0,496 & 0,059632 & 0,496 & 0,059211 & 0,496 \\
\hline 0,064971 & 0,619999 & 0,064384 & 0,62 & 0,064225 & 0,62 & 0,062839 & 0,62 & 0,062807 & 0,62 & 0,062606 & 0,62 & 0,062621 & \begin{tabular}{|c|} 
\\
\end{tabular} & 0,0626221 & 0,62 & 0,062213 & \begin{tabular}{|l|l|}
0,62 \\
\end{tabular} & 0,061661 & 0,620001 & 0,061659 & 0,6199999 & 0,060226 & 0,620001 & 0,059953 & 0,619999 & 0,059632 & 0,62 & 0,064245 & 0,62 \\
\hline 0,070628 & 0,6199999 & 0,069971 & 0,62 & 0,0698 & 0,62 & 0,068258 & 0,62 & 0,068223 & 0,62 & 0,068008 & 0,62 & 0,068021 & \begin{tabular}{|l|l} 
& 0,62 \\
\end{tabular} & 0,068019 & 0,62 & $0,0,67568$ & \begin{tabular}{|l|l}
0,62 \\
\end{tabular} & 0,066999 & 0,620000 & 0,066959 & 0,6199999 & 0,065374 & 0,6200001 & 0,065066 & 0,619999 & 0,064711 & 0,62 & 0,064245 & 0,62 \\
\hline
\end{tabular}

Tabela C.2 - FPA das correntes de defeito fase - terra - Simulação 2 


\begin{tabular}{|c|c|c|c|c|c|c|c|c|c|c|c|c|c|c|c|c|c|c|c|c|c|c|c|c|c|c|c|c|c|}
\hline $\mathrm{I1}(\mathrm{pu})$ & P1 (\%) & $\mathrm{I2}$ (pu) & P2 $(\%)$ & 13 (pu) & P3 (\%) & I4 (pu) & $\mathrm{P4} 4 \%$ & I5 (pu) & $\begin{array}{l}\text { P5 (\%) } \\
\end{array}$ & $\mathrm{II}(\mathrm{pu})$ & P66\%) & I7/(u) & P7(\%) & $\mathrm{IB}(\mathrm{pu})$ & $\mathrm{PB}(\%)$ & I9(pu) & \begin{tabular}{|l|}
$\mathbf{P 9}(\%)$ \\
\end{tabular} & $110(\mathrm{pu})$ & $\begin{array}{l}\text { P10(\%) } \\
\end{array}$ & I11(pu) & P11(\%) & I12(pu) & P12(\%) & I13(pu) & P13(\%) & 114(pu) & $\begin{array}{l}14(\%) \\
\end{array}$ & I115(pu) & P15(\%) \\
\hline 0,014057 & 0 & 0,014106 & 0 & 0,0114048 & 0 & 0,014073 & 0 & 0,014056 & 0 & $\begin{array}{ll}0,013989 \\
\end{array}$ & 0 & 0,01402 & 0 & $0,0,1404$ & 0 & $0,0,014022$ & 0 & 0,013982 & 0 & 0,013963 & 0 & 0,013895 & 0 & 0,013929 & 0 & 0,013918 & 0 & 0,013908 & 0 \\
\hline 0,014057 & 0,279999 & 0,014106 & 0,28 & 0,014048 & 0,28 & 0,014073 & 0,28 & 0,014056 & 0,28 & 0,013889 & 0,28 & 0,01402 & 0,28 & 0,01404 & 0,28 & $0,0,14022$ & 0,28 & 0,013982 & 0,28 & 0,013963 & 0,28 & 0,013895 & 0,28 & 0,013929 & 0,28 & 0,013918 & 0,28 & 0,013908 & 0,28 \\
\hline 0,019714 & 0,2799999 & 0,019693 & 0,28 & 0,019624 & 0,28 & 0,019492 & 0,28 & 0,019473 & 0,28 & 0,019392 & 0,28 & $0,0,19421$ & 0,28 & $\begin{array}{l}0,019439 \\
\end{array}$ & 0,28 & 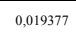 & 0,28 & 0,01928 & 0,28 & 0,019263 & 0,28 & 0,019044 & 0,28 & 0,019043 & 0,28 & 0,018998 & 0,28 & 0,018943 & 0,28 \\
\hline 0,019714 & 0,419999 & 0,019693 & 0,42 & 0,019624 & 0,42 & 0,019492 & 0,42 & 0,019473 & 0,42 & 0,019392 & 0,42 & 0,019421 & 0,42 & 0,019439 & 0,42 & \begin{tabular}{|l}
0,019377 \\
\end{tabular} & 0,42 & 0,01928 & 0,42 & 0,019263 & 0,42 & 0,019044 & 0,42 & 0,019043 & 0,42 & 0,018998 & 0,42 & 0,018943 & 0,42 \\
\hline 0,025371 & 0,419999 & 0,02528 & 0,42 & 0,0252 & 0,42 & 0,024911 & 0,42 & 0,02489 & 0,42 & 0,024794 & 0,42 & 0,024821 & 0,42 & 0,024837 & 0,42 & 0,024732 & 0,42 & 0,024578 & 0,42 & 0,024563 & 0,42 & 0,024192 & 0,42 & 0,024157 & 0,42 & 0,024078 & 0,42 & 0,023977 & 0,42 \\
\hline 0,025371 & 0,419999 & 0,02528 & 0,42 & 0,0252 & 0,42 & 0,024911 & 0,42 & 0,02489 & 0,42 & 0,024794 & 0,42 & 0,024821 & 0,42 & 0,024837 & 0,42 & 0,024732 & 0,42 & 0,024578 & 0,42 & 0,024563 & 0,42 & 0,024192 & 0,42 & 0,024157 & 0,42 & 0,024078 & 0,42 & $\begin{array}{l}0,023977\end{array}$ & 0,42 \\
\hline 0,031028 & 0,419999 & 0,030867 & 0,42 & 0,030775 & 0,42 & 0,03033 & 0,42 & 0,030308 & 0,42 & 0,030196 & 0,42 & 0,0302222 & 0,42 & 0,030236 & 0,42 & $0,0,030087$ & 0,42 & 0,029876 & 0,42 & 0,029863 & 0,42 & 0,02934 & 0,42 & 0,029272 & 0,42 & 0,029157 & 0,42 & 0,029011 & 0,42 \\
\hline 0,0311028 & 0,559998 & 0,030867 & 0,56 & 0,030075 & 0,56 & 0,03033 & 0,56 & 0,0303008 & 0,56 & 0,030196 & 0,56 & $0,0,302222$ & 0,56 & 0,030236 & 0,56 & 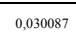 & 0,56 & 0,029876 & 0,560000 & 0,029863 & 0,559999 & 0,02934 & 0,560001 & 0,029272 & 0,559999 & 0,029157 & 0,56 & 0,029011 & 0,56 \\
\hline 0,036686 & 0,559998 & 0,036454 & 0,56 & 0,036351 & 0,56 & 0,035749 & 0,56 & 0,035725 & 0,56 & 0,035599 & 0,56 & 0,0336222 & 0,56 & 0,035634 & 0.56 & 0,035442 & \begin{tabular}{|l|l|} 
\\
0,56
\end{tabular} & 0,035175 & 0,560001 & 0,0351163 & 0,559999 & 0,034489 & 0,5600001 & 0,0344386 & 0,559999 & 0,034237 & 0,56 & 0,034045 & 0,56 \\
\hline 0,036686 & 0,559998 & 0,036454 & 0,56 & 0,0363551 & 0,56 & 0,035749 & 0,56 & 0,035725 & $0,0,56$ & 0,035599 & 0,56 & 0,0336222 & 0,56 & 0,035634 & 0,56 & $\begin{array}{l}0,035442 \\
\end{array}$ & $\begin{array}{ll}0,56 \\
\end{array}$ & 0,0351717 & 0,560000 & 0,0335163 & 0,559999 & 0,034489 & 0,560001 & $0,0,344386$ & 0,559999 & 0,0344237 & 0,56 & $0,0,034045$ & 0,56 \\
\hline 0,042343 & 0,559998 & 0,04204 & 0,56 & 0,041927 & 0,56 & 0,041168 & 0,56 & 0,041142 & 0,56 & 0,041001 & 0,56 & 0,0411023 & 0,56 & 0,041032 & 0,56 & 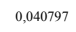 & 0,56 & 0,040473 & 0,560001 & 0,040463 & 0,559999 & 0,039637 & 0,5600001 & 0,0395 & 0,559999 & 0,039317 & 0,56 & 0,039079 & 0,56 \\
\hline 0,042343 & 0,559999 & 0,04200 & 0,56 & 0,041927 & 0,56 & 0,041168 & 0,56 & 0,041142 & 0,56 & 0,041001 & 0,56 & 0,0411023 & 0,56 & 0,041032 & 0,56 & $0,0,040797$ & \begin{tabular}{|l|l}
0,56 \\
\end{tabular} & 0,040473 & 0,560000 & 0,040463 & 0,559999 & 0,039637 & 0,5600001 & 0,0395 & 0,559999 & 0,039317 & 0,56 & 0,039079 & 0,56 \\
\hline 0,048 & 0,559998 & 0,047627 & 0,56 & 0,047502 & 0,56 & 0,0465877 & 0,56 & 0,046559 & 0,56 & 0,046404 & 0,56 & 0,0464624 & 0,56 & 0,046431 & 0,56 & 0,0466152 & 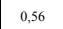 & 0,045771 & 0,560001 & 0,045763 & 0,559999 & 0,044785 & 0,5600001 & 0,044614 & 0,559999 & 0,044397 & 0,56 & 0,0444113 & 0,56 \\
\hline 0,048 & 0,559998 & 0,047627 & 0,56 & 0,047502 & 0,56 & 0,0465877 & 0,56 & 0,046559 & 0,56 & 0,046404 & 0,56 & 0,0464624 & 0,56 & 0,046431 & 0,56 & 0,046152 & \begin{tabular}{|l|l}
0,56 \\
\end{tabular} & 0,045771 & 0,5600001 & 0,045763 & 0,559999 & 0,044785 & 0,5600001 & 0,094614 & 0,559999 & 0,0444397 & 0,56 & 0,0441113 & 0,56 \\
\hline 0,053657 & 0,559998 & 0,053214 & 0,56 & 0,053078 & 0,56 & 0,052006 & 0,56 & 0,051977 & 0,56 & 0,051806 & 0,56 & 0,051824 & 0,56 & 0,051829 & 0,56 & $\begin{array}{l}0,051507 \\
\end{array}$ & 0,56 & 0,051069 & 0,560000 & 0,051063 & 0,559999 & 0,049934 & 0,5600001 & 0,049729 & 0,5599999 & 0,049477 & 0,56 & 0,049147 & 0,56 \\
\hline 0,053657 & 0,559998 & 0,053214 & 0,56 & 0,053078 & 0,56 & 0,052006 & 0,56 & 0,051977 & 0,56 & 0,051806 & 0,56 & 0,051824 & 0,56 & 0,051829 & 0.56 & $0,0,051507$ & \begin{tabular}{|l|l|}
0,56 \\
\end{tabular} & 0,051069 & 0,5600001 & 0,051063 & 0,559999 & 0,049934 & 0,5600001 & 0,049729 & 0,559999 & 0,049477 & 0,56 & 0,049147 & 0,56 \\
\hline 0,059314 & 0,559998 & 0,058801 & 0,56 & 0,058654 & 0,56 & 0,057425 & 0,56 & 0,057394 & 0,56 & 0,057208 & 0,56 & 0,057225 & 0,56 & 0,057227 & 0,56 & 0,056862 & \begin{tabular}{|l|l|} 
& 0,56 \\
\end{tabular} & 0,0566377 & 0,560001 & 0,056633 & 0,559999 & 0,055082 & 0,5600001 & 0,054843 & 0,559999 & 0,054556 & 0,56 & 0,054182 & 0,56 \\
\hline 0,059314 & 0,559998 & 0,058801 & 0,56 & 0,058654 & 0,56 & 0,057725 & 0,56 & 0,057394 & 0,56 & 0,057208 & 0,56 & 0,057225 & 0,56 & 0,057227 & 0.56 & 0,056862 & \begin{tabular}{|l|l|} 
& 0,56 \\
\end{tabular} & 0,0566377 & 0,560000 & 0,056636 & 0,559999 & 0,055082 & 0,5600001 & 0,054843 & 0,559999 & 0,054556 & 0,56 & 0,054182 & 0,56 \\
\hline 0,064971 & 0,559998 & 0,064388 & 0,56 & 0,064229 & 0,56 & 0,062844 & 0,56 & 0,062811 & 0,56 & 0,062611 & 0,56 & 0,06262525 & 0,56 & 0,062626 & 0.56 & 0,062217 & 0,56 & 0,061665 & 0,560001 & 0,061664 & 0,559999 & 0,060231 & 0,5600001 & 0,059957 & 0,559999 & 0,059636 & 0,56 & 0,059216 & 0,56 \\
\hline 0,064971 & 0,699998 & 0,064388 & 0,7 & 0,064229 & 0,7 & 0,062844 & 0,7 & 0,062811 & 0,7 & 0,062611 & 0,7 & 0,06262525 & 0,7 & 0,062626 & 0,7 & 0,062217 & 0,7 & 0,061665 & 0,700001 & 0,061664 & 0,6999999 & 0,060231 & 0,7000001 & 0,059957 & 0,6999999 & 0,059636 & 0,7 & 0,059216 & 0,7 \\
\hline 0,070628 & 0,6999988 & 0,069975 & 0,7 & $0,0,06905$ & 0,7 & 0,068263 & 0,7 & 0,068228 & 0,7 & 0,068013 & 0,7 & 0,0688226 & 0,7 & 0,068022 & 0,7 & 0,067773 & 0,7 & 0,066964 & 0,700000 & 0,066964 & 0,6699999 & 0,065379 & 0,7000001 & 0,065072 & 0,6999999 & 0,064711 & 0,7 & 0,06425 & 0,7 \\
\hline
\end{tabular}

Tabela C.3 - FPA das correntes de defeito fase - terra - Simulação 3 


\begin{tabular}{|c|c|c|c|c|c|c|c|c|c|c|c|c|c|c|c|c|c|c|c|c|c|c|c|c|c|c|c|c|c|}
\hline $11(\mathrm{pu})$ & P1 (\%) & $12(\mathrm{pu})$ & P2 $(\%)$ & $13(\mathrm{pu})$ & P3 $(\%)$ & $14(\mathrm{pu})$ & P4 (\%) & $15(\mathrm{pu})$ & P5 $(\%)$ & ${ }^{16(p u)}$ & $\mathrm{Pf}(\%)$ & $17(\mathrm{pu})$ & $\mathrm{P} 7(\%)$ & $\mathrm{I8}(\mathrm{pu})$ & P8(\%) & $19(\mathrm{pu})$ & $\mathbf{P g}(\%)$ & 110(pu) & P10(\%) & II1(pu) & $\mathrm{P} 11(\%)$ & $\mathrm{I12(pu)}$ & P12(\%) & \begin{tabular}{|l}
$113(\mathrm{pu})$ \\
\end{tabular} & $\mathrm{P} 13(\%)$ & 114(pu) & P14(\%) & ${ }^{115(p u)}$ & P15(\%) \\
\hline 0,011415 & 0 & 0,001416 & 0 & 0,001415 & 0 & 0,001415 & 0 & 0,001415 & 0 & \begin{tabular}{|l|l|l|l|l|}
\end{tabular} & 0 & 0,0001415 & 0 & 0,0014115 & 0 & 0,0014115 & 0 & 0,001414 & 0 & 0,001414 & 0 & 0,0011414 & 0 & \begin{tabular}{|l|l}
0,001414 \\
\end{tabular} & 0 & 0,001414 & 0 & 0,01414 & 0 \\
\hline 0,01415 & 0,489999 & 001416 & 0,49 & 0,001415 & 0,49 & 0,001415 & 0,49 & 0,001415 & 0,49 & \begin{tabular}{|l|l}
0,001414 \\
\end{tabular} & 0,49 & 0,001415 & 0,49 & 0,001415 & 0,49 & ,001415 & 0,49 & 0,001414 & 0,49 & 0,001414 & 0,49 & 0,001414 & 0,49 & 0,001414 & 0,49 & 0,001414 & 0,49 & 0,01414 & 0,49 \\
\hline 0,097344 & 0,489999 & 0,072311 & 0,49 & $\begin{array}{ll}0,068407 \\
\end{array}$ & 0,49 & 0,049324 & 0,49 & 0,045312 & 0,49 & $0,0,044473$ & 0,49 & 0,0411287 & 0,49 & 0,041936 & 0,49 & 0,039017 & 0,49 & 0,036782 & 0,49 & 0,036782 & 0,49 & 0,031467 & 0,49 & 0,0331 & 0,49 & 0,028698 & 0,49 & 0,027559 & 0,49 \\
\hline 0,097344 & 0,489999 & 0,072311 & 0,49 & 0,0684077 & 0,49 & 0,049324 & 0,49 & 0,045312 & 0,49 & 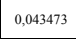 & 0,49 & 0,041287 & 0,49 & 0,041936 & 0,49 & 0,039017 & 0,49 & 0,036782 & 0,49 & 0,036782 & 0,49 & 0,031467 & 0,49 & 0,0301 & 0,49 & 0,028698 & 0,49 & 0,027559 & 0,49 \\
\hline 0,193272 & 0,489999 & 0,143207 & 0,49 & 0,1354 & $\begin{array}{l}0,49 \\
\end{array}$ & 0,097232 & 0,49 & 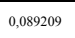 & 0,49 & 0,085532 & 0,49 & 0,08116 & 0,49 & 0,082457 & 0,49 & 0,076619 & 0,49 & 0,072149 & 0,49 & $\begin{array}{l}0,072149 \\
\end{array}$ & 0,49 & 0,006152 & 0,49 & 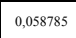 & 0,49 & 0,055983 & 0,49 & 0,053705 & 0,49 \\
\hline 0,193272 & 0,489999 & 0,143207 & 0,49 & 0,1354 & 0,49 & 0,097232 & 0,49 & 0,089209 & 0,49 & \begin{tabular}{|l}
0,085532 \\
\end{tabular} & 0,49 & 0,08116 & 0,49 & 0,082457 & 0,49 & 0,076619 & 0,49 & 0,072149 & 0,49 & 0,072149 & 0,49 & 0,006152 & 0,49 & \begin{tabular}{|l}
0,058785 \\
\end{tabular} & 0,49 & 0,055983 & 0,49 & 0,053705 & 0,49 \\
\hline $\begin{array}{l}0,2992 \\
\end{array}$ & 0,489999 & 0,214103 & 0,49 & 0,202392 & 0,49 & 0,145141 & 0,49 & 0,133107 & 0,49 & \begin{tabular}{|l|l|}
0,12759 \\
\end{tabular} & 0,49 & 0,121032 & 0,49 & 0,122978 & 0,49 & 0,114222 & 0,49 & 0,107517 & 0,49 & 0,107516 & 0,49 & 0,091573 & 0,49 & 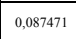 & 0,49 & $0,0,083267$ & 0,49 & $0,0,079811$ & 0,49 \\
\hline 0,2892 & 0,496093 & 0,214103 & 0,49 & 0,202392 & 0,49 & 0,145141 & 0,49 & 0,133107 & 0,49 & \begin{tabular}{|l|l}
0,12759 \\
\end{tabular} & 0,49 & 0,121032 & 0,49 & 0,122978 & 0,49 & 0,114221 & 0,49 & 0,107517 & 0,49 & 0,107516 & 0,49 & 0,091573 & 0,49 & \begin{tabular}{|l}
0,087471 \\
\end{tabular} & 0,49 & 0,083267 & 0,49 & 0,079851 & 0,49 \\
\hline 0,385129 & 0,496099 & $\begin{array}{l}0,284999 \\
\end{array}$ & 0,49 & 0,269384 & $\begin{array}{l}0,49 \\
\end{array}$ & $0,0,193049$ & 0,49 & 0,177004 & 0,49 & 0,1696499 & 0,49 & 0,160905 & 0,49 & 0,163498 & 0,49 & 0,151823 & 0,49 & 0,142884 & 0,49 & 0,142884 & 0,49 & 0,121626 & 0,49 & \begin{tabular}{|l}
0,116156 \\
\end{tabular} & 0,49 & 0,11051 & 0,49 & 0,105996 & 0,49 \\
\hline 0,385129 & 0,59659 & 0,284999 & 0,49 & 0,269384 & 0,49 & 0,193049 & 0,49 & 0,177004 & 0,49 & \begin{tabular}{|l}
0,169699 \\
\end{tabular} & 0,49 & 0,160905 & 0,49 & 0,163498 & 0,49 & 0,151823 & 0,49 & 0,142884 & 0,49 & 0,142884 & 0,49 & 0,121626 & 0,49 & \begin{tabular}{|l}
0,116156 \\
\end{tabular} & 0,49 & 0,1051 & 0,49 & 0,105996 & 0,49 \\
\hline 0,481057 & 0,59659 & 0,355895 & 0,49 & \begin{tabular}{|l}
0,336377 \\
\end{tabular} & 0,49 & 0,240958 & 0,49 & 0,220901 & 0,49 & \begin{tabular}{|l}
0,211707 \\
\end{tabular} & 0,49 & 0,200777 & 0,49 & 0,204019 & 0,49 & 0,189424 & 0,49 & 0,178251 & 0,49 & 0,178251 & 0,49 & 0,151679 & 0,49 & \begin{tabular}{|l}
0,144842 \\
\end{tabular} & 0,49 & 0,137836 & 0,49 & 0,132142 & 0,49 \\
\hline 0,481057 & 0,668009 & 0,355895 & 0,49 & 0,3363777 & 0,49 & 0,240958 & 0,49 & 0,220901 & 0,49 & \begin{tabular}{|l|l}
0,211707 \\
\end{tabular} & 0,49 & 0,200777 & 0,49 & 0,204019 & 0,49 & 0,189424 & 0,49 & 0,178251 & 0,49 & 0,178251 & 0,49 & 0,151679 & 0,49 & 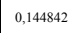 & 0,49 & 0,137836 & 0,49 & 0,132142 & 0,49 \\
\hline 0,576985 & 0,668009 & 0,426791 & 0,49 & $\begin{array}{l}0,403369 \\
\end{array}$ & 0,49 & 0,288866 & 0,49 & 0,264798 & 0,49 & \begin{tabular}{|l}
0,25376 \\
\end{tabular} & 0,49 & 0,24065 & 0,49 & 0,24454 & 0,49 & 0,227026 & 0,49 & 0,213619 & 0,49 & 0,213619 & 0,49 & 0,181732 & 0,49 & 0,173528 & 0,49 & 0,16512 & 0,49 & 0,158288 & 0,49 \\
\hline 0,576985 & 0,0683414 & 0,426799 & 0,49 & 0,403369 & 0,579431 & 0,288866 & 0,49 & 0,264798 & 0,49 & 0,253766 & 0,49 & 0,24065 & 0,49 & 0,24454 & 0,49 & 0,2277026 & 0,49 & 0,213619 & 0,49 & 0,213619 & 0,49 & 0,181732 & 0,49 & 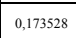 & 0,49 & 0,16512 & 0,49 & 0,158288 & 0,49 \\
\hline 0,672914 & 0,683414 & 0,497686 & 0,49 & 0,470361 & 0,579431 & 0,336775 & 0,49 & 0,308695 & 0,49 & \begin{tabular}{|l|l}
0,295824 \\
\end{tabular} & 0,49 & 0,280522 & 0,49 & 0,285061 & 0,49 & 0,264628 & 0,49 & 0,248986 & 0,49 & 0,248986 & 0,49 & 0,211785 & 0,49 & \begin{tabular}{|l|l}
0,20213 \\
\end{tabular} & 0,49 & 0,192404 & 0,49 & 0,184433 & 0,49 \\
\hline 0,672914 & 0,689488 & 0,497686 & 0,49 & 0 & 0,623658 & 0,336775 & 0,49 & 0,308695 & 0,49 & 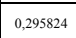 & 0,5611799 & 0,280522 & 0,49 & 0,285061 & 0,49 & 0,264628 & 0,49 & 0,248986 & 0,49 & 0,248986 & 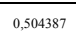 & 0,211785 & 0,49 & \begin{tabular}{|l|l}
0,202213 \\
\end{tabular} & 0,49 & 0,192404 & 0,49 & 0,184433 & 0,49 \\
\hline 0,768442 & 0,689488 & 0,568582 & 0,49 & 0,53753 & 0,623658 & 0,384683 & 0,49 & 0,352592 & 0,49 & 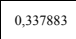 & 0,561779 & 0,320395 & 0,49 & 0,325582 & 0,49 & 0,30223 & 0,49 & 0,284353 & 0,49 & 0,284353 & 0,5043877 & 0,241838 & 0,49 & 0,230899 & 0,49 & 0,219689 & 0,49 & 0,210579 & 0,49 \\
\hline 0,768842 & 0,664105 & 0,568582 & 0,6290007 & 0,53753 & 0,6663366 & 0,384683 & 0,49 & 0,352592 & 0,518194 & $0,0,377883$ & 0,063208 & 0,320399 & 0,629444 & 0,325582 & 0,542177 & 0,03023 & $0,0,545722$ & 0,2844353 & 0,593382 & 0,284353 & $0,0,627699$ & 0,241838 & 0,623824 & 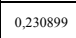 & 0,581149 & 0,219689 & 0,542215 & 0,210579 & 0,49 \\
\hline 0,864771 & 0,694105 & 0,639477 & 0,629007 & 0,6044346 & 0,665366 & 0,432591 & 0,49 & 0,39649 & 0,518194 & \begin{tabular}{|l|l}
0,379941 \\
\end{tabular} & 0,63208 & 0,360267 & 0,629444 & 0,366103 & 0,542172 & 0,339832 & $0,0,445722$ & 0,319721 & 0,593382 & 0,319721 & 0,627669 & 0,27189 & 0,6263824 & \begin{tabular}{|l|l}
0,259885 \\
\end{tabular} & 0,581149 & 0,246973 & 0,542215 & 0,236725 & 0,49 \\
\hline 0,864771 & 0,699999 & 0,6339478 & 0,7 & $0,0,644346$ & 0,7 & $\begin{array}{l}0,432591 \\
\end{array}$ & 0,7 & 0,39649 & 0,7 & 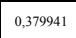 & 0,7 & 0,360267 & 0,7 & 0,366103 & 0,7 & 0,339832 & 0,7 & 0,319721 & 0,7000001 & 0,319721 & 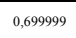 & $\begin{array}{l}0,27189 \\
\end{array}$ & 0,700001 & 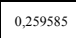 & 0,699999 & 0,246973 & 0,7 & 0,236725 & 0,7 \\
\hline 0.960699 & 0.699999 & 0.710374 & 0.7 & 0.671338 & 0.7 & 0.4805 & 0.7 & 0.440887 & 0.7 & 0.422 & 0.7 & 0.40014 & 0.7 & 0.40624 & 0.7 & 0.377434 & 0.7 & 0.355888 & 0,700001 & 0.355088 & 0.699999 & 0.301943 & 0,700001 & 0.28827 & 0.699999 & 0.274257 & 0.7 & 0.2687 & 0.7 \\
\hline
\end{tabular}

Tabela C.4 - FPA das correntes de defeito fase - terra - Simulação 4 


\begin{tabular}{|c|c|c|c|c|c|c|c|c|c|c|c|c|c|c|c|c|c|c|c|c|c|c|c|c|c|c|c|c|c|}
\hline 11 (pu) & P1 (\%) & $12(\mathrm{pu})$ & P2 (\%) & $13(\mathrm{pu})$ & P3 $(\%)$ & $\mathrm{I4}(\mathrm{pu})$ & $\mathrm{P} 4(\%)$ & $15(\mathrm{pu})$ & P5 (\%) & $\mathrm{I}(\mathrm{puu})$ & $\mathrm{P} 6(\%)$ & ${ }^{17 /(p u)}$ & P7(\%) & $\mathrm{I8}(\mathrm{pu})$ & $\mathrm{PB}(\%)$ & I9(pu) & $\mathrm{Pg}(\%)$ & ${ }_{110(p u)}$ & $\mathrm{P} 10(\%)$ & I11(pu) & P11(\%) & ${ }_{112(p u)}$ & P12\%) & ${ }_{113(p u)}$ & $\mathrm{P} 13(\%)$ & ${ }_{114(\mathrm{pu})}$ & P14(\%) & ${ }_{115(\mathrm{pu})}$ & P15 $(\%)$ \\
\hline 0,001416 & 0 & 0,001416 & 0 & $0,0,14048$ & 0 & 0,014073 & 0 & $\begin{array}{ll}0,014056 \\
\end{array}$ & 0 & 0,001415 & 0 & $\begin{array}{ll}0,01402 \\
\end{array}$ & 0 & 0,001415 & 0 & 0,014022 & 0 & 0,013982 & 0 & 0,001415 & 0 & 0,013895 & 0 & $\begin{array}{l}0,013929 \\
\end{array}$ & 0 & 0,013918 & 0 & 0,013908 & 0 \\
\hline 0,001416 & 0,669182 & 001416 & 0,698511 & 014048 & 0,28 & 0,014073 & 0,28 & 0,014056 & 0,28 & 0,001415 & 0,529877 & 0,01402 & 0,28 & 0,001415 & 0,434 & 0,014022 & 0,28 & 0,013982 & 0,279863 & 0,001415 & 0,531999 & 0,013895 & 0,267505 & 0,013929 & 0,277354 & 0,013918 & 0,28 & 0,013908 & 0,248 \\
\hline 0,096997 & 0,669182 & 0,072446 & 0,698511 & 0,019624 & 0,28 & 0,019492 & 0,28 & 0,019473 & 0,28 & 0,043521 & 0,529877 & 0,019421 & 0,28 & 0,04198 & 0,434 & 0,019377 & 0,28 & 0,01928 & 0,279863 & 0,036816 & 0,531999 & 0,019044 & 0,267505 & 0,019043 & 0,277354 & 0,018998 & 0,28 & 0,018943 & 0,248 \\
\hline 0,0969977 & 0,669182 & 0,072446 & 0,698511 & 0,019624 & 0,42 & 0,019492 & 0,42 & 0,019473 & 0,42 & 0,043521 & 0,609631 & 0,019421 & 0,42 & 0,04198 & 0,434 & 0,019377 & 0,42 & 0,01928 & 0,419795 & 0,036816 & 0,622138 & 0,019044 & 0,401257 & 0,019043 & 0,41603 & 0,018998 & 0,42 & 0,018944 & 0,372 \\
\hline $\begin{array}{l}0,192579 \\
\end{array}$ & 0,669182 & 0,143476 & 0,6985511 & 0,0252 & 0,42 & 0,024911 & 0,42 & $\begin{array}{l}0,02489 \\
\end{array}$ & 0,42 & 0,085628 & 0,609631 & $\begin{array}{l}0,224821 \\
\end{array}$ & 0,42 & 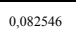 & 0,434 & 0,0247332 & 0,42 & $0,0,24578$ & 0,419795 & $0,0,72217$ & 0,6221388 & 0,024192 & 0,401257 & 0,024157 & 0,41603 & 0,024078 & 0,42 & 0,023977 & 0,372 \\
\hline 0,192579 & $\begin{array}{l}0,669182 \\
\end{array}$ & 0,143476 & 0,6985511 & 0,0252 & 0,42 & 0,024911 & 0,42 & 0,02489 & 0,42 & 0,085628 & 0,0609631 & 0,024821 & 0,42 & 0,082546 & 0,434 & $\begin{array}{l}0,024732 \\
\end{array}$ & 0,42 & 0,024578 & 0,419795 & 0,072217 & $\begin{array}{l}0,622138 \\
\end{array}$ & 0,024192 & 0,401257 & 0,024157 & 0,41603 & 0,024078 & 0,42 & $\begin{array}{l}0,023977 \\
\end{array}$ & 0,372 \\
\hline 0,28816 & 0,669182 & 0,214506 & 0,698511 & 0,030775 & 0,42 & 0,03033 & 0,42 & 0,030308 & 0,42 & 0,127734 & 0,609631 & 0,030222 & 0,42 & 0,123111 & 0,434 & $\begin{array}{l}0,030087 \\
\end{array}$ & 0,42 & 0,029876 & 0,419795 & 0,107619 & 0,622138 & 0,02934 & 0,401257 & 0,029272 & 0,41603 & 0,029157 & 0,42 & 0,029011 & 0,372 \\
\hline 0,28816 & 0,669182 & 0,214506 & 0,698511 & 0,030775 & 0,56 & 0,03033 & 0,56 & 0,030308 & 0,56 & 0,127734 & 0,609631 & 0,030222 & 0,56 & 0,123111 & 0,434 & 0,030087 & 0,56 & 0,029876 & 0,559727 & 0,107619 & 0,622138 & 0,02934 & 0,53501 & $\begin{array}{l}0,029272 \\
\end{array}$ & 0,554707 & 0,029157 & 0,56 & 0,029011 & 0,496 \\
\hline 0,383741 & 0,669182 & 0,285537 & 0,6985511 & 0,036351 & 0,56 & 0,035749 & 0,56 & 0,035725 & 0,56 & 0,169841 & 0,609631 & 0,035622 & 0,56 & 0,163676 & 0,434 & 0,035442 & 0,56 & 0,035175 & 0,559727 & 0,14302 & 0,622138 & 0,034489 & 0,53501 & 0,0343866 & 0,554707 & 0,034237 & 0,56 & 0,034045 & 0,496 \\
\hline 0,3837441 & $\begin{array}{r}0,669182 \\
\end{array}$ & 0,285537 & 0,6985511 & $\begin{array}{l}0,0363551 \\
\end{array}$ & 0,56 & $\begin{array}{l}0,035749 \\
\end{array}$ & 0,56 & $\begin{array}{l}0,035725 \\
0\end{array}$ & 0,56 & 0,169841 & $\begin{array}{l}0,609631 \\
\end{array}$ & 0,035622 & 0,56 & 0,163676 & 0,434 & 0,035442 & 0,56 & $\begin{array}{l}0,0355175 \\
\end{array}$ & $0,0,599272$ & 0,14302 & 0,622138 & $\begin{array}{r}0,034489 \\
\end{array}$ & 0,53501 & $\begin{array}{l}0,034386 \\
\end{array}$ & 0,554707 & $\begin{array}{l}0,034237 \\
\end{array}$ & 0,56 & $\begin{array}{l}0,034045 \\
\end{array}$ & 0,496 \\
\hline 0,479323 & 0,669182 & 0,356567 & 0,6985511 & 0,041927 & 0,56 & 0,041168 & 0,56 & 0,041142 & 0,56 & 0,211947 & 0,609631 & 0,041023 & 0,56 & 0,204242 & 0,434 & 0,040797 & 0,56 & 0,040473 & 0,559727 & 0,178421 & 0,622138 & $\begin{array}{l}0,039637 \\
\end{array}$ & 0,53301 & 0,0395 & 0,554707 & 0,039317 & 0,56 & 0,039079 & 0,496 \\
\hline 0,479323 & 0,669182 & 0,356567 & 0,698511 & 0,041927 & 0,56 & 0,041168 & 0,56 & 0,041142 & 0,56 & 0,211947 & 0,609631 & 0,041023 & 0,56 & 0,204242 & 0,434 & 0,040797 & 0,56 & 0,040473 & 0,559727 & 0,178421 & 0,622138 & $\begin{array}{l}0,039637 \\
\end{array}$ & 0,53301 & 0,0395 & 0,554707 & 0,039317 & 0,56 & 0,039079 & 0,496 \\
\hline 0,574904 & 0,669182 & 0,427597 & 0,698511 & 0,047502 & 0,56 & 0,046587 & 0,56 & 0,046559 & 0,56 & 0,254053 & 0,609631 & 0,046424 & 0,56 & 0,244807 & 0,434 & 0,046152 & 0,56 & 0,045771 & 0,559727 & 0,213823 & 0,622138 & 0,044785 & 0,53301 & 0,044614 & 0,554707 & 0,044397 & 0,56 & 0,044113 & 0,496 \\
\hline 0,574904 & 0,669182 & 0,427597 & 0,698511 & 0,047502 & 0,56 & 0,046587 & 0,56 & 0,046559 & 0,56 & 0,254053 & 0,609631 & 0,046424 & 0,56 & 0,244807 & 0,434 & 0,046152 & 0,56 & 0,045771 & 0,559727 & 0,213823 & 0,622138 & 0,044785 & 0,53301 & 0,044614 & 0,554707 & 0,044397 & 0,56 & 0,044113 & 0,496 \\
\hline 0,670485 & 0,669182 & 0,498627 & 0,698511 & 0,0533078 & 0,56 & 0,052006 & 0,56 & 0,051977 & 0,56 & 0,29616 & 0,609631 & 0,051824 & 0,56 & 0,285372 & 0,434 & 0,051507 & 0,56 & 0,051069 & 0,559727 & 0,249224 & 0,622138 & 0,049934 & 0,53301 & 0,049729 & 0,554707 & 0,049477 & 0,56 & 0,049147 & 0,496 \\
\hline 0,670485 & 0,675269 & 0,498627 & 0,698511 & 0,0533078 & 0,56 & 0,052006 & 0,56 & 0,051977 & 0,56 & 0,29616 & 0,609631 & 0,051824 & 0,56 & 0,285372 & 0,434 & 0,051507 & 0,56 & 0,051069 & 0,559727 & 0,249224 & 0,622138 & 0,049934 & 0,53501 & 0,049729 & 0,554707 & 0,049477 & 0,56 & 0,049147 & 0,496 \\
\hline 0,7660667 & 0,675269 & 0,569657 & 0,698511 & 0,058654 & 0,56 & 0,057425 & 0,56 & 0,057394 & 0,56 & 0,338266 & 0,609631 & 0,057225 & 0,56 & 0,325938 & 0.434 & 0,056862 & 0,56 & 0,0563677 & 0,559727 & 0,284626 & 0,622138 & 0,055082 & 0,53501 & 0,054843 & 0,554707 & 0,054556 & 0,56 & 0,054182 & 0,496 \\
\hline 0,766067 & 0,6845 & 0,5660677 & 0,6985511 & 0,058654 & 0,56 & 0,057425 & 0,56 & 0,057394 & 0,56 & 0,338266 & 0,632795 & 0,057225 & 0,56 & 0,325938 & 0,478037 & 0,056862 & 0,56 & 0,056367 & 0,559727 & 0,284626 & 0,634219 & 0,055082 & 0,53301 & 0,054843 & 0,554707 & 0,054556 & 0,56 & 0,054182 & 0,496 \\
\hline 0,861648 & 0,6845 & 0,640688 & 0,6985511 & 0,0642229 & 0,56 & 0,062844 & 0,56 & 0,062811 & 0,56 & 0,380373 & 0,632795 & 0,062625 & 0,56 & 0,366503 & 0,478037 & 0,062217 & 0,56 & 0,061665 & 0,559727 & 0,320027 & 0,634219 & 0,060231 & 0,53301 & 0,059957 & 0,554707 & 0,059636 & 0,56 & 0,059216 & 0,496 \\
\hline 0,861648 & 0,691924 & 0,0663888 & 0,7 & 0,0664229 & 0,7 & 0,062844 & 0,7 & 0,062811 & 0,7 & 0,380073 & 0,7 & 0,062625 & 0,7 & 0,366503 & 0,62 & 0,062217 & 0,7 & 0,061665 & 0,699658 & 0,320027 & 0,695613 & 0,060231 & 0,668762 & 0,059957 & 0,693384 & 0,059636 & 0,7 & 0,059216 & 0,62 \\
\hline 0.957229 & $0,0,691924$ & 0,717718 & 0,7 & 0,069805 & 0,7 & 0,068263 & 0,7 & 0,068222 & 0,7 & 0,422499 & 0,7 & 0,068026 & 0,7 & 0,407068 & 0,62 & 0,067573 & 0,7 & 0,0666964 & $0,0,99658$ & 0,355428 & 0,695613 & $0,0,065379$ & 0,068762 & $0,0,05072$ & 0,693384 & 0,0667716 & 0,7 & 0,06425 & 0,62 \\
\hline
\end{tabular}

Tabela C. 5 - FPA das correntes de defeito fase - terra - Simulação 5 


\begin{tabular}{|c|c|c|c|c|c|c|c|c|c|c|c|c|c|c|c|c|c|c|c|c|c|c|c|c|c|c|c|c|c|}
\hline (uv) & \%) & (pur) & (\%) & (pu) & P3 $3(\%)$ & 14 (pu) & P4 (\%) & $15(\mathrm{pu})$ & $\mathrm{P5}(\%)$ & $\mathrm{If(pu)}$ & $\mathrm{Pg}(\%)$ & $17(\mathrm{pur})$ & $\mathrm{P} 7(\%)$ & 8(pu) & $\mathrm{PB}(\%)$ & I9(pu) & P9(\%) & 10(pu) & P10(\%) & III(pu) & P11\%) & I12(pu) & P12\%) & I13(pu) & P131\%) & I14(pu) & $114(\%)$ & IIIf(pu) & P15(\%) \\
\hline 0,507432 & 0 & 0,625318 & 0 & 68863 & 0 & 0,530923 & 0 & 0,5007 & 0 & 0,3880804 & 0 & 0,4327112 & 0 & 4,469521 & 0 & 0,435815 & 0 & 370702 & 0 & 0,349641 & 0 & \begin{tabular}{|l|l|l}
0,281677 \\
\end{tabular} & 0 & 0,319651 & 0 & 0.305293 & 0 & 0,296586 & 0 \\
\hline 7432 & 0.34732 & 5318 & 049645 & 88663 & 0,048084 & 0,530923 & 0,14375 & 0,5007 & 0,040278 & 0,300804 & 0,03418 & 0,432712 & 0,049802 & 469521 & ,037266 & .435815 & 0,039802 & 70702 & 0,027932 & 0,344641 & ,0208928 & 1,281677 & 0,0231 & .319651 & 1.066054 & 305293 & .037297 & 296586 & .074508 \\
\hline 0,556689 & 34732 & 0351 & 19645 & 0666 & 48084 & 40789 & 4375 & 5.51587 & 440278 & 405945 & 034418 & 454442 & 149802 & 489664 & 137266 & 452458 & 0398022 & 387813 & 127932 & $0,1,368588$ & ,028928 & .296293 & 0,02231 & ,32936 & .066054 & 315184 & .037297 & , 3055107 & .077558 \\
\hline 0,556689 & 0,09742 & 500351 & 92291 & 06666 & 83914 & 0,540789 & 0,15 & 0,51587 & p,094445 & 405945 & 068361 & $\begin{array}{l}0,454442 \\
\end{array}$ & 0,074702 & .486964 & .074531 & 0,452458 & 0,079603 & .387813 & .073844 & 1,368858 & 0,067479 & 0,296293 & 0,069759 & 0,32936 & .099465 & 0.115184 & ,074593 & 0,305107 & 0,111762 \\
\hline 0,065946 & 0,09742 & 0,6773855 & .099291 & 0,544456 & 0,083914 & 0,550655 & 0,15 & 0,531039 & 0,094445 & 0,431085 & 0,068361 & 0,476171 & 0,077702 & 0,504407 & 0,0745311 & 0,4691 & 0,079603 & 0,404924 & 0,073844 & 0,388075 & 0,067779 & 0,310908 & $0,0,06759$ & 0,339069 & 0,099465 & $0 ., 325075$ & 0,074593 & 0,313628 & 0,111762 \\
\hline .605946 & .136216 & 75385 & 9291 & 14456 & 1498 & 50655 & 0,15 & 0,531039 & 48611 & 431085 & 196844 & 0,476171 & 0,099603 & .504077 & 111797 & 0,4691 & 0,119405 & 404924 & 1111601 & 1.388075 & 0,090647 & 1.310008 & .12513 & 0,339069 & 12502 & 325075 & ,1118 & 313628 & . 149016 \\
\hline 5202 & 6216 & 0418 & 291 & 2253 & 1498 & .560521 & 0,15 & 0,546209 & 0,148611 & 456225 & 6884 & 0,4979 & 0,099603 & .52185 & 11797 & 485743 & , 119405 & 222034 & 111601 & 107292 & .090647. & .325524 & .125136 & 0,348778 & 1.25027 & 334966 & ,11189 & 0,322149 & , 1,49016 \\
\hline 0,655202 & 0,166335 & 0,700418 & 0,165485 & 0,582253 & 0,136294 & 0,560521 & 0,15 & $\begin{array}{l}0,546209 \\
\end{array}$ & 0,148611 & 0,456225 & 0,118576 & 0,4979 & 0,132804 & 0,52185 & 0,149062 & 0,485743 & 0,14915 & 422034 & 0,158669 & 0,407292 & 0,139393 & 0,325524 & 0,144591 & 0,348778 & 0,149725 &., 334966 & 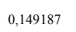 & 0,322149 & 0,15 \\
\hline 0,704459 & 0,166335 & 0,725452 & 0,165485 & 0,62005 & 0,136294 & 0,570387 & 0,15 & 0,561378 & 0,148611 & 0,481366 &, 118576 & 0,51963 & 0,132804 & 0,539293 & 0,149062 & 0,502385 & 0,14915 & 0,439145 & 0,158669 & 0,426509 & 0,139393 & 0,340139 & 0,144591 & 0,358487 & 0,149725 & 0,344857 & 0,1499187 & 0.3306 & 0,15 \\
\hline 0,704459 & 99024 & 5442 & 65485 & 2005 & 77885 & 0,570387 & 0,15 & 0,561378 & 0,15 &, 481366 & 156342 & 0,51963 & 0,166005 & ,539293 & 0,161484 & 0,502385 & 0,162417 & 0,439145 & 0.16798 & 0,426509 & 0,158988 & 0,340139 & 0,16649 & 0,358487 & 0,15 & 0,344857 & 0,162432 & 0,33067 & 0,15 \\
\hline 53716 & 9024 & 0485 & 5485 & 846 & 7085 & 6253 & 0,1 & 0,575484 & 0,15 & 66506 & 6342 & 0,541359 & 0,166005 & 556737 & 61484 & .519028 & 0,162417 & 56256 & 0,16798 & 0,45726 & , 1, 158988 & 354755 & 16649 & 0,368196 & 0,1 & 54748 & 162432 & 0,339191 & 0,15 \\
\hline 0,753716 & 0,188467 &, 750485 & 0,183097 & 57846 & 0,174245 & 0,580253 & 0,15 & 0,576548 & 0,163426 & 0,506506 & 1.178074 & 0,541359 & 0,174901 & 0,556737 & 0,174444 & 0,519028 & 0,176534 & 0,456256 & 0,187201 & 0,445726 & 0,178769 & 0,354755 & 0,181611 & 0,368196 & 0,166549 & 0,354748 & 0,174866 & 0,339191 & 162418 \\
\hline 0,802973 & 0,188467 & 0,775518 & 0,183097 & 0,695543 & 0,174245 & 0,590119 & 0,15 & 0,591717 & 0,163426 & 0,531647 & 0,178074 & 0,563088 & 0,174901 & 0,57418 & 0,174844 & 0,53367 & 0,176534 & 0,4773667 & 0,187201 & 0,4649443 & 0,178769 & 0,36937 & 0,181611 & 0,3777005 & 0,166549 & 0,364639 & 0,177865 & 0,347712 & 0,162418 \\
\hline 0,802973 & 0,194855 & 0,775518 & 0,183097 & 0,695643 & 0,191754 & 0,5900119 & 0,15 & 0,591717 & 0,181481 & 0,531647 & 0,189173 & 0,563088 & 0,183201 & 0,57418 & 0,187266 & 0,53367 & 0,189802 & 0,4773667 & 0,187201 & 0,464443 & 0,186162 & 0,36937 & 0,19152 & 0,377905 & 0,180125 & $0,0,364639$ & 0,177865 & 0,347712 & 0,174836 \\
\hline 0,85223 & 0,1948555 & 300552 & 183097 & 73344 & 0,191754 & 99985 & 0,15 & 0,6068866 & 81481 & 566787 & 89173 & 584818 & 0,183201 & 591623 & 187266 & 552312 & 0,189802 & 490478 & 187201 & 0,48416 & 0,186162 & .383986 & 1915 & 0,38761 & , 180125 & 374529 & 174865 & 0,356233 & ,1174836 \\
\hline 0,85223 & 0,197496 & 0,800552 & 0,199645 & 0,73344 & 0,195819 & 0,599985 & 0,15 & 0,6068866 & 0,181481 & 0,556787 & 0,194518 & 0,584818 & 0,191501 & 0,591623 & 0,187266 & 0,552312 & 0,189802 & 0,490478 & 0,199786 & 0,48416 & 0,19325 & 0,383986 & 0,195718 & 0,387615 & 0,190025 & 374529 & 187297 & 0,356233 & 0,187254 \\
\hline 0,901486 & 0,197446 & 0,825585 & 0,199645 & 0,771236 & 0,195819 & 0,609851 & 0,15 & 0,622056 & 0,181481 & 0,581928 & 0,194518 & 0,606547 & 0,191501 & 0,6090666 & 0,187266 & 0,568955 & 0,189802 & 0,507589 & 0,199786 & 0,503377 & 0,19325 & 0,398601 & 0,195718 & 0,397324 & 0,190025 & 0,38442 & 0,187297 & 0,364754 & 0,187254 \\
\hline 0,901486 & 0,199145 & 225585 & 99645 & 71236 & 0,199884 & 0,609851 & .197917 & 0,622056 & 0,199537 & 0,581928 & 1,198863 & 0,606547 & 0,199802 & 0,6090666 & 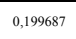 & $0,0,689955$ & 0,199717 & 0,507889 & 0 & 0,503377 & 0,196577 & 0,398601 & 0,199916 & 0,397324 & 4,196798 & 1.38442 & 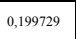 & 0,364754 & 0,199672 \\
\hline 0,950743 & 0,199145 & 850619 & 0,199645 & 809033 & 0,199884 & 0,619717 & 0,197917 & 0,637225 & 0,199537 & 0,6077068 & 0,199863 & 0,628276 & 0,199802 & 0,0626509 & $\begin{array}{l}0,199687 \\
\end{array}$ & .585597 & 0,199717 & 0,5247 & 0,199786 & 0,522594 & 0,196574 & , 413217 & 0,199916 & 0,407033 & , 1,166798 & 394311 & 0,199729 & 0,373275 & 0,199672 \\
\hline 0,950743 & 0,199999 & 0619 & 0,2 & 0,809033 & 0,2 & 0,619717 & 0,2 & 0,637725 & 0,2 & 0,607068 & 0,2 & 0,628277 & 0,2 & 0,626509 & 0,2 & 0,585597 & 0,2 & 0,5247 & 0,2 & 0,522594 & 0,2 & 0,413217 & 0,2 & 0,407033 & 0,2 & 0,394311 & 0,2 & 0,373275 & 0,2 \\
\hline 1 & 9999 & 5652 & 0,2 & 4683 & 0,2 & 9983 & 0,2 & 0,0652395 & 0,2 & 32208 & 0,2 & 0,650005 & 0,2 & 64395 & 0,2 & 0,60224 & 0.2 & 418. & 0,2 & 0,541811 & 0,2 & 0,427832 & 0,2 & 0,416742 & 0,2 & 0,404202 & 0,2 & 0,381796 & 0,2 \\
\hline
\end{tabular}

Tabela C.6 - FPA das correntes de defeito fase - fase - Simulação 1 
FPA- CURTO FASE FASE- SIMULAÇ̊̃o 2

\begin{tabular}{|c|c|c|c|c|c|c|c|c|c|c|c|c|c|c|c|c|c|c|c|c|c|c|c|c|c|c|c|c|c|}
\hline $\mathrm{II}(\mathrm{pu})$ & (\%) & pu) & $22(\%)$ & $3(\mathrm{pu})$ & $\mathrm{P}_{3}(\%)$ & pu) & P4 $4 \%)$ & $15(\mathrm{pu})$ & P5 (\%) & II 1 (pu) & P6(\%) & $17(\mathrm{pu})$ & P7(\%) & $\mathrm{I8}(\mathrm{pu})$ & $\mathrm{PB}(\%)$ & $\mathrm{Ig}(\mathrm{pu})$ & P9(\%) & $\mathrm{H10(pu)}$ & P10(\%) & $\mathrm{I11}(\mathrm{pu})$ & $111 \%)$ & 112(pu) & 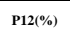 & I113(pu) & P13(\%) & $\mathrm{I14( \textrm {pu } )}$ & P144\%) & 15 (1pu) & P15\%) \\
\hline 0,507432 & 0 & 318 & & 863 & & 80923 & & 0,5007 & & 0,380804 & & 0,43 & & 0,46 & & $0,43$. & & 0,37070 & & 0,34964 & & 0,2816 & & 0,319651 & 0 & 0,305293 & 0 & 0,296586 & 0 \\
\hline 77432 & 057888 & 15318 & .082742 & 68863 & 080139 & 30923 & 239883 & .5007 & 106713 & 380804 & .056967 & 432712 & 0,083003 & 0,469521 & 0,062109 & 0,435815 & 0,066336 & 0,370702 & 0,046554 & $0,0,349641$ & 0,048214 & 0,281677 & 0,037184 & 0,319651 & 0,11009 & 0,305293 & 0,062161 & 0,296586 & 0,12418 \\
\hline 556889 & 1577888 & 50351 & 82742 & 00666 & 80139 & 10789 & 39983 & 81587 & 06773 & 405945 & 5696 & 454442 & .083003 & 0,486964 & $\overline{0,062109}$ & ,452458 & 0,066336 & 0,387813 & 0,046554 & 1368858 & .048214 & .296293 & .037184 & 0,32936 & $\overline{0,11009}$ & 0,315184 & 0,06216 &, 305107 & , 1.2418 \\
\hline 566689 & 62166 & 50351 & 65485 & 06666 & 9574 & 078 & 0,25 & 51587 & 87408 & 05945 & 1393 & 544422 & 124504 & 486964 & 124219 & 4,452458 & 1.136672 & 1387813 & 0,123074 & 3688858 & .112465: & .296293 & 11626 & ,.32933 & . 16577 & 3151 & .1243 & 30510 & $\frac{1,18627}{0.167}$ \\
\hline 55946 & 52166 & 13885 & 5485 & 14456 & 9574 & 065. & 0,25 & 11039 & 5740 & 43108. & 1392 & 4761711 & 12450 & 504407 & .124219 & 0,4691 & 132672 & 0,044924 & $\overline{0,123074}$ & 388075 & .112465: & 310908 & , 111626 & 133906 & , 16577: & 0,3250 & .1243 & 31362 & 18627 \\
\hline 5946 & 25987 & 1538: & 5 & 14456 & 184762 & 50655 & 0,25 & 83103 & 47685 & 3108 & 1.160648 & 76171 & 0,160005 & $\overline{04407}$ & $\overline{0,186328}$ & 0,04691 & 199009 & 404924 & 0,186002 & 888075 & 150849 & 310908 & 208312 & 339069 & 20837 & 2507 & 18648 & 131362 & 24836 \\
\hline 6555202 & 0,225987 & 0,700411 & 0,165485 & 0,582253 & 184762 & 6052 & 0,25 & 544209 & 0,247685 & 0,456225 & 0,16064 & 0,4979 & 0,166005 & 0,52185 & 0,186328 & ,485744 & ,1990099 & 0,422034 & 0,186002 & 17292 & 150849 & 235524 & 208312 & 348778 & 208379 & 966 & .186484 & 149 & 24836 \\
\hline 6555202 & 0,275097 & 0,700418 & 0,274705 & 0,582253 & 0,226436 & 560521 & 0,25 & 0,546209 & 0,247685 & 0,456225 & 0,196487 & 0,4979 & 0,220787 & 0,52185 & 0,248438 & 0,485743 & 0,248584 & 0,422034 & 0,263827 & 0,407292 & 0,231679 & 0,325524 & 0,2449 & 0,344878 & 0,249543 & 0,334966 & 248645 & 0,322149 & .25 \\
\hline 704459 & 0,275097 & 0,725452 & 0,274705 & 0,62005 & 0,226436 & 5770387 & 0,25 & 0,561378 & 0,247685 & 0,481366 & 0,196487 & 0,51963 & 0,220787 & 0,539293 & 0,248438 & 0,502385 & 0,248584 & 0,439145 & 0,263827 & 0,426509 & 0,231679 & 0,340139 & 0,24049 & 0,358487 & 0,249543 & 0,344857 & 0,248645 & 0,33067 & 0,25 \\
\hline 704459 & 0,295714 & 0,725452 & 0,274705 & 0,62005 & 0,259686 & 0,5770387 & 0,25 & 0,561378 & 0,25 & 0,481366 & 0,259051 & 0,51963 & 0,275569 & 0,539293 & 0,268311 & 0,502385 & 0,269811 & 0,439145 & 0,278725 & 0,426509 & 0,263695 & 0,340139 & 0,276367 & 0,358487 & 0,25 & 0,344857 & 0,268992 & 0,33067 & 0,25 \\
\hline .753716 & 0,295714 & 0,750485 & 0,274705 & 0,657746 & 0,259686 & 0,580253 & 0,25 & 0,576548 & 0,25 & 0,506506 & 0,259051 & 0,541359 & 0,275569 & 0,556737 & 0,268311 & 0,519028 & 0,269811 & 0,456256 & 0,278725 & 0,445726 & 0,263695 & 0,3347755 & 0,276367 & 0,3681196 & 0,25 & 0,354748 & 0,269892 & 0,339191 & 0,25 \\
\hline 753716 & 0,311159 & 0,750485 & 0,302955 & 0,657746 & 0,287956 & 0253 & 0,25 & 0,576548 & 0,271482 & 0,506506 & 0,294891 & 0,541359 & 0,289841 & 0,556737 & 0,28975 & 0,519028 & 0,292455 & 0,456256 & 0,309521 & 0,445726 & 0,29601 & 0,3347755 & 0,300562 & 0,366196 & 0,276479 & 0,354748 & 0,2897783 & 0,339191 & 0,269869 \\
\hline 802973 & 0,3111159 & 75518 & 02955 & 95643 & 877956 & 590119 & 0,25 & 91717 & 271482 & 831647 & 294891 & S653088 & 2898441 & 0,57418 & 0,28975 & 0.53667 & , 2922455 & 0,473367 & 0,030952 & 0,464443 & .291 & 0,3693 & 3005 & 1,377905 & 0,276479 & $0,0,364$ & 0,289 & 0 & 0,26 \\
\hline 802973 & 0,32169 & 0,775518 & 2955 & 56643 & 6806 & 9011 & $\overline{0,2}$ & ,591717 & 0,30 & 0,531647 & 0,312678 & 0,563088 & 0,0303122 & 0,57418 & 0 & 0,53367 & 368 & $0,0,43367$ & 0 & 0.464943 & .3077859 & 0 &, 316432 & .3777905 & T,29820 & 0,3646399 & 0,289783 & 0,347712 & 0,289738 \\
\hline 85223 & 0,32169 & $\overline{00552}$ & 0295 & 73344 & 3168 & 59998.5. & 0,22 & .606886 & 0,300 & 0,556787 & $0,0.312678$ & .844. & 0,030122 & 59162 & 30962 & 1552312 & 813683 & 490478 & 309521 & .48416 & 30785 & .38398 & .3164 & 3876 & $\frac{0,2982}{6}$ & 0,374 & .289 & .3562 & 288973 \\
\hline 85223 & 0,325995 & 800552 & 0,329433 & .733444 & 0,32331 & 599985 & 0,25 & 066886 & 0,30037 & 0,556787 & 0,32123 &., 584818 & 0.316402 & 81623 & 9962. & 552312 & 313683 & 90478 & 329658 & ,48416 & 0,3192 & 383986 & 323149 & .3876 & , 3140 & 0,37452 & ,3096 & .35623 & 30960 \\
\hline 901486 & 0,325995 & 25585 & 0,329433 & 771236 & 0,32331 & 609851 & 0,25 & 62205 & 0,30037 & 0,5819 & 0,32123 & 6065 & 0,31640 & 09066 & 0,30962 & 668955 & .313683 & $, 0,57789$ & 0,329658 & 50337 & 0,315 & 39860 & .1323149 & .397324 &, 31403 & 0,384 & ,3096 & .36475 & 0,30960 \\
\hline$\overline{01486}$ & 0,328634 & 588. & 0,3224433 & 1236 & 29814 & 08851 & 0,326667 & 0,622056 & 229259 & 0,581928 & 0,329781 & $\frac{0.606547}{1}$ & 0,329683 & & $0,0,3295$ & & .3229547 & 0,507589 & 0,329658 & 503377 & .32424519 & .398601 & ,329886 & 3977324 & , 32487 & 1.38442 & .329 & 364754 & 32947 \\
\hline D743 & 0,328634 & 8619 & 0,329433 & 90033 & 329814 & 0 & 0,326667 & 1,637225 & 0,329259 & $0,0,607068$ & 0,329781 & $0,0,628276$ & 0,32968 & & 0,329 & $0,58$. & 0,329547 & $0,0,5247$ & 0,329658 & .5222594 & 324519 & 13217 & 329866 & ,4077033 & 3248 & 394311 & 329 & 7352/3 & 32947 \\
\hline 50743 & 0,329999 & 0.850619 & 0,33 & 0,809033 & 0,33 & 0,619717 & 0,33 & 0,637225 & 0,33 & 0,607068 & 0,33 & 0,628277 & 0,33 & 0,626509 & 0,33 & 0,585597 & 0,33 & 0,5247 & 0,33 & 0,522594 & 0,33 & ,4132177 & 0,33 & , 4077033 & 0,33 & 0,394311 & 0,33 & 0,373275 & $0,0,33$ \\
\hline & 0,329999 & 8776552 & 0,33 & 84683 & 0,33 & ,629583 & 0,33 & 0,652395 & 0,33 & 0,632208 & 0,33 & 0,650005 & 0,33 & 0,643952 & 0,33 & 0,60224 & 0,33 & 0,541811 & 0,33 & 0,541811 & 0,33 & ,427832 & 0,33 & , 4167672 & 0,33 & 0,404202 & 0,33 & 0,381796 & 0 \\
\hline
\end{tabular}

Tabela C.7 - FPA das correntes de defeito fase - fase - Simulação 2 


\begin{tabular}{|c|c|c|c|c|c|c|c|c|c|c|c|c|c|c|c|c|c|c|c|c|c|c|c|c|c|c|c|c|c|}
\hline (pu) & 1 (\%) & 2 (pu) & $2(\%)$ & 3 (pu) & $3(\%)$ & $14(\mathrm{pu})$ & (\%) & 15 (pu) & P5 $(\%)$ & ${ }^{\mathrm{I}(\text { (p) }}$ & P6(\%) & $17($ pu $)$ & $\mathrm{P} 7(\%)$ & I8(pu) & $\mathrm{PB}(\%)$ & 19(pu) & P9(\%) & I10(pu) & P10(\%) & II1(pu) & P11(\%) & $112(\mathrm{pu})$ & P12(\%) & $113(\mathrm{pu})$ & P13(\%) & 114(pu) & P14\%) & I15(pu) & P15 \\
\hline 0,507432 & 0 & 0,625318 & 0 & $\begin{array}{l}0,468863 \\
\end{array}$ & 0 & 0,530923 & 0 & 0,5007 & 0 & 0,380804 & 0 & 0,432712 & 0 & 0,469521 & 0 & 0,4335815 & 0 & 0,370702 & 0 & 0,349641 & 0 & 0,281677 & 0 & 0,319651 & 0 & 0,305293 & 0 & 0,296586 & 0 \\
\hline ,507732 & 30254 & 5318 & 031801 & 8863 & 47738 & 0923 & 100931 & 5007 & 0,038071 & 10804 & 029846 & 432712 & 0.03297 & 99521 & ,0.033644 & 435815 & 033027 & 70702 & 0,02755 & 0,349641 & .028026 & 8167 & 0,019051 & 319651 & .054432 & 0529 & 0,036891 & 9658 & .04068 \\
\hline 56689 & 0254 & 50423 & 31801 & 06727 & 47738 & 40827 & 00931 & 15911 & 0,038071 & 405983 & 129846 & 0,454482 & ,0302097 & 487004 & 033644 & 0,452493 & .033027 & .387841 & 0,02755 & 0,368886 & ,028026 & 296311 & , 019051 & 0,329377 & 0.054332 & 0,3152 & 0,036891 & 0,305122 & 0,040685 \\
\hline 0.566899 & 85268 & 0,650423 & 062013 & \begin{tabular}{|l}
0,506727 \\
\end{tabular} & 70647 & 0,540827 & 0,15 & 0,515911 & 0,074089 & 0,405983 & 056218 & 0,454482 & 0,05792 & 187004 & 0,064485 & 0,452493 & .063937 & 0.387841 & 0,065985 & 0,368886 & 0.057431 & 0,296311 & 0,053232 & 0,329377 & 1.098726 & 0,3152 & 0,070945 & 0,305122 & 0,07892 \\
\hline 0,605946 & 0,085268 & 0,675527 & 0,062013 & 0,54459 & 0,070647 & 0,550732 & 0,15 & 0,531122 & 0,074089 & 0,431163 & 0,056218 & 0,476252 & 0,05792 & ,504487 & 0,064485 & 0,469171 & 0,063937 & 0,404981 & 0,065985 & 0,388132 & 0,057431 & 0,310944 & 0,053232 & 0,339103 & 0,098726 & 0,325107 & 0,070945 & 0,313657 & 0,07892 \\
\hline 05946 & 4713 & 0,675527 & 80104 & 54459 & 04385 & 550732 & 0,15 & 0,531122 & 0,10859 & 4.431163 & 085996 & 476252 & 183465 & 50487 & 93923 & 169171 & 092729 & 404981 & 09377 & , ,388132 & .088335 & 3.10944 & 102496 & , ,33916 & 112228 & .325107 & 10337 & 0.313657 &, 115194 \\
\hline 0,655202 & 34713 & 0,700632 & 90104 & 82454 & 04385 & 50637 & 0,15 & 0,546332 & 0,10859 & 0,456342 & 0,0859966 & 0,498022 & 883465 & 0,52197 & 0,093923 & 0,485848 & $\begin{array}{l}0,092729 \\
\end{array}$ & 0,422121 & 0,093777 & 0,407378 & 0.083835 & 0,325578 & 0,102496 & 0,34883 & 0.12228 & .335014 & 0,103377 & 0,322193 & 0,115194 \\
\hline 0,655202 & 0,16331 & 0,700632 & 0,118018 & 0,582454 & 0,128658 & 0,560637 & 0,15 & 0,546332 & 0,141711 & 0,456342 & 0,115489 & 0,498022 & 0,115445 & 0,52197 & ${ }^{0,12196}$ & 0,485848 & 0,120243 & 0,422121 & 0,120472 & 0,407378 & 0,120221 & 0,325578 & 0,13429 & 0,34883 & ,144537 & 0,335014 & 0,134187 & 0,322193 & 0,149672 \\
\hline 0,704499 & 0,16331 & 0,725737 & 0,118018 & $0,0,620318$ & 0,128658 & 0,570542 & 0,15 & 0,561543 & 0,141711 & 0,481521 & 0,115489 & \begin{tabular}{|l|l}
0,519792 \\
\end{tabular} & 0,115445 & 0,539453 & 0,12196 & 0,502526 & 0,120243 & 0,43926 & 0,120472 & 0,426624 & 0,120221 & 0,340212 & 0,13429 & 0,358556 & 0,144537 & 0,344921 & 0,134187 & 0,330728 & 0,149672 \\
\hline 4459 & 0,17 & 737 & 26466 & 0318 & 0205 & 0542 & 0,1 & 154 & 0,15 & 81521 & 12458 & 519792 & 145543 & 39453 & 56383 & 025226 & 154973 & 0,43926 & 0,148057 & 0,426624 & .152189 & 40212 & 1.154243 & 0.35855 & 0,15 & 344921 & 1.125668 & 0,330728 & 0.15 \\
\hline 0,753716 & 0,17888 & 0,750842 & 52646 & 0,658182 & 50205 & 0,580447 & 0,15 & 0,576753 & 0,15 & 0.5067 & \begin{tabular}{l|l}
0,142458 \\
\end{tabular} & 0,541562 & 0,145543 & .56936 & 0,156383 & 0,519203 & 0,154973 & 0,4564 & 0,148057 & 0,445869 & 0,152189 & 0,354845 & 0,154243 & 0,368282 & 0,15 &, 354829 & 0,152568 & ,.339264 & 0,15 \\
\hline 0,753716 & 0,188439 & 0,750842 & 0,169257 & 0,658182 & 0,169656 & 0,580447 & 0,15 & 0,576753 & 0,160023 & 0,5067 & 0,167111 & 0,541562 & 0,17396 & 0,556936 & 0,167445 & 0,519203 & 0,168207 & 0,4564 & 0,175893 & 0,445869 & 0,173423 & 0,354845 & 0,177395 & 0,368282 & 0,162255 & 0,354829 & 0,162973 & 0,339264 & 0,157716 \\
\hline 0,802973 & 0,188439 & 0,775946 & 0,169257 & \begin{tabular}{|l|l}
0,696046 \\
\end{tabular} & 0,169656 & 0,590351 & 0,15 & 0,591964 & 0,160023 & 0,531879 & $0,0,1671111$ & \begin{tabular}{|l|l} 
\\
\end{tabular} & 0,17396 & 0,574419 & 0,167445 & 0,535881 & 0,168207 & 0,47354 & 0,175893 & 0,465115 & 0,173423 & 0,369479 & 0,177795 & 0,378009 & 0,163255 & 0,364736 & 0,162973 & 0,347799 & 0,157716 \\
\hline 0,802973 & 94848 & , 775946 & 177561 & \begin{tabular}{|l}
0,696046 \\
\end{tabular} & 87712 & .590351 & 0,15 & 0,591964 & 70556 & 531879 & 184135 & 563331 & $\begin{array}{r}0,181089 \\
\end{array}$ & 574419 & 176168 & 535881 & 0,176817 & 0,47354 & 0,182409 & 0,4655115 & 1883159 & 369479 & ,190711 & 0,37800 & 0,17852 & 364736 & .172977 & 347799 & 0.16879 \\
\hline 0,85223 & 0,194448 & 0,801051 & 177561 & \begin{tabular}{|l|l|}
0,73391 \\
\end{tabular} & 0,187712 & 0,600256 & 0,15 & 0,607174 & 0,170556 & 0,557058 & 0,1841355 & 0,585101 & 0,181089 & 0,591902 & 0,176168 & 0,552558 & 0,176817 & 0,490679 & 0,182409 & 0,444361 & 0,183159 & 0,384112 & 0,190714 & 0,387735 & 0,178521 & 0,374643 & 0,172973 & 0,366334 & 1,16879 \\
\hline 0,85223 & 0,197323 & 0,801051 & 0,185335 & 0,73391 & 0,192157 & 0,600256 & 0,15 & 0,607174 & 0,180906 & 0,557058 & 0,189786 & 0,585101 & 0,187722 & 0,591902 & 0,184423 & 0,552558 & 0,184862 & 0,490679 & 0,18867 & 0,484361 & 0,191535 & 0,384112 & 0,194419 & 0,387735 & 0,187098 & 0,374643 & 0,182432 & 0,356334 & 0,179575 \\
\hline 0,901486 & 0,197323 & 0,826156 & 185335 & 0,771773 & 0,192157 & 0,6610161 & 0,15 & 0,6223855 & 0,180906 & 0,582237 & $0,0,1897866$ & 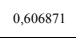 & 0,187722 & 0,609385 & 0,184423 & 0,569236 & 0,184862 & 0,507819 & 0,18867 & 0,503607 & 0,191535 & 0,398746 & 0,194419 & 0,397461 & 0,187098 & 0,38455 & 0,182432 & 0,36487 & 0,179575 \\
\hline 0,901486 & 1.198726 & 826156 & 92755 & 71773 & 6194 & 510161 & 7141 & 22385 & 90567 & 82237 & 95097 & 506871 & , 194059, & 609385 & 192367 & 669236 & .122595 & , 507819 & 1.19442 & 0,503607 & 196322 & 398746 & 197168 & 0,397461 & 193746 & .38455 & 0,191351 & 1.36487 & 1.90032 \\
\hline 0,950743 & 0,198726 & 0,85126 & 0,192755 & \begin{tabular}{l|l}
0,809637 \\
\end{tabular} & 0,196194 & 0,620066 & 0,17141 & 0,6375955 & 0,190567 & 0,607416 & \begin{tabular}{l|l}
0,195007 \\
\end{tabular} & $\begin{array}{l}0,628641 \\
\end{array}$ & 0,194059 & 0,6268688 & 0,192367 & 0,585914 & 0,192595 & 0,524959 & 0,19442 & 0,522853 & 0,196322 & 0,41338 & 0,197168 & 0,407188 & 0,193746 & 0,394457 & 0,191351 & 0,373405 & 0,190032 \\
\hline 0.950743 & 0,200001 & 0,85126 & 0,2 & $0,0,809637$ & 0,2 & 20066 & 0,2 & 0,637595 & 0,2 & 0,6074 & 0,2 & 628641 & 0,2 & 0,626868 & 0, & 0,585914 & 0,2 & 0,5249 & 0,2 & 0,522853 & 0,2 & 0,41338 & 0,2 & 0,407188 & 0,2 & 394457 & 0,2 & , 373405 & 0,2 \\
\hline 1 & 00000 & 6365 & 0,2 & 47501 & 0,2 & 29971 & 0,2 & 52806 & 0,2 & 32596 & 0,2 & 50411 & 0,2 & 4435 & & 602591 & 0,2 & 0,542098 & 0,2 & ,542098 & 0, & 42801 & 0,2 & ,4469614 & 0,2 & 40436 & 0,2 & $0 ., 381944$ & 0,2 \\
\hline
\end{tabular}

Tabela C.8 - FPA das correntes de defeito fase - fase - Simulação 3 


\begin{tabular}{|c|c|c|c|c|c|c|c|c|c|c|c|c|c|c|c|c|c|c|c|c|c|c|c|c|c|c|c|c|c|}
\hline 1 (pu) & $1(\%)$ & (pu) & \%) & $3(\mathrm{pu})$ & P3 (\%) & 4 (pu) & (\%) & $15(\mathrm{pu})$ & P5 $(\%)$ & If(pu) & P66\%) & (put) & $\mathrm{P} 7(\%)$ & I8(pur) & P8(\%) & 19(pu) & P9(\%) & 110(pu) & P10\%) & III(pu) & P11(\%) & I12(pu) & P12(\%) & I13(pu) & P13(\%) & I14(pu) & P14(\%) & III(pu) & P15\% \\
\hline 0,507432 & 0 & 0,0625318 & 0 & 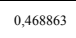 & 0 & 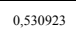 & 0 & 0,5007 & 0 & 1.380804 & 0 & 0,4327112 & 0 & \begin{tabular}{|l|l}
0,469521 \\
\end{tabular} & 0 & 0,435815 & 0 & 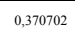 & 0 & 0,349641 & 0 & \begin{tabular}{|l|l|l}
0,281677 \\
\end{tabular} & 0 & 0,319651 & 0 & 0,305293 & 0 & 0,296586 & 0 \\
\hline 0,507432 & 034732 & 25318 & 149645 & 0,468863 & 0,048084 & 530923 & 0,14375 & 0,5007 & 0,040278 & 808004 & 0,03418 & 0,432712 & 0,044802 & 1.66521 & 0,037266 & .435815 & .093802 & 0.370702 & 0,0279322 & 1,346641 & 0,028928 & \begin{tabular}{|l|l}
0,281677 \\
\end{tabular} & 0,02231 & 319651 & 0,066054 & 0,305293 & ,0,0372977 & 296586 & 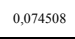 \\
\hline 0,556689 & 34732 & 50351 & 49645 & 50666 & 0,048084 & 540789 & 14375 & 0,51587 & .040278 & 405945 & .03418 & 0,454442 & 0,044802 & .486964 & .037266 & 0,452458 & 0398002 & 387813 & 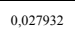 & 0,368858 & .028928 & 0,296293 & 0,02231 & 0,32936 & .066054 & 0,315184 & 0,037297 & $, \quad, 305107$ & $0,0,74508$ \\
\hline 0,556689 & 097421 & 500351 & 92921 & 0,50666 & 0,083914 & .540789 & 0,15 & 0,51587 & 0,094445 & 405945 & \begin{tabular}{|l}
0,068331 \\
\end{tabular} & $\begin{array}{l}0,454442 \\
\end{array}$ & 0,0747702 & 0,489644 & 0,074531 & 0,452458 & .079603 & 0,387813 & 0,073844 & 0,368858 & 0,067479 & \begin{tabular}{|l}
0,296293 \\
\end{tabular} & $\begin{array}{l}0,069759 \\
\end{array}$ & 0,32936 & 0,0994655 & 0,315184 & $\begin{array}{l}0,074593 \\
\end{array}$ & 0,305107 & 0,111762 \\
\hline 0,605946 & 0,097421 & 0,6773855 & 0,099291 & 0,544456 & 0,083914 & 0,550655 & 0,15 & 0,531039 & 0,094445 & 0,4311085 & $0,0,083361$ & 0,476171 & $0,0,77702$ & \begin{tabular}{|l|l}
0,50407 \\
\end{tabular} & 0,0745311 & 0,4691 & 0,079603 & \begin{tabular}{|l}
0,404924 \\
\end{tabular} & 0,073844 & 0,388075 & 0,067779 & 0,310908 & $0,0,06759$ & 0,339069 & 0,099465 & 0,325075 & 0,074593 & 0,313628 & 0,111762 \\
\hline .605946 & 6217 & 75385 & 9929 & 544456 & 111498 & 50653 & 0,1 & 0,531039 & 148611 & 431085 & 096844 & 0,476171 & .099603 & .504407 & 1111797,. & 0,4691 & . 119405 & :404924 & , 111601 & 0,388075 & 0,090647 & 0,310908 & 0,125136 & 0,339069 & , 12502 &., 3250 & 0.11189 & .3136 & 0,149 \\
\hline 655202 & 6217 & 10418 & 9291 & 82253 & 11498 & 60521 & 0,15 & 0,546209 & 148611 & 156225 & 96844 & 0,479 & .099603 & 0,52185 & 0,111797 & 0,485743 & 119405 & 422034 & .11160 & 0,407292 & .090647. & 1.325524 & 0,125136 & 1.348788 & 12502 & , 1344966 & , 111189 & 0,322145 & 0,149016 \\
\hline 0,655202 & 0,166336 & 0,700418 & 0,165485 & \begin{tabular}{|l|l}
0,58253 \\
\end{tabular} & 0,136294 & 0,560521 & 0,15 & $\begin{array}{l}0,546209 \\
\end{array}$ & 0,148611 & 0,456225 & 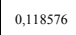 & 0,4979 & 0,132804 & 0,52185 & 0,149062 & 0,485744 & 0,14915 & 0,422034 & 0,158669 & 0,407292 & 0,139393 & 0,325524 & 0,1444991 & 0,348778 & 0,149725 & 0,334966 & 0,149187 & 0,322149 & 0,15 \\
\hline 0,704459 & 0,166336 & 0,725452 & 165485 & \begin{tabular}{|l|l}
0,62005 \\
\end{tabular} & 0,136294 & \begin{tabular}{|l|l}
0,570387 \\
\end{tabular} & 0,15 & 0,561378 & 0,148611 & 0,481366 & \begin{tabular}{|l}
0,118876 \\
\end{tabular} & 0,51963 & 0,132804 & \begin{tabular}{|l}
0,539293 \\
\end{tabular} & 0,149062 & 0,502385 & 0,14915 & 0,4439145 & 0,158669 & 0,426509 & 0,139393 & 0,340139 & 0,144591 & 0,358487 & 0,149725 & 0,344857 & 0,149187 & 0,33067 & 0,15 \\
\hline 0,704459 & 9025 & 25452 & 65485 & 0,62005 & 0,157085 & 570387 & 0,15 & 0,561378 & 0,15 & .481366 & 1,156342 & 0,51963 & 0,166005 & 0,539293 & 0,161484 & 0,502385 & 0,162417 & \begin{tabular}{|l|l}
0,439145 \\
\end{tabular} & 0,16798 & 0,426509 & 0,158988 & 0,340139 & 0,16649 & 0,358487 & 0,15 & 0,34485 & 0,162432 & 0,33067 & 0,15 \\
\hline 153716 & 99025 & 150485 & 65485 & 57846 & 0,157085 & .58025 & 0,15 & 0,576548 & $0,1:$ & 16506 & 0,156342 & 0,541359 & 0,166005 & 56637 & 0,161484 & 0,519028 & 162417 & 156256 & 0,16798 & 0,445726 & , 1, 158988 & .354755 & 0,1664 & 36819 & 0,15 & .1354748 & 0,162432 & 0,339191 & 0,15 \\
\hline 0,753716 & 0,188468 & 0,750485 & 183097 & $0,0,657846$ & 0,174245 & 0,580253 & 0,15 & 0,576548 & 0,163426 & 1.506506 & \begin{tabular}{|l|l|l|l|l|}
\end{tabular} & 0,541359 & 0,1744901 & 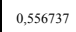 & 0,174444 & 0,519028 & 0,176534 & 0,456256 & 0,187201 & 0,445726 & 0,178769 & 0,354755 & 0,1816111 & 1.368196 & 166549 & 344748 & .174865 & 339191 & .162418 \\
\hline 0,802973 & 0,188468 & 0,775518 & 0,183097 & 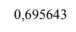 & 0,174245 & 0,590119 & 0,15 & 0,591717 & 0,163426 & 0,531647 & \begin{tabular}{|l|l|l}
0,178074 \\
\end{tabular} & 0,563088 & 0,174901 & \begin{tabular}{|l|l}
0,57418 \\
\end{tabular} & 0,174444 & 0,53567 & 0,176534 & \begin{tabular}{|l|l}
0,473367 \\
\end{tabular} & 0,187201 & 0,464943 & 0,178769 & 0,36937 & 0,181611 & 0,377905 & \begin{tabular}{|l}
0,166549 \\
\end{tabular} & 0,364639 & 0,174865 & 0,347712 & 0,162418 \\
\hline 0,802973 & 0,194856 & 0,775518 & 0,183097 & $0,0,695643$ & 0,191754 & \begin{tabular}{ll|l}
0,590111 \\
\end{tabular} & 0,15 & 0,591717 & 0,181481 & 0,531647 & 0,189173 & 0,563088 & 0,188201 & 0,57418 & 0,1877266 & $0,0,53567$ & 0,189802 & 0 & 0,187201 & 0,4649443 & 0,186162 & \begin{tabular}{|l|l}
0,36937 \\
\end{tabular} & 0,19152 & 0,3777005 & 0 & 0,3646393 & 0,174865 & 0,3477112 & 0,1744366 \\
\hline 0,85223 & .194856 & 800552 & 183097 & 0,73344 & 0,191754 & .599985 & 0,15 & 0,6068866 & 0,181481 & 556787 & 0.189173 & 0,584818 & 183201 & 591623 & 0,187266 & 0,552312 & 189802 & ,490478 & 0,187201 & 0,484 & 0,186162 & .383986 & 19152 & 0,387615 & ,180125 & 1,374529 & 0,174865 & .356233 & , 174836 \\
\hline 0,85223 & 0,197497 & 800552 & 0,199645 & \begin{tabular}{|l|l}
0,73344 \\
\end{tabular} & 0,195819 & 0,599985 & 0,15 & 0,606886 & 0,181481 & 0,556787 & \begin{tabular}{|l|l|l|l|l} 
\\
0,194518
\end{tabular} & 0,584818 & 0,191501 & \begin{tabular}{|l}
0,591623 \\
\end{tabular} & 0,187266 & 0,552312 & 0,189802 & \begin{tabular}{|l|l|l|l|l} 
\\
\end{tabular} &, 199786 & 0,48416 & 0,19325 & 0,383986 & 0,195718 & 0,387615 & 190025 & 374529 & 0,187297 &, 356233 & 0,187254 \\
\hline 0,901486 & 0,197497 & 0,825585 & 0,199645 & \begin{tabular}{|l|l}
0,711236 \\
\end{tabular} & 0,195819 & 0,609851 & 0,15 & 0,622056 & 0,181481 & 0,581928 & \begin{tabular}{|l|l|l|}
0,19418 \\
\end{tabular} & 0,606547 & 0,191501 & \begin{tabular}{|l|l}
0,609066 \\
\end{tabular} & 0,187266 & 0,568955 & 0,189802 & 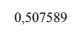 & 0,199786 & 0,503377 & 0,19325 & 0,398601 & 0,195718 & 0,397724 & 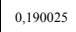 & 0,38442 & 0,187297 & 0,364754 & 0,187254 \\
\hline 0,901486 & 199146 & 825855 & 99645 & 0,771236 & 0,199884 & .609851 & 197917 & 0,622056 & 0,199537 & 0,581928 & 0,199863 & 0,606547 & 0,199802 & 0,609066 & 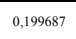 & 0,568955 & 0,199717 & $\begin{array}{ll}0,507589 \\
\end{array}$ & 0,199786 & 0,503377 & 0,196577 & 0,398601 & 0,199916 & 0,397324 & 0,196798 & 0,38442 & 0,199729 & 0,364754 & 0,199672 \\
\hline 0,950743 & 0,199146 & 0,850619 & 0,199645 & 0,809033 & 0,199884 & 0,619717 & 0,197917 & 0,637225 & 0,199537 & 0,607068 & 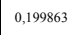 & 0,628276 & 0,199802 & 0,626509 & \begin{tabular}{|l|l|l|} 
& 199687
\end{tabular} & 0,585597 & 0,199717 & 0,5247 & 0,199786 & 0,522594 & 0,196574 & 0,413217 & 0,199916 & 0,407033 & 0,196798 & 0,394311 & 0,199729 & 0,373275 & 0,199672 \\
\hline 0,950743 & 0,2 & 0,850619 & 0,2 & $0,0,809033$ & 0,2 & 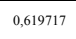 & 0,2 & 0,637225 & 0,2 & 0,607068 & 0,2 & 0,628276 & 0,2 & \begin{tabular}{|l|l}
0,625509 \\
\end{tabular} & 0,2 & 0,585597 & 0,2 & 0,5247 & 0,2 & 0,522594 & 0,2 & 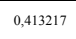 & 0,2 & 0,407033 & 0,2 & 0,394311 & 0,2 & 0,373275 & 0,2 \\
\hline 1 & 0,2 & 776522 & 0,2 & 44683 & 0,2 & 29583 & 0,2 & 0,652395 & 0,2 & 632208 & 0,2 & 0,650000 & 0,2 & \begin{tabular}{|l}
0,643952 \\
\end{tabular} & 0,2 & 0,60224 & 0,2 & 0,541811 & 0, & 0,5418 & 0,2 & 0,4277832 & 0,2 & 0,416742 & 0,2 & 0,404202 & 0,2 & 0,381796 & 0,2 \\
\hline
\end{tabular}

Tabela C.9 - FPA das correntes de defeito fase - fase - Simulação 4 


\begin{tabular}{|c|c|c|c|c|c|c|c|c|c|c|c|c|c|c|c|c|c|c|c|c|c|c|c|c|c|c|c|c|c|}
\hline 1 (pu) & l\%) & 12 (pu) & P2 (\%) & $\mathrm{I3}(\mathrm{pu})$ & P3 (\%) & I4 (pu) & $\mathrm{P4}(\%)$ & $15(\mathrm{pu})$ & P5 (\%) & $\mathrm{I}(\mathrm{pu})$ & P6(\%) & 17(pu) & $\mathrm{P} 7 \%$ ) & $18(\mathrm{pu})$ & $\mathrm{P} 8(\%)$ & $19(p u)$ & P9(\%) & ${ }_{110(p u)}$ & $\mathrm{P} 10(\%)$ & $111(\mathrm{pu})$ & P11(\%) & $\mathrm{I12(pu)}$ & P12(\%) & $113(\mathrm{pu})$ & \begin{tabular}{|l|l} 
P13(\%) \\
\end{tabular} & I114(pu) & P14(\%) & 115(pu) & P15(\%) \\
\hline 0,507432 & 0 & 0,0625318 & 0 & \begin{tabular}{|l}
0,4688663 \\
\end{tabular} & 0 & 0,530923 & 0 & 0,5007 & 0 & 0,380804 & 0 & 0,432712 & 0 & \begin{tabular}{|l|l}
0,469521 \\
\end{tabular} & 0 & 0,435815 & 0 & \begin{tabular}{|l|l}
0,370702 \\
\end{tabular} & 0 & 0,3446411 & 0 & \begin{tabular}{|l}
0,281677 \\
\end{tabular} & 0 & 0,319651 & 0 & 0,305293 & 0 & 296586 & 0 \\
\hline 0,507432 & 0,0212 & 25318 & 31801 & 68863 & 0,047738 & 30923 & 0,100931 & .5007 & 0,038071 & 880804 & 0,029846 & 0,4327112 & 0,0302927 & 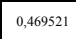 & 0,056074 & 0,435815 & 0,033027 & .370702 & 0,02755 & 0,349641 & 0,032712 & 0,281677 & 0,031752 & 0,319651 & 0,054432 & 0,305293 & 0,0368991 & 0,296586 & $0,0,6780$ \\
\hline 0,556689 & 12212 & 50423 & 31801 & 06727 & 047738 & 540827 & 100931 & 15911 & 038071 & 405983 & 029846 & 0,454482 & .0302027 & .487004 & 056074 & 0,452493 & 0.33027 & 1387841 & 0,02755 & 0,368886 & .032712 & 0,296311 & 0,031752 & 0,329377 & 0.054432 & 0,3152 & 0,036891 & 0,305122 & 0,067809 \\
\hline 556689 & 90115 & 500423 & 62013 & 0,506727 & 0,070647 & 0,540827 & 0,15 & 0,515911 & 0,074089 & 405983 & 0,056218 & 0,454482 & 0,05792 & 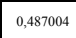 & 0,107475 & 0,452493 & 0.063377 & $0,0,387841$ & 0,065985 & 0,3688866 & 0,061883 & 0,2963111 & $0,0,077464$ & 0,329377 & 106886 & 0,3152 & 0,070945 & 0,305122 & 0,131533 \\
\hline 0.065946 & 2015 & 75527 & 62013 & :4459 & 870647 & 55073 & 0,1 & .53112 & ,074089 & 431163 & 056218 & 0,476252 & 05792 & .504487 & , 10747 & 0,469177 & 066393 & .40498. & .06598 & 0,38813 & ,061883 & 1,31094 & 0,077464 & 0,33910 & 100886 & 1,32510 & .07094 & .31365 & ,13153 \\
\hline 0.5946 & 59936 & 775527 & 90104 & 54459 & 104385 & 550732 & 0,15 & 0,531122 & 0,10859 & 431163 & 88996 & 0,476252 & .083465 & .504487 & 16653 & 0,46917 & 092729 & 0,40481 & 0,09377 & 1.38813 & .087813 & 310944 & 13740 & .3391 & 13055 & 3251 & .10337 & .31365 & 1,19989 \\
\hline 0,655202 & 35936 & 200632 & 090104 & 82454 & 0,1043855 & \begin{tabular}{|l}
0,560637 \\
\end{tabular} & 0,15 & 0,546332 & 0,10859 & .456342 & \begin{tabular}{l|l} 
& 0,05996
\end{tabular} & 0,498022 & \begin{tabular}{|l}
0,083465 \\
\end{tabular} & 0,52197 & 0,156539 & 0,485844 & 0,092729 & 0,422121 & 0,093777 & 0,407378 & 0,087813 & 0,325578 & 0,137409 & 0,34883 & 0,13055 &., 335014 & 0,103377 & 0,322193 & o,191989 \\
\hline 0,655202 & 0,166344 & 700632 & 0,118018 & 0,582454 & 0,128658 & \begin{tabular}{|l|l}
0,560637 \\
\end{tabular} & 0,15 & 0,546332 & 0,141711 & 0,456342 & \begin{tabular}{|l}
0,115489 \\
\end{tabular} & 0,498022 & 0,115445 & 0,52197 & \begin{tabular}{|l}
0,203267 \\
\end{tabular} & 0,485848 & 0,120243 & 0,422121 & 0,120472 & 0,407378 & 0,125191 & 0,325578 & 0,176748 & 0,34883 & , 152887 & 0,335014 & 0,13418 & 0,322193 & 0,249454 \\
\hline 0,704459 & 6344 & 25737 & 18018 & 20318 & 28658 & 50542 & 0,15 & .561543 & 0,1417711 & 481521 & 1115489 & , ,519792 & 115445 & .539453 & ,203267 & 0,502526 & 120243 & 0,4392 & $, 1,120472$ & 0,426624 & ,125191 & 1,340212 & 0,176748 & 1.385556 & 152807 & , 344921 & 0,1341 & 0.3072 & ,.24945 \\
\hline 459 & 2446 & 5737 & 2646 & 0318 & 1205 & 0,5775427 & 0,1 & 6154 & 0,15 & 8152 & 0,142458 & 519792 & 45543 & 9453 & 26008. & .502526 & 1544973 & 439326 & $1480:$ & ,42662 & , 156586 & 3402 & 0,1997 & 0,35856 & , 158269 & .344921 & 0,152568 & 0,330728 & .25 \\
\hline 0,753716 & 0,182446 & 0,750842 & 152646 & 0,6588182 & 0,150205 & 0,580447 & 0,15 & 0,576753 & 0,15 & 0,5067 & \begin{tabular}{|l}
0,142458 \\
\end{tabular} & 0,541562 & 0,145543 & 0,556936 & 0,260088 & 0,519203 & 0,154973 & 0,4564 & 0,148057 & 0,445869 & 0,156586 & 0,354845 & 0,199734 & 0,368282 & 0,158269 & 0,354829 & 0,152566 & 0,339264 & 0,25 \\
\hline 0,753716 & 0,19518 & 0,750842 & 0,169257 & 0,658182 & 0,169656 & 0,580447 & 0,15 & 0,576753 & 0,160023 & 0,5067 & \begin{tabular}{|l|l|l|} 
& 0,16711
\end{tabular} & 0,541562 & \begin{tabular}{|l}
0,17396 \\
\end{tabular} & \begin{tabular}{|l}
0,556936 \\
\end{tabular} & 0,277912 & 0,519203 & 0,168207 & 0,4564 & 0,176321 & 0,445869 & 0,177438 & 0,354845 & 0,225716 & 0,368282 & 0,171524 & 0,354829 & 0,162973 & 0,339264 & 0,262026 \\
\hline 0,802973 & 0,19518 & 0,775946 & 169257 & 696046 & 69656 & 0,590351 & 0,15 & 0,591964 & 0,160023 & 0,531879 & \begin{tabular}{|l|l|}
0,16711 \\
\end{tabular} & 0,563331 & \begin{tabular}{|l}
0,17396 \\
\end{tabular} & \begin{tabular}{|l|l}
0,574419 \\
\end{tabular} & 0,277912 & 0,535881 & 0,168207 & \begin{tabular}{|l|l}
0,47354 \\
\end{tabular} & 0,176321 & 0,4655115 & 0,177438 & 0,369479 & 0,225716 & 0,378009 & 0,171524 & 0,364736 & 0,162973 & 0,34779 & 2.262026 \\
\hline 0,802973 & 20575 & 775946 & 77561 & \begin{tabular}{|l|l}
0,696046 \\
\end{tabular} & 87712 & 9035 & 0,15 & 0,591964 & 0,170556 & 31879 & 18413 & 0,563331 & 181089 & 574419 & 29186 & ,535881 & 177681 & 0,47354 & , 18288: & 0,4651 & 1896 & .36947 & 0,2414 & 0,378009 & 1882 & 647 & ,1729 & .347 & 28006: \\
\hline 0,85223 & 0,20575 & 0,801051 & 177561 & \begin{tabular}{|l|l}
0,73391 \\
\end{tabular} & 0,187712 & 0,600256 & 0,15 & 0,6607174 & 0,170556 & 0,557058 & $0,0,184135$ & 0,585101 & 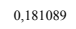 & \begin{tabular}{|l|l}
0,591902 \\
\end{tabular} & 0,291868 & 0,552558 & 0,176817 & \begin{tabular}{|l|l}
0,490679 \\
\end{tabular} & 0,182837 & 0,484361 & 0,189692 & 0,384112 & 0,241477 & 0,387735 & \begin{tabular}{|l}
0,188276 \\
\end{tabular} & 0,374643 & 0,172973 & 0,356334 & 0,280065 \\
\hline 0,85223 & 0,208694 & 0,801051 & 0,185335 & \begin{tabular}{|l|l}
0,73391 \\
\end{tabular} & 0,192157 & 0,600256 & 0,15 & 0,607774 & 0,180906 & 0,557058 & \begin{tabular}{|l}
0,189786 \\
\end{tabular} & 0,585101 & 0,187722 & \begin{tabular}{|l|l}
0,591902 \\
\end{tabular} & \begin{tabular}{|l}
0,305077 \\
\end{tabular} & 0,552558 & 0,184862 & \begin{tabular}{|l}
0,490679 \\
\end{tabular} & 0,189098 & 0,484361 & 0,197917 & 0,384112 & 0,244882 & 0,387735 & 0,197849 & 0,374643 & 0,182432 & 0,356334 & 0,297319 \\
\hline 0,901486 & 0,208694 & 826156 & 185335 & $0,0,711773$ & 0,192157 & .610161 & 0,15 & 0,6223855 & 0,180900 & 0,582237 & 0,189786 & 0,606871 & 0,1877222 & 0,609385 & \begin{tabular}{|l}
0,305077 \\
\end{tabular} & 0,569236 & 0,184862 & \begin{tabular}{|l}
0,507819 \\
\end{tabular} & 0,189098 & 0,503607 & 0,197917 & 0,398746 & 0,244882 & 0,397461 & 0,197849 & 0,38455 & 0,182432 & 0,36487 & 0,297319 \\
\hline 0,9014466 & 0,21119 & 0,826156 & 92755 & |0,771773 & 0,196194 & 610161 & .17741 & 0,622385 & 0,190667 & 82237 & 195097 & 0,060677 & 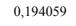 & 609385 & 317787 & 0,569236 & 192595 & :07819 & 0,194488 & 0,503607 & 0,202618 & 398746 & 0,24793 & 0,397461 & 204496 & .384455 & 0,191351 & 0,36487 & .3.314051 \\
\hline 0,950743 & 0,21119 & 0,85126 & 0,192755 & \begin{tabular}{|l|l}
0,809637 \\
\end{tabular} & 0,196194 & $0,0,620066$ & \begin{tabular}{|l|l|}
0,1714 \\
\end{tabular} & $\begin{array}{l}0,637595 \\
\end{array}$ & 0,190567 & 0,607716 & 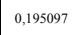 & 0,628641 & 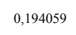 & \begin{tabular}{|l|l}
0,626868 \\
\end{tabular} & 0,317787 & 0,585914 & 0,192595 & 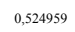 & 0,194848 & 0,522853 & 0,202618 & 0,41338 & 0,24793 & 0,4077188 & \begin{tabular}{|l|l}
0,20496 \\
\end{tabular} & 0,394457 & 0,191355 & 0,373405 & 0,314051 \\
\hline 0,950743 & 0,2131212 & 0,85126 & 0,2 & $0,8,80963$ & 0,2 & 2006 & 0,2 & $\begin{array}{l}0,637595 \\
5\end{array}$ & 0,2 & 6074 & 0, & 0,628641 & $0, z$ & \begin{tabular}{|l}
0,62686 \\
\end{tabular} & 0,33 & 0,585914 & 0, & \begin{tabular}{|l|l}
0,524959 \\
\end{tabular} & 0,200557 & 0,522853 & 0,207127 & 0,41338 & 0,250763 & 0,407788 & 0,21075 & 0,394457 & 0,2 & 0,373405 & 0,33 \\
\hline 1 & .213121 & 873655 & 0,2 & 0,847501 & 0,2 & 29971 & 0,2 & 652806 & 0,2 & 625966 & 0 & 0,65041 & 0,2 & \begin{tabular}{|l}
0,644351 \\
\end{tabular} & 0,33 & 0,60259 & 0,2 & 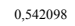 & 0,20057 & 0.542008 & 0,207127 & 0,428013 & 0,250763 & .416914 & \begin{tabular}{|l|l}
0,2107 \\
\end{tabular} & 0,40436 & 0,2 & 0,381941 & 0,33 \\
\hline
\end{tabular}

Tabela C.10 - FPA das correntes de defeito fase - fase - Simulação 5 


\section{C.3 - Fluxo de Potência}

A Tabela C.11 ilustra o valor das correntes e tensões em pu em todas as barras, no ano 0 e no ano 5. O valor de base considerado para a tensão é igual a $11,9 \mathrm{kV}$ e a Potência de base igual a 100 MVA.

\begin{tabular}{|c|c|c|c|c|c|}
\hline \multicolumn{2}{|c|}{$\begin{array}{l}\text { Número } \\
\text { Da barra }\end{array}$} & \multirow{2}{*}{$\begin{array}{c}\text { Tensão } \\
\text { (pu) } \\
\text { Ano } 0\end{array}$} & \multirow{2}{*}{$\begin{array}{c}\text { Tensão } \\
\text { (pu) } \\
\text { Ano } 5\end{array}$} & \multirow{2}{*}{$\begin{array}{c}\text { Corrent } \\
\text { e (pu) } \\
\text { Ano } 0\end{array}$} & \multirow{2}{*}{$\begin{array}{c}\text { Corrente } \\
\text { (pu) } \\
\text { Ano } 5\end{array}$} \\
\hline Atual & $\begin{array}{c}\text { Anterio } \\
r\end{array}$ & & & & \\
\hline 0001 & 0000 & 1,0000 & 1,0000 & 0,0262 & 0,0315 \\
\hline 0002 & 0001 & 0,9996 & 0,9996 & 0,0262 & 0,0315 \\
\hline 0003 & 0002 & 0,9996 & 0,9995 & 0,0262 & 0,0315 \\
\hline 0004 & 0003 & 0,9992 & 0,9990 & 0,0262 & 0,0315 \\
\hline 0005 & 0004 & 0,9966 & 0,9959 & 0,0262 & 0,0315 \\
\hline 0006 & 0005 & 0,9966 & 0,9959 & 0,0262 & 0,0315 \\
\hline 0007 & 0006 & 0,9956 & 0,9947 & 0,0257 & 0,0309 \\
\hline 0008 & 0006 & 0,9966 & 0,9959 & 0,0005 & 0,0006 \\
\hline 0009 & 0007 & 0,9945 & 0,9933 & 0,0231 & 0,0278 \\
\hline 0010 & 0007 & 0,9956 & 0,9947 & 0,0024 & 0,0029 \\
\hline 0011 & 0008 & 0,9965 & 0,9958 & 0,0003 & 0,0003 \\
\hline 0012 & 0009 & 0,9944 & 0,9933 & 0,0001 & 0,0002 \\
\hline 0013 & 0009 & 0,9941 & 0,9929 & 0,0224 & 0,0270 \\
\hline 0014 & 0010 & 0,9954 & 0,9945 & 0,0022 & 0,0027 \\
\hline 0015 & 0012 & 0,9944 & 0,9933 & 0,0000 & 0,0000 \\
\hline 0016 & 0013 & 0,9941 & 0,9929 & 0,0068 & 0,0082 \\
\hline 0017 & 0013 & 0,9939 & 0,9927 & 0,0154 & 0,0185 \\
\hline 0018 & 0014 & 0,9952 & 0,9942 & 0,0017 & 0,0020 \\
\hline 0019 & 0015 & 0,9944 & 0,9933 & 0,0000 & 0,0000 \\
\hline 0020 & 0016 & 0,9931 & 0,9917 & 0,0065 & 0,0078 \\
\hline 0021 & 0017 & 0,9937 & 0,9924 & 0,0154 & 0,0185 \\
\hline 0022 & 0018 & 0,9949 & 0,9939 & 0,0012 & 0,0014 \\
\hline 0023 & 0019 & 0,9944 & 0,9933 & 0,0000 & 0,0000 \\
\hline 0024 & 0020 & 0,9928 & 0,9913 & 0,0058 & 0,0070 \\
\hline
\end{tabular}




\begin{tabular}{|l|l|l|l|l|l|}
\hline 0025 & 0020 & 0,9931 & 0,9917 & 0,0003 & 0,0004 \\
\hline 0026 & 0021 & 0,9932 & 0,9919 & 0,0153 & 0,0183 \\
\hline 0027 & 0022 & 0,9949 & 0,9939 & 0,0000 & 0,0000 \\
\hline 0028 & 0022 & 0,9949 & 0,9939 & 0,0005 & 0,0006 \\
\hline 0029 & 0024 & 0,9927 & 0,9913 & 0,0057 & 0,0069 \\
\hline 0030 & 0025 & 0,9931 & 0,9916 & 0,0001 & 0,0002 \\
\hline 0031 & 0026 & 0,9932 & 0,9919 & 0,0142 & 0,0171 \\
\hline 0032 & 0026 & 0,9932 & 0,9918 & 0,0009 & 0,0011 \\
\hline 0033 & 0029 & 0,9927 & 0,9913 & 0,0003 & 0,0004 \\
\hline 0034 & 0029 & 0,9926 & 0,9911 & 0,0054 & 0,0065 \\
\hline 0035 & 0031 & 0,9931 & 0,9917 & 0,0142 & 0,0171 \\
\hline 0036 & 0032 & 0,9932 & 0,9918 & 0,0005 & 0,0006 \\
\hline 0037 & 0032 & 0,9932 & 0,9918 & 0,0003 & 0,0004 \\
\hline 0038 & 0033 & 0,9927 & 0,9913 & 0,0002 & 0,0002 \\
\hline 0039 & 0034 & 0,9926 & 0,9911 & 0,0004 & 0,0004 \\
\hline 0040 & 0034 & 0,9924 & 0,9908 & 0,0043 & 0,0052 \\
\hline 0041 & 0034 & 0,9926 & 0,9911 & 0,0007 & 0,0008 \\
\hline 0042 & 0035 & 0,9931 & 0,9917 & 0,0001 & 0,0001 \\
\hline 0043 & 0035 & 0,9928 & 0,9914 & 0,0141 & 0,0170 \\
\hline 0044 & 0036 & 0,9932 & 0,9918 & 0,0000 & 0,0000 \\
\hline 0045 & 0036 & 0,9932 & 0,9918 & 0,0002 & 0,0002 \\
\hline 0046 & 0037 & 0,9932 & 0,9918 & 0,0001 & 0,0001 \\
\hline 0047 & 0039 & 0,9926 & 0,9911 & 0,0002 & 0,0002 \\
\hline 0048 & 0040 & 0,9923 & 0,9908 & 0,0005 & 0,0006 \\
\hline 0049 & 0040 & 0,9924 & 0,9908 & 0,0033 & 0,0040 \\
\hline 0050 & 0041 & 0,9925 & 0,9910 & 0,0006 & 0,0007 \\
\hline 0051 & 0043 & 0,9928 & 0,9913 & 0,0003 & 0,0004 \\
\hline 0052 & 0043 & 0,9922 & 0,9906 & 0,0133 & 0,0160 \\
\hline 0053 & 0049 & 0,9919 & 0,9902 & 0,0022 & 0,0027 \\
\hline 0054 & 0050 & 0,9925 & 0,9910 & 0,0002 & 0,0003 \\
\hline 0055 & 0052 & 0,9922 & 0,9906 & 0,0002 & 0,0002 \\
\hline 0056 & 0052 & 0,9911 & 0,9893 & 0,0124 & 0,0149 \\
\hline 0057 & 0053 & 0,9917 & 0,9900 & 0,0005 & 0,0006 \\
\hline
\end{tabular}




\begin{tabular}{|l|l|l|l|l|l|}
\hline 0058 & 0056 & 0,9911 & 0,9892 & 0,0120 & 0,0144 \\
\hline 0059 & 0058 & 0,9909 & 0,9890 & 0,0046 & 0,0055 \\
\hline 0060 & 0058 & 0,9907 & 0,9889 & 0,0074 & 0,0089 \\
\hline 0061 & 0059 & 0,9909 & 0,9890 & 0,0017 & 0,0021 \\
\hline 0062 & 0059 & 0,9906 & 0,9887 & 0,0025 & 0,0030 \\
\hline 0063 & 0059 & 0,9909 & 0,9890 & 0,0002 & 0,0002 \\
\hline 0064 & 0060 & 0,9907 & 0,9889 & 0,0074 & 0,0089 \\
\hline 0065 & 0061 & 0,9906 & 0,9887 & 0,0009 & 0,0010 \\
\hline 0066 & 0062 & 0,9906 & 0,9887 & 0,0025 & 0,0030 \\
\hline 0067 & 0064 & 0,9890 & 0,9868 & 0,0073 & 0,0087 \\
\hline 0068 & 0066 & 0,9906 & 0,9886 & 0,0016 & 0,0019 \\
\hline 0069 & 0067 & 0,9890 & 0,9868 & 0,0027 & 0,0032 \\
\hline 0070 & 0067 & 0,9890 & 0,9868 & 0,0044 & 0,0053 \\
\hline 0071 & 0068 & 0,9905 & 0,9886 & 0,0003 & 0,0004 \\
\hline 0072 & 0069 & 0,9885 & 0,9861 & 0,0025 & 0,0030 \\
\hline 0073 & 0070 & 0,9886 & 0,9862 & 0,0044 & 0,0053 \\
\hline 0074 & 0072 & 0,9882 & 0,9858 & 0,0019 & 0,0023 \\
\hline 0075 & 0072 & 0,9885 & 0,9861 & 0,0002 & 0,0002 \\
\hline 0076 & 0073 & 0,9880 & 0,9856 & 0,0038 & 0,0046 \\
\hline 0077 & 0073 & 0,9885 & 0,9862 & 0,0002 & 0,0003 \\
\hline 0078 & 0074 & 0,9882 & 0,9857 & 0,0017 & 0,0020 \\
\hline 0079 & 0076 & 0,9880 & 0,9855 & 0,0001 & 0,0001 \\
\hline 0080 & 0076 & 0,9878 & 0,9854 & 0,0034 & 0,0041 \\
\hline 0081 & 0078 & 0,9878 & 0,9854 & 0,0017 & 0,0020 \\
\hline 0082 & 0080 & 0,9875 & 0,9850 & 0,0032 & 0,0039 \\
\hline 0083 & 0081 & 0,9878 & 0,9853 & 0,0015 & 0,0019 \\
\hline 0084 & 0082 & 0,9874 & 0,9849 & 0,0027 & 0,0033 \\
\hline 0085 & 0082 & 0,9875 & 0,9850 & 0,0002 & 0,0003 \\
\hline 0086 & 0083 & 0,9878 & 0,9853 & 0,0001 & 0,0002 \\
\hline 0087 & 0083 & 0,9878 & 0,9853 & 0,0002 & 0,0002 \\
\hline 0088 & 0083 & 0,9877 & 0,9853 & 0,0008 & 0,0010 \\
\hline 0089 & 0084 & 0,9874 & 0,9849 & 0,0027 & 0,0033 \\
\hline 0090 & 0088 & 0,9877 & 0,9852 & 0,0001 & 0,0001 \\
\hline
\end{tabular}




\begin{tabular}{|l|l|l|l|l|l|}
\hline 0091 & 0088 & 0,9877 & 0,9852 & 0,0003 & 0,0004 \\
\hline 0092 & 0089 & 0,9872 & 0,9846 & 0,0016 & 0,0019 \\
\hline 0093 & 0089 & 0,9874 & 0,9848 & 0,0010 & 0,0012 \\
\hline 0094 & 0092 & 0,9872 & 0,9846 & 0,0001 & 0,0002 \\
\hline 0095 & 0092 & 0,9872 & 0,9846 & 0,0011 & 0,0013 \\
\hline 0096 & 0093 & 0,9873 & 0,9847 & 0,0010 & 0,0012 \\
\hline 0097 & 0093 & 0,9874 & 0,9848 & 0,0000 & 0,0000 \\
\hline 0098 & 0095 & 0,9872 & 0,9846 & 0,0001 & 0,0002 \\
\hline 0099 & 0095 & 0,9872 & 0,9846 & 0,0000 & 0,0000 \\
\hline 0100 & 0095 & 0,9872 & 0,9845 & 0,0003 & 0,0004 \\
\hline 0101 & 0096 & 0,9872 & 0,9846 & 0,0008 & 0,0009 \\
\hline 0102 & 0097 & 0,9874 & 0,9848 & 0,0000 & 0,0000 \\
\hline 0103 & 0099 & 0,9872 & 0,9846 & 0,0000 & 0,0000 \\
\hline 0104 & 0101 & 0,9872 & 0,9846 & 0,0002 & 0,0002 \\
\hline 0105 & 0101 & 0,9872 & 0,9846 & 0,0001 & 0,0002 \\
\hline 0106 & 0104 & 0,9872 & 0,9846 & 0,0000 & 0,0000 \\
\hline
\end{tabular}

Tabela C.11 - Correntes e tensões de todos os trechos da rede em pu

\section{C.4 - Correntes de curto-circuito}

A Tabela C.12 ilustra o valor das correntes de curto-circuito; trifásico assimétrico ( $3 \phi$ Ass) e

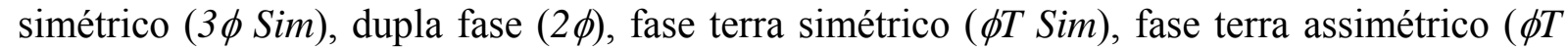
Ass)e fase terra mínimo ( $\phi$ T Min) com impedância de defeito de $40 \Omega$, em todas as barras da rede elétrica em estudo.

\begin{tabular}{|c|c|c|c|c|c|c|}
\hline \multirow{2}{*}{$\begin{array}{c}N^{\boldsymbol{o}} \\
\text { da } \\
\text { barra }\end{array}$} & \multicolumn{6}{|c|}{$\begin{array}{c}\text { Correntes de } \\
\text { Curto-Circuito (A) }\end{array}$} \\
\cline { 2 - 7 } & $\mathbf{3} \boldsymbol{\phi}$ Ass & $\mathbf{3} \boldsymbol{\phi}$ Sim & $\mathbf{2 \phi}$ & $\boldsymbol{\phi}$ T Sim & $\boldsymbol{\phi}$ T Ass & $\boldsymbol{\phi}$ T Min \\
\hline \hline 0001 & 8490 & 4852 & 4202 & 4852 & 8490 & 172 \\
\hline 0002 & 8341 & 4766 & 4128 & 4650 & 8137 & 172 \\
\hline 0003 & 8330 & 4760 & 4122 & 4635 & 8111 & 172 \\
\hline
\end{tabular}




\begin{tabular}{|l|l|l|l|l|l|l|}
\hline 0004 & 8106 & 4659 & 4035 & 4410 & 7673 & 172 \\
\hline 0005 & 6932 & 4126 & 3573 & 3405 & 5721 & 171 \\
\hline 0006 & 6923 & 4121 & 3569 & 3397 & 5708 & 171 \\
\hline 0007 & 6724 & 4002 & 3466 & 3219 & 5408 & 171 \\
\hline 0008 & 6915 & 4116 & 3565 & 3389 & 5694 & 171 \\
\hline 0009 & 6359 & 3785 & 3278 & 2898 & 4869 & 171 \\
\hline 0010 & 6716 & 3998 & 3462 & 3212 & 5396 & 171 \\
\hline 0011 & 5513 & 3750 & 3248 & 2930 & 4307 & 170 \\
\hline 0012 & 4918 & 3415 & 2958 & 2506 & 3683 & 169 \\
\hline 0013 & 6258 & 3725 & 3226 & 2815 & 4729 & 170 \\
\hline 0014 & 5885 & 3822 & 3310 & 2992 & 4608 & 170 \\
\hline 0015 & 4566 & 3333 & 2886 & 2428 & 3496 & 169 \\
\hline 0016 & 6251 & 3721 & 3222 & 2810 & 4720 & 170 \\
\hline 0017 & 6174 & 3675 & 3182 & 2747 & 4615 & 170 \\
\hline 0018 & 5191 & 3605 & 3122 & 2752 & 4045 & 169 \\
\hline 0019 & 4561 & 3330 & 2883 & 2423 & 3490 & 169 \\
\hline 0020 & 4963 & 3309 & 2865 & 2325 & 3580 & 170 \\
\hline 0021 & 6094 & 3627 & 3141 & 2684 & 4510 & 170 \\
\hline 0022 & 4257 & 3275 & 2836 & 2427 & 3325 & 168 \\
\hline 0023 & 4491 & 3278 & 2839 & 2376 & 3422 & 169 \\
\hline 0024 & 4688 & 3189 & 2762 & 2198 & 3297 & 169 \\
\hline 0025 & 4956 & 3304 & 2861 & 2320 & 3573 & 170 \\
\hline 0026 & 5625 & 3516 & 3045 & 2542 & 4067 & 170 \\
\hline 0027 & 4065 & 3127 & 2708 & 2294 & 3143 & 168 \\
\hline 0028 & 4042 & 3109 & 2692 & 2279 & 3122 & 168 \\
\hline 0029 & 4683 & 3186 & 2759 & 2195 & 3292 & 169 \\
\hline 0030 & 4735 & 3221 & 2789 & 2245 & 3367 & 169 \\
\hline 0031 & 5619 & 3512 & 3041 & 2537 & 4059 & 170 \\
\hline 0032 & 5506 & 3442 & 2980 & 2453 & 3925 & 170 \\
\hline 0033 & 4677 & 3181 & 2755 & 2191 & 3286 & 169 \\
\hline 0034 & 4583 & 3118 & 2700 & 2125 & 3188 & 169 \\
\hline 0035 & 5562 & 3476 & 3011 & 2493 & 3989 & 170 \\
\hline 0036 & 4984 & 3322 & 2877 & 2338 & 3506 & 170 \\
\hline
\end{tabular}




\begin{tabular}{|c|c|c|c|c|c|c|}
\hline 0037 & 4813 & 3274 & 2835 & 2293 & 3440 & 169 \\
\hline 0038 & 4422 & 3071 & 2659 & 2096 & 3081 & 169 \\
\hline 0039 & 4577 & 3114 & 2696 & 2122 & 3182 & 169 \\
\hline 0040 & 4456 & 3032 & 2625 & 2040 & 3059 & 169 \\
\hline 0041 & 4579 & 3115 & 2698 & 2122 & 3183 & 169 \\
\hline 0042 & 5027 & 3352 & 2903 & 2370 & 3556 & 170 \\
\hline 0043 & 5465 & 3416 & 2958 & 2420 & 3871 & 170 \\
\hline 0044 & 4912 & 3275 & 2836 & 2284 & 3426 & 169 \\
\hline 0045 & 4631 & 3216 & 2785 & 2241 & 3295 & 169 \\
\hline 0046 & 4177 & 3049 & 2640 & 2099 & 3023 & 168 \\
\hline 0047 & 4564 & 3105 & 2689 & 2114 & 3171 & 169 \\
\hline 0048 & 4074 & 2829 & 2450 & 1848 & 2717 & 168 \\
\hline 0049 & 4452 & 3029 & 2623 & 2037 & 3055 & 169 \\
\hline 0050 & 4287 & 2977 & 2578 & 2008 & 2952 & 168 \\
\hline 0051 & 4505 & 3129 & 2709 & 2158 & 3172 & 169 \\
\hline 0052 & 5116 & 3259 & 2822 & 2237 & 3513 & 170 \\
\hline 0053 & 3791 & 2767 & 2396 & 1832 & 2639 & 167 \\
\hline 0054 & 3959 & 2890 & 2502 & 1924 & 2770 & 168 \\
\hline 0055 & 4759 & 3173 & 2748 & 2160 & 3327 & 169 \\
\hline 0056 & 4638 & 3012 & 2608 & 1973 & 3098 & 169 \\
\hline 0057 & 3185 & 2450 & 2122 & 1608 & 2203 & 166 \\
\hline 0058 & 4634 & 3009 & 2606 & 1971 & 3035 & 169 \\
\hline 0059 & 4506 & 2926 & 2534 & 1887 & 2906 & 169 \\
\hline 0060 & 4446 & 2964 & 2567 & 1934 & 2978 & 169 \\
\hline 0061 & 4502 & 2923 & 2532 & 1884 & 2902 & 169 \\
\hline 0062 & 4152 & 2825 & 2446 & 1809 & 2713 & 169 \\
\hline 0063 & 4299 & 2866 & 2482 & 1828 & 2816 & 169 \\
\hline 0064 & 4442 & 2961 & 2565 & 1931 & 2974 & 169 \\
\hline 0065 & 3505 & 2558 & 2215 & 1620 & 2332 & 167 \\
\hline 0066 & 4149 & 2822 & 2444 & 1806 & 2710 & 168 \\
\hline 0067 & 3722 & 2716 & 2353 & 1747 & 2515 & 168 \\
\hline 0068 & 3990 & 2771 & 2399 & 1768 & 2599 & 168 \\
\hline 0069 & 3719 & 2714 & 2351 & 1744 & 2512 & 168 \\
\hline
\end{tabular}




\begin{tabular}{|c|c|c|c|c|c|c|}
\hline 0070 & 3719 & 2714 & 2351 & 1744 & 2512 & 168 \\
\hline 0071 & 3519 & 2569 & 2225 & 1627 & 2342 & 167 \\
\hline 0072 & 3289 & 2530 & 2191 & 1631 & 2235 & 166 \\
\hline 0073 & 3586 & 2617 & 2267 & 1677 & 2414 & 167 \\
\hline 0074 & 3117 & 2398 & 2076 & 1553 & 2128 & 165 \\
\hline 0075 & 3237 & 2490 & 2157 & 1604 & 2198 & 166 \\
\hline 0076 & 3218 & 2475 & 2144 & 1581 & 2166 & 166 \\
\hline 0077 & 3267 & 2513 & 2176 & 1606 & 2200 & 166 \\
\hline 0078 & 3115 & 2396 & 2075 & 1551 & 2126 & 165 \\
\hline 0079 & 3097 & 2382 & 2063 & 1527 & 2092 & 165 \\
\hline 0080 & 3162 & 2432 & 2107 & 1553 & 2127 & 166 \\
\hline 0081 & 2634 & 2251 & 1949 & 1468 & 1909 & 164 \\
\hline 0082 & 3954 & 2349 & 2034 & 1499 & 2053 & 165 \\
\hline 0083 & 2615 & 2235 & 1936 & 1458 & 1896 & 164 \\
\hline 0084 & 3008 & 2314 & 2004 & 1476 & 2022 & 165 \\
\hline 0085 & 2943 & 2264 & 1961 & 1444 & 1979 & 165 \\
\hline 0086 & 2512 & 2147 & 1860 & 1401 & 1822 & 164 \\
\hline 0087 & 2506 & 2141 & 1855 & 1398 & 1817 & 163 \\
\hline 0088 & 2536 & 2167 & 1877 & 1414 & 1839 & 164 \\
\hline 0089 & 3006 & 2312 & 2003 & 1475 & 2020 & 165 \\
\hline 0090 & 2306 & 1971 & 1707 & 1289 & 1676 & 162 \\
\hline 0091 & 2402 & 2053 & 1778 & 1341 & 1744 & 163 \\
\hline 0092 & 2881 & 2216 & 1919 & 1414 & 1838 & 164 \\
\hline 0093 & 2895 & 2227 & 1929 & 1399 & 1917 & 165 \\
\hline 0094 & 2504 & 2140 & 1854 & 1366 & 1776 & 164 \\
\hline 0095 & 2791 & 2147 & 1859 & 1352 & 1852 & 164 \\
\hline 0096 & 2752 & 2117 & 1833 & 1304 & 1787 & 164 \\
\hline 0097 & 2894 & 2226 & 1928 & 1398 & 1915 & 165 \\
\hline 0098 & 2706 & 2082 & 1803 & 1295 & 1774 & 164 \\
\hline 0099 & 2789 & 2145 & 1858 & 1350 & 1850 & 164 \\
\hline 0100 & 2673 & 2056 & 1781 & 1273 & 1745 & 164 \\
\hline 0101 & 2704 & 2080 & 1801 & 1273 & 1744 & 164 \\
\hline 0102 & 2368 & 2024 & 1753 & 1275 & 1657 & 163 \\
\hline
\end{tabular}




\begin{tabular}{|l|l|l|l|l|l|l|}
\hline 0103 & 2322 & 1985 & 1719 & 1253 & 1630 & 163 \\
\hline 0104 & 2625 & 2019 & 1749 & 1223 & 1676 & 164 \\
\hline 0105 & 2630 & 2023 & 1752 & 1226 & 1680 & 164 \\
\hline 0106 & 2603 & 2002 & 1734 & 1209 & 1657 & 164 \\
\hline
\end{tabular}

Tabela C.12 - Correntes de defeito em todos os trechos da rede em estudo. 